\title{
DIRETRIZES PARA O DIMENSIONAMENTO E DETALHAMENTO DE PILARES DE EDIFÍCIOS EM CONCRETO ARMADO
}

\begin{abstract}
FÁBIO AUGUSTO AUFIERI
Dissertação apresentada à Escola de Engenharia de São Carlos, da Universidade de São Paulo, como parte dos requisitos para obtenção do Título de Mestre em Engenharia de Estruturas.
\end{abstract}

ORIENTADOR: José Samuel Giongo

São Carlos

1997

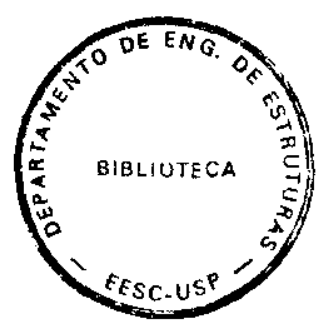




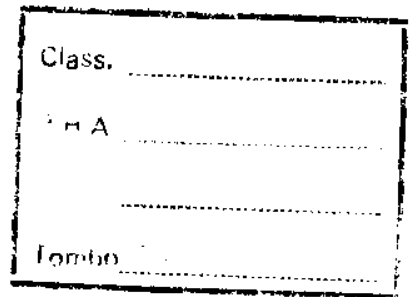

Ficha catalográfica preparada pela Seção de Tratamento da Informaçāo do Serviço de Biblioteca - EESC-USP

Aufieri, Fabio Augusto

Diretrizes para o dimensionamento e detalhamento de pilares de edifícios em concreto armado / Fábio Augusto Aufieri. -- São Carlos, 1997.

Dissertação (Mestrado) - Escola de Engenharia de São Carlos-Universidade de São Paulo, 1997. Área: Engenharia de Estruturas orientador: Prof. Dr. José Samuel Giongo

1. Pilares em concreto armado. 2. Estabilidade global. 3. Dimensionamento de pilares.

4. Detalhamento de pilares. I. Título. 
Aos meus pais, Luiz Ricardo e Ilona Sylvia, pelo apoio oferecido em toda a minha vida. À Ricardo, Marcos e Silvia, meus queridos irmãos. 


\section{AGRADECIMENTOS}

Ao professor José Samuel Giongo pela amizade e indicação dos caminhos a serem seguidos neste trabalho.

Ao meu amigo Francisco Totti Júnior, pela amizade e convivência durante o desenvolvimento deste trabalho.

Ao CNPq - Conselho Nacional de Pesquisa Científica e Tecnológica, pela bolsa de estudos fornecida.

Aos funcionários do Departamento de Estruturas, pela presteza e dedicação demonstrados em todas as ocasiões.

Aos meus pais e irmãos, minha eterna gratidão. 


\section{SUMÁRIO}

LISTA DE FIGURAS

LISTA DE TABELAS

iv

LISTA DE SÍMBOLOS

$\mathrm{v}$

LISTA DE SIGLAS

$\mathrm{x}$

RESUMO

$\mathrm{xi}$

ABSTRACT

xii

CAPÍTULO 1: INTRODUÇÃO

1.1. Objetivo

CAPÍtUlO 2: ESCOLHA DA FORMA DA ESTRUTURA E PRÉ DIMENSIONAMENTO DE PILARES

2.1. Aspectos gerais

2.2. Determinação da forma da estrutura

2.3. Pré - dimensionamento de pilares

2.3.1. Pré - dimensionamento por áreas de influência 2.3.1.1. Determinação do coeficiente $\varphi$

2.3.2. Pré - dimensionamento através das reações das vigas 12

CAPÍTULO 3: ESTABILIDADE GLOBAL $\quad 13$

3.1. Sistermas estruturais de contraventamento 13

3.2. Sistemas estruturais contraventados 16

3.3. Parâmetro de instabilidade $\alpha \quad 16$

3.3.1. Obtenção do valor de $\mathrm{EI}_{\text {eq }}$

3.3.2. Valor de $\alpha_{\text {lim }}$

3.4. Coeficiente $\gamma_{2}$

3.5. Análise de estruturas de nós móveis 23

CAPÍTULO 4: AÇÕES NAS ESTRUTURAS 25

4.1. Ações permanentes 25

4.2. Ações variáveis $\quad 27$

4.3. Ações excepcionais 30 
4.4. Ações devidas ao vento 30

4.4.1. Procedimentos para o cálculo de forças devidas ao vento em edificações $\quad 30$

4.5. Combinações de ações $\quad 37$

$\begin{array}{ll}\text { 4.5.1. Combinações últimas } & 38\end{array}$

4.5.2. Combinações de utilização 40

CAPÍTULO 5: INSTABILIDADE DE PILARES 43

5.1. Compressão axial 43

5.2. Flexão composta 47

5.3. Diagrama momento fletor - curvatura $\quad 50$

5.4. Diagrama momento fletor - força normal - curvatura 51

5.5. Método geral 54

5.6. Método do pilar padrão com o método geral 55

5.7. Método simplificado da NBR - 6118/78 57

CAPÍTULO 6: EXCENTRICIDADES PARA O DIMENSIONAMENTO DE $\begin{array}{ll}\text { PILARES } & 60\end{array}$

6.1. Excentricidade acidental 62

6.2. Excentricidade de segunda ordem 63

6.3. Excentricidade inicial 64

6.4. Excentricidade suplementar 65

6.5. Situações de projeto e de cálculo para o dimensionamento de pilares 66

6.5.1. Pilar interno curto $(\lambda \leq 40) 66$

6.5.2. Pilar interno medianamente esbelto $(40 \leq \lambda \leq 80) \quad 67$

$\begin{array}{ll}\text { 6.5.3. Pilar de extremidade curto } & 68\end{array}$

6.5.4. Pilar de extremidade medianamente esbelto 68

$\begin{array}{ll}\text { 6.5.5. Pilar de canto curto } & 69\end{array}$

6.5.6. Pilar de canto medianamente esbelto $\quad 70$

CAPÍTULO 7: DETALHAMENTO DAS ARMADURAS DE PILARES 72

7.1. Ancoragem das barras $\quad 72$

$\begin{array}{ll}\text { 7.1.1. Aderência por adesão } & 72\end{array}$

$\begin{array}{ll}\text { 7.1.2. Aderência por atrito } & 73\end{array}$ 
7.1.3. Aderência mecânica

7.2. Comprimento de ancoragem $\quad 74$

7.3. Armadura transversal nas ancoragens das barras $\quad 81$

7.4. Emendas das barras $\quad 82$

7.4.1. Emendas por traspasse $\quad 82$

7.4.2. Proporção de barras emendadas $\quad 83$

7.4.3. Comprimento de traspasse $\quad 84$

7.4.4. Armadura transversal nas emendas por traspasse 84

7.5. Disposições construtivas de pilares $\quad 85$

7.5.1. Condições ambientais $\quad 86$

$\begin{array}{ll}\text { 7.5.2. Cobrimento das armaduras } & 87\end{array}$

7.5.3. Armadura longitudinal 88

7.5.4. Armadura transversal 90

CAPÍTULO 8: EXEMPLOS DE CÁLCULO 93

8.1. Pilar P22 105

$\begin{array}{ll}\text { 8.2. Pilar P13 } & 121\end{array}$

CAPÍTULO 9: CONCLUSÕES $\quad 127$

CAPÍTULO 10: REFERÊNCIAS BIBLIOGRÁFICAS 129

CAPÍTULO 11: BIBLIOGRAFIA 131

APÊNDICE $1+132$ 


\section{LISTA DE FIGURAS}

FIGURA 2.1 - Áreas de influência 7

FIGURA 2.2 - Substituição da flexão oblíqua por uma flexo - compressão equivalente 11 [NBR6118/78]

FIGURA 3.1 - Sistemas estruturais de contraventamento 14

FIGURA 3.2 - Constante de mola de cada sistema estrutural de contraventamento $\quad 15$

FIGURA 3.3 - Parcela de absorção dos esforços horizontais para cada sistema de contraventamento

FIGURA 3.4 - Modelo proposto por Beck e König para avaliação da deformabilidade de um pilar

FIGURA 3.5 - Estabilidade global com análise tridimensional $\quad 18$

FIGURA 3.6 - Forma do pavimento tipo (exemplo) 19

FIGURA 3.7 - Associação das estruturas de contraventamento na direção x 20

FIGURA 3.8 - Associação das estruturas de contraventamento na direção y 20

FIGURA 4.1 - Isopletas da velocidade básica do vento $\mathrm{V}_{\mathrm{o}}$ [NBR - 6118] 31

FIGURA 4.2 - Fator topográfico $S_{1}$ [NBR - 6123/88] 32

FIGURA 5.1 - Instabilidade na compressão centrada [FUSCO] 43

FIGURA 5.2 - Formas de equilibrio: regime elástico [ FUSCO] 46

FIGURA 5.3 - Formas de equilíbrio: regime anelástico [ FUSCO ] 47

FIGURA 5.4 - Flexão de barras esbeltas no regime elástico [ FUSCO ] 47

FIGURA 5.5 - Estabilidade na flexo - compressão [ FUSCO ] $\quad 48$

FIGURA 5.6 - Instabilidade na flexão composta: regime elástico [ FUSCO ] 49

FIGURA 5.7 - Instabilidade na flexão composta: regime anelástico [ FUSCO ] 49

FIGURA 5.8 - Curvatura na flexão simples 50

FIGURA 5.9 - Curvatura na flexo - compressão 51

FIGURA 5.10 - Diagrama M - N - 1/r

FIGURA 5.11 - Método geral

FIGURA 5.12 - Pilar padrão 56

FIGURA 5.13 - Método do pilar padrão com o método geral 57

FIGURA 5.14 - Método simplificado da NBR - 6118/78 58 
FIGURA 6.1 - Forma de um pavimento tipo 60

FIGURA 6.2 - Corte AA $\quad 60$

FIGURA 6.3 - Equilíbrio das ações resultantes da excentricidade de forma

FIGURA 6.4 - Imperfeições geométricas localizadas $\quad 62$

FIGURA 6.5 - Esquema estrutural dos momentos iniciais devidos às ligações $\begin{array}{ll}\text { monolíticas } & 64\end{array}$

FIGURA 6.6 - Efeito da superposição de pilares 65

$\begin{array}{ll}\text { FIGURA 7.1 - Aderência por adesão } & 73\end{array}$

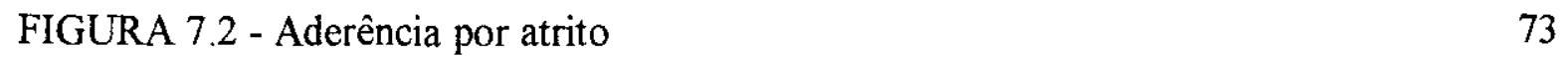

FIGURA 7.3 - Aderência mecânica $\quad 73$

FIGURA 7.4 - Comprimento de ancoragem $\quad 74$

FIGURA 7.5 - Equilibrio de um elemento de bloco de concreto armado 74

FIGURA 7.6 - Zonas de boa e má aderência $\quad 77$

$\begin{array}{ll}\text { FIGURA } 7.7 \text { - Armadura transversal soldada } & 78\end{array}$

FIGURA 7.8 - Confinamento do concreto devido ao cobrimento 79

FIGURA 7.9 - Confinamento provocado pela presença da armadura transversal $\quad 80$

FIGURA 7.10 - Equilíbrio concreto $x$ aço no processo de ancoragem 81

FIGURA 7.11 - Emendas por traspasse $\quad 83$

FIGURA 7.12 - Proporção de barras emendadas $\quad 83$

FIGURA 7.13 - Emenda de barras comprimidas $\quad 85$

FIGURA 7.14 - Flambagem local das barras longitudinais $\quad 90$

FIGURA 7.15 - Armadura transversal $\quad 91$

FIGURA 7.16 - Estribos curvilíneos 91

FIGURA 8.1 - Planta baixa do sub solo 94

FIGURA 8.2 - Planta baixa do pavimento térreo 95

FIGURA 8.3 - Planta baixa do play - ground 96

FIGURA 8.4 - Planta baixa do pavimento - tipo 97

FIGURA 8.5 - Planta baixa da casa de máquinas $\quad 98$

FIGURA 8.6 - Planta baixa dos reservatórios 99

FIGURA 8.7 - Forma do pavimento térreo $\quad 100$

FIGURA 8.8 - Forma do play - ground $\left(1^{\circ}\right.$ pav. ) 101 
FIGURA 8.9 - Forma do pavimento de transição ( $2^{\circ}$ pav. ) 102

FIGURA 8.10 - Forma do pavimento tipo ( $3^{\circ}$ pav. ao $17^{\circ}$ pav. ) 103

FIGURA 8.11 - Forma da cobertura ( $18^{\circ}$ pav. ) 104

FIGURA 8.12 - Esquema da prumada do pilar P22 105

FIGURA 8.13 - Situações de cálculo no trecho $\underline{A} \quad 107$

FIGURA 8.14 - Seção transversal do pilar P22 no trecho $\underline{\mathrm{A}} \quad 108$

FIGURA 8.15 - Situações de cálculo no trecho $\underline{\mathrm{B}} \quad 111$

FIGURA 8.16 - Seção transversal do pilar P22 no trecho B $\quad 112$

FIGURA 8.17 - Situações de cálculo no trecho C 114

FIGURA 8.18 - Seção transversal do pilar P22, no trecho $\underline{\mathrm{C}} \quad 115$

FIGURA 8.19 - Situações de cálculo no trecho $\underline{\mathrm{D}} \quad 117$

FIGURA 8.20 - Seção transversal do Pilar P22 no trecho D $\quad 118$

FIGURA 8.21 - Situações de cálculo no trecho $\underline{\mathrm{D}} \quad 119$

FIGURA 8.22 - Detalhamento da prumada do pilar P22 120

$\begin{array}{ll}\text { FIGURA } 8.23 \text { - Esquema da prumada do pilar P13 } & 121\end{array}$

FIGURA 8.24 - Seção transversal do pilar P13 no trecho $\underline{A} \quad 123$

FIGURA 8.25 - Seção transversal do pilar P13 nos trechos B e $\underline{\mathrm{C}} \quad 125$

FIGURA 8.26 - Situação crítica para o pilar P13, no último tramo 126

FIGURA 8.27 - Detalhamento da prumada do pilar P13. 126

FIGURA AP.1 - Ação do vento na edificação 133 


\section{LISTA DE TABELAS}

TABELA 2.1 - Valores de resistência do aço com deformação de 0,2 \%

TABELA 2.2 - Valores recomendados para o pré-dimensionamento de pilares

TABELA 3.1 - Fator de ajuste para análise do efeito de segunda ordem global, proposto por VASCONCELOS

TABELA 4.1 - Peso específico de materiais de construção [NBR - 6118] 26

TABELA 4.2 - Ações permanentes por unidade de área 27

TABELA 4.3 - Valores mínimos das cargas acidentais verticais 28

TABELA 4.4 - Valores para o fator $\mathrm{S}_{2} \quad 35$

TABELA 4.5 - Valores mínimos do fator estatístico $S_{3}$

TABELA 4.6 - Coeficientes de ponderação para as ações permanentes[NBR - 8681] 41

TABELA 4.7 - Efeitos de recalques de apoio e da retração dos materiais[NBR - 8681] 41

TABELA 4.8 - Coeficientes de ponderação para as ações variáveis[NBR - 8681] 41

TABELA 4.9 - Valores os fatores de combinação e dos fatores de utilização [NBR - 8681] 42

TABELA 7.1 - Proporção máxima de barras emendadas na mesma seção transversal $\quad 84$

TABELA 7.2 - Características do concreto de acordo com as condições ambientais $\quad 87$

TABELA 7.3 - Cobrimento das armaduras $\quad 88$

TABELA 7.4 - Recomendações para armadura longitudinal $\quad 89$

TABELA 7.5 - Recomendações para armadura transversal 92 


\section{LISTA DE SÍMBOLOS}

$\mathrm{N}_{\mathrm{k}}$ - Esforço normal de serviço, $\mathrm{kN}$

$\mathrm{V}_{\mathrm{kx}}$ - Cortante de serviço na direção do eixo $\mathrm{x}, \mathrm{kN}$

$\mathrm{V}_{\mathrm{ky}}$ - Cortante de serviço na direção do eixo $\mathrm{y}, \mathrm{kN}$

$\mathrm{M}_{\mathrm{kx}}$ - Momento de serviço na direção do eixo $\mathrm{x}, \mathrm{kNm}$

$\mathrm{M}_{\mathrm{ky}}$ - Momento de serviço na direção do eixo $\mathrm{y}, \mathrm{kNm}$

$\lambda$ - Índice de esbeltez

$\mathrm{A}_{\mathrm{c}}$ - Área da seção transversal de um pilar, $\mathrm{cm}^{2}$

$A_{i}$ - Área de influência de um pilar, $m^{2}$

g - Carregamento permanente uniformemente distribuído, $\mathrm{kN} / \mathrm{m}$

$\mathrm{q}$ - Carregamento acidental uniformemente distribuído, $\mathrm{kN} / \mathrm{m}$

$\sigma_{\text {id }}$ - Tensão ideal de cálculo do concreto, $\mathrm{kN} / \mathrm{cm}^{2}$

$\mathrm{f}_{\mathrm{cd}}$ - Resistência de cálculo do concreto, $\mathrm{kN} / \mathrm{cm}^{2}$

$\mathrm{A}_{\mathrm{cc}}$ - Área de concreto comprimido, $\mathrm{cm}^{2}$

$\mathrm{f}_{\mathrm{sd}}$ - Resistência de cálculo do aço com deformação de $0,2 \%, \mathrm{kN} / \mathrm{cm}^{2}$

$\mathrm{A}_{\mathrm{s}}$ - Área da seção transversal da armadura longitudinal, $\mathrm{cm}^{2}$

$\mathrm{N}_{\mathrm{d}}$ - Valor de cálculo do esforço normal, $\mathrm{kN}$

$\rho$ - Taxa geométrica de armadura, $\%$

$\mathrm{e}_{\mathrm{a}}$ - Excentricidade acidental, $\mathrm{cm}$

$v_{d}$ - Valor adimensional do esforço normal

$\mu_{d}$ - Valor adimensional do momento fletor

$k$ - Coeficiente

e - Excentricidade de cálculo, cm

$e_{i}$ - Excentricidade inicial, $\mathrm{cm}$

$e_{x, \text { eq }}$ - Excentricidade equivalente em relação ao eixo $x, \mathrm{~cm}$

$\beta$ - Coeficiente que relaciona a flexão obliqua com a flexão composta

$\omega$ - Taxa mecânica de armadura

$\varphi$ - Coeficiente para pré - dimensionamento de pilares

$\gamma_{z}$ - Coeficiente para avaliação da estabilidade global de uma estrutura 
E - Módulo de deformação longitudinal do concreto, $\mathrm{kN} / \mathrm{cm}^{2}$

I - Momento de inércia, $\mathrm{cm}^{4}$

(EI)eq - Módulo de rigidez da estrutura do edificio equivalente a um pilar de seção constante engastado na base e livre no topo, $\mathrm{kN} . \mathrm{cm}^{2}$

a - Deslocamento no topo do edificio, submetido à esforços horizontais, $\mathrm{cm}$

$\alpha_{\text {lim }}$ - Valor limite para caracterizar uma estrutura como deslocável ou indeslocável, segundo o parâmentro de instabilidade $\alpha$

$M_{\text {tot,d }}$ - Valor que representa uma primeira avaliação dos esforços de segunda ordem global, $\mathrm{kNm}$

$\mathrm{M}_{\text {Itotd }}$ - Momento total de todas as componentes de força horizontal, $\mathrm{kNm}$

$\mathrm{V}_{\mathrm{o}}$ - Velocidade básica do vento, $\mathrm{m} / \mathrm{s}$

$\mathrm{V}_{\mathrm{k}}$ - Velocidade característica do vento, $\mathrm{m} / \mathrm{s}$

$\mathrm{S}_{1}$ - Fator topográfico

$\mathrm{S}_{2}$ - Fator que considera a rugosidade do terreno

$\mathrm{S}_{3}$ - Fator estatístico

$\mathrm{q}$ - Pressão dinâmica do vento, $\mathrm{N} / \mathrm{m}^{2}$

$c_{p}$ - Coeficiente de pressão

$\Delta P$ - Pressão efetiva que o vento exerce sobre a estrutura, $N / m^{2}$

$c_{\mathrm{pe}}$ - Coeficiente de pressão externa

$c_{p i}$ - Coeficiente de pressão interna

$\mathrm{F}_{\mathrm{c}}$ - Força externa à edificação, $\mathrm{kN}$

$F_{i}$ - Força interna à edificação, $k N$

$\mathrm{C}_{\mathrm{e}}$ - Coeficiente de forma externo

$\mathrm{C}_{\mathrm{i}}$ - Coeficiente de forma interno

$\mathrm{C}_{\mathrm{f}}$ - Coeficiente de força

$\mathrm{F}_{\mathrm{d}}$ - Valor de cálculo das ações, $\mathrm{kN}$

$\mathrm{F}_{\text {Gi.k }}$ - Valor característico das ações permanentes, $\mathrm{kN}$

$F_{\text {Q1,k }}$ - Valor característico da ação variável considerada como ação principal para a combinação, $\mathrm{kN}$

$\mathrm{F}_{\text {Q,exec }}$ - Valor da ação transitória excepcional, $\mathrm{kN}$

$\psi_{\text {oj }}$ - Fator de combinação adotado nas combinações normais 
$\psi_{\text {oj,ef }}$ - Fator de combinação efetivo de cada uma das demais variáveis que podem agir simultaneamente com a ação principal $\mathrm{F}_{\mathrm{Q} 1}$, durante a situação transitória

$\psi_{\text {ij }}$ - Fator de combinação para as combinações raras

$\psi_{2 \mathrm{j}}$ - Fator de combinação para as combinações quase - permanentes e frequentes de utilização

$\mathrm{F}$ crit - Carga crítica de Euler ou carga de flambagem, $\mathrm{kN}$

$\ell_{e}$ - Comprimento de flambagem, $m$

$\mathrm{M}_{\text {ext }}$ - Momento externo atuante, $\mathrm{kNm}$

$\mathrm{M}_{\text {int }}$ - Momento interno atuante. $\mathrm{kNm}$

$1 / \mathrm{r}$ - Curvatura da barra

$\varepsilon_{\mathrm{c}}$ - Deformação no concreto

$\beta_{\mathrm{x}}$ - Razão entre a posição da linha neutra e o braço de alavanca da armadura (x/d)

$\phi_{1}$ - Coeficiente que avalia o desaprumo de uma edificação

$\mathrm{M}_{\text {eng }}$ - Momento no apoio extremo da viga supondo engastamento perfeito no pilar, $\mathrm{kNm}$

$M_{\text {vig }}$ - Momento fletor de engastamento elástico de viga em pilar de extremidade, $\mathrm{kNm}$

$r_{\text {inf }}$ - Índice de rigidez de tramo de pilar inferior

$r_{\text {sup }}$ - Índice de rigidez de tramo de pilar superior

$\mathrm{r}_{\text {vig }}$ - Índice de rigidez de tramo extremo de viga ligado a pilar

$\mathrm{M}_{\text {sup }}$ - Momento fletor em tramo de pilar superior, $\mathrm{kNm}$

$\mathrm{M}_{\text {inf }}$ - Momento fletor em tramo de pilar inferior, $\mathrm{kNm}$

$\mathbf{e}_{i c}$ - excentricidade inicial na seção intermediária de um tramo de pilar, cm

$e_{i a} e_{i b}$ - Excentricidades iniciais nas extremidades de um tramo de pilar, $\mathrm{cm}$

$\mathrm{e}_{\mathrm{ig}}$ - excentricidade inicial referente às ações de longa duração, $\mathrm{cm}$

$\phi$ - Coeficiente de fluência

$\mathrm{N}_{\mathrm{ggd}}$ - Força normal de cálculo referente às ações de longa duração, $\mathrm{kN}$

$\mathrm{E}_{\mathrm{c}}$ - Módulo de deformação longitudinal secante do concreto, $\mathrm{kN} / \mathrm{cm}^{2}$

$\mathrm{e}_{2}$ - excentricidade local de segunda ordem, $\mathrm{cm}$

$f_{\text {bd }}$ - Tensão de aderência entre aço e concreto, $\mathrm{kN} / \mathrm{cm}^{2}$ 
$\sigma_{t}$ - Pressão transversal originada em virtude da retração do concreto, $\mathrm{kN} / \mathrm{cm}^{2}$

$\&$ - Comprimento de ancoragem, $\mathrm{cm}$

$\mathrm{f}_{\mathrm{yd}}$ - Resistência de escoamento do aço, $\mathrm{kN} / \mathrm{cm}^{2}$

$\mathrm{u}$ - perímetro da barra, $\mathrm{cm}$

$\mathrm{n}_{1}$ - Coeficiente que considera o tipo de aço

$\mathrm{n}_{2}$ - Coeficiente que considera as situações de aderência

$\mathrm{n}_{3}$ - Coeficiente que considera a bitola das barras ancoradas

$\mathrm{f}_{\mathrm{ctd}}$ - Valor da resistência de cálculo do concreto à tração, $\mathrm{kN} / \mathrm{cm}^{2}$

$\ell_{\mathrm{b}, \text { nec }}$ - Comprimento de ancoragem necessário, $\mathrm{cm}$

$a_{1}$ - Coeficiente que considera a forma da extremidade da barra

$A_{\text {s,cal }}$ - Área da seção transversal da armadura, calculada com o esforço a ancorar, $\mathrm{cm}^{2}$

$\mathrm{A}_{\mathrm{s}, \mathrm{ex}}$ - Área da seção transversal da armadura existente, $\mathrm{cm}^{2}$

$\ell_{\mathrm{b}, \text { red }}$ - Comprimento de ancoragem , cm

$a_{2}$ - Coeficiente que considera a influência de uma ou mais barras soldadas transversalmente à armadura

$a_{3}$ - Coeficiente que considera o efeito do confinamento provocado pela presença de armadura transversal

cd - Coeficiente que considera o confinamento do concreto devido ao cobrimento

$\mathrm{a}_{4}$ - Coeficiente que considera o confinamento provocado pela presença de armadura transversal

$\sum \mathrm{A}_{\mathrm{st}}$ - Área da seção de armadura transversal existente ao longo de $\ell_{\mathrm{bnec}} \mathrm{cm}^{2}$

$A_{\text {st,min }}$ - Área da seção transversal mínima, $\mathrm{cm}^{2}$

$a_{5}$ - Coeficiente que considera o confinamento provocado por compressão transversal

$\ell_{\mathrm{b} \text { min }}$ - Valores mínimos admitidos para o comprimento de ancoragem para barras comprimidas, $\mathrm{cm}$

$\mathrm{A}_{\mathrm{sw}}$ - Área da seção transversal das barras da armadura de cisalhamento, $\mathrm{cm}^{2}$

n - Número de camadas com barras ancoradas na mesma seção

m - Número máximo de barras ancoradas na seção, em uma camada

$\ell_{1}$ - Comprimento de traspasse da barra superior, $\mathrm{cm}$ 
$\iota_{2}$ - Comprimento de traspasse da barra inferior, $\mathrm{cm}$

$\phi_{\min }$ - Diâmetro mínimo da barra longitudinal da armadura, mm

$\phi_{\operatorname{máx}}$ - Diâmetro máximo da barra longitudinal da armadura, mm

$\mathrm{s}_{\min }$ - Espaçamento mínimo entre as armaduras longitudinais, $\mathrm{cm}$

$\mathrm{S}_{\max }$ - Espaçamento máximo entre as armaduras longitudinais, $\mathrm{cm}$

$\mathrm{A}_{\mathrm{s} \text { min }}$ - Área mínima da seção transversal da armadura longitudinal, $\mathrm{cm}^{2}$

$\mathrm{A}_{s \text { máx }}$ - Área máxima da seção transversal da armadura longitudinal, $\mathrm{cm}^{2}$

$\mathrm{d}_{\text {agr }}$ - Diâmetro médio do agregado graúdo componente do concreto, $\mathrm{cm}$

b - Largura do pilar, cm

$\mathrm{h}$ - Altura do pilar, $\mathrm{cm}$

$\phi_{\mathrm{t}}$ - Diâmetro da armadura transversal, $\mathrm{mm}$

$\mathrm{a}_{\min }$ - Menor dimensão do pilar, cm

$\phi_{\ell}$ - Diâmetro da armadura longitudinal, $\mathrm{mm}$

$\mathrm{f}_{\mathrm{ck}}$ - Resistência característica do concreto à compressão, $\mathrm{kN} / \mathrm{cm}^{2}$ 


\section{LISTA DE SIGLAS}

CNPq: Conselho Nacional de Desenvolvimento Científico e Tecnológico

EESC - USP: Escola de Engenharia de São Carlos / Universidade de São

Paulo

EUROCODE: European Code

NBR - Norma Brasileira: Norma Brasileira Registrada

SAP: Structural Analysis Program 


\title{
RESUMO
}

AUFIERI, F.A. Diretrizes para o Dimensionamento e Detalhamento de Pilares de Edificios em Concreto Armado. São Carlos, 1997. 146p. Dissertação (Mestrado) - Escola de Engenharia de São Carlos, Universidade de São Paulo.

Este trabalho tem o objetivo de transmitir aos Engenheiros de Estruturas o conhecimento teórico necessário para o dimensionamento e detalhamento de pilares usuais de edificios em concreto armado.

A definição das posições dos pilares em uma estrutura, bem como uma estimativa da seção transversal dos mesmos são abordadas neste trabalho.

O estudo da estabilidade global, realizado no Capítulo 3 , nos permite avaliar se os deslocamentos ocorridos na estrutura em função das ações horizontais e verticais, geram esforços de segunda ordem consideráveis ou não.

A instabilidade de pilares será comentada no Capítulo 5, bem como os Métodos desenvolvidos para avaliar se um determinado pilar é estável ou instável.

$\mathrm{O}$ detalhamento de pilares segundo as prescrições do Texto Base para a revisão da NBR - 6118/78, bem como o desenvolvimento de exemplos de dimensionamento de pilares estão contidos neste trabalho nos Capítulos 7 e 8 , respectivamente.

\author{
Palavras - chave: Pilares em concreto armado - Estabilidade \\ global - Dimensionamento de pilares - \\ Detalhamento de pilares.
}




\begin{abstract}
AUFIERI, F.A Directions for Design and Detail of Columns in Reinforced Concrete Buildings. São Carlos, 1997. 146p. Dissertation (M.S. Degree) - Escola de Engenharia de São Carlos, Universidade de São Paulo.
\end{abstract}

The objective of this work is to transmit to the structural engineers the necessary theoretical knowledge for the design. and detail of usual columns in reinforced concrete buildings.

The definition of the columns positions in the structure, as well as an estimate of their cross section will be explained in this work.

The global stability study, described in chapter 3 , allows us to evaluate whether the deformations ocurred in the structure due to horizontal and vertical actions, cause considerable second order strength or not.

The columns instability will be commented in chapter 5 , as well as the methods developed to evaluate whether a specific column is stable or instable.

The columns detail as prescribed in the Basic Text for the Revision of NBR $6118 / 78$, and also the development of examples for columns design are in chapter 7 and 8 , respectively.

Key - words: Reinforced concrete columns - Global stability - Columns design - Columns detailing. 


\section{CAPÍTULO 1: INTRODUÇÃO}

Pilares são elementos lineares constituintes da estrutura, submetidos predominantemente a esforços axiais de compressão.

Em edificios residenciais ou comerciais, os pilares e vigas formam pórticos espaciais que são responsáveis por absorver os esforços verticais e horizontais atuantes na estrutura

As lajes transferem as ações, que atuam normal ao seu plano, às vigas nas quais estão apoiadas que, por sua vez, as transmitem aos pilares. Os carregamentos horizontais, devidos a ação do vento, são transmitidos aos pórticos através das alvenarias de fechamento. As ações horizontais são distribuídas entre os pilares pelo efeito de diafragma realizado pelas lajes.

Feito o levantamento das ações atuantes em uma determinada estrutura, os esforços atuantes nos pilares, ou seja, força normal $\left(N_{k}\right)$, cortantes $\left(V_{k x}\right.$ e $\left.V_{k y}\right)$ e momentos fletores $\left(\mathrm{M}_{\mathrm{kx}}\right.$ e $\left.\mathrm{M}_{\mathrm{ky}}\right)$ são determinados através da Estática das Estruturas.

A NBR - $6118 / 78$ permite, para a obtenção dos esforços nos pilares de uma maneira simplificada, que o pórtico seja substituído por uma viga contínua, desde que algumas considerações sejam feitas:

- esta simplificação não é válida para esforços horizontais;

- nos pilares de extremidade, deverá ser considerado que atue no pilar um

momento fletor proporcional às rigidezes da viga e dos pilares que concorrem para a ligação.

O pré-dimensionamento das seções transversais dos pilares, pode ser feito de uma maneira simples, utilizando o processo das áreas de influência. Este processo consiste em dividir os pavimentos em áreas de acordo com as posições dos pilares, com isso, as ações atuantes em cada área são absorvidas pelo pilar correspondente.

De acordo com a posição dos pilares na estrutura, eles são classificados em pilar interno, de extremidade ou de canto. Os pilares internos ou intermediários são submetidos a compressão centrada, visto que, as excentricidades de forma podem ser desprezadas. Os pilares de extremidade, por sua vez, estão submetidos a flexão normal composta, pois além da força axial de compressão existe o momento fletor decorrente da ligação da viga com o 
pilar. E finalmente, os pilares de canto estão submetidos a uma flexão obliqua composta, visto que, existe a força normal de compressão e os momentos fletores nas duas direções.

Os pilares podem ser subdivididos, também, de acordo com a esbeltez que apresentam. Quando o seu índice de esbeltez $(\lambda)$ for menor ou igual a 40, têm-se os chamados pilares curtos, ou seja, não há a necessidade da consideração das excentricidades de segunda ordem locais. Se $40<\lambda \leq 80$, os pilares são chamados de medianamente esbeltos e a consideração dos esforços de segunda ordem locais se faz necessário. $O$ pilar $\operatorname{com} \lambda>80$, é chamado de esbelto e deve-se considerar no seu dimensionamento os esforços adicionais provocados pela fluência. No presente trabalho, os pilares estudados terão um indice de esbeltez no máximo igual a 140.

\subsection{OBJETIVO}

Este trabalho tem como meta, discutir os assuntos importantes que um profissional da área de estruturas deve se ater ao efetuar o dimensionamento de pilares usuais de edificios em concreto armado.

De uma maneira sucinta, o processo para dimensionar um pilar em concreto armado, segue as seguintes etapas:

- definição da forma da estrutura e pré - dimensionamento de pilares;

- estabilidade global do edificio;

- ações a considerar em uma estrutura;

- estado limite último de instabilidade;

- excentricidades das ações nos pilares de acordo com a posição dos mesmos na estrutura e de sua esbeltez;

- estado limite último de ruína;

- detalhamento das armaduras dos pilares

Este trabalho apresenta como novidade, o estudo do desaprumo aplicado ao dimensionamento de pilares de acordo com as prescrições estabelecidas no Texto Base para revisão da NBR - 6118 de novembro de 1992. Além disso, toda a teoria referente ao detalhamento de pilares é baseada também nas determinações especificadas no Texto Base acima mencionado. 
Outra meta deste trabalho, foi estabelecer um roteiro detalhado de todas as etapas importantes no dimensionamento e detalhamento de pilares em concreto armado, afim de que alunos de graduação em Engenharia Civil possam recorrer para esclarecer eventuais dúvidas. 


\section{CAPÍTULO 2: ESCOLHA DA FORMA DA ESTRUTURA E PRÉ-DIMENSIONAMENTO DE PILARES}

\subsection{ASPECTOS GERAIS}

Geralmente os edificios residenciais ou comerciais são constituídos pelos seguintes pavimentos: sub-solo, térreo, pavimento-tipo e cobertura. Nesta divisão, a área destinada às garagens se situa, geralmente, no sub-solo, podendo este apresentar mais de um pavimento.

O pavimento térreo é utilizado para recepção, sala de jogos, piscina, salão de festas e também, eventualmente, pode apresentar garagens. Os pavimentos-tipo são destinados aos apartamentos e acima da cobertura encontram-se a casa de máquinas e caixa d'água elevada. Vale lembrar que a divisão apresentada acima é o que ocorre na maioria das vezes porém, pode perfeitamente ser alterada de acordo com o projeto arquitetônico proposto.

\subsection{DETERMINAÇÃO DA FORMA DA ESTRUTURA}

A determinação da forma de uma estrutura deve ser desenvolvida, procurando-se seguir o projeto arquitetônico. Sendo assim, o engenheiro calculista deve, na fase de anteprojeto, levantar todos os detalhes arquitetônicos que possam ser úteis na determinação da modulação dos pavimentos. Além do projeto arquitetônico, existem outros projetos (instalações hidráulicas, elétricas, ar-condicionado, etc.) que devem também ser analisados e discutidos a fim de se obter a forma definitiva da estrutura.

A forma da estrutura está diretamente ligada à algumas dimensões econômicas que o engenheiro deve respeitar, quando possivel, na distribuição dos pilares e por conseqüência a definição das vigas e lajes.

CEOTTO 1985 J traz algumas indicações de áreas e espaçamentos econômicos que facilitam a modulação da estrutura.

Os pilares devem estar posicionados na estrutura de maneira que os eixos entre pilares adjacentes se situem entre os limites de $4,5 \mathrm{~m}$ a $5,5 \mathrm{~m}$, quando possivel. 
A área de influência econômica por pilar, deve resultar entre $15 \mathrm{~m}^{2}$ a $20 \mathrm{~m}^{2}$ por pavimento. As taxas de armadura econômica devem se situar entre $2 \%$ e $3 \%$, o consumo de aço deve estar situado entre $130 \mathrm{~kg} / \mathrm{m}^{3}$ a $220 \mathrm{~kg} / \mathrm{m}^{3}$ no pavimento mais solicitado.

Quando a prumada de pilares de um determinado pavimento, interferir com o pavimento inferior, deve-se prever uma estrutura de transição a fim de que os esforços sejam desviados e, consequentemente, absorvidos por pilares em outras posições.

Nos edificios usuais as áreas destinadas aos elevadores e escadas são comuns em todos os pavimentos, sendo assim, nessas regiões posicionam-se pilares com grande rigidez, com a função de colaborar na absorção das ações horizontais (vento).

Os demais pilares são locados de maneira que se consiga formar pórticos que também contribuam para absorver os esforços horizontais. Determinadas as posições dos pilares, as vigas, por sua vez, também ficam definidas e consequentemente as lajes. $\mathrm{Na}$ determinação da posição das vigas é conveniente, quando possivel, que as mesmas estejam localizadas coincidindo com as paredes do pavimento superior, caso contrário, as lajes devem ser dimensionadas para suportar a ação proveniente das paredes.

\subsection{PRÉ - DIMENSIONAMENTO DE PILARES}

Uma vez definida a forma da estrutura, o engenheiro deve fazer o prédimensionamento dos elementos constituintes da edificação para conhecer as ações permanentes. Em função da utilização e consultando a NBR - 6120[1980] se conhecem as ações variáveis normais.

Para os pilares, existem dois processos usados com frequência e que já se tornaram de domínio para os engenheiros que são:

- pré-dimensionamento por áreas de influência;

- pré-dimensionamento através das reações das vigas.

\subsubsection{Pré - dimensionamento por áreas de influência}

O pré-dimensionamento das seções transversais de pilares através do método das áreas de influência, consiste em dividir os pavimentos em áreas de acordo com as posições 'dos pilares. Sendo assim, a ação vertical atuante em cada área deverá ser absorvida pelo pilar correspondente. 
O método em questão, prevê a divisão do pavimento, seguindo algumas recomendações, em áreas delimitadas por figuras geométricas, supondo que o carregamento uniformemente distribuido sobre as mesmas, seja absorvido pelo pilar correspondente, suposto submetido a uma compressão centrada.

A divisão do pavimento deverá seguir as seguintes recomendações (vide FIGURA 2.1):

$-0,45 \ell$ : adotado no caso de pilar de extremidade ou de canto na direção da menor dimensão do pilar;

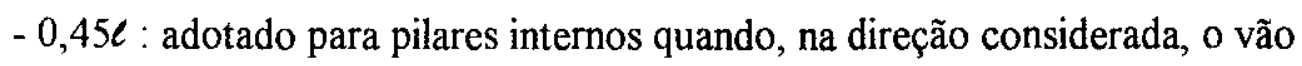
consecutivo ou seu carregamento superar em $20 \%$ o valor correspondente ao vão em questão;

- 0,55e : complemento do vão dos casos anteriores;

- 0,50e : adotado no caso de pilar de extremidade ou de canto na direção da maior dimensão do pilar;

- 0,50€ : adotado para pilar interno quando, na direção considerada, o vão consecutivo e seu carregamento diferirem menos de $20 \%$ do valor correspondente ao vão em questão;

Em casos onde exista lajes em balanço, a área de influência resulta da soma da área da mesma com a área das lajes adjacentes, com o vão nesta direção dividido ao meio.

Para se entender melhor a divisão do pavimento, é mostrada na FIGURA 2.1 um pavimento de um edificio imaginário com a sua respectiva divisão em figuras geométricas, respeitando o processo das áreas de influência. 


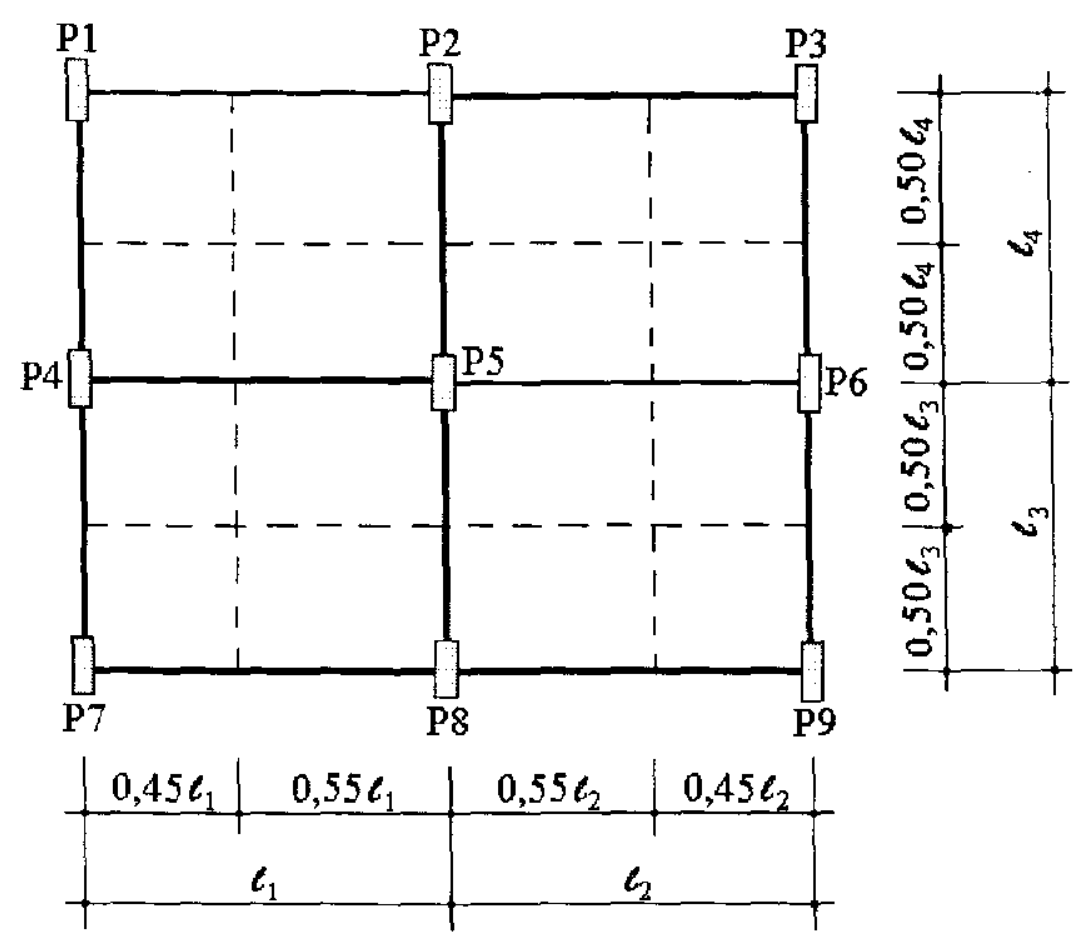

FIGURA 2.1. - Áreas de Influência

Pelo fato de dividir o pavimento em retângulos, esse processo pode gerar resultados distorcidos da realidade para o caso de pavimentos com distribuição irregular de vãos e consequentemente de carregamentos.

O valor da área da seção transversal de um determinado pilar, usando-se o método das áreas de influências, é obtido através da seguinte expressão:

$$
A_{c}=\frac{\varphi \cdot A_{i} \cdot(g+q) \cdot(n+0,70)}{\sigma_{i d}}
$$

sendo:

$\varphi$ - coeficiente que majora as ações axiais em virtude das solicitações nos pilares serem consideradas centradas;

$A_{i}$ - área de influência do pilar;

$\mathrm{n}$ - número de pavimentos acima do tramo de pilar que se deseja fazer o prédimensionamento;

$\mathrm{g}+\mathrm{q}$ - carregamento uniformemente distribuido;

$\sigma_{i d}$ - tensão ideal de cálculo do concreto. 
$\mathrm{O}$ valor de $\mathrm{g}+\mathrm{q}$ pode ser determinado para cada área de influência considerando-se o valor das ações devidas ao peso próprio da estrutura, do material de revestimento do piso e forro, paredes de alvenaria e das ações de utilização. Usualmente esse valor é adotado entre $8 \mathrm{kN} / \mathrm{m}^{2}$ e $12 \mathrm{kN} / \mathrm{m}^{2}$.

$\mathrm{Na}$ expressão (2.1), o valor 0,70 corresponde a ação na cobertura, que pode ser adotada como sendo $70 \%$ da ação no pavimento tipo.

$O$ valor da tensão ideal $\left(\sigma_{i d}\right)$ é obtido ao se fazer o equilíbrio entre a ação externa e a força resistente em uma peça comprimida de concreto armado, como se segue:

$$
\mathrm{N}_{\mathrm{d}}<0,85 \mathrm{f}_{\mathrm{cd}} \cdot \mathrm{A}_{\mathrm{cc}}+\mathrm{f}_{\mathrm{sd}} \cdot \mathrm{A}_{\mathrm{s}}
$$

sendo:

$\mathrm{N}_{\mathrm{d}}$ - valor de cálculo da força normal solicitante;

$\mathrm{f}_{\mathrm{cd}}$ - resistência de cálculo do concreto;

$\mathrm{A}_{\mathrm{cc}}$ - área de concreto comprimido;

$\mathrm{f}_{\mathrm{sd}}$ - resistência de cálculo do aço relativa a deformação de $0,2 \%$;

$\mathrm{A}_{\mathbf{s}}$ - área da seção transversal da armadura longitudinal.

Rearranjando a equação (2.2), obtém-se:

$$
\begin{aligned}
& N_{d}=0,85 f_{c d} \cdot\left(A_{c}-A_{s}\right)+f_{s d} \cdot A_{s} \\
& N_{d}=0,85 f_{c d} \cdot A_{c}+A_{s} \cdot\left(f_{s d}-0,85 f_{c d}\right)
\end{aligned}
$$

Dividindo-se os membros da equação por $\mathrm{A}_{c}$, obtém-se:

$$
\frac{N_{d}}{A_{c}}=0,85 f_{c d}+\frac{A_{s}}{A_{c}}\left(f_{s d}-0,85 f_{c d}\right)
$$

Chamando de $\rho$ a taxa de armadura, obtida pela razão de $\mathrm{A}_{s}$ por $\mathrm{A}_{c}$, tem-se:

$$
N_{d}=\left[0,85 f_{c d}+\rho \cdot\left(f_{s d}-0,85 f_{c d}\right)\right] \cdot A_{c}
$$

Dividindo-se $\mathrm{N}_{\mathrm{d}}$ por $\mathrm{A}_{\mathrm{c}}$, obtém-se a tensão ideal $\left(\sigma_{i d}\right)$ dada pela seguinte expressão:

$$
\sigma_{\mathrm{id}}=0,85 \mathrm{f}_{\mathrm{cd}}+\rho \cdot\left(\mathrm{f}_{\mathrm{sd}}-0,85 \mathrm{f}_{\mathrm{cd}}\right)
$$

Os valores de $\mathrm{f}_{\mathrm{sd}}$ relativos a deformação de $0,2 \%$ estão contidos na TABELA 2.1. 
TABELA 2.1 - Valores da resistência do aço com deformação de $0,2 \%$

\begin{tabular}{|c|c|}
\hline Categoria do aço & $\mathbf{f}_{\text {sd }}$ (MPa) \\
\hline CA -25 & 217 \\
\hline CA -50 & 420 \\
\hline CA -60 & 400 \\
\hline
\end{tabular}

\subsubsection{Determinação do coeficiente $\alpha$}

\section{(a) Pilares Internos}

Os pilares internos ou intermediários são submetidos a uma compressão centrada. Porém, para levar em consideração eventuais erros de execução da estrutura, é necessário considerar uma excentricidade. A NBR-6118/78 prevê que se adote nesses casos, uma excentricidade acidental $\left(\mathrm{e}_{\mathrm{a}}\right)$, tomando-se o maior dos dois valores abaixo:

$$
\mathrm{e}_{\mathrm{a}}=\mathrm{h} / 30 \geq 2,0 \mathrm{~cm}
$$

sendo:

$\mathrm{h}$ - dimensão do pilar perpendicular ao eixo de flexão;

Sendo assim, considerando um pilar interno com $20 \mathrm{~cm}$ de largura, resulta uma excentricidade acidental de $2,0 \mathrm{~cm}$, fazendo com que o pilar fique submetido a uma flexão composta.

A NBR-6118/78 permite a transformação de uma flexão composta em uma compressão centrada desde que $v_{d} \geq 0,70$, majorando-se a força normal na proporção de $1+$ $\mathrm{ke} / \mathrm{h} \geq 1,10$.

sendo:

$$
e=e_{a}+e_{2}
$$

e - excentricidade de cálculo;

$\mathrm{e}_{\mathrm{a}}$ - excentricidade acidental;

$\mathrm{e}_{2}$ - excentricidade de segunda ordem;

h - dimensão do pilar na direção correspondente a menor rigidez;

$\mathrm{k}=3$, para seções retangulares com pelo menos dois terços da armadura dispostos ao longo das bordas perpendiculares ao lado de altura $h$;

$\mathrm{k}=4$, para demais seções retangulares e para seções circulares.

De acordo com o que foi exposto, obtém-se o valor de $\alpha$ conforme se segue: 
$N_{d}=\varphi \cdot N_{k}$

Resultando em:

$\mathrm{N}_{\mathrm{d}}=1,40 \mathrm{~N}_{\mathrm{k}} \cdot(1+\mathrm{ke} / \mathrm{h})$

Substituindo os valores, obtém-se:

$\therefore \mathrm{N}_{\mathrm{d}}=1,82 \mathrm{~N}_{\mathrm{k}} \Rightarrow \varphi=1,82$

\section{(b) Pilares de Extremidade}

Os pilares de extremidade estão submetidos a uma flexão composta, decorrente da força normal oriunda das reações das vigas e um momento fletor proveniente da ligação das vigas com o pilar em apenas uma direção. Da mesma forma que foi feito para o pilar interno, o coeficiente $\alpha$ é obtido, fazendo-se uma majoração da carga axial.

Supondo as mesmas condições especificadas para o caso do pilar interno e tomandose o valor da excentricidade inicial como $5 \%$ do valor de $h$, conforme indicações de FUSCO[1986], obtém-se:

$$
\mathrm{e}_{\mathrm{i}}=0,05 \cdot \mathrm{h} \Rightarrow \mathrm{e}_{\mathrm{i}}=1,0 \mathrm{~cm}
$$

Então:

$$
\begin{aligned}
& e=2,0 \mathrm{~cm}+1,0 \mathrm{~cm} \therefore \mathrm{e}=3,0 \mathrm{~cm} \\
& \mathrm{~N}_{\mathrm{d}}=\varphi \cdot \mathrm{N}_{\mathrm{k}}
\end{aligned}
$$

Resultando em:

$\mathrm{N}_{\mathrm{d}}=1,40 \mathrm{~N}_{\mathrm{k}} \cdot(1+\mathrm{ke} / \mathrm{h})$

Substituindo os valores, obtém-se:

$$
\therefore \mathrm{N}_{\mathrm{d}}=2,03 \mathrm{~N}_{\mathrm{k}} \Rightarrow \varphi=\mathbf{2 , 0 3}
$$

\section{(c) Pilares de Canto}

No caso de seções retangulares com armadura igual nos quatro lados, a NBR6118/78 permite a substituição da flexão oblíqua por uma flexo-compressão normal equivalente, em uma direção principal, com a excentricidade $\left(e_{x}+\beta e_{y} \cdot h / b\right)$ em que $e_{x}$ e $e_{y}$ são as projeções de e sobre os eixos principais, considerando-se direção $\mathrm{x}$ aquela em que $e_{x}>e_{y} \cdot h / b$, de acordo com a FIGURA 2.2 , onde é dado o valor de $b$. 


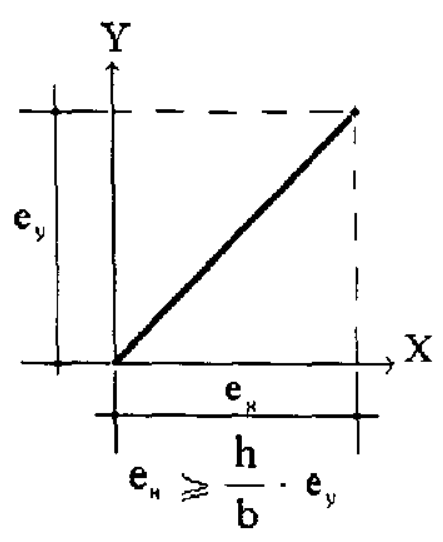

Situaçáo para o cálculo

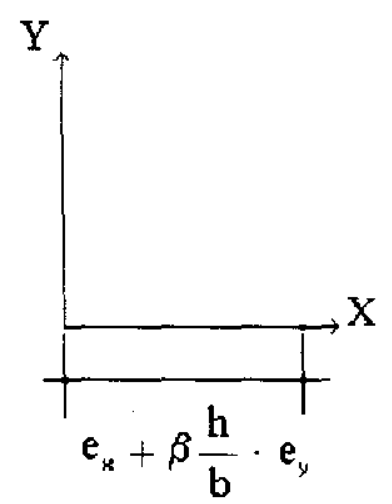

Situação equivalente

FIGURA. 2.2 - Substituição da flexão oblíqua por uma flexo-compressão equivalente (NBR-6118/78).

De acordo com o exposto anteriormente e supondo que o pilar apresenta uma seção de $20 \mathrm{~cm} \times 70 \mathrm{~cm}$ e além disso a excentricidade inicial é da ordem de $5 \%$ do valor do comprimento do lado correspondente, têm-se:

$$
v_{d} \cdot e_{x, e q}=v_{d} \cdot \frac{e_{x}}{h_{x}}+\beta \cdot v_{d} \cdot \frac{e_{y}}{h_{y}}
$$

Cancelando $v_{\mathrm{d}}$, obtém-se:

$$
\mathrm{e}_{\mathrm{x}, \mathrm{eq}}=\frac{\mathrm{e}_{\mathrm{x}}}{\mathrm{h}_{\mathrm{x}}}+\beta \cdot \frac{\mathrm{e}_{\mathrm{y}}}{\mathrm{h}_{\mathrm{y}}}
$$

Sabendo que a excentricidade de cálculo, resulta da soma da excentricidade acidental com a excentricidade inicial, obtém-se:

$$
\begin{aligned}
& \mathrm{e}_{\mathrm{x}}=0,05 \cdot 20+2,0 \therefore \mathrm{e}_{\mathrm{x}}=3,0 \mathrm{~cm} \\
& \mathrm{e}_{\mathrm{y}}=0,05.70+70 / 30 \therefore \mathrm{e}_{\mathrm{y}}=5,8 \mathrm{~cm} \\
& \therefore \mathrm{e}_{\mathrm{x}, \mathrm{eq}}=\frac{3,0}{20}+\beta \cdot \frac{5,8}{70}
\end{aligned}
$$

Supondo ainda que:

$$
\begin{aligned}
& v_{d}=0,70 \\
& \omega=0,50
\end{aligned}
$$


$O$ valor de $\beta$ resulta em 0,52 e o valor de $e_{x, \text { eq }}$ é obtido:

$$
\Rightarrow \mathrm{e}_{\mathrm{x}, \mathrm{eq}}=0,19
$$

Obtido o valor de $e_{x}$ eq, a flexão composta pode ser transformada em uma compressão centrada do mesmo modo utilizado para os pilares internos e de extremidade:

$$
\mathrm{N}_{\mathrm{d}}=\varphi \cdot \mathrm{N}_{\mathrm{k}}
$$

sendo:

$$
\mathrm{N}_{\mathrm{d}}=1,4 \cdot(1+3 \cdot \mathrm{e} / \mathrm{h}) \cdot \mathrm{N}_{\mathrm{k}}
$$

Tomando-se o valor de e/h igual a $e_{x, e q}$ :

$$
\begin{aligned}
& N_{d}=1,4 \cdot(1+3.0,22) \cdot N_{k} \\
& N_{d}=2,32 \cdot N_{k} \Rightarrow \varphi=\mathbf{2 , 3 2}
\end{aligned}
$$

Sendo assim, para o pré-dimensionamento de pilares usuais de edificios, utilizando o processo das áreas de influência, aconselha-se adotar os valores indicados na TABELA 2.2.

TABELA 2.2 - Valores recomendados para o pré-dimensionamento de pilares.

\begin{tabular}{|c|c|}
\hline Pilar & $\varphi$ \\
\hline Interno & 1,80 \\
\hline Extremidade & 2,00 \\
\hline Canto & 2,30 \\
\hline
\end{tabular}

É importante ressaltar que os valores acima mencionados servem para dar uma noção da dimensão do pilar, podendo sofrer alterações que ficam a critério do projetista.

\subsubsection{Pré -dimensionamento através das reações das vigas}

Este processo requer o cálculo estático dos pavimentos a fim de se obter as reações das vigas nos pilares. De posse do somatório de todas as reações das vigas em cada pilar, o pré-dimensionamento do mesmo é feito dividindo-se a ação de pré - dimensionamento obtida pela tensão ideal.

$$
A_{c}=\frac{N_{d}}{\sigma_{i d}}
$$




\section{CAPÍTULO 3: ESTABILIDADE GLOBAL}

Ao se efetuar o dimensionamento de um edificio em concreto armado, deve-se realizar o dimensionamento dos elementos constituintes da estrutura e também verificar a estabilidade global da mesma.

A verificação da estabilidade global de uma determinada estrutura é fundamental pois, é esta análise que possibilita avaliar se os deslocamentos ocorridos na estrutura, em decorrência do carregamento aplicado, produzem esforços adicionais consideráveis ou não. Tais esforços são chamados de esforços de $2^{\circ}$ ordem globais.

$\mathrm{Na}$ prática, os momentos fletores de $2^{\circ}$ ordem globais em uma estrutura são desprezados quando não excedem $10 \%$ dos momentos fletores de $1^{\circ}$ ordem, nestes casos a estrutura em questão é chamada de indeslocável ou de nós fixos. Caso contrário, se os momentos fletores de $2^{\circ}$ ordem ultrapassarem $10 \%$ dos momentos fletores de $1^{\circ}$ ordem, então têm-se as estruturas ditas deslocáveis ou de nós móveis e o cômputo dos esforços de $2^{\circ}$ ordem globais, no dimensionamento da estrutura, é obrigatório.

As estruturas de nós fixos, podem ser subdivididas em sistemas estruturais de contraventamento e sistemas estruturais contraventados.

\subsection{SISTEMAS ESTRUTURAIS DE CONTRAVENTAMENTO}

Sistemas estruturais de contraventamento são aqueles responsáveis pela absorção dos esforços horizontais atuantes na estrutura. Devem apresentar grande rigidez sem, contudo, interferir na arquitetura da edificação. Os sistemas estruturais de contraventamento mais utilizados são os pilares-parede, núcleos estruturais, pórticos associados e treliças metálicas, sendo que, a utilização de cada sistema estará diretamente ligada a possibilidade de adaptação da mesma na arquitetura.

Os pilares-parede ou paredes estruturais e as treliças metálicas, estão geralmente localizados nas paredes laterais, devido a sua grande dimensão. Os núcleos estruturais já estão definidos pela posição das caixas de elevador e de escada do projeto arquitetônico e os pórticos associados podem estar localizados em qualquer posição da estrutura, tomando-se 
o cuidado de não utilizar alturas de vigas que interfiram com as aberturas de portas e esquadrias ( FIGURA 3.1).

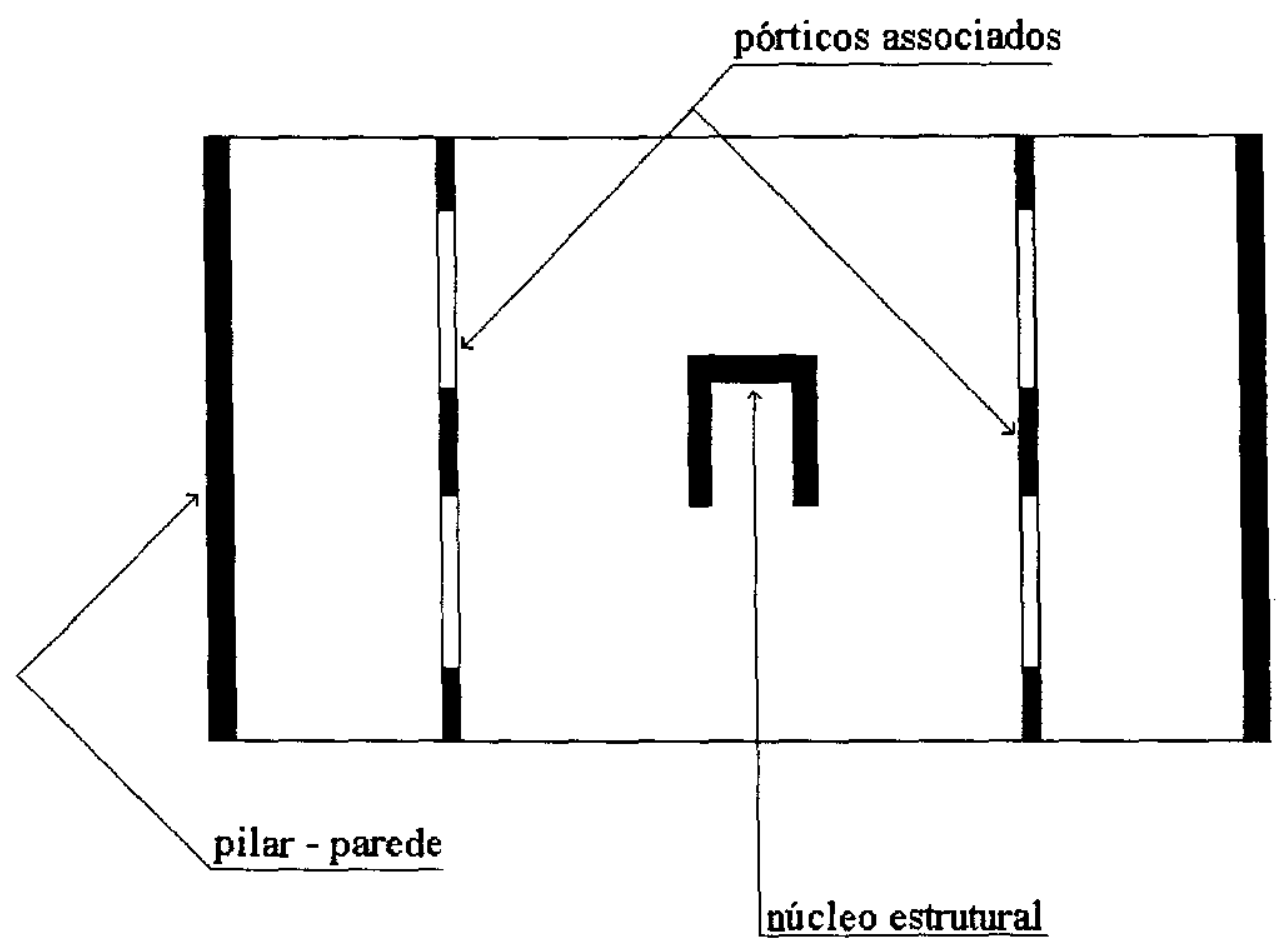

FIGURA 3.1 - Sistemas estruturais de contraventamento.

O sistema estrutural em pórticos associados é possivel devido a presença das lajes que apresentam grande rigidez no seu plano e dividem os esforços horizontais entre os vários pórticos de acordo com a rigidez de cada um. Esta rigidez que cada pórtico apresenta, pode ser associada a uma constante de mola $(\mathrm{k}$ ) determinada ao se avaliar o deslocamento que cada pórtico apresenta para uma dada força horizontal constante aplicada (FIGURA 3.2). 


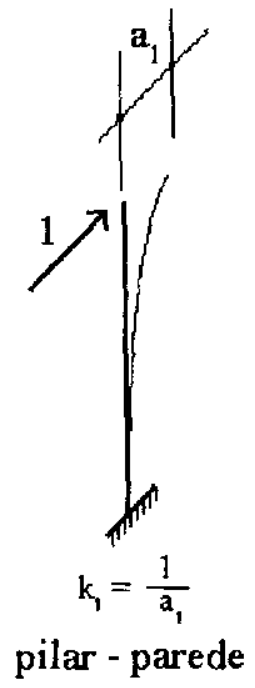

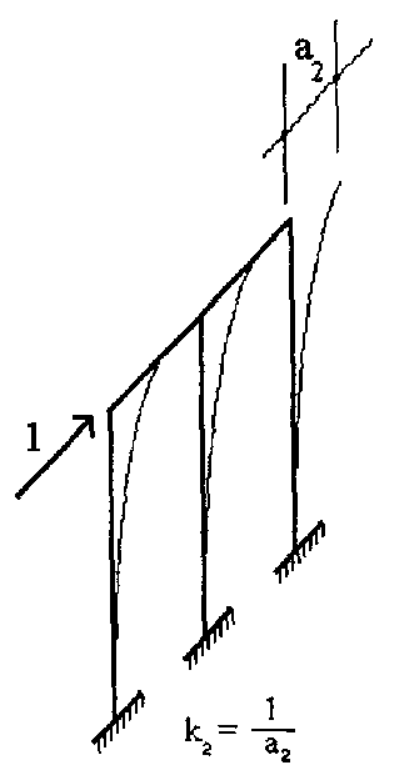

pórticos associados

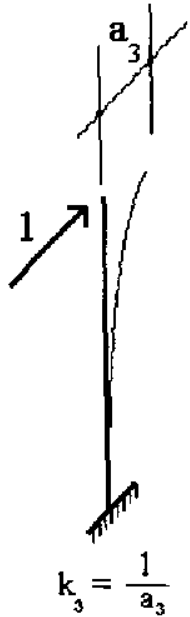

núcleo rígido

FIGURA 3.2 - Constante de mola de cada sistema estrutural de contraventamento.

Definidas as constantes de mola de cada sistema estrutural de contraventamento, as parcelas dos esforços horizontais que cada sistema irá absorver serão determinadas pelo cálculo estático de uma viga rigida sobre apoios elásticos, conforme FIGURA 3.3.

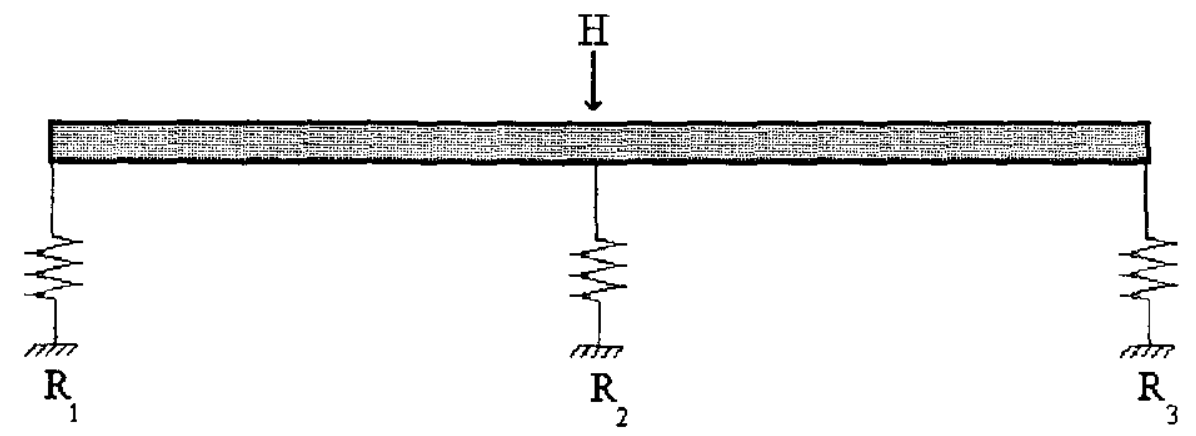

FIGURA 3.3 - Parcela de absorção dos esforços horizontais para cada sistema de contraventamento.

Logo, as reações $R_{1}, R_{2}$ e $R_{3}$ irão solicitar os sistemas de contraventamento formado por pilares-parede, pórticos associados e núcleos rígidos, respectivamente. 


\subsection{SISTEMAS ESTRUTURAIS CONTRAVENTADOS}

São os elementos estruturais que absorvem apenas os carregamentos verticais existentes na estrutura.

É interessante ressaltar que nas estruturas de nós fixos os esforços de $2^{\circ}$ ordem globais são dispensáveis, porém os elementos isolados que constituem a estrutura, devem ser dimensionados considerando os esforços de $2^{\circ}$ ordem locais, quando existirem.

Nos escritórios, a avaliação se uma estrutura é indeslocável ou não é feita basicamente fazendo-se o uso de dois processos distintos, a saber:

(a) Parâmetro de Instabilidade $\alpha$

(b) Coeficiente $\gamma_{z}$

\subsection{PARÂMETRO DE INSTABILIDADE $\alpha$}

O Parâmetro de Instabilidade $\alpha$ foi concebido por BECK $\boldsymbol{e}$ KÖNIG em 1966 a fim de avaliar a deformabilidade de um pilar isolado. $O$ modelo utilizado, consistia de um pilar engastado na base e livre no topo de seção constante e considerando que o material constituinte do pilar apresentava comportamento elástico-linear (FIGURA 3.4).

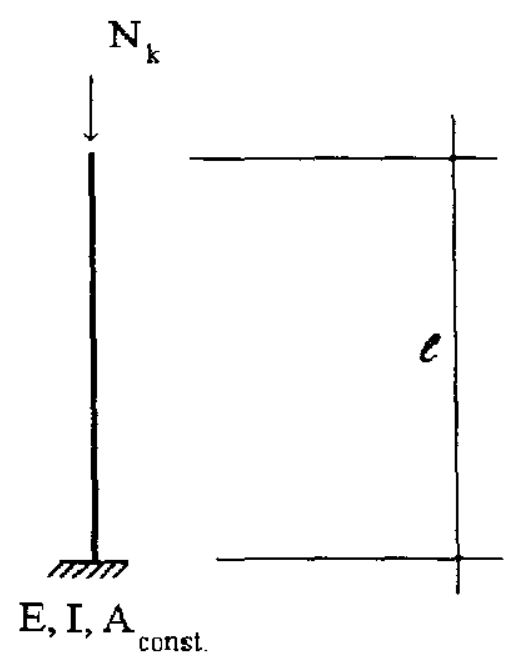

FIGURA 3.4 - Modelo proposto por BECK E KÖNIG para avaliação da deformabilidade de um pilar 
sendo:

$\ell$ - altura do pilar;

$N_{k}$ - ação vertical no pilar;

EI - módulo de rigidez da seção transversal do pilar.

Baseado neste modelo, FRANCO e VASCONCELOS[1991] avaliaram a estabilidade global de um edificio, supondo que este era formado por um único pilar com rigidez equivalente às estruturas de contraventamento do edificio. Sendo assim, propuseram a seguinte expressão para a obtenção do valor de $\alpha$, a fim de se estimar a estabilidade global de uma estrutura:

$$
\alpha=\ell \cdot \sqrt{\frac{\mathrm{N}_{\mathrm{k}}}{\mathrm{EI}}}
$$

sendo:

H - altura total do edificio, medido a partir do topo da estrutura de fundação;

$\mathrm{N}_{\mathrm{k}}$ - somatório das ações verticais atuantes no edificio;

$\mathrm{EI}$ eq - módulo de rigidez das estruturas de contraventamento do edifício equivalente a de um pilar de seção constante, engastado na base e livre no topo.

De acordo com a expressão (3.1), verifica-se que, a exceção do valor de EI eq, a obtenção do parâmetro de instabilidade $\alpha$ é simples.

\subsubsection{Obtenção do Valor de EI eq}

A obtenção do valor do módulo de rigidez equivalente, implica ao projetista a utilização de softwares específicos para o cálculo estático de estruturas. A análise da estabilidade global de uma estrutura pode ser feita considerando a estrutura tridimensional ou plana, e esta escolha está diretamente ligada à capacidade do software.

$\mathrm{Na}$ análise tridimensional, o valor do módulo de rigidez equivalente é obtido ao se avaliar o deslocamento no topo da estrutura ao ser submetida a um carregamento distribuido ao longo de sua altura. Com o valor desse deslocamento, obtém-se o valor de EI cq associando a estrutura a um pilar de seção constante de mesma altura, engastado na base e 
livre no topo submetido ao mesmo carregamento distribuído ao longo de sua altura e que apresente o mesmo deslocamento no topo (FIGURA 3.5).

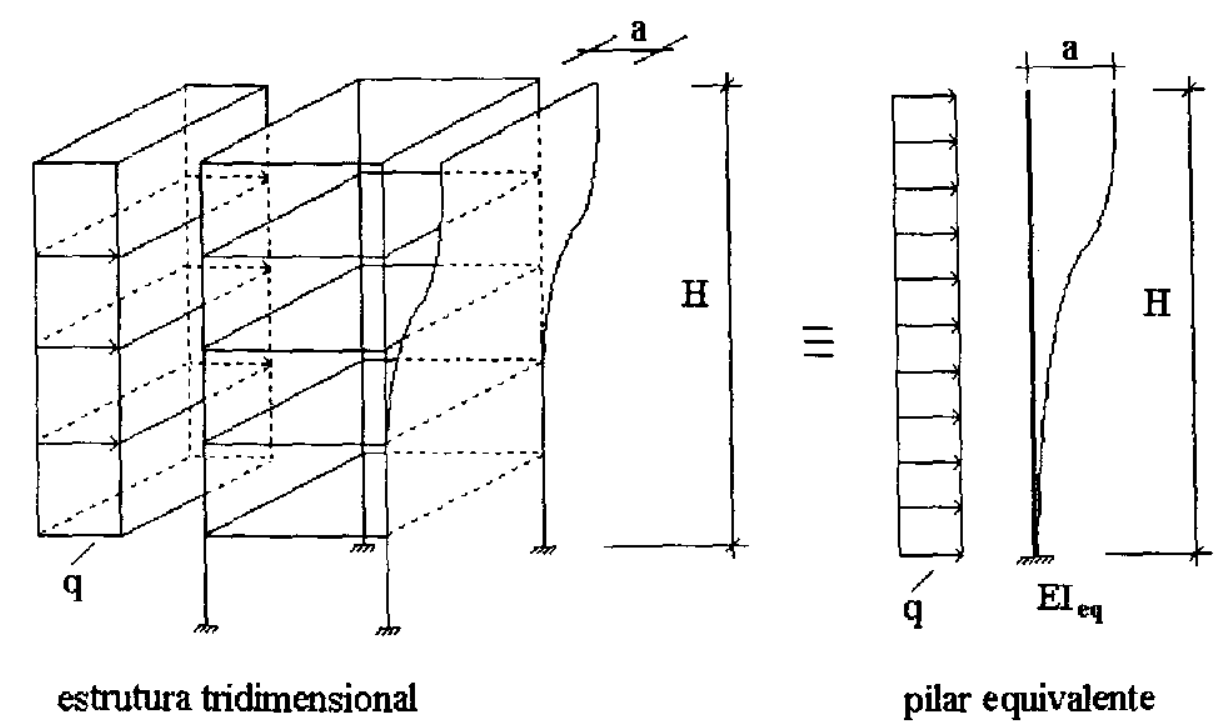

FIGURA 3.5 - Estabilidade global com análise tridimensional.

sendo:

$\mathrm{H}$ - altura total do edificio, medida a partir do topo da fundação;

$\mathrm{q}$ - carregamento uniformemente distribuído (geralmente adota-se $\mathrm{q}=1,00 \mathrm{kN} / \mathrm{m})$;

a - flecha obtida no topo do edificio (arquivo de resultados do software);

EI eq - módulo de rigidez equivalente.

De posse do arquivo de resultados do software utilizado para o cálculo estático, obtém-se o valor de El eq através da expressão (3.2) advinda da Resistência dos Materiais para a obtenção da flecha de uma barra engastada, submetida a um carregamento distribuido:

$$
\mathrm{EI}_{\mathrm{eq}}=\frac{\mathrm{qH}^{4}}{8 \mathrm{a}}
$$

A análise da estabilidade pelo modelo tridimensional, exige a utilização de softwares mais complexos onde a entrada de dados para alimentação do programa é muito trabalhosa, 
sendo assim, nos escritórios de projeto estrutural é comum a adoção do modelo bidimensional a fim de se fazer a análise da estabilidade global de uma estrutura.

O procedimento é semelhante ao utilizado no modelo tridimensional, bastando para isso se fazer uma associação das estruturas de contraventamento (pórticos, pilares-parede e núcleos rigidos) que atuam nas direções analisadas. Essa associação entre estruturas de contraventamento independentes que atuam na mesma direção, é possível em razão das lajes de piso que possuem grande rigidez no seu plano e funcionam dessa maneira como barras birotuladas de grande rigidez, unindo uma estrutura de contraventamento a outra. Na entrada de dados do software, as barras que representam as lajes e as vigas devem possuir uma seção transversal elevada a fim de evitar que ocorram deformações axiais nas mesmas, fazendo com que os resultados obtidos se afastem da hipótese assumida.

Com o intuito de esclarecer o que foi exposto anteriormente, apresenta-se a seguir um exemplo da forma de um pavimento típico de um edificio de 8 andares (FIGURA 3.6).

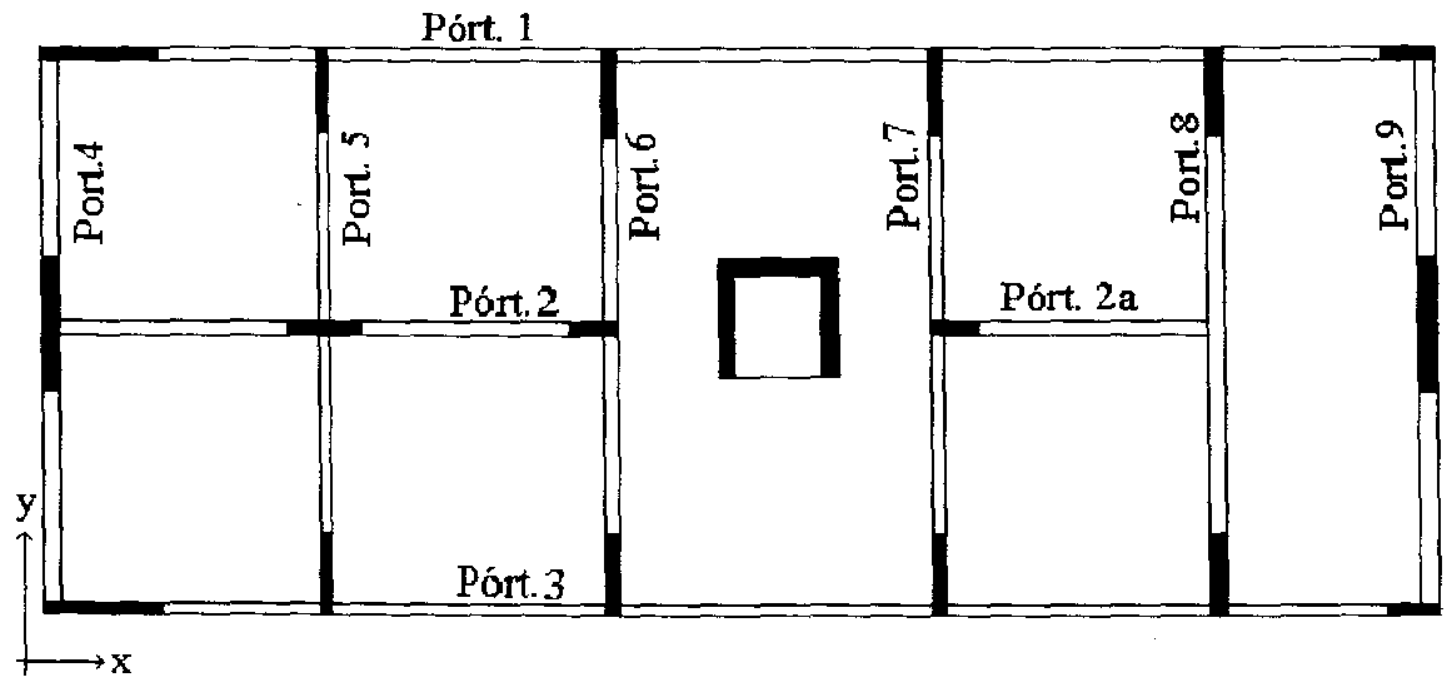

FIGURA 3.6 - Forma do pavimento tipo (exemplo).

De acordo com a FIGURA 3.6 a análise da estabilidade global utilizando-se o modelo bidimensional, deve ser feita com as associação dos pórticos 1, 2, 2a, 3 e núcleo ao se analisar a direção x (FIGURA 3.7), ao passo que, na direção y a associação deverá ser feita com os pórticos 4, 5, 6, 7, 8, 9 e núcleo (FIGURA 3.8). 


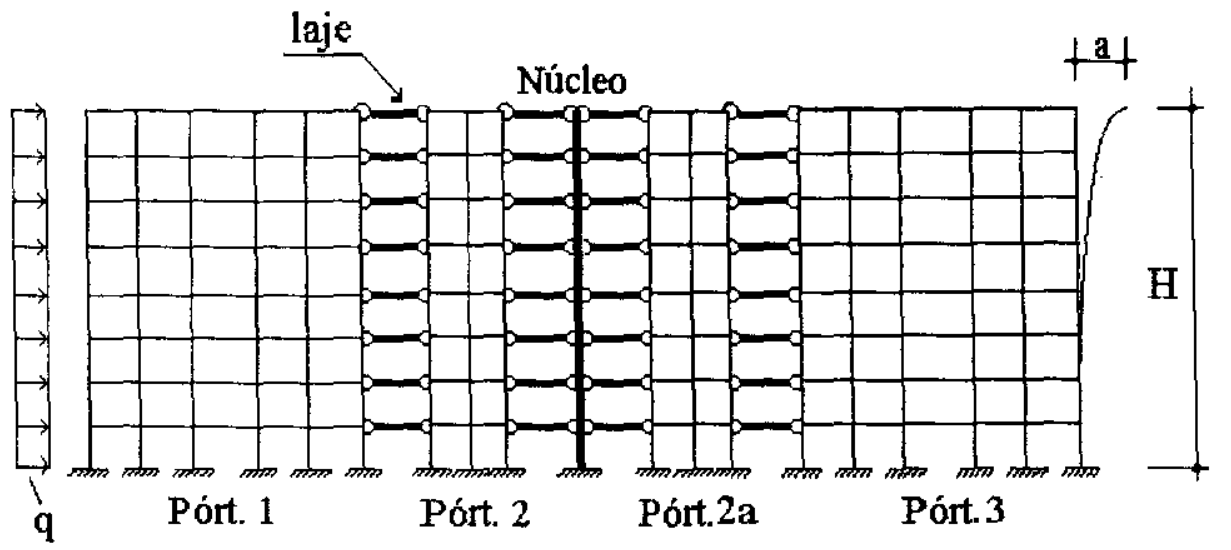

FIGURA 3.7 - Associação das estruturas de contraventamento na direção x.

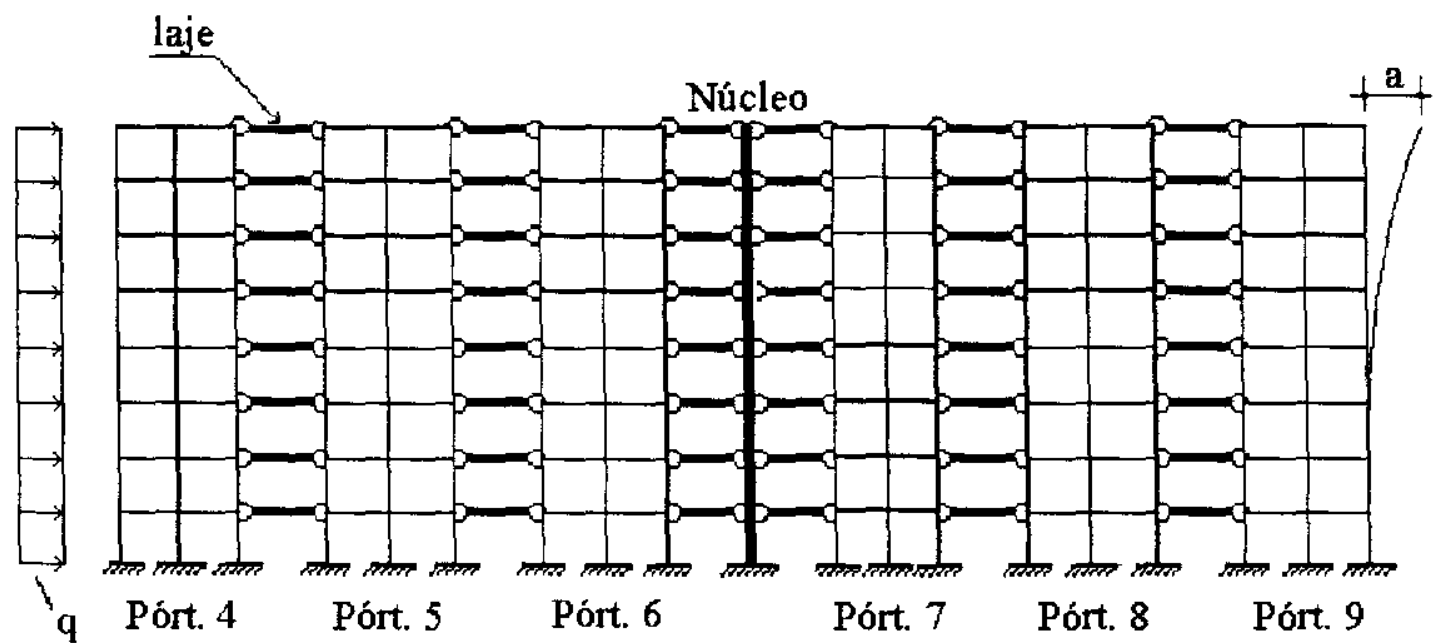

FIGURA 3.8 - Associação das estruturas de contraventamento na direção y.

O coeficiente $\alpha$ no modelo bidimensional é obtido da mesma maneira que no modelo tridimensional, substituindo as estruturas de contraventamento numa determinada direção por um pilar equivalente que produza a mesma flecha no topo ao ser submetido a um carregamento semelhante da estrutura real de contraventamento [ expressão (3.1)]. O valor de $\mathrm{EI}_{\mathrm{eq}}$, do pilar equivalente, é obtido pela mesma expressão (3.2) utilizada no modelo tridimensional.

A não linearidade física é estimada, como sugere $M A C$ GREGOR/1977J, com uma minoração das inércias das vigas e pilares, afim de que a fissuração seja considerada:

$$
\begin{aligned}
& I_{\text {vigas }}=0,60 \cdot I_{\text {vigas, real }} \\
& I_{\text {pilares }}=0,80 \cdot I_{\text {pilares, real }}
\end{aligned}
$$




\subsubsection{Valor de $\alpha_{\lim }$}

Viu-se anteriormente como se obtém o valor do coeficiente $\alpha$ fim de avaliar a estabilidade global de um edificio. É necessário então, definir valores limites do coeficiente $\alpha$ para que se consiga distinguir uma estrutura de nós fixos de uma estrutura de nós móveis. BECK E KÖNIG[1966], propuseram inicialmente o valor 0,60 para o parâmetro $\alpha_{\mathrm{lim}}$, a fim de se fazer a distinção entre estruturas móveis e fixas.

FRANCO/1985], cita em seu trabalho que o parâmetro $\alpha$ lim varia de acordo com as estruturas de contraventamento que o edificio apresenta. Se a estrutura de contraventamento for formada, principalmente, por pilares-parede, o parâmetro de instabilidade $\alpha$ lim é igual a 0,70 . O valor de $\alpha_{\text {lim }}$ vale 0,60 se as estruturas de contraventamento forem compostas de pilares-parede e pórticos (contraventamento misto). Caso as estruturas de contraventamento do edificio se baseiem apenas na associação de pórticos, então o valor de $\alpha$ lim passa a ser igual a 0,50 .

VASCONCELOS[1985], propõe que o valor do parâmetro $\alpha$ lim seja função do número de pavimentos de uma estrutura, de acordo com a expressão (3.3):

$$
\alpha \lim =\frac{1,00}{\sqrt{1,20}} \cdot\left(0,88-0,44 \cdot 10^{-0,144 n}\right)
$$

sendo:

n - número de pavimentos da estrutura.

O Texto Base para a revisão da NBR-6118/78, prescreve os seguintes valores para $\alpha_{\lim :}$

$$
\begin{aligned}
& \alpha_{\lim }=0,20+0,10^{\prime} \mathrm{n} ; \text { se } \mathrm{n} \leq 3 \\
& \alpha_{\lim }=0,60 ; \text { se } \mathrm{n}>3
\end{aligned}
$$

sendo:

$\mathrm{n}$ - número de niveis de barras horizontais (pavimentos) acima da fundação ou nível pouco deslocável do sub-solo. 


\subsection{COEFICIENTE $\gamma_{z}$}

Trata-se também de um processo para avaliar a sensibilidade da estrutura aos efeitos de segunda ordem. Esta avaliação pode ser feita a partir dos resultados de uma análise de primeira ordem, considerando comportamento elástico-linear.

O parâmetro $\gamma_{2}$ foi apresentado por VASCONCELOS E MÁRIO FRANCO[1991], com a intenção de simplificar o processo de obtenção dos esforços de segunda ordem, a partir da avaliação dos deslocamentos horizontais da estrutura. Sendo assim, o coeficiente $\gamma_{z}$ majora os esforços globais de primeira ordem a fim de se obter os esforços finais, incluindo os de segunda ordem.

$\mathrm{Na}$ análise de primeira ordem os esforços horizontais em uma estrutura provocam deslocamentos dos nós da mesma, gerando um acréscimo de momento fletor na base provocado pela somatória das excentricidades horizontais multiplicadas pelos carregamentos verticais em cada nó. Esses acréscimos de momentos fletores produzem novos deslocamentos, que por sua vez geram novos momentos fletores na base. Esse processo ocorre por várias etapas e tende a se equilibrar se a estrutura for estável, obtendo-se desta maneira os momentos fletores finais, incluindo os de segunda ordem.

O Texto Base para a revisão da NBR - 6118/78, traz a seguinte expressão para o cálculo do coeficiente $\gamma_{\mathrm{z}}$ :

$$
\gamma_{\mathrm{z}}=\frac{1}{1-\frac{\mathrm{M}_{\mathrm{tot}, \mathrm{d}}}{\mathrm{M}_{\mathrm{ttot}, \mathrm{d}}}}
$$

sendo:

$$
\begin{aligned}
& M_{1 t o t, d} \text { - momento total de todas as componentes de força horizontal, com } \\
& \text { seu valor de cálculo, em relação a base da estrutura; } \\
& M_{\text {tot,d - }} \text { valor que representa uma primeira avaliação dos esforços de segunda } \\
& \text { ordem global e é dado pelo produto de todas as forças verticais da } \\
& \text { estrutura, com seu valor de cálculo, pelos respectivos deslocamentos } \\
& \text { horizontais, obtidos em teoria de primeira ordem, de seus pontos de } \\
& \text { aplicação. }
\end{aligned}
$$


De acordo com o exposto acima, a estrutura é classificada como de nós fixos se o coeficiente $\gamma_{z} \leq 1,10$. Caso contrário, a estrutura deverá ser calculada considerando-se os efeitos globais de segunda ordem.

\subsection{ANÁLISE DE ESTRUTURAS DE NÓS MÓVEIS}

Se os processos mostrados anteriormente indicarem que uma edificação se constitui de nós móveis, caberá ao engenheiro decidir pela mudança da forma da estrutura, isto é, enrijecê-la a fim de que seus nós sejam considerados fixos em uma nova análise da estabilidade global ou fazer o cálculo do edifício considerando os esforços de segunda ordem globais e admitindo a não linearidade fisica do concreto estrutural.

Caso se opte pela não mudança da forma da estrutura, os esforços de segunda ordem globais poderão ser obtidos através do processo $\mathrm{P}-\Delta$, método bastante utilizado nos escritórios de projeto estrutural a fim de se obter os esforços de segunda ordem globais em uma estrutura.

Este processo consiste em um cálculo iterativo que transforma os deslocamentos sucessivos obtidos pela estrutura, em esforços horizontais equivalentes. Essa iteração é realizada até se observar uma convergência dos valores de deformação da estrutura, o que indicaria que a estrutura é estável e os esforços obtidos são de segunda ordem. Este processo considera a não linearidade geométrica do fenômeno, a não linearidade fisica é estimada, como sugere MAC GREGOR/1977], exatamente da mesma maneira realizada na análise da estabilidade global.

$$
\begin{aligned}
& I_{\text {vigas }}=0,60 \cdot I_{\text {vigas, real }} \\
& I_{\text {pilares }}=0,80 \cdot I_{\text {pilares, real }}
\end{aligned}
$$

O Texto Base para a revisão da NBR - $6118 / 78$, prevê uma análise de segunda ordem aproximada com o auxilio do coeficiente $\gamma_{2}$. Se 1,10 $\leq \gamma_{z} \leq 1,20$ permite-se avaliar os esforços de segunda ordem global a partir da multiplicação dos esforços horizontais por $\gamma_{\mathrm{z}}$.

VASCONCELOS [1987], propõe, para os casos onde o coeficiente $\gamma_{z}$ se encontra entre os limites 1,10 e 1,20; outra análise simplificada para obtenção dos esforços de segunda ordem global, que consiste na majoração das ações horizontais por um coeficiente k, dado pela expressão (3.5): 


$$
\mathrm{k}=1+\frac{1}{\left[\frac{\alpha_{\mathrm{cr}}^{2}}{1,2 \cdot \alpha^{2}}-1\right] \cdot \gamma}
$$

sendo:

k - fator de majoração das cargas horizontais;

$\alpha$ - parâmetro de instabilidade;

$\gamma$ - fator de ajuste (Tabela 1.3);

$\alpha_{\mathrm{cr}}=2,80-1,10^{\cdot} \mathrm{e}^{-0,22 \mathrm{n}} ; \mathrm{n}$ - número de pavimentos;

TABELA 3.1 - Fator de ajuste para análise do efeito de segunda ordem global, proposto por VASCONCELOS.

\begin{tabular}{|c|c|c|c|c|c|c|c|c|}
\hline $\mathbf{n}$ & $\mathbf{1}$ & $\mathbf{2}$ & $\mathbf{3}$ & $\mathbf{4}$ & $\mathbf{5}$ & $\mathbf{1 0}$ & $\mathbf{2 0}$ & $>\mathbf{2 0}$ \\
\hline $\boldsymbol{y}$ & 0,60 & 0,92 & 1,07 & 1,20 & 1,27 & 1,39 & 1,46 & 1,52 \\
\hline
\end{tabular}




\section{CAPÍTULO 4: AÇÕES NAS ESTRUTURAS}

Segundo o Texto Base para a revisão da NBR - 6118/78, ações são definidas como as causas que provocam esforços ou deformações nas estruturas.

O EUROCODE[1989] define ações como sendo forças ou cargas aplicadas às estruturas, podendo ser diretas, como por exemplo o peso próprio da estrutura ou indiretas, como a retração, efeito da temperatura e recalques de apoio.

Ao se efetuar uma análise estrutural, deve-se considerar todas as ações que possam produzir efeitos desfavoráveis à estrutura em questão, levando-se em conta os possiveis estados limites últimos e os de utilização.

De acordo com a NBR-8681[1984], as ações nas edificações podem ser divididas em:

- ações permanentes;

- ações variáveis;

- ações excepcionais.

\subsection{AÇÕES PERMANENTES}

Ações permanentes são aquelas que ocorrem com valores praticamente constantes durante toda a vida da estrutura. Também são consideradas como permanentes as ações que crescem no tempo tendendo a um valor limite constante.

As ações permanentes são consideradas com seus valores representativos mais desfavoráveis para a segurança. Podem ser ainda subdivididas em ações permanentes diretas e indiretas, a saber:

(a) Ações Permanentes Diretas;

As ações permanentes diretas são formadas pelo peso próprio da estrutura e pelos pesos dos elementos construtivos fixos, das instalações permanentes, empuxos devidos ao peso próprio de terras não removíveis e de outras ações permanentes sobre elas aplicadas.

A NBR-6120[1980], traz alguns pesos especificos de materiais de construção que devem ser adotados, quando não se dispuser de determinação experimental, no levantamento dos carregamentos (TABELA 4.1). 
TABELA 4.1 - Peso específico de materiais de construção (NBR-6120).

\begin{tabular}{|c|c|c|}
\hline \multicolumn{2}{|r|}{ Materiais } & Peso específico \\
\hline Rochas & $\begin{array}{l}\text { Arenito } \\
\text { Basalto } \\
\text { Gneiss } \\
\text { Granito } \\
\text { Mármore e calcário }\end{array}$ & $\begin{array}{l}26 \\
30 \\
30 \\
28 \\
28\end{array}$ \\
\hline $\begin{array}{c}\text { Blocos } \\
\text { Artificiais }\end{array}$ & $\begin{array}{l}\text { Blocos de argamassa } \\
\text { Cimento amianto } \\
\text { Lajotas cerâmicas } \\
\text { Tijolos furados } \\
\text { Tijolos maciços } \\
\text { Tijolos sílico-calcáreos }\end{array}$ & $\begin{array}{l}22 \\
20 \\
18 \\
13 \\
18 \\
20\end{array}$ \\
\hline $\begin{array}{l}\text { Revestimentos } \\
\text { e Concretos }\end{array}$ & $\begin{array}{l}\text { Argamassa de cal, cimento e areia } \\
\text { Argamassa de cimento e areia } \\
\text { Argamassa de gesso } \\
\text { Concreto simples } \\
\text { Concreto armado }\end{array}$ & $\begin{array}{c}19 \\
21 \\
12,5 \\
24 \\
25\end{array}$ \\
\hline Madeiras & $\begin{array}{l}\text { Pinho e cedro } \\
\text { Louro, imbuia e pau óleo } \\
\text { Guajuvirá, guatambu e grápia } \\
\text { Angico, cabriuva e ipê róseo }\end{array}$ & $\begin{array}{c}5 \\
6,5 \\
8 \\
10\end{array}$ \\
\hline Metais & $\begin{array}{l}\text { Aço } \\
\text { Alumínio } \\
\text { Bronze } \\
\text { Chumbo } \\
\text { Cobre } \\
\text { Ferro Fundido } \\
\text { Estanho } \\
\text { Latão } \\
\text { Zinco }\end{array}$ & $\begin{array}{c}78,5 \\
28 \\
85 \\
114 \\
89 \\
72,5 \\
74 \\
86 \\
72\end{array}$ \\
\hline $\begin{array}{c}\text { Materiais } \\
\text { Diversos }\end{array}$ & $\begin{array}{l}\text { Alcatrão } \\
\text { Asfalto } \\
\text { Borracha } \\
\text { Papel } \\
\text { Plástico em folhas } \\
\text { Vidro plano }\end{array}$ & $\begin{array}{l}12 \\
13 \\
17 \\
15 \\
21 \\
16\end{array}$ \\
\hline
\end{tabular}

Além da TABELA 4.1, existem alguns pesos por unidade de área de alguns materiais constituintes dos edificios usuais que podem ser úteis, a fim de se fazer o levantamento das cargas permanentes atuantes em uma estrutura (TABELA 4.2). 
TABELA 4.2 - Ações permanentes por unidade de área.

\begin{tabular}{|c|c|c|}
\hline Item & Material & $\begin{array}{c}\text { Ação } \\
\left(k N / m^{2}\right)\end{array}$ \\
\hline \multirow{8}{*}{ Paredes } & Tijolos maciços, com $25 \mathrm{~cm}$ de espessura & 4,0 \\
\hline & Tijolos maciços, com $15 \mathrm{~cm}$ de espessura & 2,5 \\
\hline & Tijolos furados, com $23 \mathrm{~cm}$ de espessura & 3,2 \\
\hline & Tijolos furados, com $13 \mathrm{~cm}$ de espessura & 2,2 \\
\hline & Tijolos de concreto, com $23 \mathrm{~cm}$ de espessura & 3,5 \\
\hline & Tijolos de concreto, com $13 \mathrm{~cm}$ de espessura & 2,2 \\
\hline & Tijolos de concreto celular, com $23 \mathrm{~cm}$ de espessura & 0,8 \\
\hline & Tijolos de concreto celular, com $13 \mathrm{~cm}$ de espessura & 0,5 \\
\hline \multirow{4}{*}{ Cobertura } & Com telhas cerâmicas, com madeiramento & 1,2 \\
\hline & Com telhas de fibrocimento, com madeiramento & 0,4 \\
\hline & Com telhas de alumínio e estrutura de aço & 0,3 \\
\hline & Com telha de alumínio e estrutura de alumínio & 0,2 \\
\hline \multirow[t]{2}{*}{ Forros } & Com painéis de gesso, com estrutura de madeira e aço & 0,5 \\
\hline & Com blocos sólidos de gesso & 0,7 \\
\hline \multirow[t]{2}{*}{ Caixilhos } & Com estrutura de aluminio, com vidros & 0,2 \\
\hline & Com estrutura de aço, com vidros & 0,3 \\
\hline \multirow[t]{2}{*}{ Telhas } & De fibrocimento tipo canalete 43 & 0,28 \\
\hline & De fibrocimento tipo canalete 90 & 0,25 \\
\hline
\end{tabular}

(b) Ações Permanentes Indiretas;

As ações permanentes indiretas são aquelas que solicitam à estrutura após a mesma sofrer deformações impostas, ou seja:

- recalques de apoio;

- forças de protensão;

- retração dos materiais.

\subsection{AÇÕES VARIÁVEIS}

As ações variàveis são aquelas que atuam na estrutura em decorrência do seu uso, ou seja, são as ações resultantes em função da presença de pessoas, móveis, materiais diversos, veiculos, vento, forças de frenagem em pontes, variações de temperatura, etc. Em função de sua probabilidade de ocorrência durante a vida da construção, as ações são classificadas em normais ou especiais.

(a) Ações Variáveis Normais: são as ações variáveis com grande possibilidade de ocorrência, sendo assim, a sua consideração passa a ser obrigatória no projeto estrutural de uma dada edificação. 
(b) Ações Variáveis Excepcionais: em certas estruturas sujeitas às ações de origem sísmica ou cargas acidentais de natureza ou de intensidade especiais, elas também devem ser admitidas como ações variáveis.

A NBR-6120[1980] prevê valores mínimos a serem adotados para as ações variáveis verticais (TABELA 4.3).

TABELA 4.3 - Valores mínimos das ações acidentais verticais.

\begin{tabular}{|c|c|c|}
\hline \multicolumn{2}{|r|}{ Local } & \multirow{2}{*}{\begin{tabular}{|c|}
$\begin{array}{c}\text { Carga } \\
(\mathbf{k N} / \mathbf{m} 2)\end{array}$ \\
4,0 \\
\end{tabular}} \\
\hline Arquibancada & & \\
\hline Balcões & $\begin{array}{l}\text { Mesma carga da peça com a qual se } \\
\text { comunicam }^{(1)}\end{array}$ & - \\
\hline \multirow[t]{2}{*}{ Bancos } & Escritórios e banheiros & 2,0 \\
\hline & Salas de diretoria e de gerência & 1,5 \\
\hline \multirow[b]{3}{*}{ Bibliotecas } & Sala de leitura & 2,5 \\
\hline & Sala para depósito de livros & 4,0 \\
\hline & $\begin{array}{l}\text { Sala com estantes de livros a ser deter- } \\
\text { minada em cada caso ou } 2,5 \mathrm{kN} / \mathrm{m} 2 \\
\text { por metro de altura observado, porém } \\
\text { o valor mínimo de }\end{array}$ & 6,0 \\
\hline $\begin{array}{l}\text { Casas de } \\
\text { Máquinas }\end{array}$ & $\begin{array}{l}\text { (incluindo o peso das máquinas) a ser } \\
\text { determinada em cada caso, porém com o } \\
\text { valor mínimo de }\end{array}$ & 7,5 \\
\hline \multirow{3}{*}{ Cinemas } & Platéia com assentos fixos & 3,0 \\
\hline & Estúdio e platéia com assentos móveis & 4,0 \\
\hline & Banheiro & 2,0 \\
\hline \multirow{4}{*}{ Clubes } & $\begin{array}{l}\text { Sala de refeições e de assembléia com } \\
\text { assentos fixos }\end{array}$ & 3,0 \\
\hline & Sala de assembléia com assentos móveis & 4,0 \\
\hline & \begin{tabular}{|l|} 
Salão de danças e salão de esportes \\
\end{tabular} & 5,0 \\
\hline & Sala de bilhar e banheiro & 2,0 \\
\hline \multirow[t]{2}{*}{ Corredores } & Com acesso ao público & 3,0 \\
\hline & Sem acesso ao público & 2,0 \\
\hline $\begin{array}{l}\text { Cozinhas não } \\
\text { Residenciais }\end{array}$ & $\begin{array}{l}\text { A ser determinada em cada caso, porém } \\
\text { com o mínimo de }\end{array}$ & 3,0 \\
\hline Depósitos & A ser determinada em cada caso ${ }^{(2)}$ & - \\
\hline \multirow{2}{*}{$\begin{array}{c}\text { Edificios } \\
\text { Residenciais }\end{array}$} & Dormitórios, sala, copa, cozinha e banheiro & 1,5 \\
\hline & Dispensa, área de serviço e lavanderia & 2,0 \\
\hline
\end{tabular}


TABELA 4.3 - Valores minimos das cargas acidentais verticais (cont.).

\begin{tabular}{|c|c|c|}
\hline \multirow[t]{2}{*}{ Escadas } & Com acesso ao público & 3,0 \\
\hline & Sem acesso ao público & 2,5 \\
\hline \multirow[t]{2}{*}{ Escolas } & Anfiteatro com assentos fixos & - \\
\hline & Corredor e sala de aula & 3,0 \\
\hline \multirow[t]{2}{*}{ Escritórios } & Outras salas & 2,0 \\
\hline & Salas de uso geral e banheiro & 2,0 \\
\hline Forros & Sem acesso a pessoas & 0,5 \\
\hline $\begin{array}{l}\text { Galerias de } \\
\text { arte } \\
\end{array}$ & $\begin{array}{l}\text { A ser determinada em cada caso, porém } \\
\text { com o mínimo de }\end{array}$ & 3,0 \\
\hline Lojas & $\begin{array}{l}\text { A ser determinada em cada caso, porém } \\
\text { com o mínimo de }\end{array}$ & 3,0 \\
\hline $\begin{array}{c}\text { Garagens e } \\
\text { Estacionamento }\end{array}$ & $\begin{array}{l}\text { Para veículos de passageiros ou semelhan- } \\
\text { tes com carga máxima de } 25 \mathrm{kN} \text { por vei- } \\
\text { culo. Valores de } \phi \text { conforme }{ }^{(3)}\end{array}$ & 3,0 \\
\hline $\begin{array}{l}\text { Ginásio de } \\
\text { Esportes }\end{array}$ & & 5,0 \\
\hline \multirow[t]{2}{*}{ Hospitais } & $\begin{array}{l}\text { Dormitórios, enfermarias, sala de recupe- } \\
\text { ração, sala de cirurgia, sala de raio X e ba- } \\
\text { nheiro }\end{array}$ & 2,0 \\
\hline & Corredor & 3,0 \\
\hline Laboratórios & $\begin{array}{l}\text { Incluindo equipamentos, a ser determinada } \\
\text { em cada caso, porém com o mínimo de }\end{array}$ & 3,0 \\
\hline Lavanderias & Incluindo equipamentos & 3,0 \\
\hline Lojas & & 4,0 \\
\hline Restaurantes & & 3,0 \\
\hline \multirow[b]{2}{*}{ Teatros } & Palco & 5,0 \\
\hline & $\begin{array}{l}\text { Demais dependências: cargas iguais às es- } \\
\text { pecificadas para cinemas }\end{array}$ & - \\
\hline \multirow[b]{4}{*}{ Terraços } & Sem acesso ao público & 2,0 \\
\hline & Com acesso ao público & 3,0 \\
\hline & Inacessivel a pessoas & 0,5 \\
\hline & $\begin{array}{l}\text { Destinados a heliportos elevados: as car- } \\
\text { gas deverão ser fornecidas pelo órgão } \\
\text { competente do Ministério da Aeronáutica }\end{array}$ & - \\
\hline \multirow[t]{2}{*}{ Vestíbulo } & Sem acesso ao público & 1,5 \\
\hline & Com acesso ao público & 3,0 \\
\hline
\end{tabular}

(1) - Ao longo dos parapeitos e balcões devem ser consideradas aplicadas uma ação horizontal de $0,8 \mathrm{kN} / \mathrm{m}$ na altura do corrimão e uma carga vertical mínima de $2,0 \mathrm{kN} / \mathrm{m}$. 
(2) - No caso de armazenagem em depósitos e na falta de valores experimentais, o peso dos materiais armazenados pode ser obtido através dos pesos específicos aparentes que constam da Tabela 4.3.

(3) - O valor do coeficiente $\phi$ de majoração das cargas acidentais a serem consideradas no projeto de garagens e estacionamentos para veículos deve ser determinado do seguinte modo:

$$
\begin{aligned}
& \phi=1,00 ; \text { quando } \ell \geq \ell_{0} ; \\
& \phi=\iota_{0} \leq 1,43 ; \text { quando } \ell \leq \iota_{0} ;
\end{aligned}
$$

sendo:

$$
\begin{aligned}
& \ell \text { - o vão de uma viga ou o menor vão de uma laje; } \\
& \ell_{0}=3,0 \text { m para o caso de lajes e } \ell_{0}=5,0 \text { m para o caso de vigas; }
\end{aligned}
$$

\subsection{AÇÕES EXCEPCIONAIS}

As ações excepcionais são as que têm duração extremamente curta e muito baixa probabilidade de ocorrência durante a vida da construção, mas que devem ser consideradas nos projetos de determinadas estruturas. Como exemplo de ações excepcionais pode-se citar: explosões, choques de veículos, incêndios, enchentes ou sismos excepcionais.

\subsection{AÇÕES DEVIDAS AO VENTO}

A ação do vento deve ser considerada em todas as edificações onde o seu efeito produza esforços estáticos ou dinâmicos consideráveis.

\subsubsection{Procedimento para o Cálculo de Forças Devidas ao Vento em Edificações}

(a)_Velocidade Básica do Vento $-V_{o}(\mathrm{~m} / \mathrm{s})$ : Segundo a NBR- 6123[1988], a velocidade básica do vento $\left(V_{0}\right)$ é a velocidade de uma rajada de três segundos, excedida em média uma vez em 50 anos, a 10 metros acima do terreno, em campo aberto e plano.

A FIGURA 4.1 apresenta o gráfico das isopletas de velocidade básica no Brasil, com intervalos de $5 \mathrm{~m} / \mathrm{s}$. 


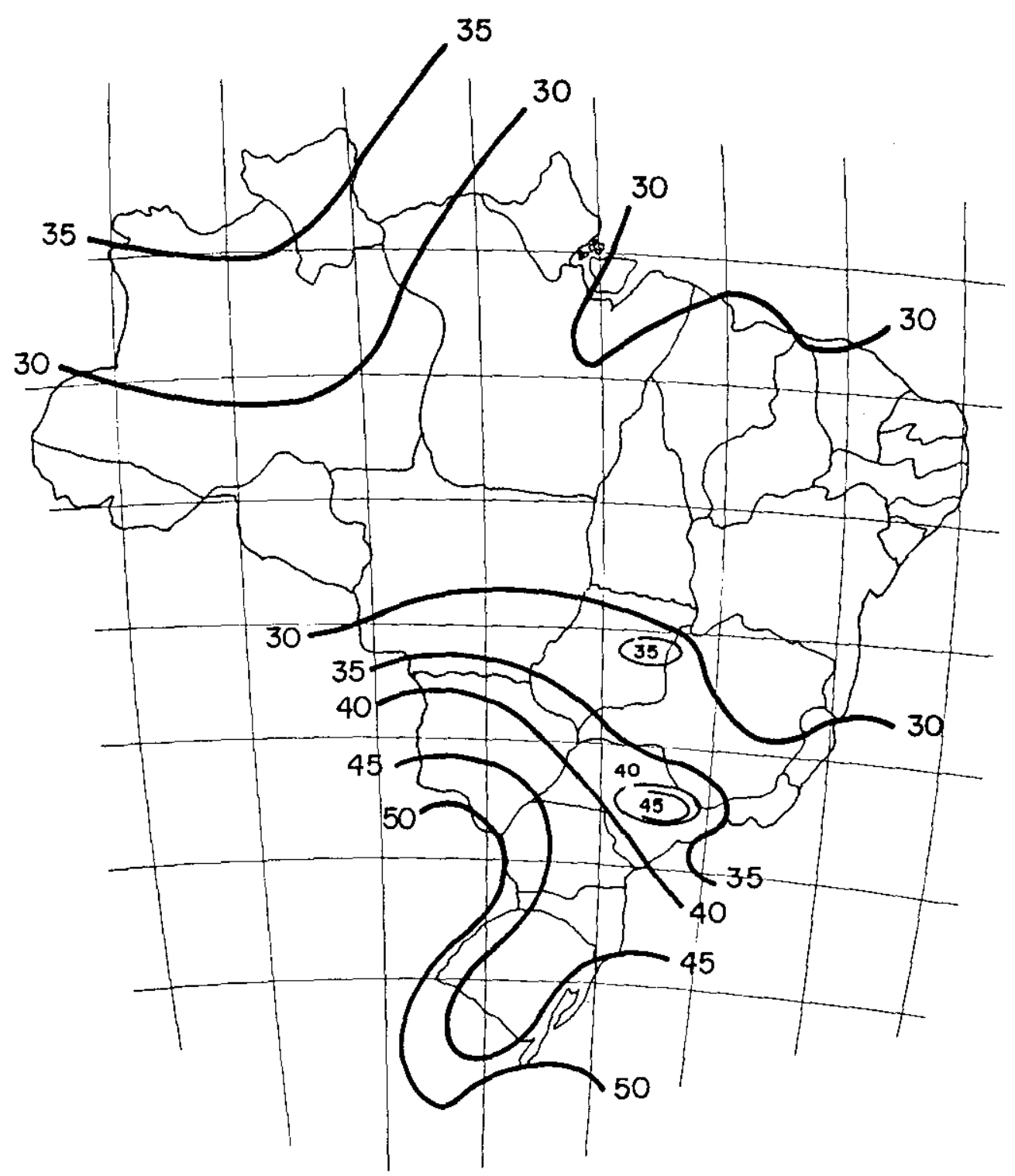

FIGURA 4.1 - Isopletas da velocidade básica do vento $V_{0}$ [NBR-6123].

(b) Velocidade Característica do Vento $-V_{k}(\mathrm{~m} / \mathrm{s})$ : A velocidade característica do vento é obtida através da multiplicação da velocidade básica do vento $\left(\mathrm{V}_{\mathrm{o}}\right)$ pelos fatores $S_{1}, S_{2}$ e $S_{3}$, definidos a seguir:

$$
V_{k}=V_{o} \cdot S_{1} \cdot S_{2} \cdot S_{3}
$$

(c) Fator S1: O fator topográfico $S_{1}$, considera as variações do relevo do terreno e é determinado do seguinte modo:

- terreno plano ou fracamente acidentado: $S_{1}=1,0$; 
- taludes e morros,

-taludes e morros alongados nos quais pode ser admitido um fluxo de ar bidimensional soprando no sentido indicado na FIGURA 4.2.
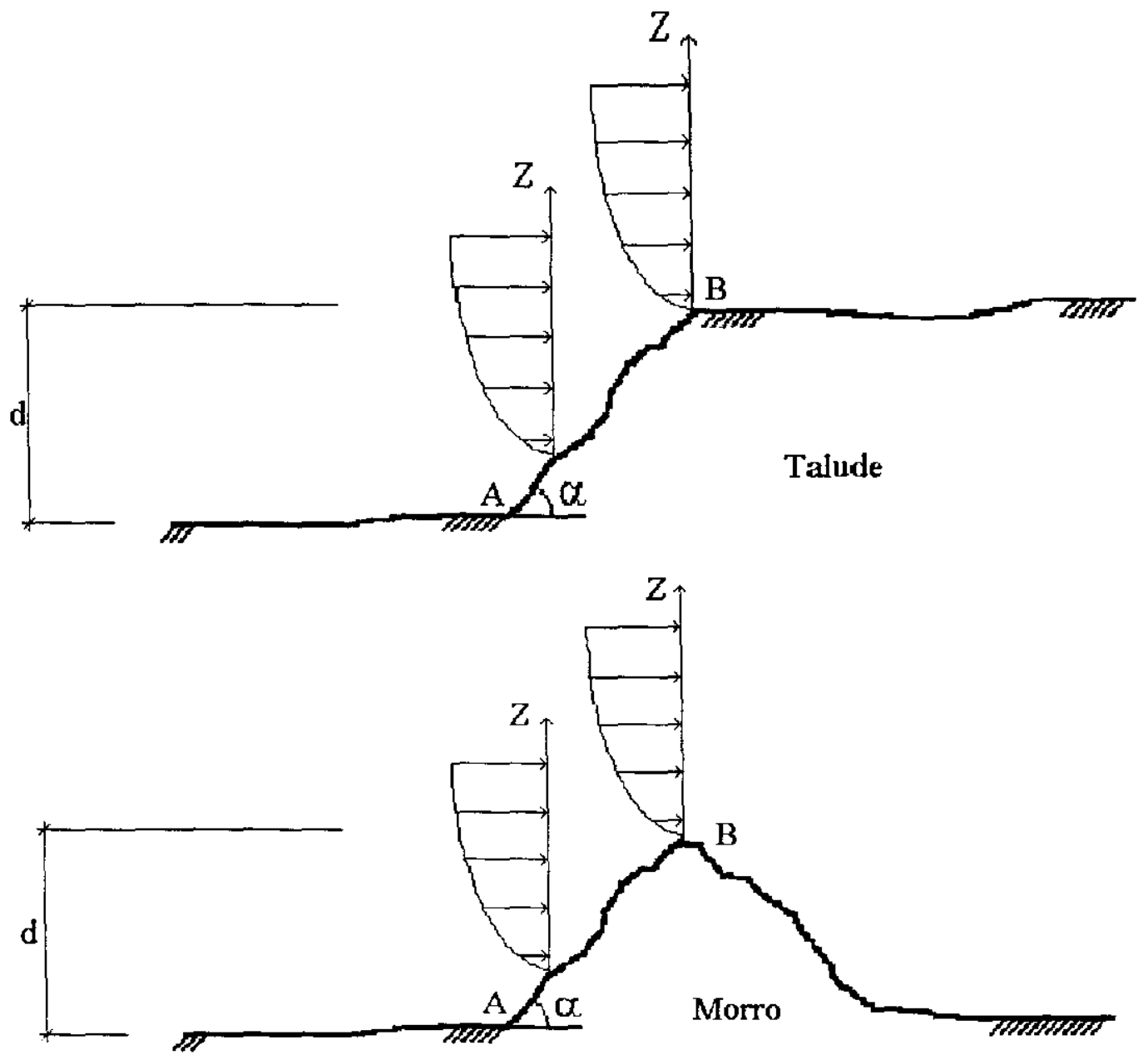

FIGURA 4.2 - Fator topográfico $S_{1}(N B R$ - 6123).

- No ponto A ( morro) e nos pontos A e C ( talude ): $S_{1}=1,0$;

- No ponto $\mathrm{B}, \mathrm{S}_{\mathrm{I}}$ é função de $\mathrm{z}$ :

$$
\begin{aligned}
& \alpha \leq 3^{\circ}: S_{1}=1,0 ; \\
& 6^{\circ} \leq \alpha \leq 17^{\circ}: S_{1}=1,0+(2,5-z / d) \cdot \operatorname{tg}\left(\alpha-3^{\circ}\right) \geq 1,0 ; \\
& \alpha \geq 45^{\circ}: S_{1}=1,0+(2,5-z / d) \cdot 0,31 \geq 1,0 ;
\end{aligned}
$$

Para valores de $\alpha$ entre os limites acima, é conveniente se fazer uma interpolação linear

sendo:

z - altura medida a partir de superficie do terreno no ponto considerado;

d - diferença de nível entre a base e o topo do talude ou morro; 
$\alpha$ - inclinação média do talude ou encosta do morro.

- vales profundos, protegidos de vento em qualquer direção: $S_{1}=0,9$ :

(d) Fator $S_{2}: O$ fator $S_{2}$ considera o efeito combinado da rugosidade do terreno, da variação da velocidade do vento com a altura acima do terreno e das dimensões da edificação ou parte da edificação em consideração.

Segundo a NBR - 6123, a rugosidade do terreno é classificada em cinco categorias, a saber:

- Categoria I: superficies lisas de grande dimensões, com mais de $5 \mathrm{~km}$ de extensão, medida na direção e sentido do vento incidente:

- mar calmo;

- lagos e rios;

- pântanos sem vegetação.

- Categoria II: terrenos abertos em nivel ou aproximadamente em nível, com poucos obstáculos isolados, tais como árvores e edificações baixas:

- zonas costeiras planas;

- pântanos com vegetação rala;

- campos de aviação;

- pradarias e charnecas;

- fazendas sem sebes ou muros.

- Categoria III: terrenos planos ou ondulados com obstáculos, tais como sebes e muros, poucos quebra-ventos de árvores, edificações baixas e esparsas:

- granjas e casas de campo, com exceção das partes com matos;

- fazendas com sebes e/ou muros;

- subúrbios e considerável distância do centro, com casas baixas e esparsas.

- Categoria IV: terrenos cobertos por obstáculos numerosos e pouco espaçados, em zona florestal, industrial ou urbanizada:

- zonas de parques e bosques com muitas árvores;

- cidades pequenas e seus arredores;

- subúrbios densamente construidos de grandes cidades; 
- áreas industriais plena ou parcialmente desenvolvida.

- Categoria V: terrenos cobertos por obstáculos numerosos, grandes, altos e pouco espaçados:

- florestas com árvores altas de copas isoladas;

- centros de grandes cidades;

- complexos industriais bem desenvolvidos.

Quando o vento atua em uma edificação, as dimensões horizontais e verticais da mesma também influem no intervalo de tempo necessário para que a ação do vento englobe a estrutura. A NBR- 6123, prevê, para o cálculo de $S_{2}$, a distinção de três classes de estrutura de acordo com as respectivas dimensões:

- Classe A: Todas as unidades de vedação, seus elementos de fixação e peças individuais de estruturas sem vedação. Toda edificação na qual a maior dimensão horizontal ou vertical não exceda $20 \mathrm{~m}$.

- Classe B: Toda edificação ou parte da edificação para a qual a maior dimensão horizontal ou vertical da superfície frontal esteja entre $20 \mathrm{e}$ $50 \mathrm{~m}$.

- Classe C: Toda edificação ou parte da edificação para a qual a maior dimensão horizontal ou vertical da superficie frontal exceda $50 \mathrm{~m}$

Para edificações onde a maior dimensão horizontal ou vertical exceda $80 \mathrm{~m}$, o intervalo de tempo necessário para que a ação do vento englobe a estrutura, poderá ser obtida com as indicą̧ões do Anexo A da NBR - 6123.

A seguir será mostrado, na TABELA 4.4, os valores de $S_{2}$ recomendados pela NBR -6123 . 
TABELA 4.4 - Valores para o fator $S_{2}$.

\begin{tabular}{|c|c|c|c|c|c|c|c|c|c|c|c|c|c|c|c|}
\hline \multirow{4}{*}{$\begin{array}{c}\% \\
(m)\end{array}$} & \multicolumn{15}{|c|}{ Categoria } \\
\hline & \multicolumn{3}{|c|}{ I } & \multicolumn{3}{|c|}{11} & \multicolumn{3}{|c|}{ III } & \multicolumn{3}{|c|}{ IV } & \multicolumn{3}{|c|}{ v } \\
\hline & \multicolumn{3}{|c|}{ Classe } & \multicolumn{3}{|c|}{ Classe } & \multicolumn{3}{|c|}{ Classe } & \multicolumn{3}{|c|}{ Classe } & \multicolumn{3}{|c|}{ Classe } \\
\hline & A & B & C & A & B & C & A & B & C & A & B & C & A & B & C \\
\hline$\geq 5$ & 1,06 & 1,04 & 1,01 & 0,94 & 0,92 & 0,89 & 0,83 & 0,86 & 0,82 & 0,79 & 0,76 & 0,73 & 0,74 & 0,72 & 0,67 \\
\hline 10 & 1,10 & 1,09 & 1,06 & 1,00 & 0,98 & 0,95 & 0,94 & 0,92 & 0,88 & 0,86 & 0,83 & 0,80 & 0,74 & 0,72 & 0,67 \\
\hline 15 & 1,13 & 1,12 & 1,09 & 1,04 & 1,02 & 0,99 & 0,98 & 0,96 & 0,93 & 0,90 & 0,88 & 0,84 & 0,79 & 0,76 & 0,72 \\
\hline 20 & 1,15 & 1,14 & 1,12 & 1,06 & 1,04 & 1,02 & 1,01 & 0,99 & 0,96 & 0,93 & 0,91 & 0,88 & 0,82 & 0,80 & 0,76 \\
\hline 30 & 1,17 & 1,17 & 1,15 & 1,10 & 1,08 & 1,06 & 1,05 & 1,03 & 1,00 & 0,98 & 0,96 & 0,93 & 0,87 & 0,85 & 0,82 \\
\hline 40 & 1,20 & 1,19 & 1,17 & 1,13 & 1,11 & 1,09 & 1,08 & 1,06 & 1,04 & 1,01 & 0,99 & 0,96 & 0,91 & 0,89 & 0,86 \\
\hline 50 & 1,21 & 1,21 & 1,19 & 1,15 & 1,13 & 1,12 & 1,10 & 1,09 & 1,06 & 1,04 & 1,02 & 0,99 & 0,94 & 0,93 & 0,89 \\
\hline 60 & 1,22 & 1,22 & 1,21 & 1,16 & 1,15 & 1,14 & 1,12 & 1,11 & 1,09 & 1,07 & 1,04 & 1,02 & 0,97 & 0,95 & 0,92 \\
\hline 80 & 1,25 & 1,24 & 1,23 & 1,19 & 1,18 & 1,17 & 1,16 & 1,14 & 1,12 & 1,10 & 1,08 & 1,06 & 1,01 & 1,00 & 0,97 \\
\hline 100 & 1,26 & 1,26 & 1,25 & 1,22 & 1,21 & 1,20 & 1,18 & 1,17 & 1,15 & 1,13 & 1,11 & 1,09 & 1,05 & 1,03 & 1,01 \\
\hline 120 & 1,28 & 1,28 & 1,27 & 1,24 & 1,23 & 1,22 & 1,20 & 1,20 & 1,18 & 1,16 & 1,14 & 1,12 & 1,07 & 1,06 & 1,04 \\
\hline 140 & 1,29 & 1,29 & 1,28 & 1,25 & 1,24 & 1,24 & 1,22 & 1,22 & 1,20 & 1,18 & 1,16 & 1,14 & 1,10 & 1,09 & 1,07 \\
\hline 160 & 1,30 & 1,30 & 1,29 & 1,27 & 1,26 & 1,25 & 1,24 & 1,23 & 1,22 & 1,20 & 1,18 & 1,16 & 1,12 & 1,11 & 1,10 \\
\hline 180 & 1,31 & 1,31 & 1,31 & 1,28 & 1,27 & 1,27 & 1,26 & 1,25 & 1,23 & 1,22 & 1,20 & 1,18 & 1,14 & 1,14 & 1,12 \\
\hline 200 & 1,32 & 1,32 & 1,32 & 1,29 & 1,28 & 1,28 & 1,27 & 1,26 & 1,25 & 1,23 & 1,21 & 1,20 & 1,16 & 1,16 & 1,14 \\
\hline 250 & 1,34 & 1,34 & 1,33 & 1,31 & 1,31 & 1,31 & 1,30 & 1,29 & 1,28 & 1,27 & 1,25 & 1,23 & 1,20 & 1,20 & 1,18 \\
\hline 300 & - & - & - & 1,34 & 1,33 & 1,33 & 1,32 & 1,32 & 1,31 & 1,29 & 1,27 & 1,26 & 1,23 & 1,23 & 1,22 \\
\hline 350 & - & - & - & 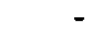 & - & - & 1,34 & 1,34 & 1,33 & 1,32 & 1,30 & 1,29 & 1,26 & 1,26 & 1,26 \\
\hline 400 & - & - & - & - & - & - & - & - & & 1,34 & 1,32 & 1,32 & 1,29 & 1,29 & 1,29 \\
\hline 420 & - & - & - & - & - & - & - & - & - & 1,35 & 1,35 & 1,33 & 1,30 & 1,30 & 1,30 \\
\hline 450 & - & - & - & $\cdot$ & - & - & - & - & - & - & - & - & 1,32 & 1,32 & 1,32 \\
\hline 500 & - & - & - & - & - & 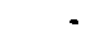 & - & - & - & 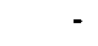 & - & - & 1,34 & 1,34 & 1,34 \\
\hline
\end{tabular}

(e) Fator $S_{3}$ : $O$ fator $S_{3}$ é baseado em conceitos estatísticos e considera o grau de segurança que uma determinada estrutura deverá apresentar de acordo com o seu uso. A NBR - 6123 recomenda valores para o fator estatístico $S_{3}$ de acordo com a TABELA 4.5 .

TABELA 4.5 - Valores mínimos do fator estatístico $S_{3}$.

\begin{tabular}{|c|c|c|}
\hline Grupo & Descrição & $\mathbf{S}_{3}$ \\
\hline 1 & $\begin{array}{c}\text { Edificações cuja ruina total ou parcial po- } \\
\text { de afetar a segurança ou possibilidade de } \\
\text { socorro a pessoas após uma tempestade } \\
\text { destrutiva (hospitais, quartéis de bombei- } \\
\text { ros e de forças de segurança, centrais de } \\
\text { comunicação, etc.) }\end{array}$ & 1,10 \\
\hline
\end{tabular}


TABELA 4.5 - Valores mínimos do fator estatístico $\mathrm{S}_{3}$ (cont.).

\begin{tabular}{|c|l|c|}
\hline Grupo & \multicolumn{1}{|c|}{ Descrição } & $\mathbf{S}_{3}$ \\
\hline 2 & $\begin{array}{l}\text { Edificação para hotéis e residências. Edi- } \\
\text { ficações e indústria com alto fator de o- } \\
\text { cupação. }\end{array}$ & 1,00 \\
\hline 3 & $\begin{array}{l}\text { Edificações e instalações industriais com } \\
\text { baixo fator de ocupação (depósitos, silos, } \\
\text { construções rurais, etc.) }\end{array}$ & 0,95 \\
\hline 4 & $\begin{array}{l}\text { Vedações ( telhas, vidros, painéis de ve- } \\
\text { dação, etc.) }\end{array}$ & 0,88 \\
\hline 5 & $\begin{array}{l}\text { Edificações temporárias. Estruturas dos } \\
\text { grupos 1 a 3 durante a construção. }\end{array}$ & 0,83 \\
\hline
\end{tabular}

(f) Pressão dinâmica (q): Obtido o valor de $V_{k}$ a partir da expressão (4.1), é possível calcular a pressão dinâmica exercida pelo vento na estrutura de acordo com a expressão (4.2).

$$
q=0,613 \cdot V_{k}^{2}
$$

sendo:

q - pressão dinâmica exercida pelo vento na estrutura $\left(\mathrm{N} / \mathrm{m}^{2}\right)$;

$\mathrm{V}_{k}$ - velocidade característica do vento $(\mathrm{m} / \mathrm{s})$

(g)_Coeficientes de pressão $\left(\mathrm{c}_{\mathrm{p}}\right)$ : De uma maneira simplificada, pode-se definir coeficiente de pressão como sendo um adimensional que multiplicado pela pressão dinâmica $(\mathrm{q})$, resulta na pressão efetiva $(\Delta \mathrm{P})$ que o vento exerce sobre a estrutura:

$$
c_{\mathrm{p}}=\Delta \mathrm{P} / \mathrm{q}
$$

sendo

$c_{p}$ - coeficiente de pressão;

$\Delta \mathrm{P}$ - pressão efetiva que o vento exerce sobre a estrutura;

q - pressão dinâmica.

Os coeficientes de pressão podem ser externos $\left(c_{p e}\right)$ ou internos $\left(c_{p i}\right)$ à estrutura. Valores positivos dos coeficientes de pressão externa ou interna indicam sobrepressões e valores negativos correspondem à sucções. 
(h) Coeficientes de forma: A força do vento sobre um elemento plano de edificação de área $\mathrm{A}$, atua em direção perpendicular ao mesmo, sendo dada por:

$$
\mathrm{F}=\mathrm{F}_{\mathrm{e}}-\mathrm{F}_{\mathrm{i}}
$$

sendo:

$\mathrm{F}_{\mathrm{e}}$ - força externa à edificação, agindo na superficie plana de área $\mathrm{A}$;

$\mathrm{F}_{\mathrm{i}}$ - força interna à edificação, agindo na superficie plana de área $\mathrm{A}$.

Portanto:

$$
F=\left(C_{e}-C_{i}\right) \cdot q \cdot A
$$

sendo:

$\mathrm{C}_{\mathrm{e}}$ - coeficiente de forma externo;

$\mathrm{C}_{\mathrm{i}}$ - coeficiente de forma interno.

Valores positivos dos coeficientes de forma externo e interno correspondem a sobrepressões e valores negativos correspondem sucções.

(i) Coeficientes de força: O coeficiente de força é um adimensional que multiplicado pela pressão dinâmica e pela área efetiva, nos fornece o valor da força exercida pelo vento em um determinado ponto de uma estrutura

$$
F=C_{f} \cdot q \cdot A
$$

sendo:

$\mathrm{C}_{\mathrm{f}}$ - coeficiente de força, especificado em cada caso;

A - área de referência, especificada em cada caso.

Este capitulo têm o objetivo apenas de definir alguns parâmetros importantes para o cálculo da ação do vento nas estruturas, sendo assim, ao se efetuar o levantamento dos esforços em uma dada edificação, o estudo da NBR - 6123, de uma forma mais detalhada, se faz necessário.

\subsection{COMBINAÇÕES DE AÇÕES}

Ao se fazer o levantamento das ações atuantes em uma determinada estrutura, com o intuito de dimensioná-la, o projetista deve prever combinações de ações que apresentam uma probabilidade não desprezível de atuarem simultaneamente sobre a 
estrutura, durante um período preestabelecido. Essas combinações devem ser estudadas de maneira que se consiga determinar os efeitos mais desfavoráveis que elas possam apresentar.

As combinações de ações devem garantir, também, que os estados limites últimos e os de utilização sejam verificados.

Entende-se por estado limite último como o colapso ou outra forma de ruina estrutural, de modo que a segurança da estrutura seja comprometida:

- perda de equilíbrio global ou parcial;

- deformação plástica excessiva;

- transformação de parte ou totalidade da estrutura num sistema hipostático;

- perda de instabilidade.

Além do colapso de uma estrutura, a mesma pode se tornar inapta se por algum motivo, a sua utilização se tornar comprometida, ou seja, a estrutura atingir o estado limite de utilização:

- deformações excessivas;

- vibrações excessivas;

- fissuras de grande amplitude.

\subsubsection{Combinações Últimas}

Ao se verificar a segurança de uma estrutura quanto aos estados limites últimos, os carregamentos atuantes devem ser admitidos respeitando as combinações últimas, previstas na NBR - 8681 .

As combinações últimas são classificadas em normal, especial ou de construção e excepcional.

(a) Combinações Últimas Normais: são as combinações referentes às ações provenientes do uso da estrutura, ou seja, ações permanentes e variáveis comuns da edificação:

$$
\mathrm{F}_{\mathrm{d}}=\sum_{\mathrm{i}=1}^{\mathrm{m}} \gamma_{\mathrm{gi}} \mathrm{F}_{\mathrm{Gi} . \mathrm{k}}+\gamma_{\mathrm{q}}\left[\mathrm{F}_{\mathrm{Ql} . \mathrm{k}}+\sum_{\mathrm{j}=2}^{\mathrm{n}} \psi_{\mathrm{oj}} \mathrm{F}_{\mathrm{Qj} . \mathrm{k}}\right]
$$

sendo:

$F_{d}$ - valor de cálculo das ações;

$F_{\text {(ii.k }}$ - valor caracteristico das ações permanentes; 
$\mathrm{F}_{\mathrm{Q} 1, \mathrm{k}}$ - valor característico da ação variável considerada como ação principal para a combinação;

$\psi_{\mathrm{oj}} \mathrm{F}_{\mathrm{Qj}, \mathrm{k}}$ - valor reduzido de combinação de cada uma das demais ações variáveis.

Em alguns casos é necessário considerar o efeito das cargas permanentes como favorável e desfavorável, com os respectivos coeficientes de ponderação e a partir daí, estimar qual situação é mais crítica.

(b) Combinações Últimas Especiais: são as combinações das ações permanentes com as ações variáveis especiais, que superam em intensidade os efeitos produzidos pelas ações variáveis comuns da edificação:

$$
\mathrm{F}_{\mathrm{d}}=\sum_{\mathrm{i}=1}^{\mathrm{m}} \gamma_{\mathrm{gi}} \mathrm{F}_{\mathrm{Gi}, \mathrm{k}}+\gamma_{\mathrm{q}}\left[\mathrm{F}_{\mathrm{Ql}, \mathrm{k}}+\sum_{\mathrm{j}=2}^{\mathrm{n}} \psi_{\mathrm{oj}, \mathrm{ef}} \mathrm{F}_{\mathrm{Qj}, \mathrm{k}}\right]
$$

sendo:

$$
\begin{aligned}
& F_{\text {Gi,k }} \text { - valor característico das ações permanentes; } \\
& F_{\mathrm{Q} 1, \mathrm{k}} \text { - valor característico da ação variável admitida como principal para a } \\
& \text { situação transitória considerada; } \\
& \psi_{\mathrm{oj}, \mathrm{ef}} \text { - fator de combinação efetivo de cada uma das demais variáveis que } \\
& \text { podem agir simultaneamente com a ação principal } \mathrm{F}_{\mathrm{Q} 1} \text {, durante a } \\
& \quad \text { situação transitória. }
\end{aligned}
$$

O fator $\psi_{\mathrm{oj}, \mathrm{cf}}$ é igual ao fator $\psi_{\mathrm{oj}}$ adotado nas combinações normais, salvo quando a ação principal $\mathrm{F}_{\mathrm{Q} 1}$ tiver um tempo de atuação muito pequeno, caso em que $\psi_{\mathrm{oj}, \text { ef }}$ pode ser tomado com o correspondente $\psi_{2 \mathrm{j}}$.

(c) Combinações Últimas Excepcionais: essas combinações são utilizadas quando há a necessidade de se considerar o efeito das ações excepcionais ( explosões, abalos sísmicos, etc.):

$$
F_{d}=\sum_{i=1}^{m} \gamma_{g i} F_{G i, k}+F_{Q . e x c}+\gamma_{\mathrm{u}} \sum_{j=1}^{n} \psi_{o j, e f} F_{Q j, k}
$$

sendo:

$$
\begin{aligned}
& F_{\text {(ij.k }} \text { - valor característico das ações permanentes; } \\
& F_{\text {Q.cxc }} \text { - valor da ação transitória excepcional; }
\end{aligned}
$$




$$
\begin{gathered}
\psi_{\mathrm{oj}, \mathrm{ef}} \mathrm{F}_{\mathrm{Oj}, \mathrm{k}} \text { - valor reduzido de combinação de cada uma das demais ações } \\
\text { variáveis. }
\end{gathered}
$$

\subsubsection{Combinações de Utilização}

Essas combinações são ainda subdivididas em quase-permanentes, freqüentes e raras, de acordo com a ordem de grandeza de permanência na estrutura.

(a) Combinações Quase-Permanentes: são as combinações que podem atuar durante grande parte da vida útil da estrutura. São normalmente utilizadas para a verificação do estado limite de deformações excessivas:

$$
\mathrm{F}_{\mathrm{d}, \text { uti }}=\sum_{\mathrm{i}=1}^{\mathrm{m}} \mathrm{F}_{\mathrm{Gi}, \mathrm{k}}+\sum_{\mathrm{j}=1}^{\mathrm{n}} \psi_{2 \mathrm{j}} \mathrm{F}_{\mathrm{Qj}, \mathrm{k}}
$$

As variáveis são as mesmas já especificadas no item anterior.

(b) Combinações Freqüentes de Utilização: são as combinações que se repetem várias vezes durante a vida útil da estrutura. São normalmente utilizadas para a verificação dos estados limites de compressão excessiva, abertura de fissuras e vibrações excessivas:

$$
\mathrm{F}_{\mathrm{d}, \text { uti }}=\sum_{\mathrm{i}=1}^{\mathrm{m}} \mathrm{F}_{\mathrm{Gi}, \mathrm{k}}+\psi_{\mathrm{I}} \mathrm{F}_{\mathrm{Q} 1, \mathrm{k}}+\sum_{\mathrm{j}=2}^{\mathrm{n}} \psi_{2 \mathrm{j}} \mathrm{F}_{\mathrm{Qj}, \mathrm{k}}
$$

(c) Combinações Raras: são as combinações que atuam apenas algumas vezes durante a vida útil da estrutura. São utilizadas para a verificação dos estados limites de formação de fissuras e descompressão:

$$
F_{d, u t i}=\sum_{i=1}^{m} F_{\text {Gi.k }}+F_{Q 1, k}+\sum_{j=2}^{n} \psi_{1 j} F_{Q j, k}
$$

De acordo com a formulação apresentada anteriormente para as combinações de ações últimas e de utilização, precisa-se definir os coeficientes de ponderação das ações permanentes, variáveis e excepcionais 
TABELA 4.6 - Coeficientes de ponderação para as ações permanentes(NBR - 8681).

\begin{tabular}{|c|c|c|c|c|}
\hline Combinações & \multicolumn{2}{|c|}{$\begin{array}{c}\text { Efeitos } \\
\text { Efeitos } \\
\end{array}$} & $\begin{array}{c}\text { Grande Variabilidade } \\
\text { Pequena Variabilidade }\end{array}$ \\
\cline { 2 - 5 } & Desfavoráveis & Favoráveis & Desfavorávei & Favoráveis \\
\hline Normais & $\gamma_{\mathrm{g}}=1,40$ & $\gamma_{\mathrm{g}}=0,90$ & $\gamma_{\mathrm{g}}=1,30$ & $\gamma_{\mathrm{g}}=1,00$ \\
Especiais ou de & $\gamma_{\mathrm{g}}=1,30$ & $\gamma_{\mathrm{g}}=0,90$ & $\gamma_{\mathrm{g}}=1,20$ & $\gamma_{\mathrm{g}}=1,00$ \\
Excepcionais & $\gamma_{\mathrm{g}}=1,20$ & $\gamma_{\mathrm{g}}=0,90$ & $\gamma_{\mathrm{g}}=1,10$ & $\gamma_{\mathrm{g}}=1,00$ \\
\hline
\end{tabular}

Entende-se por ações permanentes de grande variabilidade, quando o peso próprio da estrutura não superar $75 \%$ da totalidade dos pesos permanentes. Caso contrário, as ações permanentes são chamadas de pequena variabilidade.

TABELA 4.7 - Efeitos de recalques de apoio e da retração dos materiais(NBR - 8681).

\begin{tabular}{|c|c|c|}
\hline \multirow{2}{*}{ Combinações } & \multicolumn{2}{|c|}{ Efeitos } \\
\cline { 2 - 3 } & Desfavoráveis & Favoráveis \\
\hline Normais & $\gamma_{\mathrm{e}}=1,20$ & $\gamma_{\mathrm{e}}=1,00$ \\
Especiais ou de construção & $\gamma_{\mathrm{e}}=1,20$ & $\gamma_{\mathrm{e}}=1,00$ \\
Excepcionais & $\gamma_{\mathrm{e}}=0$ & $\gamma_{\mathrm{e}}=0$ \\
\hline
\end{tabular}

TABELA 4.8 - Coeficientes de ponderação para as ações variáveis(NBR - 8681).

\begin{tabular}{|c|c|c|}
\hline Combinações & $\begin{array}{c}\text { Ações variáveis em geral } \\
\text { incluída as cargas } \\
\text { móveis }\end{array}$ & Efeitos de temperatura \\
\hline Normais & $\gamma_{\mathrm{q}}=1,40$ & $\gamma_{\mathrm{e}}=1,20$ \\
Especiais ou de & $\gamma_{\mathrm{q}}=1,20$ & $\gamma_{\mathrm{e}}=1,00$ \\
Excepcionais & $\gamma_{\mathrm{q}}=1,00$ & $\gamma_{\mathrm{e}}=0$ \\
\hline
\end{tabular}


TABELA 4.9 - Valores dos fatores de combinação e dos fatores de utilização

(NBR - 8681).

\begin{tabular}{|c|c|c|c|}
\hline Ações em geral & $\psi_{0}$ & $\Psi_{1}$ & $\Psi_{2}$ \\
\hline - Variações uniformes de temperatura em relação à média anual local & 0,6 & 0,5 & 0,3 \\
\hline - Pressão dinâmica do vento nas estruturas em geral & 0,4 & 0,2 & 0 \\
\hline $\begin{array}{l}\text { - Pressão dinâmica do vento nas estruturas em que a ação variável } \\
\text { principal tem pequena variabilidade durante grandes intervalos de } \\
\text { tempo (exemplo: edificios de habitação) }\end{array}$ & 0,6 & 0,2 & 0 \\
\hline Cargas acidentais dos edifícios & $\psi_{0}$ & $\psi_{1}$ & $\psi_{2}$ \\
\hline $\begin{array}{l}\text { - Locais em que não há predominância de pesos de equipamentos que } \\
\text { permaneçam fixos por longos períodos de tempo, nem de elevadas } \\
\text { concentrações de pessoas }\end{array}$ & 0,4 & 0,3 & 0,2 \\
\hline $\begin{array}{l}\text { - Locais em que há predominância de pesos de equipamentos que } \\
\text { permaneçam fixos por longos períodos de tempo, ou de elevadas con- } \\
\text { centrações de pessoas }\end{array}$ & 0,7 & 0,6 & 0,4 \\
\hline - Bibliotecas, arquivos, oficinas e garagens & 0,8 & 0,7 & 0,6 \\
\hline Cargas móveis e seus efeitos dinâmicos & $\psi_{0}$ & $\psi_{1}$ & $\psi_{2}$ \\
\hline - Pontes de pedestres & 0,4 & 0,3 & $0,2^{(2)}$ \\
\hline - Pontes rodoviárias & 0,6 & 0,4 & $0,2^{(*)}$ \\
\hline - Pontes ferroviárias (ferrovias não especializadas) & 0,8 & 0,6 & $0,4^{(*)}$ \\
\hline
\end{tabular}

${ }^{(*)}$ - Admite-se $\psi_{2}=0$ quando a ação variável principal corresponde a um efeito sísmico. 


\section{CAPÍTULO 5. INSTABILIDADE DE PILARES}

\subsection{COMPRESSÃO AXIAL}

As barras retas carregadas axialmente com uma força de compressão crescente, podem atingir um Estado Limite, a partir do qual a forma reta de equilibrio é instável. Esta carga é chamada de carga crítica ou carga de flambagem. No regime elástico (materiais apresentam comportamento elástico-linear) com cargas $\mathrm{F}>\mathrm{F}$ crit, a forma estável de equilíbrio passa a ser a configuração fletida [FIGURA 5.1 (a)].

Para peças de concreto armado submetidas à carga crítica, têm-se um Estado Limite Último pois, para cargas pouco superiores a carga de flambagem, o deslocamento apresentado representa uma porcentagem considerável do comprimento da barra, fazendo com que surjam esforços adicionais elevados, ocasionando a ruptura da seção por flexão composta [FIGURA 5.1 (b)].

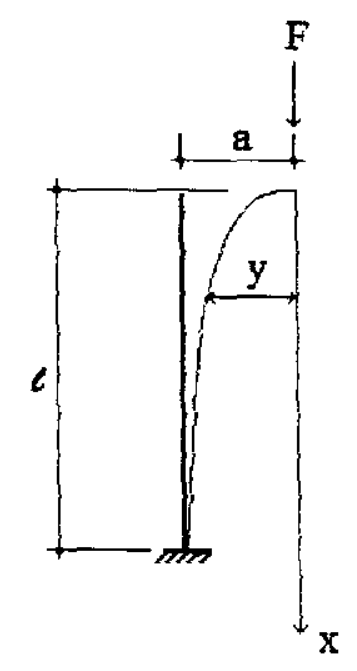

(a)

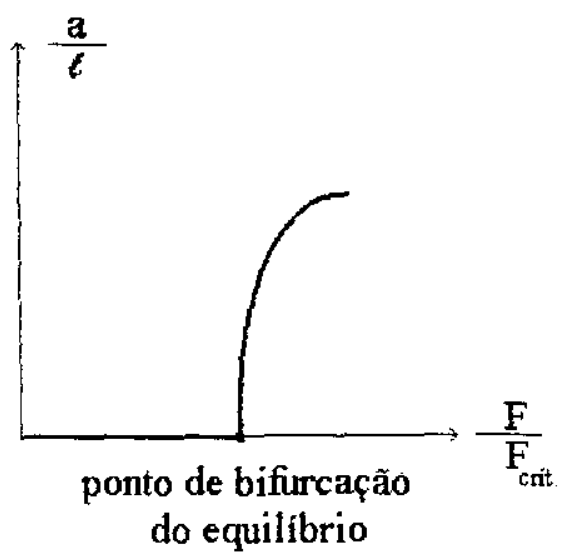

(b)

FIGURA 5.1 - Instabilidade na compressão centrada - FUSCOI1986].

O ponto de bifurcação do equilibrio, mostrado na FIGURA 5.1 (b), significa que a barra atingiu a flambagem, sendo assim, este ponto separa a forma reta instável da configuração fletida estável.

A obtenção dos valores das flechas para a configuração fletida de equilíbrio, requer a utilização da expressão exata da curvatura: 


$$
\frac{1}{r}-\frac{\frac{d^{2} y}{d x^{2}}}{\left[1+\left(\begin{array}{c}
d y \\
d x
\end{array}\right)^{2}\right]^{3}}
$$

O valor da carga crítica pode ser facilmente obtida, utilizando-se a expressão simplificada da elástica, visto que, para pequenos deslocamentos $(\mathrm{dy} / \mathrm{dx})^{2} \cong 1$ :

$$
\frac{1}{\Gamma}=\frac{d^{2} y}{d x^{2}}=-\frac{M}{E I}=-\frac{F \cdot y}{E I}
$$

Resultando em:

$$
y^{\prime \prime}+\frac{F \cdot y}{E I}-0
$$

A fim de facilitar a solução da equação diferencial, faz-se a seguinte simplificação:

$$
\mathrm{k}^{2}-\frac{\mathrm{F} \cdot \mathrm{y}}{\mathrm{EI}} \Rightarrow \mathrm{y}^{\prime \prime}+\mathrm{k}^{2} \mathrm{y}-0
$$

Cuja solução é a seguinte:

$$
y=A \operatorname{sen} k x+B \cos k x
$$

Trabalhando com as condições de contorno de maneira que não se tenha apenas a solução trivial, obtém-se:

$$
\mathrm{A}=0 \quad \text { e } \quad \operatorname{cosk} \ell=0 \Rightarrow \mathrm{k} \ell=\pi / 2 \quad \therefore \mathrm{k}=\pi / 2 \ell
$$

Substituindo o valor de $\mathrm{k}$, obtém-se a expressão da carga crítica: 


$$
\mathrm{F}_{\text {crit }}=\frac{\pi^{2} \mathrm{EI}}{4 e^{2}}
$$

Para condições de contorno diferentes, a expressão (5.6) fica generalizada da seguinte forma:

$$
F_{c r i t}=\frac{\pi^{2} E I}{\iota^{2}}
$$

sendo:

$\zeta_{e}$ - comprimento de flambagem, de acordo com as vinculações existentes nas extremidades das barras;

Admitindo-se que a linha elástica da barra após a flambagem, seja uma função senoidal da forma:

$$
y=\operatorname{asen} \frac{\pi}{\ell} \mathrm{x}
$$

Então a expressão da curvatura aproximada, é da seguinte forma:

$$
\frac{1}{r} \cong \frac{d^{2} y}{d x^{2}}=-\left(\frac{\pi}{c}\right)^{2} y
$$

Por outro lado a expressão exata da curvatura é dada pela expressão (5.10):

$$
\frac{1}{r}=-\frac{\left(\frac{\pi}{\ell}\right)^{2} y}{\left[1+\left(\frac{\pi}{\ell}\right)^{2} \cdot\left(a^{2}-y^{2}\right)\right]^{3 / 2}}
$$


O equilíbrio de barras retas axialmente comprimidas é atingido quando os momentos externos atuantes se equivalerem aos momentos internos mobilizados nas barras:

$$
\mathrm{M}_{\mathrm{ext}}=\mathrm{M}_{\mathrm{int}}
$$

sendo:

$$
\begin{aligned}
& M_{\text {ext }}=F \cdot y-\text { momento externo atuante; } \\
& M_{\text {int }}=1 / r \cdot E I \text { - momento interno mobilizado pela barra. }
\end{aligned}
$$

Se a barra submetida a um carregamento centrado, tiver um comportamento elástico, então as formas de equilíbrio podem ser verificadas através das FIGURA 5.2(a) e 5.2(b), considerando a expressão simplificada e exata da curvatura, respectivamente.

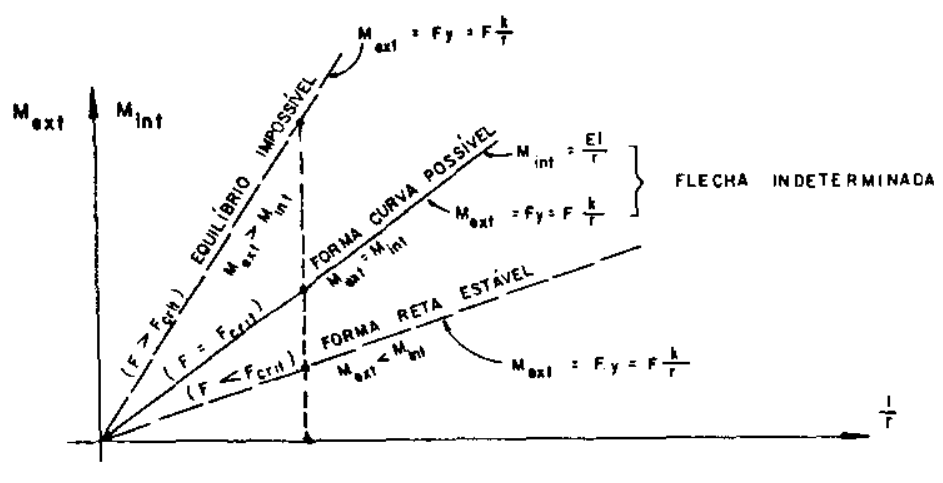

(a)

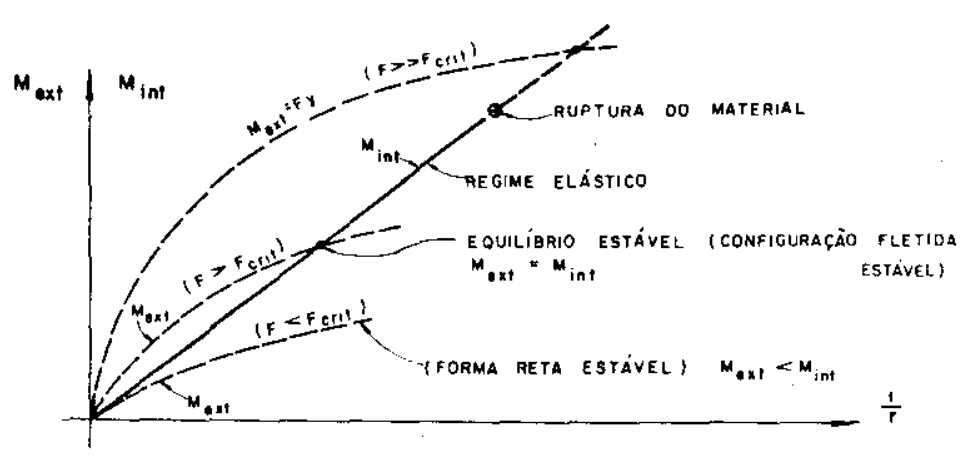

(b)

FIGURA 5.2 - Formas de equilibrio: regime elástico [FUSCO/.

Por outro lado se a barra axialmente comprimida, tiver um comportamento anelástico, então as formas de equilibrio estão contidas na FIGURA 5.3. 


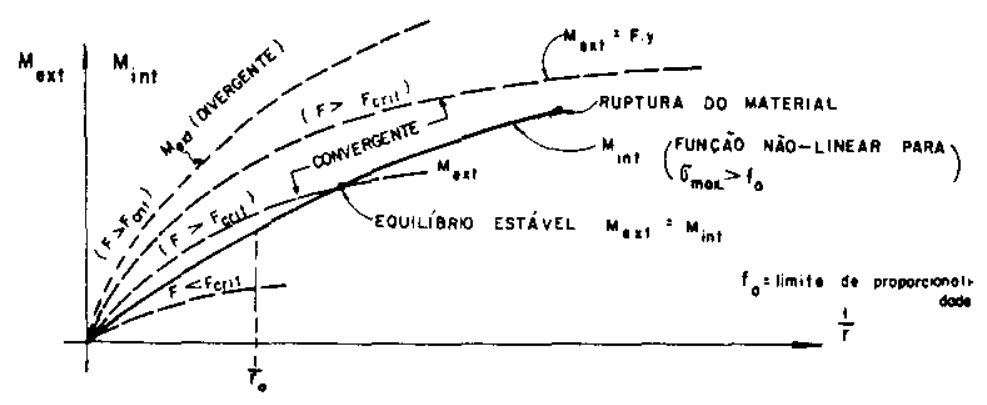

FIGURA 5.3 - Formas de equilibrio: regime anelástico /FUSCOI.

\subsection{FLEXÃO COMPOSTA}

Considerando a barra da FIGURA 5.4, submetida a uma ação aplicada com uma excentricidade, pode-se calcular as flechas da mesma com a expressão (5.12):

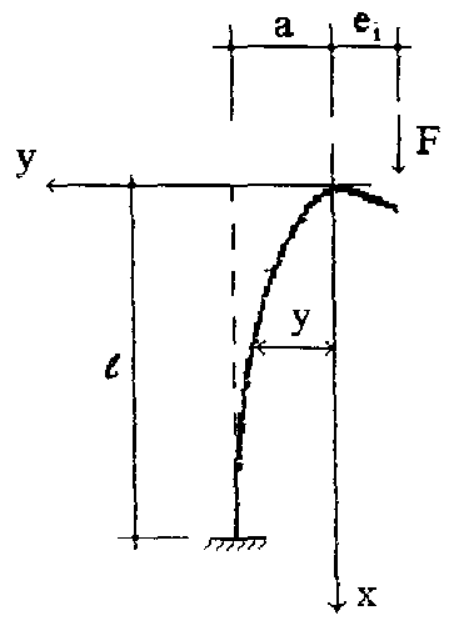

FIGURA 5.4 - Flexão de barras esbeltas no regime elástico [FUSCO/.

$$
\frac{1}{r} \equiv \frac{d^{2} y}{d x^{2}}=-\frac{M}{E I}
$$

sendo:

$$
M=F\left(e_{i}+y\right)
$$

Para analisar a estabilidade da configuração deformada das barras submetidas à flexo-compressão, admita-se que a barra da FIGURA 5.5 tenha uma linha elástica senoidal. 


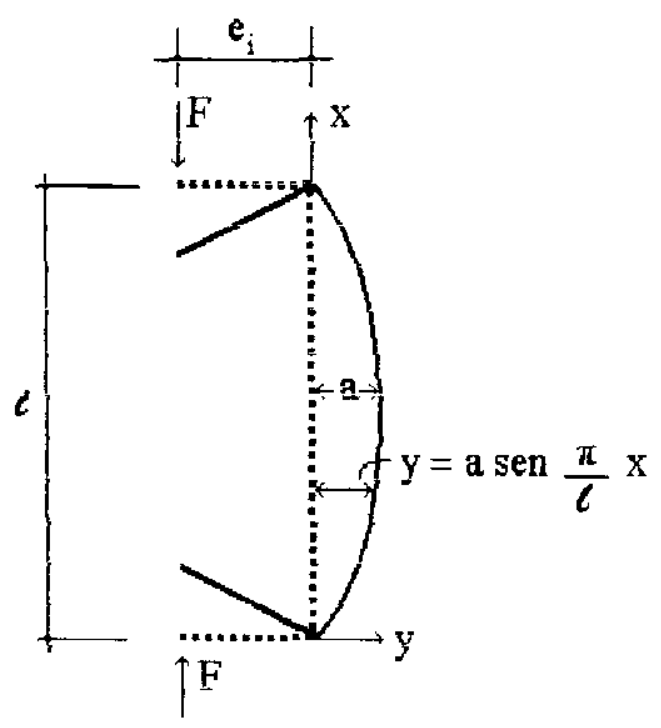

FIGURA 5.5 - Estabilidade na flexo-compressão [FUSCOI.

Sabendo que:

$$
y=\operatorname{asen} \frac{\pi}{l} x
$$

Admitindo-se a expressão simplificada da curvatura, tém-se:

$$
\frac{1}{r} \cong \frac{d^{2} y}{d x^{2}}=-a\left(\frac{\pi}{\ell}\right)^{2} \operatorname{sen} \frac{\pi}{\ell} x
$$

Que resulta:

$$
\frac{1}{r} \cong \frac{d^{2} y}{d x^{2}}=-\left(\frac{\pi}{\ell}\right)^{2} y
$$

Isolando y e trabalhando com valores absolutos, obtém-se:

$$
\mathrm{y} \cong\left(\frac{a}{\pi}\right)^{2} \cdot \frac{1}{\mathrm{r}}
$$

Sendo assim, o momento externo $\mathrm{M}_{\mathrm{ext}}$ será uma função linear da curvatura da seção:

$$
M_{\text {ext }}=F\left(e_{i}+y\right)=F \cdot e_{i}+F\left(\frac{l}{\pi}\right)^{2} \cdot \frac{1}{r}
$$

Pode-se concluir, então, que sempre haverá, no regime elástico, uma configuração de equilibrio, visto que, tanto o $M_{\text {cxt }}$ quanto o $M_{\text {int }}$ variam linearmente com a curvatura. Sendo assim, a barra atingirá um estado limite último apenas se houver a ruptura do material (FIGURA 5.6). 


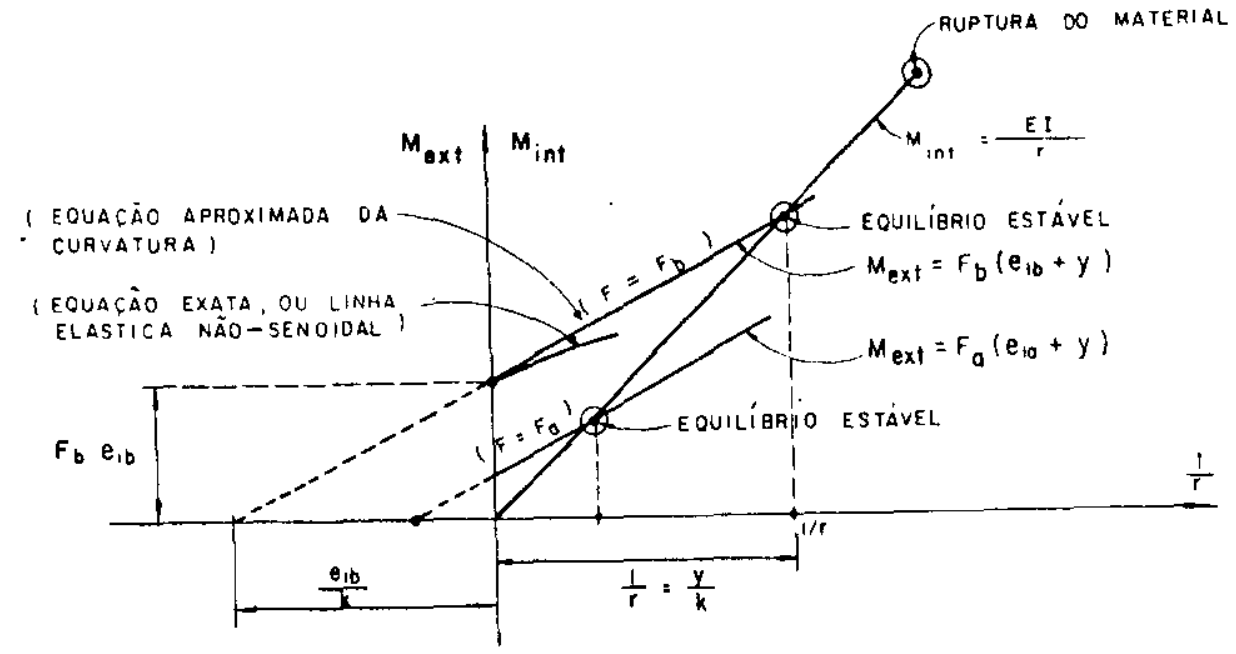

FIGURA 5.6 - Instabilidade na flexão composta: regime elástico [FUSCO].

Se, por outro lado, for ultrapassado o regime de proporcionalidade, o diagrama de $\mathrm{M}_{\text {int }}$ não será mais uma reta, possibilitando o aparecimento de um novo fenômeno de instabilidade. Isto é, passará a existir uma carga $\mathrm{F}_{\text {crit, }}$ onde a função $\mathrm{M}_{\text {ext }}$ é tangente a curva de $\mathbf{M}_{\text {int. }}$ Para cargas inferiores a crítica, é possivel o equilibrio estável, ao passo que, para cargas superiores a crítica o equilibrio é impossivel (FIGURA 5.7).

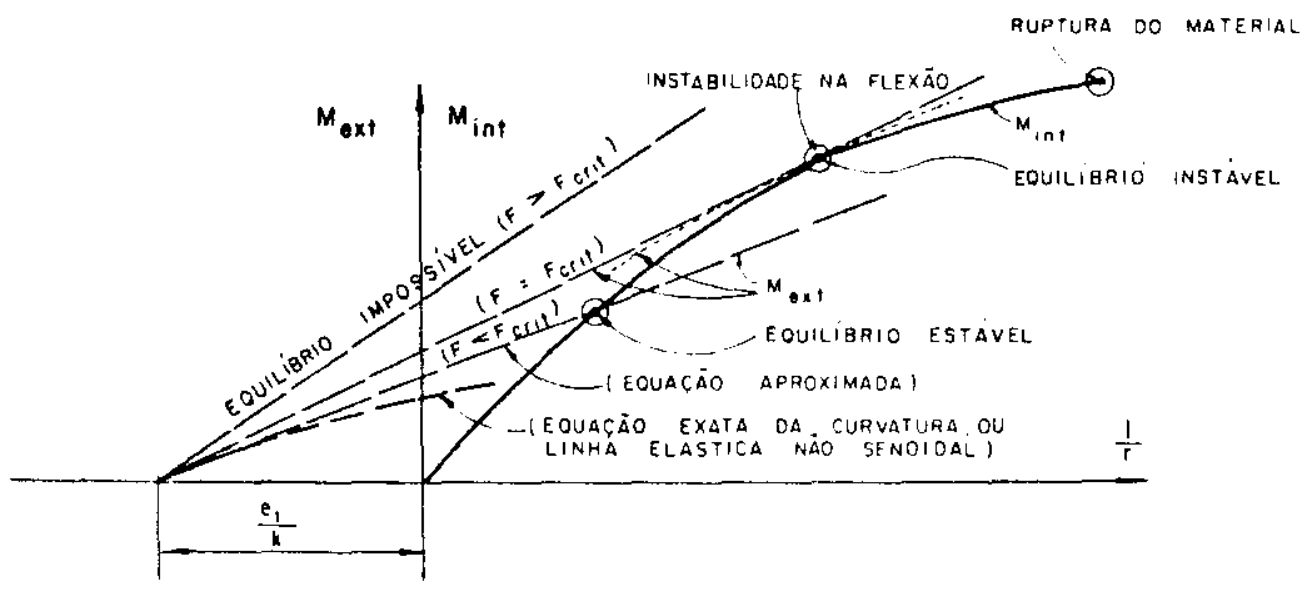

FIGURA 5.7 - Instabilidade na flexão composta: regime anelástico [FUSCO/ 


\subsection{DIAGRAMA MOMENTO FLETOR - CURVATURA}

Considere-se a deformação da barra de FIGURA 5.8 submetida a flexão simples.

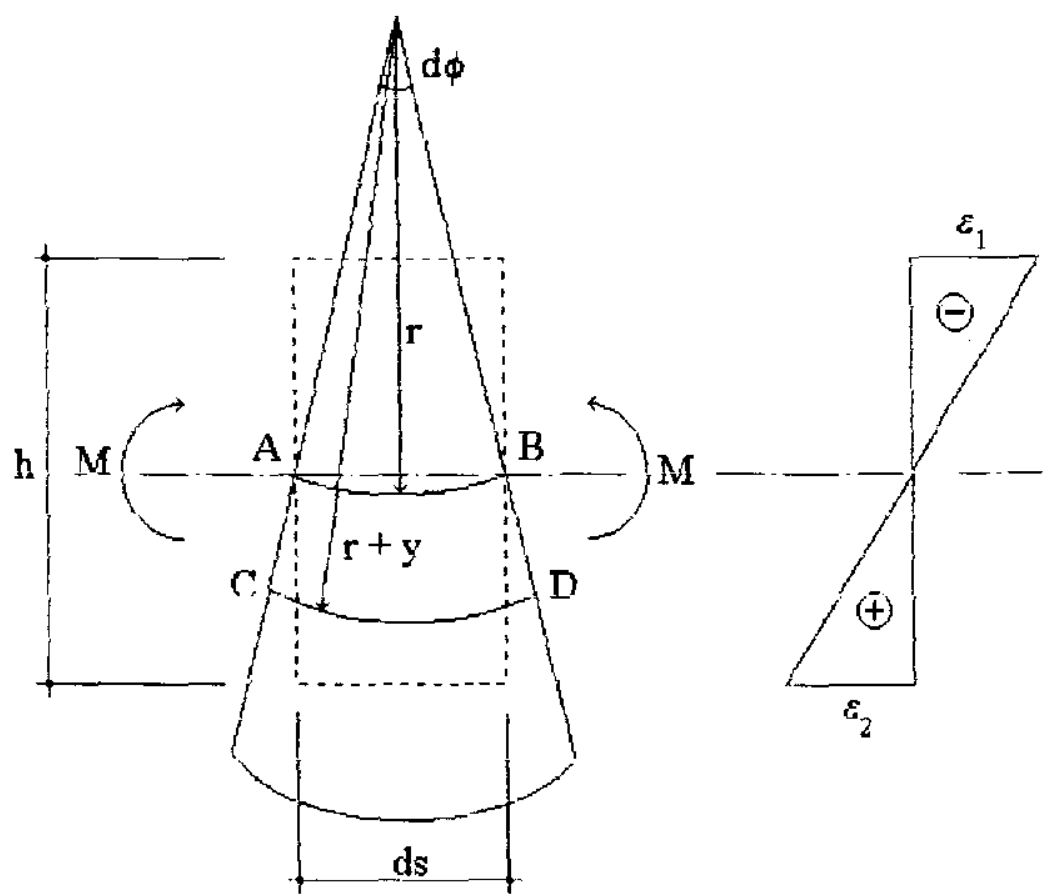

FIGURA 5.8 - Curvatura na flexão simples.

A fibra média $A B$ vale:

$$
\mathrm{AB}=\mathrm{rd} \phi=\mathrm{ds}
$$

Por outro lado, considerando o alongamento da fibra $\mathrm{CD}$, tém-se:

$$
C D=(r+y) d \phi=r d \phi+y d \phi=d s+y d \phi
$$

ou:

$$
C D=d s(1+e)=d s+e d s
$$

Igualando as expressões (5.19) e (5.20), obtém-se:

$$
\mathrm{y} d \phi=\mathrm{eds}
$$

Logo,

$$
\frac{1}{\mathrm{r}}=\frac{\mathrm{d} \phi}{\mathrm{ds}}=\frac{\varepsilon}{\mathrm{y}}
$$


Observando a equação (5.22) e considerando uma seção transversal em concreto armado submetida a flexão simples, concluí-se:

$$
\frac{1}{r}=\frac{\varepsilon_{c}+\varepsilon_{\mathrm{s}}}{\mathrm{d}} ; \mathrm{e}_{\mathrm{c}} \text { e e em valores absolutos }
$$

\subsection{DIAGRAMA MOMENTO FLETOR - FORÇA NORMAL - CURVATURA}

Observando o diagrama de deformações da FIGURA 5.9, observa-se que na flexocompressão a curvatura da barra depende somente da diferença entre a deformação total e a deformação da fibra situada no nível do centro de gravidade da seção.

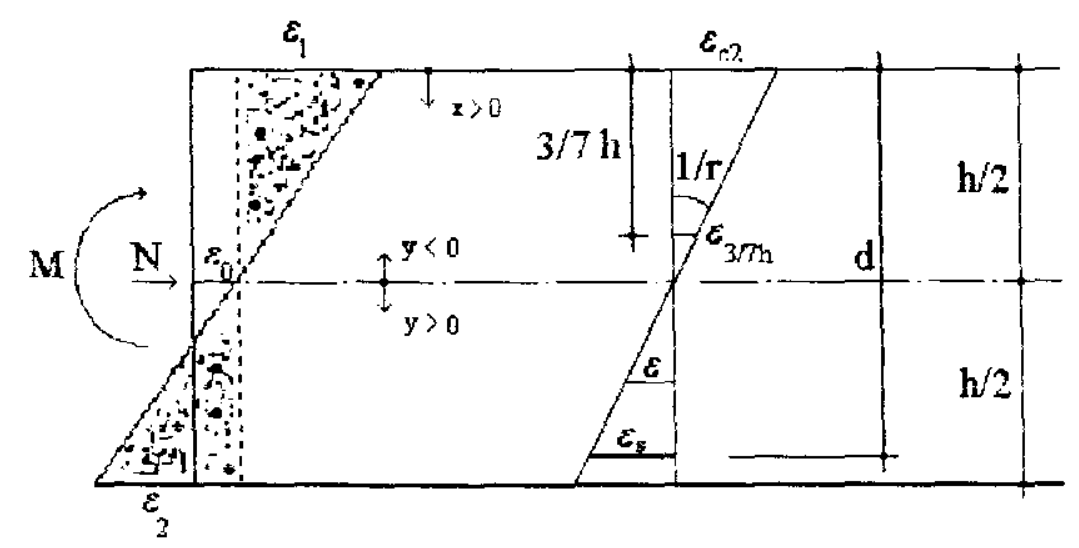

FIGURA 5.9 - Curvatura na flexo-compressão.

Baseado na FIGURA 5.9, consegue-se obter as seguintes equações de compatibilidade:

$$
\frac{\varepsilon_{c 2}}{\mathrm{x}}=\frac{\varepsilon_{\mathrm{s}}}{\mathrm{d}-\mathrm{x}}-\frac{\varepsilon_{3} / \mathrm{h}}{\frac{3}{7} \mathrm{~h}-\mathrm{x}}-\frac{\varepsilon}{\mathrm{y}-\mathrm{y}_{\mathrm{o}}}-\frac{1}{\mathrm{r}}
$$

Isolando o valor de e, tém-se:

$$
\varepsilon--\varepsilon_{02} \frac{y-y_{0}}{x}-\varepsilon: \frac{y-y_{0}}{d-x}-\varepsilon_{3}: \frac{y-y_{0}}{\frac{3}{7} h-x}
$$

Definindo as deformações em função de $1 / \mathrm{r}$, obtém-se: 


$$
\varepsilon_{\mathrm{c} 2}=-\frac{1}{\mathrm{~T}} \mathrm{x} ; \varepsilon s=\frac{1}{\mathrm{~T}}(\mathrm{~d}-\mathrm{x}) ; \varepsilon 3 / \mathrm{h}=\frac{1}{\mathrm{~T}}\left(\frac{3}{7} \mathrm{~h}-\mathrm{x}\right) ; \varepsilon=\frac{1}{\mathrm{r}}\left(\mathrm{y}-\mathrm{y}_{\mathrm{o}}\right)
$$

Em termos adimensionais, a deformação fica assim definida:

$$
\begin{gathered}
y_{0}=\mathrm{x}-\mathrm{h} / 2 ; \quad \beta_{\mathrm{x}}=\mathrm{x} / \mathrm{d} ; \quad \beta_{\mathrm{y}}=\mathrm{y} / \mathrm{d} \\
\varepsilon=\frac{1}{\mathrm{r}}\left(\mathrm{y}-\mathrm{x}+\frac{\mathrm{h}}{2}\right)=\frac{\mathrm{d}}{\mathrm{r}}\left(\frac{\mathrm{y}}{\mathrm{d}}-\frac{\mathrm{x}}{\mathrm{d}}+\frac{\mathrm{h}}{2 \mathrm{~d}}\right)=\frac{\mathrm{d}}{\mathrm{r}}\left(\beta_{\mathrm{y}}+\frac{\mathrm{h}}{2 \mathrm{~d}}-\beta_{\mathrm{x}}\right)
\end{gathered}
$$

Fazendo:

$$
\begin{aligned}
& \beta_{\circ}=\beta_{y}+\frac{h}{2 d} \\
& \Rightarrow \varepsilon=\frac{d}{r}\left(\beta_{0}-\beta_{x}\right)
\end{aligned}
$$

É necessário, ainda, definir valores limites de $\beta_{\mathrm{x}}$, a fim de evitar que os limites últimos de deformação sejam ultrapassados, a partir de uma dada curvatura $1 / \mathrm{r}$. Imaginando os domínios 1 e 2 de deformação e substituindo em (5.28) e (5.29), obtém-se o valor de $\beta_{x \text { Iinf: }}$

$$
\beta_{x \text { linf }} \geq-\frac{0.01}{\frac{d}{r}}+1
$$

Utilizando as condições de contorno definidas nos domínios de deformação 3,4 e $4 a$, obtém-se o valor de $\beta_{\mathrm{x} \text { 1sup: }}$

$$
\beta_{\text {xisq }} \leq \frac{0.0035}{\frac{d}{r}}
$$

Trabalhando com as propriedades do domínio de deformação 5, fica-se determinado o outro limitante superior para o valor de $\beta_{\mathrm{x}}$ :

$$
\hat{\beta}_{\text {xzapp }} \leq \frac{0.002}{\frac{d}{r}}+\frac{3 h}{7 d}
$$

As equações de equilibrio de uma barra de concreto armado, submetida a uma flexão composta são as seguintes: 


$$
\begin{aligned}
& N_{i=t}=\int_{-\frac{h}{2}}^{y_{0}} b \cdot \sigma \cdot d y+\sum_{1}^{n} A s \cdot \sigma s \\
& M_{z=x}=\int_{\frac{-b}{2}}^{y v} b \cdot y \cdot \sigma \cdot d y+\sum_{1}^{n} A s_{i} \cdot \sigma s: y
\end{aligned}
$$

As expressões (5.33) e (5.34), permitem a determinação de $M$ e $N$ em função de $1 / r$, lembrando que o valor de $\beta_{\mathrm{x}}$ deve estar compreendido entre os limites estabelecidos pelas expressões (5.30), (5.31) e (5.32). O processo para a obtenção do diagrama $M-N-1 / r$, é iterativo e segue as seguintes etapas:

(a) para um dado pilar, deve-se saber a distribuição das barras na seção transversal, o valor de $d^{\prime} / h$, a categoria do aço, o concreto utilizado e a força normal atuante;

(b) fixa-se os valores de $v$ e $\omega$;

(c) para cada valor de $1 / \mathrm{r}$, de termina-se $\beta_{\mathrm{x}}$ por tentativas de maneira que $v_{\mathrm{int}}$ $=v_{\mathrm{ext}}$

(d) calcula-se $\mu$ com a expressão (5.34) e obtém-se um ponto do diagrama $\mathrm{M}$ $-N-1 /$ r (FIGURA 5.10).

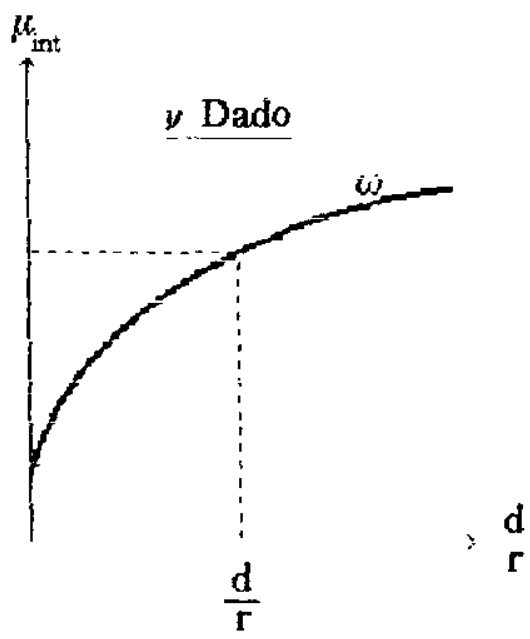

FIGURA 5.10 - Diagrama $\mathrm{M}-\mathrm{N}-\mathrm{l} / \mathrm{r}$. 


\subsection{MÉTODO GERAL}

$O$ principio do método geral, consiste em verificar se a série de momentos $M_{\text {int }}$ e $M_{\text {ext }}$ é divergente e o pilar perde a estabilidade ou se é convergente e ele assume uma configuração fletida estável.

A posição deformada final deve ser estável, de flecha a no topo, com equilíbrio entre esforços externos e internos, respeitando as compatibilidades entre curvaturas e sem haver na seção crítica deformação convencional de ruptura do concreto ou deformação plástica excessiva na armadura.

Inicialmente não se conhece o valor da flecha a no topo do pilar e nem a expressão da deformada. Este processo é de verificação, ou seja, dado um determinado pilar já armado, verifica-se, que a seção do engastamento resiste a $\mathbf{M}_{d}$, consequentemente todas as seções resistirão.

Baseado na FIGURA 5.11, segue-se um roteiro para a utilização do método geral para verificação da estabilidade de pilares:

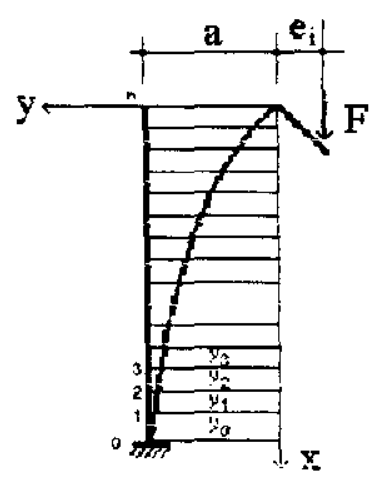

FIGURA 5.11 - Divisão de um tramo de pilar para aplicação do Método Geral.

(a) adotar um valor para a, sendo assim, o momento de segunda ordem é igual a;

$$
\mathrm{M}_{2}=\mathrm{F} \cdot \mathrm{a}
$$

(b) logo, o momento total na seção do engastamento fica;

$$
\mathrm{M}=\mathrm{M}_{1}+\mathrm{M}_{2}=\mathrm{F}\left(\mathrm{e}_{1}+\mathrm{a}\right)
$$


(c) com o valor de $\mathrm{M}$ na seção $\underline{0}$, obtém-se, a partir do diagrama $\mathrm{M}$ - $\mathrm{N}$ - 1/r, a curvatura, ou seja;

$$
\mu_{0}=\left(\frac{1}{r}\right)_{0}=-\left(y^{\prime \prime}\right)_{0}
$$

(d) dividindo-se o pilar em $\mathrm{n}$ trechos e, com o emprego de diferenças finitas, calcula-se numericamente $(y \text { ") })_{0}$ pela expressão;

$$
\left(\mathrm{y}^{\prime \prime}\right)_{0}=\frac{\mathrm{y} \mathrm{l}-2 \mathrm{y}_{\mathrm{l}}+\mathrm{yl}}{\Delta \mathrm{x}^{2}}=-\left(\frac{1}{\mathrm{r}}\right)_{0}
$$

(e) considerando $y_{0}=a$, determina-se $y_{1}$ pela expressão abaixo;

$$
\mathrm{yl}=-\frac{\Delta \mathrm{x}^{2}}{2}\left(\frac{1}{\mathrm{r}}\right)_{0}+\mathrm{y}_{0}
$$

(f) de posse de $y_{1}, o$ processo se repete;

$$
y_{i+1}=2 y_{i}-y_{i-1}-\Delta x^{2}\left(\frac{1}{r}\right)_{i}
$$

(g) repete-se o processo até se obter $y_{n}$ :

(h) se $y_{n}=0$, então a forma da curva é a configuração fletida estável. Caso contrário, ou seja, $\mathrm{y}_{\mathrm{n}} \neq 0$, então recomeça-se o processo com um novo valor de $\underline{\text { a. }}$

Este processo é muito trabalhoso, exigindo o uso de computadores e é aconselhável apenas no caso de pilares muito altos e esbeltos. Para casos usuais, o CEB e a NBR - 6118/78 propõem uma aproximação que é o Método do Pilar Padrão.

\subsection{MÉTODO DO PILAR PADRÃo COM O MÉTODO GERAL}

Pilar padrão é um pilar em balanço com uma distribuição de curvaturas que provoque na sua extremidade uma flecha a dada por:

$$
a=\frac{p^{2}}{10}\left(\frac{1}{r}\right)
$$

A NBR - 6118/78 propõe uma aproximação do método geral que consiste em adotar para a equação da elástica uma função senoidal. $O$ processo do pilar padrão é aplicável a barras de seção transversal constante, inclusive a armadura, ao longo do seu comprimento. 
Adotando-se para a equação da elástica a seguinte equação:

$$
y=\operatorname{asen} \frac{\pi x}{2 \ell}
$$

E analisando as condições de contorno da FIGURA 5.12, tém-se:

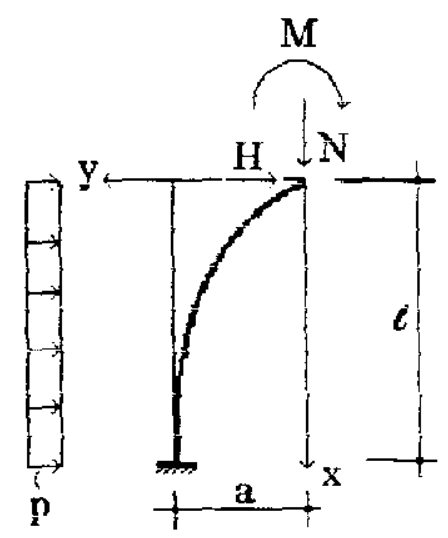

FIGURA 5.12 - Pilar padrão.

$$
\begin{aligned}
& x=0 \Rightarrow y=0 \\
& x=\iota \Rightarrow y=a \\
& x=\iota \Rightarrow y^{\prime}=0 \\
& x=\iota \Rightarrow y^{\prime \prime}=-\left(\frac{1}{r}\right)_{0}=\frac{M}{E !}
\end{aligned}
$$

Portanto:

$$
\begin{aligned}
& y^{\prime}=-a \frac{\pi}{2 \ell} \cos \frac{\pi x}{2 \ell} \\
& y^{\prime \prime}=-\frac{a \pi^{2}}{4 \ell^{2}} \operatorname{sen} \frac{\pi x}{2 \ell}
\end{aligned}
$$

Substituindo:

$$
\frac{a \pi^{2}}{4 \ell^{2}}=-\left(\frac{1}{r}\right)_{0} \therefore a=\frac{4 \ell^{2}}{\pi^{2}}\left(\frac{1}{r}\right)_{\text {base }}
$$

Considerando $\ell=2 \ell$ e $\pi^{2} \cong 10$, tém-se:

$$
\mathrm{a}=\frac{e \mathrm{e}^{2}}{10}\left(\frac{1}{r}\right)_{\text {base }}
$$


Observando a equação $(5,46)$, concluí-se que a flecha é proporcional à curvatura da base. Desse modo, pode ser construído o diagrama $(\mathrm{M}, \mathrm{N}, \mathrm{l} / \mathrm{r})$ da seção da base do pilar padrão, sem a necessidade de integração das curvaturas ao longo do comprimento do pilar.

A curva do momento interno pode ser traçada, quando da posse do diagrama $(\mathrm{M}, \mathrm{N}$, $\mathrm{l} / \mathrm{r}$ ) e com a força normal conhecida, pois:

$$
\mathrm{M}_{\text {int }}=\text { função }(1 / \mathrm{r})
$$

O momento externo solicitante vale:

$$
\begin{gathered}
M_{\text {ext }}=M_{1}+M_{2} \\
M_{2, \text { base }}=\mathrm{F} \cdot a=N \cdot a=N \cdot \frac{l \mathrm{e}^{2}}{10}\left(\frac{1}{r}\right)_{\text {base }}
\end{gathered}
$$

E portanto o momento de primeira ordem será:

$$
M_{1, \text { base }}=M_{\text {int }}-M_{2, \text { base }}
$$

A verificação do estado limite último de instabilidade utilizando o processo do pilar padrão é obtido ao se traçar uma reta paralela à reta da função $\mathbf{M}_{2}$, que seja tangente á curva de $M_{\text {int }}$ (FIGURA 5.13).

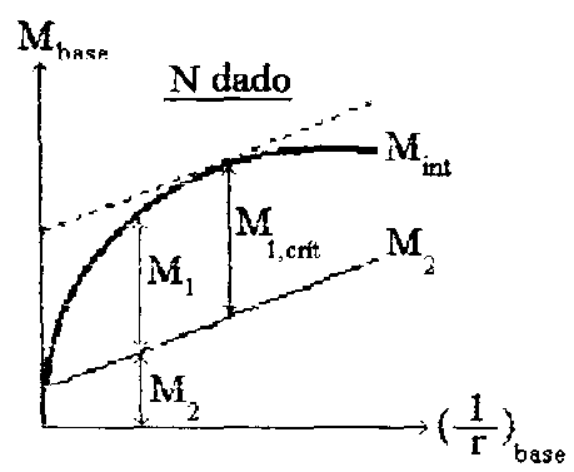

FIGURA 5.13 - Método do pilar padrão com o método geral.

\subsection{MÉTODO SIMPLIFICADO DA NBR - $6118 / 78$}

Este processo é baseado no Método do Equilíbrio com o conceito do pilar padrão. Da análise do diagrama $\mathrm{M}-\mathrm{N}-\mathrm{I} / \mathrm{r}$ (FIGURA 5.14), podem-se obter algumas conclusões: 


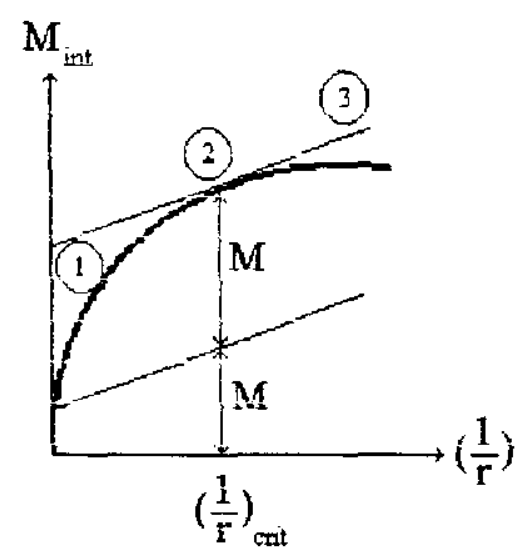

FIGURA 5.14 - Método Simplificado da NBR - 6118/78.

- na região (1), a tensão na armadura aumenta linearmente até a resistência de escoamento $f_{\mathrm{yd}}$;

- na região (2), é atingida a resistência de escoamento da armadura;

- na região (3), a tensão na armadura permanece constante e, para haver aumento de momento interno, ocorrerá variação na braço de alavanca.

Aumentar o braço de alavanca significa modificar a posição da linha neutra, diminuindo a zona comprimida do concreto. Isto significa que a curvatura para a qual ocorre a perda de estabilidade e a curvatura para o escoamento da armadura são praticamente iguais.

Estas conclusões permitem dimensionar a seção mais solicitada com $N_{d}$ e $M_{1 d}+M_{2 d}$, já verificando a instabilidade. $O$ dimensionamento, portanto é feito à flexão composta.

O valor da curvatura crítica $(1 / \mathrm{r})_{\text {crit }}$, assume um valor convencional proposto pela NBR $-6118 / 78$ que vale:

$$
\left(\frac{1}{I}\right)_{\text {conv }}=\frac{0,0035+\frac{f_{y d}}{E_{S}}}{(v+0.5) \cdot h}
$$

sendo:

$$
\begin{aligned}
& v-\frac{F_{d}}{A_{u} \cdot f_{u s}}, \operatorname{com} v+0,5 \geq 1,0, \\
& h \text { - lado paralelo à excentricidade acidental considerada, do retângulo } \\
& \quad \text { circunscrito à seção. }
\end{aligned}
$$


A NBR $-6118 / 78$ recomenda que o processo em questão seja usado para pilares com indice de esbeltez $\lambda \leq 80$, pois para valores maiores, o processo é contra a segurança, em alguns casos.

Em resumo, para se verificar a estabilidade em pilares de concreto armado pode-se seguir as recomendações abaixo:

$-\lambda \leq 80 \Rightarrow$ processo simplificado da NBR - 6118/78;

$-80<\lambda \leq 140 \Rightarrow$ processo do pilar padrão;

$-140<\lambda \leq 200 \Rightarrow$ processo exato;

$-\lambda>200 \Rightarrow$ inadmissivel pela NBR $-6118 / 78$. 


\section{CAPÍTULO 6: EXCENTRICIDADES PARA O DIMENSIONAMENTO DE PILARES}

$\mathrm{Na}$ forma de uma estrutura as posições de vigas e pilares são adotadas em função do projeto arquitetônico, fazendo, na maioria dos casos, que ocorra uma excentricidade de forma entre o eixo da viga e do pilar. Observando a FIGURA 6.1, nota-se que na ligação das vigas VT01 e VT05 com o pilar P1, ocorre a excentricidade de forma.

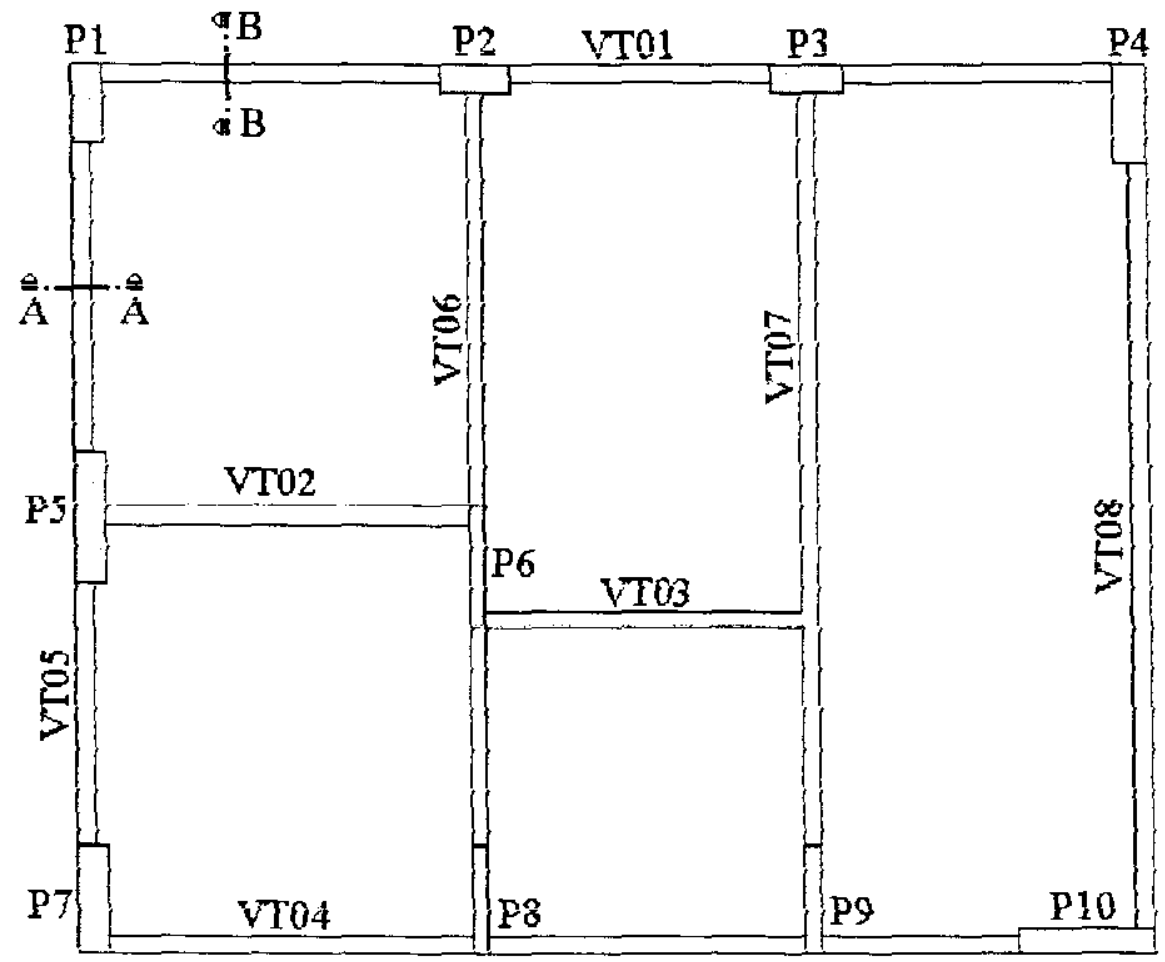

FIGURA 6.1 - Forma de um pavimento tipo.

Analisando o corte AA, têm-se as posições das ações verticais no pilar PI.

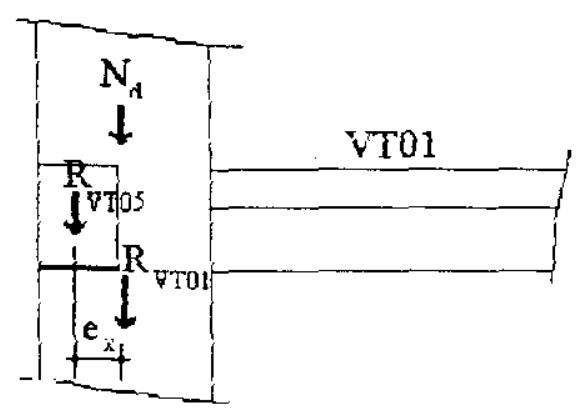

FIGURA 6.2 - Corte AA. 
Com o intuito de demonstrar porque a excentricidade de forma é desprezada no dimensionamento de pilares, faz-se o equilíbrio das ações em relação ao C.G. do Pilar P1 (FIGURA 6.3):
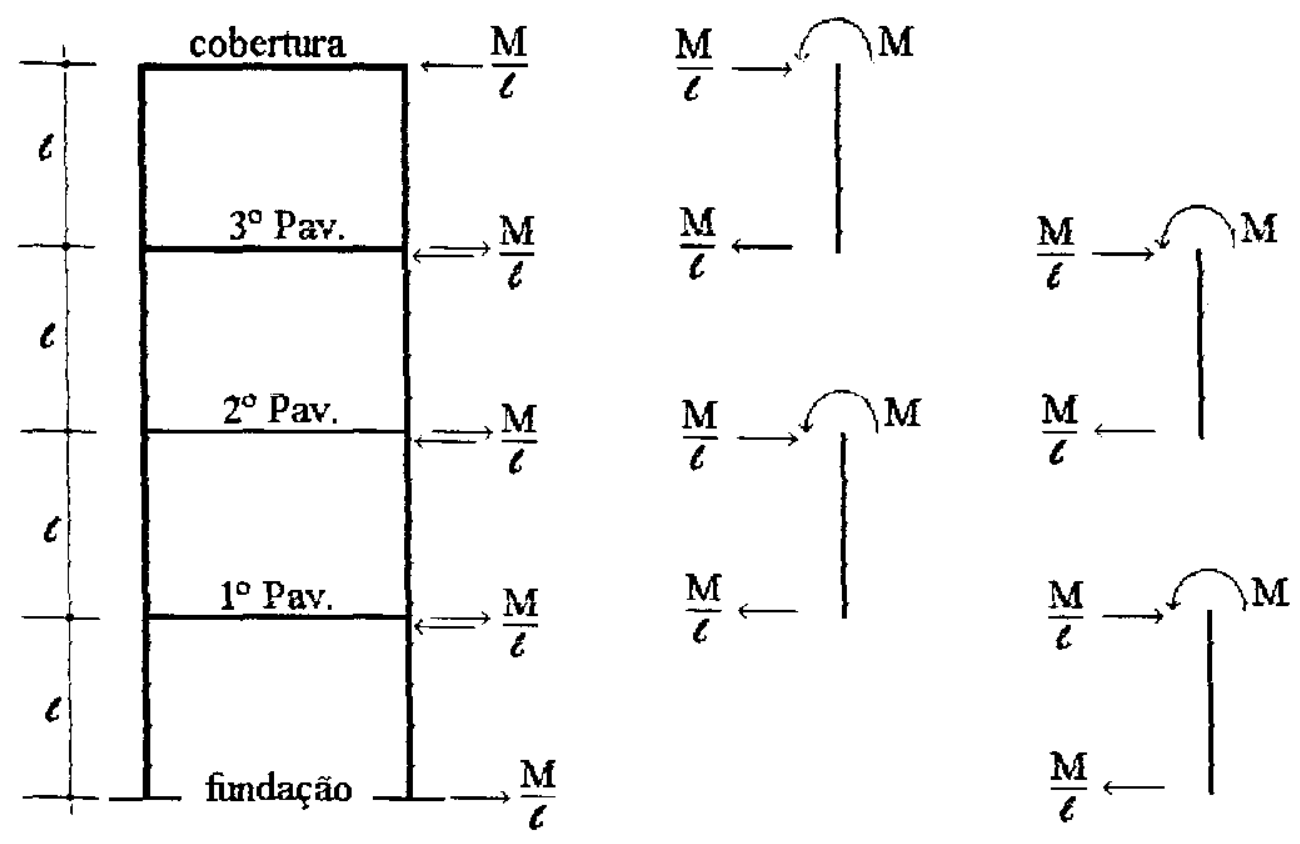

$$
\begin{aligned}
& \mathrm{M}=\mathrm{R}_{\mathrm{VTO5}} \cdot \mathrm{e}_{\mathrm{x}} \\
& \mathrm{N}=\mathrm{R}_{\mathrm{VT05}}
\end{aligned}
$$

FIGURA 6.3 - Equilibrio das ações resultantes da excentricidade de forma.

- em todos os pavimentos, exceto a fundação e a cobertura, os esforços resultantes da excentricidade de forma da viga VT01 no pilar PI se equilibram;

- na cobertura e na fundação, as ações horizontais, provenientes da excentricidade de forma, são absorvidos pelas lajes e vigas dos respectivos pavimentos.

Sendo assim, pode-se não considerar a excentricidade de forma no dimensionamento de pilares. 


\subsection{EXCENTRICIDADE ACIDENTAL}

A NBR - 6118/78 prevê que se utilize no dimensionamento de pilares em concreto armado, uma excentricidade a fim de que erros na execução da estrutura sejam considerados. A excentricidade acidental $\left(e_{a}\right)$ é adotada como o maior entre os seguintes:

$$
\mathrm{e}_{\mathrm{a}}=\frac{\mathrm{h}}{30}>2,0 \mathrm{~cm}
$$

É sabido que os valores recomendados pela NBR - 6118/78 são conservativos e usualmente os projetistas de estruturas de concreto armado adotam $e_{a}=1,0 \mathrm{~cm}$ para todos os casos.

No Texto Base para a revisão da NBR - 6118/78, a excentricidade acidental é substituida pela consideração do efeito do desaprumo ou da falta de retilinidade do eixo do pilar. Admite-se que, nos casos usuais, a consideração da falta de retilinidade seja suficiente.

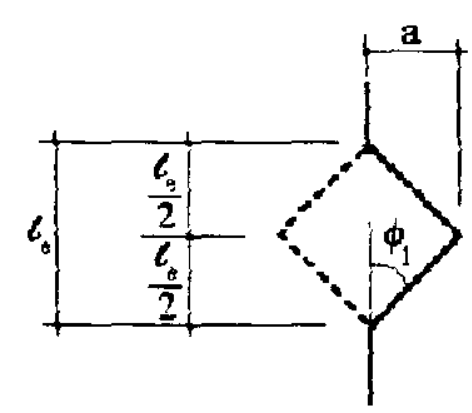

Falta de retilinidade

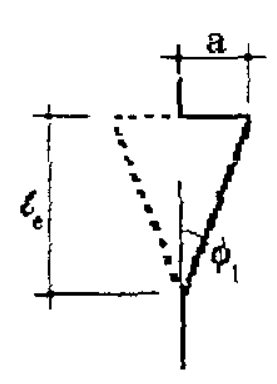

Desaprumo

FIGURA 6.4 - Imperfeições geométricas localizadas.

Na FIGURA 6.4 as grandezas geométricas têm os seguintes significados:

$$
\begin{aligned}
& \phi_{1}-\frac{1}{100 \sqrt{\iota_{\mathrm{c}}}} \geq \phi_{\mathrm{I}_{\text {min }}} \\
& \ell_{\mathrm{e}} \text { - altura total do pilar em metros; } \\
& \text { a - valor do efeito de desaprumo ou falta de retilinidade a ser considerada no } \\
& \quad \text { dimensionamento; }
\end{aligned}
$$

Deve ser considerado um valor mínimo de $\phi_{1}$ dado por: 
$\phi_{\min }-\frac{1}{400}$ para estruturas pouco deslocáveis;

$\phi_{1 \min }=\frac{1}{200}$ para estruturas deslocáveis ou efeito de imperfeições

geométricas.

\subsection{EXCENTRICIDADE DE SEGUNDA ORDEM}

No Capítulo 5 que trata sobre Instabilidade de Pilares, foi visto que para barras retas com seção transversal constante e simétrica, inclusive a armadura, submetida a flexo compressão e com esbeltez entre 40 e 80 , podem-se considerar as deformações na barra de modo simplificado. A consideração dos esforços de segunda ordem pode ser feita, utilizando-se a seguinte expressão, indicada na NBR - 6118/78:

$$
\frac{1}{r}-\frac{0,0035+\frac{f_{y d}}{E_{s}}}{\left(v_{d}+0,5\right) h} ; \text { com } v_{d}+0,5>1
$$

sendo:

$$
v_{d}-\frac{N_{d}}{A_{c} f_{c d}} ; \text { força normal relativa adimensional. }
$$

O momento fletor de segunda ordem ocorre na seção intermediária do tramo do pilar, visto que, para estruturas indeslocáveis a ligação viga - pilar é considerada como um nó fixo.

Para pilares $\operatorname{com} \lambda<40$ a consideração da excentricidade de segunda ordem não se faz necessária, por outro lado, para pilares esbeltos $(\lambda>80)$ a consideração dos esforços adicionais, ocasionadas pela deformação da estrutura, deve ser feita por processos exatos ou simplificados, desde que, devidamente justificados. 


\subsection{EXCENTRICIDADE INICIAL}

Nas ligações de vigas com pilares extremos, ocorre um monolitismo entre os mesmos, gerando um momento fletor inicial nas extremidades dos tramos dos pilares.

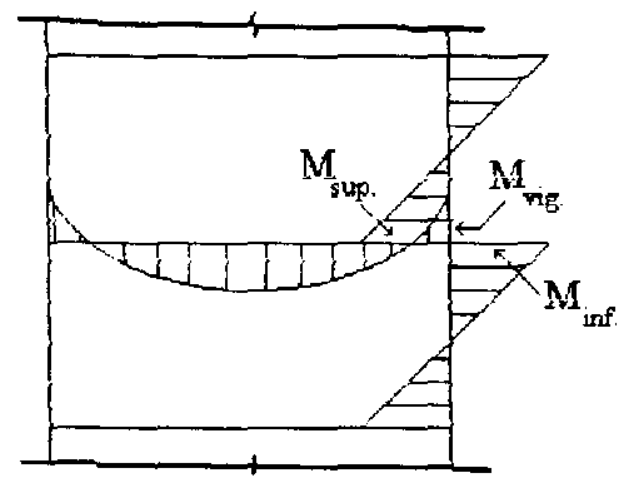

FIGURA 6.5 - Esquema estrutural dos momentos iniciais devidos às ligações monoliticas.

Observando-se a FIGURA 6.5, concluí-se que o momento absorvido pelo pilar na ligação é proporcional às rigidezes da viga e do pilar. A NBR 6118/78 indica que para uma avaliação simplificada dos valores destes momentos fletores pode ser considerado:

$$
\begin{aligned}
& M_{\text {sup }}=M_{\text {eng }} \cdot \frac{r_{\text {sup }}}{r_{\text {vig }}+r_{\text {sup }}+r_{\text {inf }}} \\
& M_{\text {unf }}-M_{\text {eng }} \cdot \frac{r_{\text {inf }}}{r_{\text {vig }}+r_{\text {sup }}+r_{\text {inf }}}
\end{aligned}
$$

sendo:

$\mathbf{M}_{\mathrm{cng}}$ - momento de engastamento perfeito no tramo extremo da viga, considerada engastada nos dois apoios;

As excentricidades iniciais dos pilares resultam em:

$$
e_{\text {ibase }}-\frac{M_{\text {hase }}}{N}
$$




$$
\mathrm{e}_{\text {itopo }}=\frac{\mathrm{M}_{\text {topo }}}{\mathrm{N}}
$$

Nas seções intermediárias de pilares de estruturas indeslocáveis não submetidas à carregamentos transversais, a NBR - $6118 / 78$ prevê que se considere uma excentricidade inicial $e_{i c}$ de acordo com a expressão (6.9) (FIGURA 6.6):

$$
\mathrm{e}_{\mathrm{iC}}=0,6 \mathrm{e}_{\mathrm{i \Lambda}_{\mathrm{A}}}+0,4 \mathrm{e}_{\mathrm{iB}} \geq 0,4 \mathrm{e}_{\mathrm{i \Lambda}_{\Lambda}}
$$

sendo:

$\mathrm{e}_{\mathrm{i}}$ - excentricidade inicial na seção intermediária de um tramo de pilar; $e_{i A}$ e $e_{{ }_{B}}$ - excentricidade iniciais nas extremidades de um tramo de pilar.

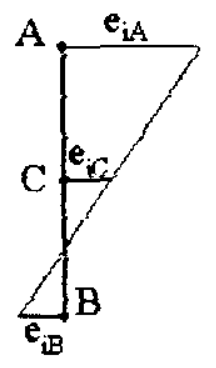

FIGURA 6.6 - Excentricidade inicial na seção intermediária de pilares de estruturas indeslocáveis.

A excentricidade $e_{i A}$ é suposta sempre positiva e maior que $e_{i B}$, além disso, $e_{i B}$ é negativa se elas forem de sentidos opostos.

\subsection{EXCENTRICIDADE SUPLEMENTAR}

Para pilares esbeltos além das excentricidades vistas anteriormente, deve-se considerar a deformação lenta do concreto. Esta consideração é feita através de uma expressão aproximada, visto que, o coeficiente de fluência $\phi$ só pode ser estimado, o que torna o cálculo teórico das deformações, produzidas pela deformação lenta, errôneo.

Sendo assim, admite-se que todos os carregamentos são de curta duração e a excentricidade devido a fluência será dada por: 


$$
e_{c}=\left(e_{i_{g}}+e_{a}\right)\left[\exp \left(\frac{\phi N_{g d}}{N_{c r}-N_{g d}}\right)\right]
$$

sendo:

$\mathrm{N}_{\mathrm{cr}}=\frac{10 \cdot \mathrm{E}_{\mathrm{c}} \cdot \mathrm{I}}{e_{\mathrm{e}}^{2}}$ a carga critica de Euler;

$e_{\mathrm{ig}}$ - excentricidade inicial referente às ações de longa duração;

$e_{a}$ - excentricidade acidental;

$\phi$ - coeficiente de fluência;

$\mathrm{N}_{\mathrm{gd}}$ - força normal de cálculo referente às ações de longa duração;

$E_{c}=0,90 \cdot 6600 \cdot \sqrt{f_{c k}+3,5}(\mathrm{MPa}):$ módulo de clasticidade longitudinal

secante do concreto.

\subsection{SITUAÇÕES DE PROJETO E DE CÁLCULO PARA O DIMENSIONAMENTO DE PILARES}

As situações de projeto e de cálculo dependem basicamente de dois fatores:

- localização do pilar na forma da estrutura;

- esbeltez do pilar.

A posição do pilar na estrutura permite saber à quais esforços este está submetido. Sabe-se que os pilares internos estão solicitados basicamente por esforços de compressão, porém no seu dimensionamento deve-se prever uma flexão oriunda da excentricidade acidental e de segunda ordem, no caso de pilares esbeltos. Os pilares de extremidade são solicitados à flexão normal composta em razão do momento resultante da ligação monolítica entre viga e pilar em uma direção. Já os pilares de canto devem ser dimensionados para absorver a flexão oblíqua composta, resultante da ligação monolítica entre vigas e pilar em duas direções distintas.

Por outro lado, a esbeltez de um pilar indica se a consideração dos esforços adicionais provenientes das deformações de segunda ordem locais e da fluência devem ser considerados. 


\subsubsection{Pilar Interno Curto $(\lambda \leq 40)$}

Os pilares internos e curtos são dimensionados a flexo - compressão, sendo que, o momento fletor é originado em função da excentricidade acidental.

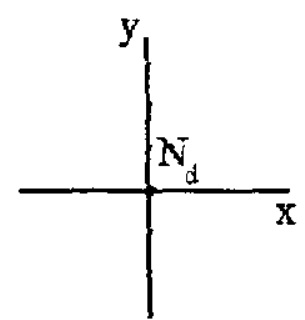

SITUAÇÃO DE PROJETO

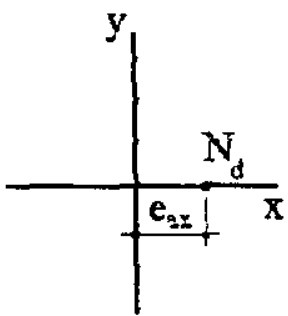

( I)

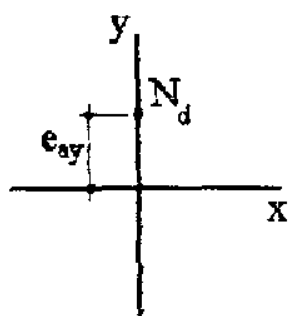

(II)

\section{SITUAÇÕES \\ DE CÁlCULO}

O dimensionamento deve ser feito para as situações ( I ) e ( II ), sem contudo, somar as armaduras.

A NBR - 61 18[1978] permite uma simplificação para o dimensionamento de pilares internos curtos que consiste em majorar a força normal de compressão na proporção de $\mathrm{l}+6 / \mathrm{h}$, onde $\mathrm{h}$ é o menor lado do retângulo mais estreito circunscrito à seção.

\subsubsection{Pilares Internos Medianamente Esbeltos $(40<\lambda \leq 80)$}

Os pilares internos medianamente esbeltos devem ser dimensionados, também, à flexão normal composta, sendo que a flexão é oriunda das excentricidades acidentais e de segunda ordem.

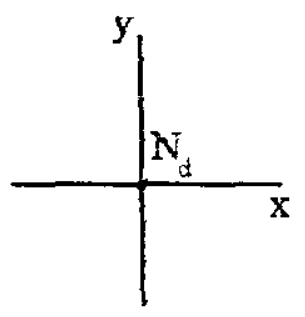

SITUAÇÃO DE

PROJETO

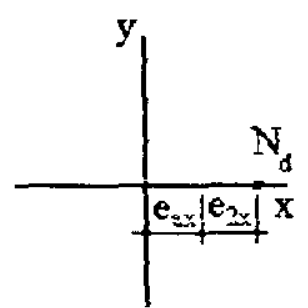

(I) seçâo intermediária

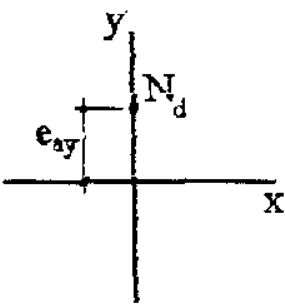

(II)

SITUAÇÕES DE

CÁlCULO 
A NBR - 6118/78 permite uma simplificação para dimensionamento de barras medianamente esbeltas com carregamento suposto centrado com seção transversal constante inclusive a armadura, que consiste em se majorar a força normal de compressão de $1+\mathrm{ke} / \mathrm{h} \geq 1,10$.

sendo:

$\mathrm{e}=\mathrm{e}_{\mathrm{a}}+\mathrm{e}_{2}$

$k=3$ : seções retangulares com pelo menos dois terços da armadura dispostos ao longo das bordas perpendiculares ao lado de altura $\mathrm{h}$;

$k=4$ : demais seções retangulares e seções circulares.

\subsubsection{Pilares de Extremidade Curtos}

Os pilares de extremidade curtos estão submetidos à flexão normal composta, sendo que a flexão é provocada pelas excentricidades acidental e inicial.

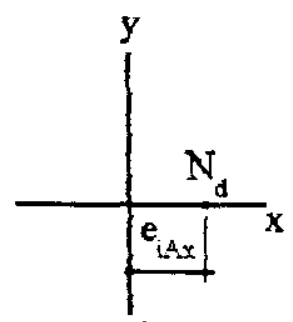

seçẫo de topo

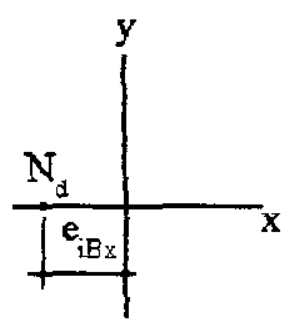

seção de base

SITUACÕES DE PROJETO

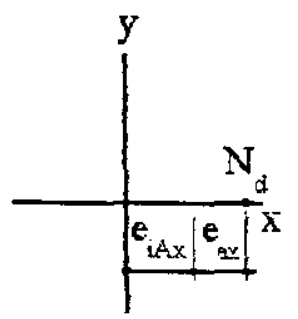

( I )

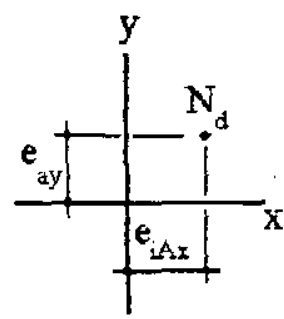

(II)

SITUAÇÕES DE CÁLCULO

O dimensionamento deve ser feito para a situação de cálculo ( I ), ou seja, utilizandose os ábacos de flexão normal composta e em seguida deve-se verificar a situação de cálculo ( II ) com os ábacos de flexão oblíqua composta.

\subsubsection{Pilares de Extremidade Medianamente Esbeltos}


O dimensionamento deve ser como foi exposto para o caso de pilares de extremidade curtos, incluindo na flexão a parcela referente à excentricidade de segunda ordem na seção intermediária.
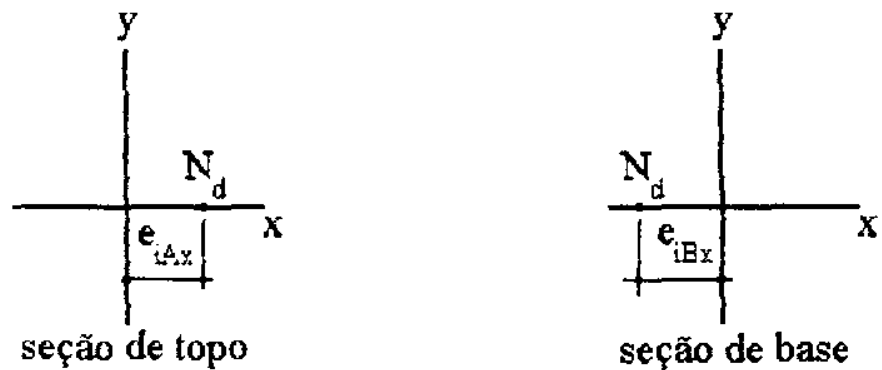

\section{SITUAÇÕES DE PROJETO}

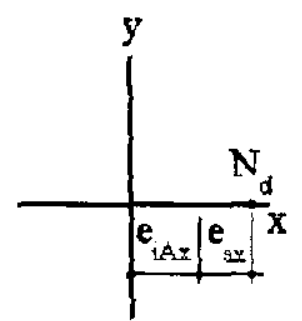

(I)

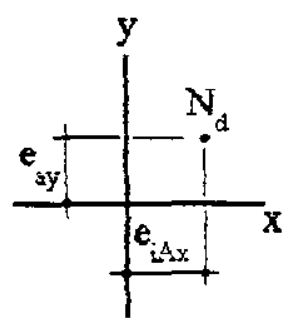

(II)

seções de topo/base
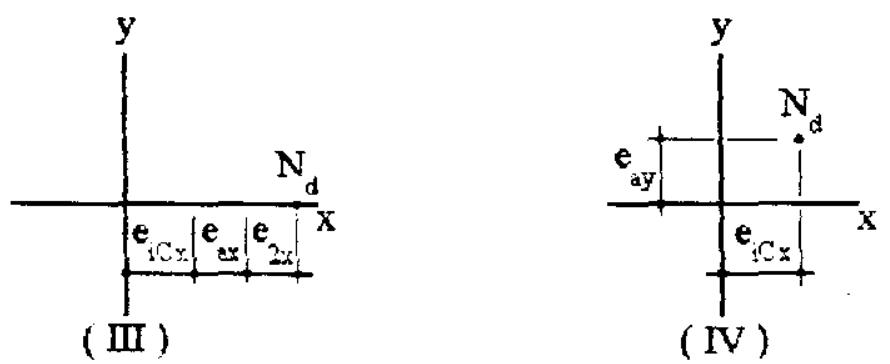

seção intermediária

\section{SITUACÕES DE CÁlCULO}

Para o dimensionamento dos pilares de extremidade medianamente esbeltos, deve-se verificar, para cada caso, qual a situação de cálculo mais desfavorável e obter as armaduras para tal situação. Em seguida, deve ser feita uma verificação para as demais situações de cálculo. 


\subsubsection{Pilares de Canto Curtos}

Os pilares de canto curtos devem ser dimensionados à flexão oblíqua, visto que a excentricidade inicial especificada no ítem 6.3 ocorre em duas direções distintas.

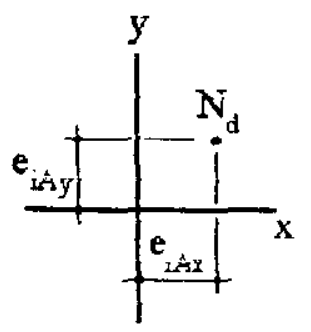

seção de topo

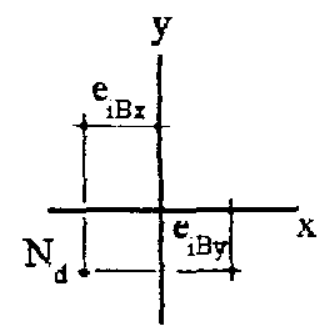

seção de base

\section{SITUAÇÕES DE PROJETO}
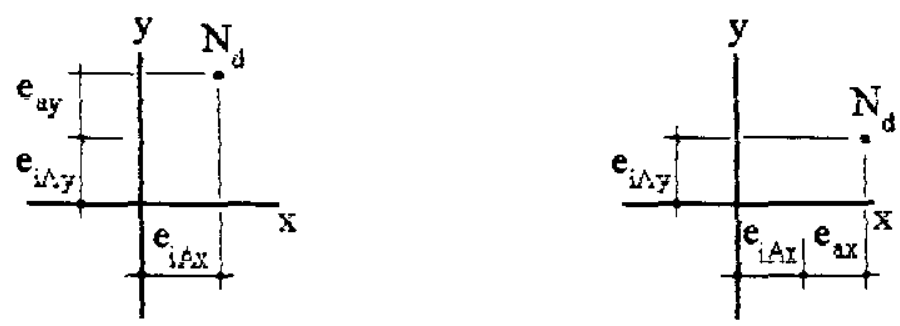

seção de topo

\section{SITUAÇÕES DE CÁlCULO}

Deve-se analisar a situação de cálculo mais desfavorável, para cada caso, e obter a armadura para tal situação. Posteriormente deve-se fazer uma verificação para as situações de cálculo restantes.

\subsubsection{Pilares de Canto Medianamente Esbeltos}

Os pilares de canto medianamente esbeltos também são calculados à flexão oblíqua composta considerando a excentricidade de segunda ordem na direção onde o indice de esbeltez $(\lambda)$ supera 40 . 


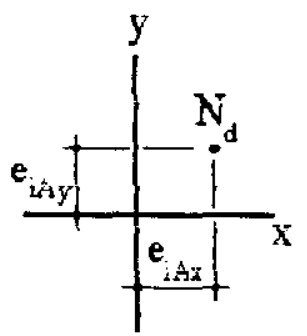

seção de topo

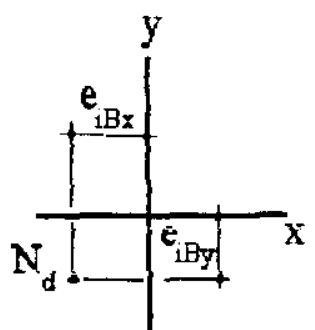

seção de base

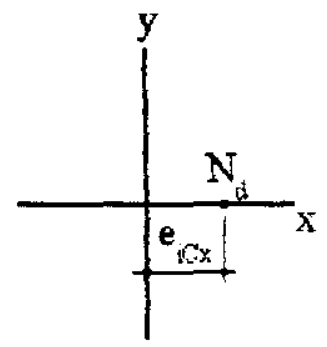

seção intermediária

SITUACÕEES DE PROJETO
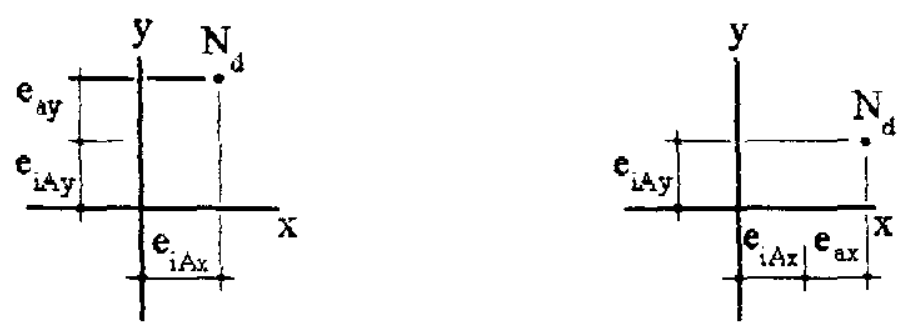

seções de topo
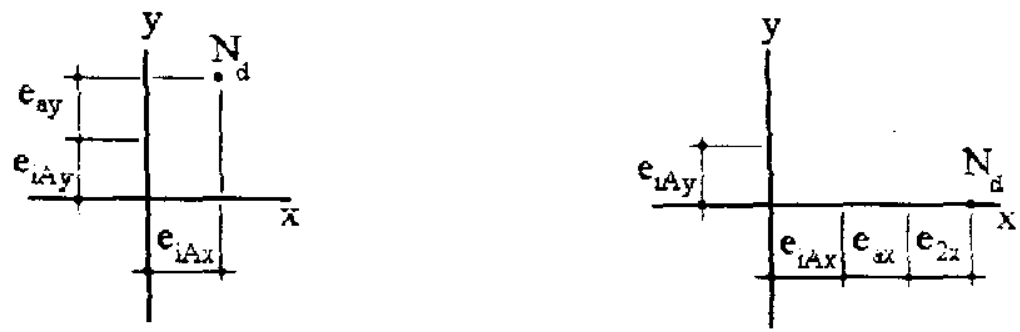

seção intermediária 
As armaduras devem ser obtidas ao analisar a situação de cálculo mais desfavorável, utilizando-se os ábacos de flexão oblíqua composta. Vale lembrar que a verificação para as demais situações de cálculo também se faz necessário. 


\section{CAPÍTULO 7: DETALHAMENTO DAS ARMADURAS DE PILARES}

Neste capitulo, são abordados os tópicos relevantes que devem ser observados ao se efetuar o detalhamento de pilares de concreto armado.

\subsection{ANCORAGEM DAS BARRAS}

Entende-se por ancoragem, como o fenômeno de transferência de tensão, numa peça de concreto armado, do aço para o concreto, fazendo-se com que os dois elementos permaneçam solidários. Este processo ocorre devido à aderência existente entre aço e concreto.

Para se entender melhor o processo de aderência das barras de aço nas estruturas de concreto armado, pode-se dividi-lo em três sub-processos a saber;

- aderência por adesão;

- aderêncía mecânica;

- aderência por atrito

Vale lembrar que a divisão do fenômeno da aderência citada acima, é simplesmente para facilitar o entendimento do processo, não sendo possivel distinguir tais etapas no cálculo da ancoragem das barras nas estruturas de concreto armado.

\subsubsection{Aderência por Adesão}

Ao se ensaiar um bloco de concreto moldado sobre uma placa de aço (FIGURA 7.1), observa-se que ocorre uma adesão entre os dois materiais para uma determinada força $N_{1}$ aplicada. Esta adesão é proveniente de ligações físico-químicas que ocorrem durante o processo de cura do concreto. 


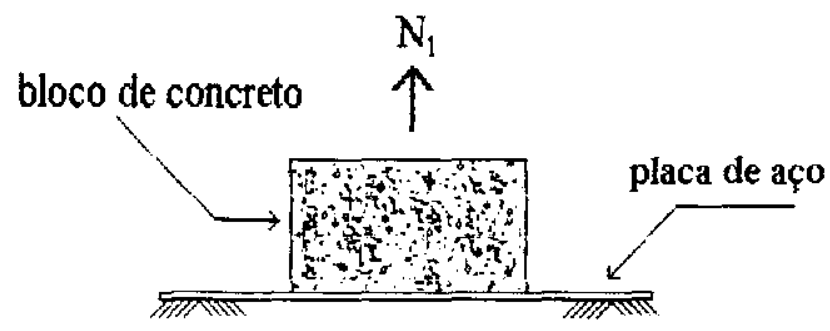

FIGURA 7.1 - Aderència por adesão.

\subsubsection{Aderência por Atrito}

Ao se efetuar um ensaio de arrancamento de uma barra colocada dentro de um bloco de concreto (FIGURA 7.2), observa-se que a força $\mathrm{N}_{2}$ que provoca o arrancamento da barra do bloco de concreto é superior à força $N_{1}$ obtida no ensaio de adesão. Concluí-se a partir dai, que existe uma parcela de aderència proveniente do atrito entre aço e concreto. Essa força depende do coeficiente de atrito existente entre aço e concreto que é função da rugosidade da barra e de uma pressão transversal originada em virtude da retração do concreto.
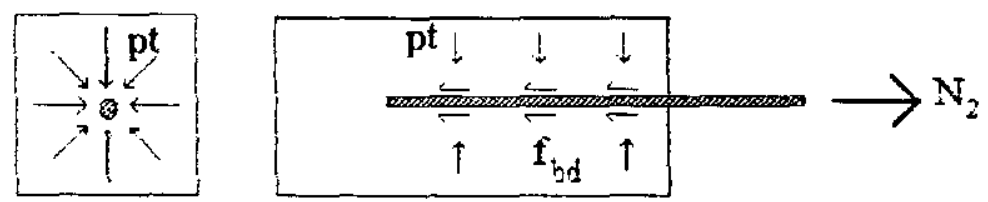

FIGURA 7.2 - Aderência por atrito.

\subsubsection{Aderência Mecânica}

Essa parcela de aderência, denominada de mecânica é proveniente das saliências existentes ao longo das barras de aço submetidas à força $\mathrm{N}_{3}$ (FIGURA 7.3).

As saliências funcionam como apoio para as barras, fazendo com que apareçam forças de compressão nessas áreas, contribuindo com o processo de aderência.

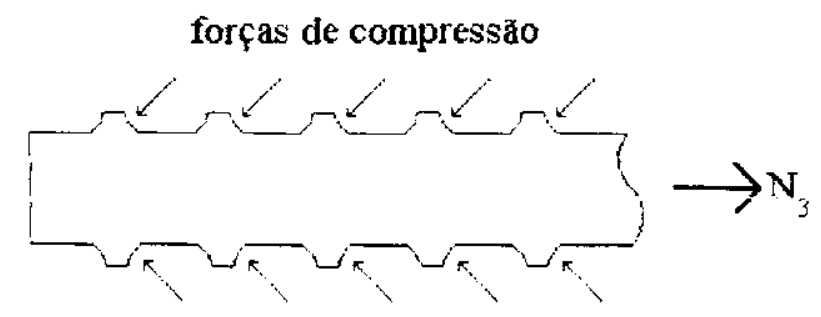

FIGURA 7.3 - Aderència mecànica. 


\subsection{COMPRIMENTO DE ANCORAGEM}

De acordo com o que foi apresentado anteriormente, sabe-se que o processo de ancoragem é aquele onde ocorre a transferência de tensões do aço para o concreto e viceversa. Sendo assim, é necessário definir agora o comprimento que a barra de aço, componente da estrutura de concreto armado, deve ter para que essa transferència de tensão ocorra de maneira satisfatória.

Ao se observar a FIGURA 7.4, nota-se que o comprimento $c_{b}$, é suficiente e necessário para haver uma mobilização das tensões tangenciais $\mathrm{f}_{b d}$ a partir do ponto $A$, onde se dá o inicio da ancoragem.

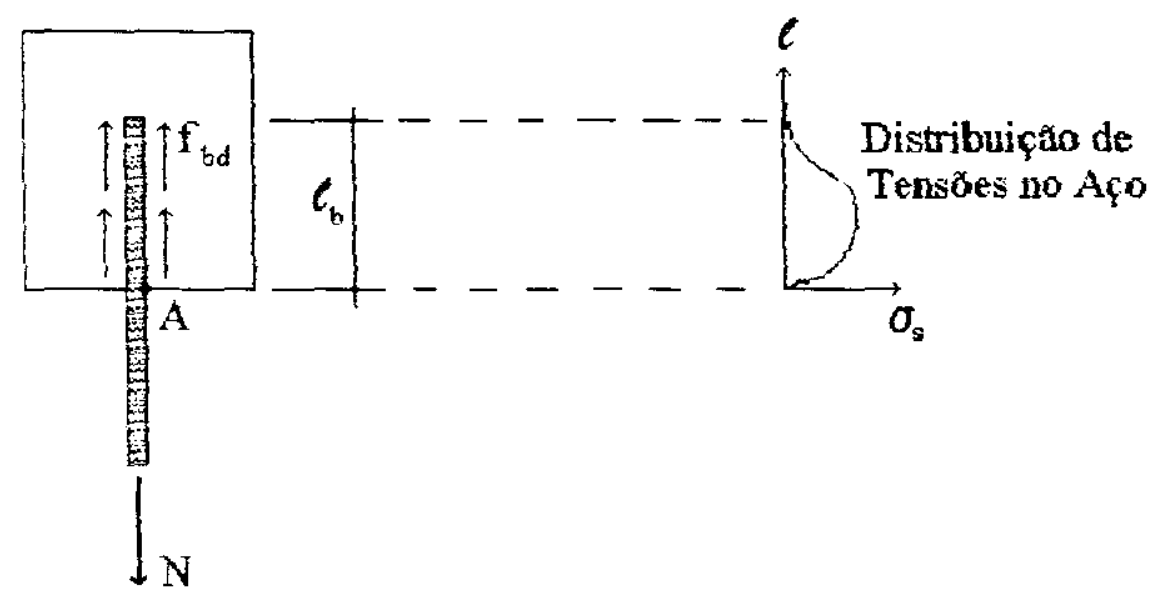

FIGURA 7.4 - Comprimento de ancoragem.

Destacando-se um elemento do bloco de concreto armado de comprimento $\mathrm{dx}$ e fazendo o equilibrio, obtém-se:

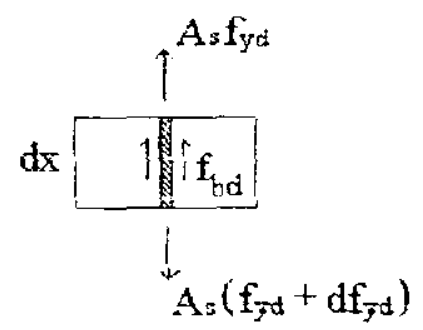

FIGURA 7.5 - Equilibrio de um elemento de bloco de concreto armado.

$$
f_{b d} \cdot u \cdot d x=A_{s} \cdot d f_{y d}
$$




$$
f_{b d}=\frac{A_{s}}{u} \cdot \frac{d f_{y d}}{d x} \Rightarrow f_{b d}=\frac{\pi \phi^{2}}{4 \cdot 2 \pi \phi} 2 \frac{f_{y d}}{\xi_{b}}
$$

Isolando o valor de $\varsigma_{b}$, obtém-se a seguinte expressão:

$$
\xi_{\mathrm{b}}=\frac{\phi}{4} \cdot \frac{\mathrm{f}_{\mathrm{yd}}}{\mathrm{f}_{\mathrm{bd}}}
$$

sendo:

$\phi$ - diâmetro da barra a ser ancorada;

$f_{y d}$ - tensão de escoamento do aço;

$f_{b d}$ - tensão de aderência entre concreto e aço;

$\mathrm{u}$ - perimetro da barra de aço.

A expressão (7.3), fornece o comprimento de ancoragem reta que uma barra de aço deve ter para estar devidamente ancorada na peça de concreto armado.

O Texto Base para revisão da NBR - 6118/78 traz algumas diferenças em relação a NBR - 6118/78 para o cálculo da tensão de aderência entre armadura e concreto, levando em consideração o tipo de aço, condições de aderência, bitola das armaduras e resistência à tração do concreto.

$$
\mathrm{f}_{\mathrm{bd}}=\mathrm{n}_{1} \cdot \mathrm{n}_{2} \cdot \mathrm{n}_{3} \cdot \mathrm{f}_{\mathrm{ctd}}
$$

sendo:

$n_{1}$ - coeficiente que considera o tipo de aço;

$$
\begin{aligned}
& \mathrm{n}_{1}=1,00 \text { para } \mathrm{CA}-25 \\
& \mathrm{n}_{1}=1,40 \text { para } \mathrm{CA}-60 \\
& \mathrm{n}_{1}=2,25 \text { para } \mathrm{CA}-50
\end{aligned}
$$

$\mathrm{n}_{2}$ - coeficiente que considera as situações de aderência;

$\mathrm{n}_{2}=1,00$ para situações de boa aderência

$\mathrm{n}_{2}=0,70$ para situações de má aderència

$\mathrm{n}_{3}$ - coeficiente que considera a bitola das barras ancoradas:

$$
\begin{aligned}
& \mathrm{n}_{3}=1,00 \text { para } \phi \leq 32 \mathrm{~mm} . \\
& \mathrm{n}_{3}=\frac{132-\phi}{100} \text { para } \phi>32 \mathrm{~mm}, \phi \mathrm{em} \mathrm{mm} .
\end{aligned}
$$


$\mathrm{f}_{\text {ctd }}$ - valor de cálculo da resistência do concreto à tração.

$$
\begin{aligned}
& f_{\text {ctd }}=\frac{f_{c d}}{10} \text { para } f_{c k} \leq 18 \mathrm{MPa} . \\
& f_{\text {ctd }}=0,06 f_{\text {ck }}+0,7 \mathrm{MPa} \text { para } \mathrm{f}_{\mathrm{ck}}>18 \mathrm{MPa} .
\end{aligned}
$$

Foi visto que o coeficiente $\mathrm{n}_{2}$ considera as situações de aderência que uma barra de aço pode estar submetida. O Texto Base para revisão da NBR - 6118/78, traz as seguintes especificações quanto às situações de aderência:

(a) Concretagem com fôrmas convencionais: Consideram-se em boa situação quanto à aderência, os trechos das barras que estejam em uma das posições seguintes:

- com inclinação não inferior a $45^{\circ}$ sobre a horizontal;

- horizontais ou com inclinação menor que $45^{\circ}$ sobre a horizontal, desde que localizados no máximo $30 \mathrm{~cm}$ acima da face inferior da peça ou da junta de concretagem mais próxima, quando $\mathrm{h}<60 \mathrm{~cm}$, ou desde que localizadas a mais de $30 \mathrm{~cm}$ abaixo da face superior ou da junta de concretagem mais próxima, quando $\mathrm{h}>60 \mathrm{~cm}$.

Os trechos das barras em outras condições, são considerados em má situação quanto à aderência.

(b) Concretagem com formas deslizantes: Sob essas condições, as barras devem ser consideradas em má situação quanto à aderència.

A FIGURA 7.6 ilustra alguns exemplos de zonas de boa e de má aderência. 

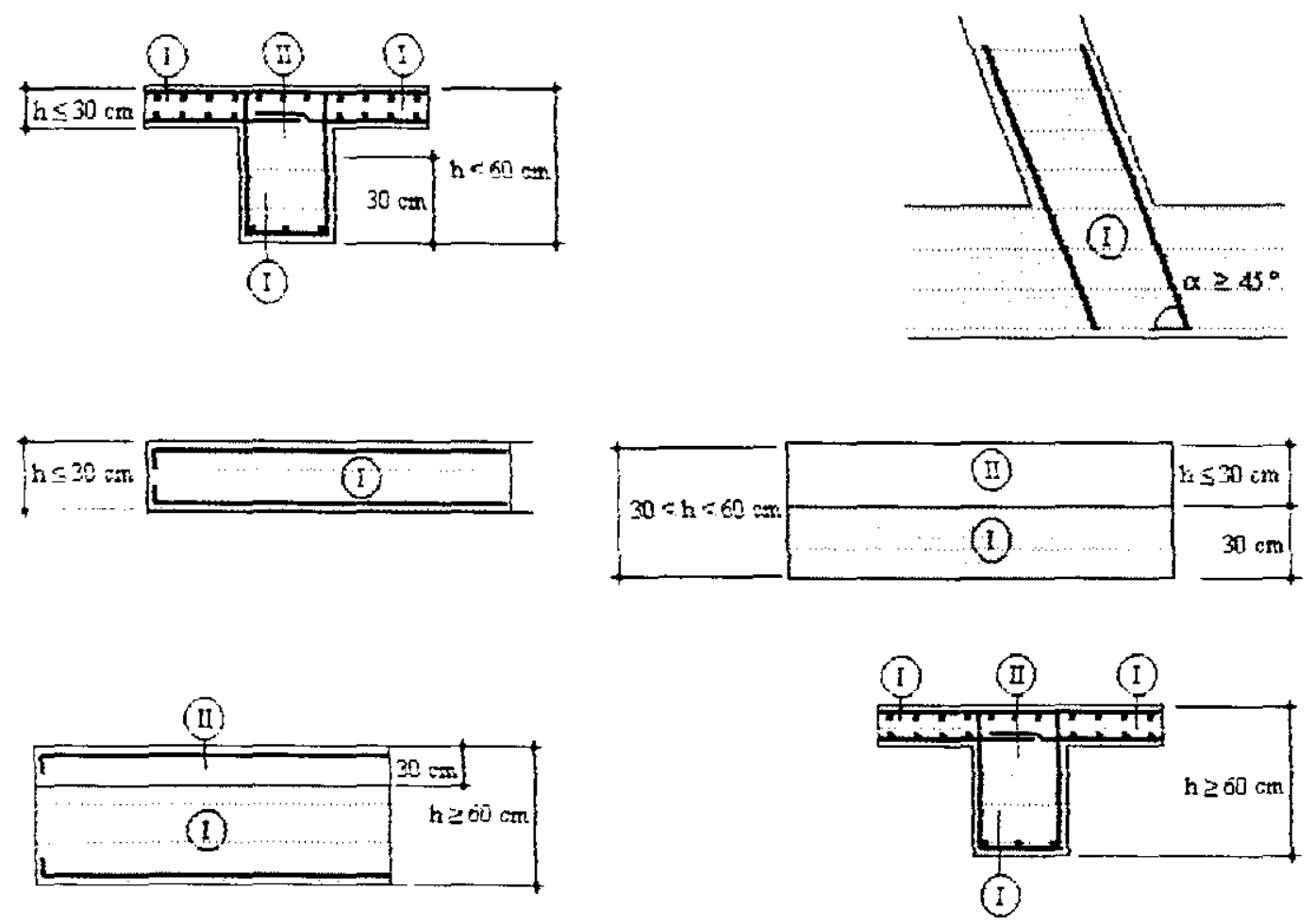

(I) zonas de boa aderència

(II) zonas de má aderència

FIGURA 7.6 - Zonas de boa e má aderència.

Nos casos em que a armadura efetiva for maior que a armadura obtida no dimensionamento, as barras de aço da armadura estão submetidas a uma tensão inferior a de escoamento. O Texto Base para a revisão da NBR - 6118/78 prevê uma correção do comprimento $\varsigma_{b}$ para um novo valor $\ell_{\text {b nec }}$ de acordo com a expressão (7.5).

$$
\ell_{\mathrm{b}, \text { nec }}=\mathrm{a}_{1} \cdot \ell_{\mathrm{b}} \cdot \frac{\mathrm{A}_{\mathrm{s} . \mathrm{cal}}}{\mathrm{A}_{\mathrm{s}, \mathrm{ex}}}
$$

sendo:

$\ell_{\mathrm{b} \text { nec }}$ - comprimento de ancoragem necessário;

$a_{1}$ - considera a forma da extremidade da barra: 
$a_{1}=1,00$ para ancoragens retas sem ganchos.

$a_{1}=0,70$ para ancoragens retas de barras tracionadas com gancho, desde que o cobrimento do gancho, no plano perpendicular ao de curvatura, seja $\geq 3 \phi$, caso contrário $\mathrm{a}_{1}=1,00$.

4 - comprimento de ancoragem, obtido conforme expressão (7.3);

$A_{\text {s cal }}$ - área da seção transversal da armadura, calculada com o esforço a ancorar;

$A_{\text {sex }}$ - área da seção de armadura existente.

O Texto Base para a revisão da NBR - $6118 / 78$ prevê que o comprimento de ancoragem necessário $\left(\ell_{\mathrm{n}} \mathrm{nc}\right)$ pode ainda ser reduzido para um comprimento $\ell_{\mathrm{b}}$ red, através da aplicação sucessivas de coeficientes de minoração, conforme expressão (7.6).

$$
\ell_{\mathrm{h} \text {. red }}=\ell_{\mathrm{h}, \text { nac }} \cdot \mathrm{a}_{2} \cdot \mathrm{a}_{3} \cdot \mathrm{a}_{4} \cdot \mathrm{a}_{5} \geq \ell_{\mathrm{h}, \text { min }}
$$

sendo:

$\mathrm{a}_{2}$ - considera a influência de uma ou mais barras soldadas transversalmente à armadura;

$\mathrm{a}_{2}=0,70$ tanto para barras comprimidas ou tracionadas, desde que obedecido o indicado na FIGURA 7.7.
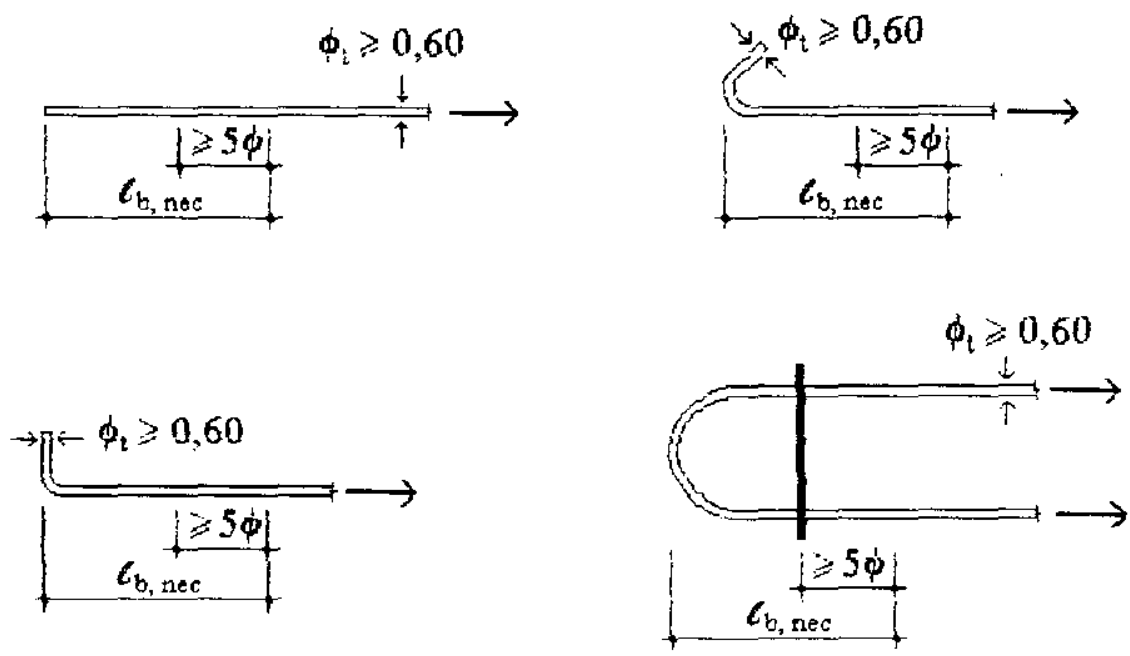

FIGURA 7.7 - Armadura transversal soldada. 
$a_{i}$ - considera o efeito do confinamento provocado pela presença de armadura transversal (valores de cd de acordo com a FIGURA.7.8);

$a_{3}=1-0,15 \frac{c d-n \phi}{\phi}$ com $0,70 \leq a_{3} \leq 1,00$, para barras tracionadas com ancoragem reta.

$a_{3}=1-0,15 \frac{c d-3 \phi}{\phi}$ com $0,70 \leq a 3 \leq 1,00$, para barras tracionadas com ancoragem em gancho ou laço.

$a_{3}=1,00$ para barras comprimidas.

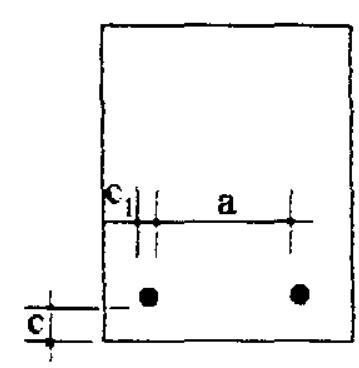

Barras retas $\mathrm{n}=1$ $c d \leqslant\left\{\begin{array}{l}a / 2 \\ c_{1} \\ c\end{array}\right.$

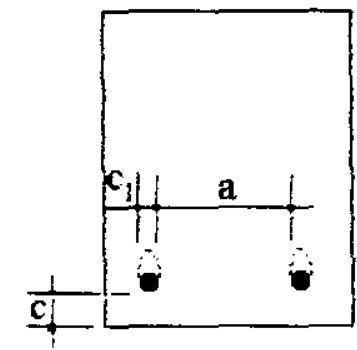

Barras com ganchos $\mathrm{n}=3$

$\mathrm{cd} \leqslant\left\{\begin{array}{l}\mathrm{a} / 2 \\ c_{1}\end{array}\right.$

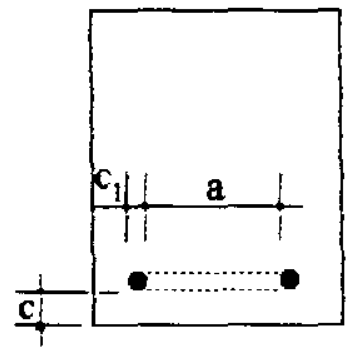

Laços horizontais

$\mathrm{n}=3$

$\mathrm{cd}=\mathrm{c}$

FIGURA 7.8 - Confinamento do concreto devido ao cobrimento.

$a_{4}$ - considera o confinamento provocado pela presença de armadura transversal;

$a_{4}=1-k \lambda$, com $0,70 \leq a_{4} \leq 1,00$ para barras tracionadas com ou sem ganchos e alças.

$a_{4}=1,00$ para barras comprimidas e barras entalhadas ou lisas, mesmo tracionadas.

sendo:

$$
\lambda=\frac{\sum A_{t: t}-A_{\text {min }}}{A_{s}}
$$


$\Sigma \mathrm{A}_{\mathrm{st}}$ - área da seção de armadura transversal existente ao longo de $\ell_{\text {bnec; }}$

$A_{s t, \text { min }}$ - área da seção de armadura transversal mínima; $k=0,10$ ou 0,05 ou 0 , em função da posição relativa entre a barra ancorada e a armadura transversal, conforme FIGURA 7.9.
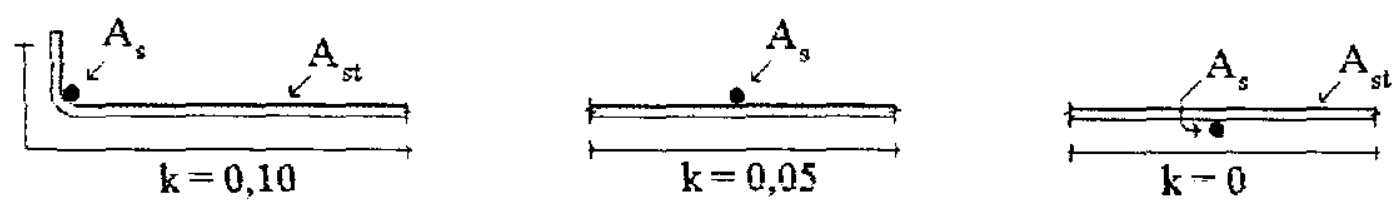

FIGURA 7.9 - Confinamento provocado pela presença da armadura transversal.

$a_{5}$ - considera o confinamento provocado por compressão transversal

$a_{5}=I-0,04 p$, com $0,70 \leq a_{5} \leq 1,00$ para barras tracionadas com ou sem ganchos ou alças e também barras comprimidas de alta aderência.

$a_{5}=1,00$ para barras entalhadas ou lisas.

sendo:

p - a pressão transversal média em estado limite último ao longo do comprimento de ancoragem necessário, perpendicular ao plano de fendilhamento (em MPa).

$\ell_{\mathrm{b} \text { min }}$ - valores mínimos admitidos para o comprimento de ancoragem para barras comprimidas, segundo o Texto Base para a revisão da NBR - $6118 / 78$ $4_{\min } \geq 0,3 \mathrm{a}_{s} \ell_{b}, 10 \phi, 100 \mathrm{~mm}$ 


\subsection{ARMADURA TRANSVERSAL NAS ANCORAGENS DAS BARRAS}

De acordo com a FIGURA 7.10, observa-se que em barras submetidas à compressão, caso particular de pilares, e ancoradas em concreto, aparecem tensões de tração e de compressão à fim de se estabelecer o equilibrio da estrutura no processo de transmissão de esforços do aço para o concreto.

Essas tensões de tração, podem provocar o afastamento das seções de concreto ao redor das barras de aço, prejudicando a aderência.

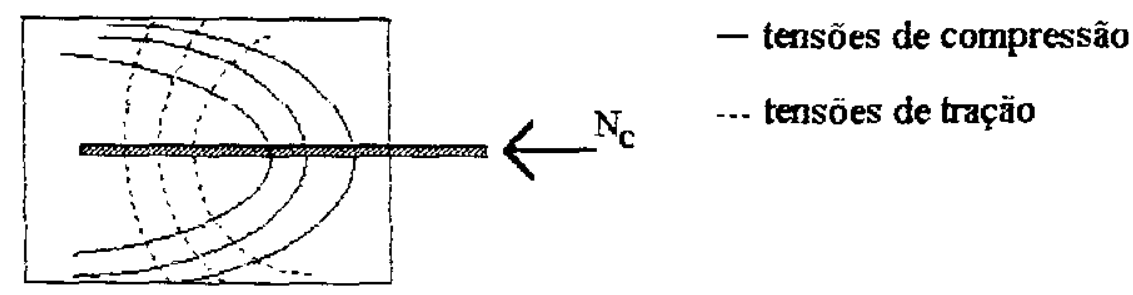

FIGURA 7.10 - Equilibrio concreto $\mathrm{x}$ aço no processo de ancoragem.

Com o intuito de se evitar essa situação indesejável, deve-se prever no detalhamento das estruturas, sob essas condições, uma armadura transversal à barra solicitada. O Texto Base para a revisão da NBR - 6118/78 prescreve o cálculo dessa armadura como segue:

\section{- BARRAS COM $\phi \leq 32 \mathrm{~mm}$ :}

Ao longo do comprimento de ancoragem das armaduras, deve ser prevista armadura transversal cuja área mínima, não deve ser inferior a $25 \%$ da área da barra ancorada de maior diâmetro.

\section{- BARRAS COM $\phi>32 \mathrm{~mm}$ :}

Devem ser dispostas armaduras transversais espaçadas de no máximo $5 \phi(\phi-$ diâmetro da barra ancorada), paralelas à face tracionada e laterais com os seguintes valores minimos ao longo do comprimento de ancoragem:

- Na Direção paralela à face tracionada:

$$
A_{s t}=0,25 \cdot A_{s} \cdot n
$$

- Na direção perpendicular à face tracionada:

$$
\mathrm{A}_{\mathrm{sw}}=0,25 \cdot \mathrm{A}_{\mathrm{s}} \cdot \mathrm{m}
$$


sendo:

As - área da barra ancorada;

n - número de camadas com barras ancoradas na mesma seção;

m - número máximo de barras ancoradas na seção, em uma camada.

Vale lembrar, que as armaduras longitudinal e transversal quando não forem constituídas por aços da mesma categoria, as áreas das armaduras transversais devem ser multiplicadas pela relação entre as tensões de escoamento de cálculo das armaduras longitudinal e transversal.

Se já existir uma armadura transversal ao longo do comprimento de ancoragem e essa armadura apresentar uma área superior à especificada acima, então não é necessário haver a complementação se $\phi \leq 32 \mathrm{~mm}$.

Quando se tratar de barras comprimidas, pelo menos una das barras constituintes da armadura transversal deve situar-se a uma distância igual a $4 \phi$ ( barra ancorada), além da extremidade da barra.

\subsection{EMENDAS DAS BARRAS}

Em algumas situações de projeto a colocação de uma armadura, para absorver esforços de tração ou de compressão, necessita de emendas. Essas emendas podem ocorrer por limitação do comprimento das barras ou à fim de se facilitar os processos construtivos. As emendas, nesses casos, podem ser:

- por traspasse;

- com luvas rosqueadas;

- com solda;

- com outros dispositivos devidamente justificados, como luvas com preenchimento metálico.

\subsubsection{Emendas por Traspasse}

Este tipo de emenda é o mais utilizado em virtude da sua simplicidade de execução. A transmissão dos esforços de uma barra para outra emendada ocorre através de mobilização de bielas comprimidas de concreto na seção onde as barras estão justapostas ( FIGURA 7.11). 


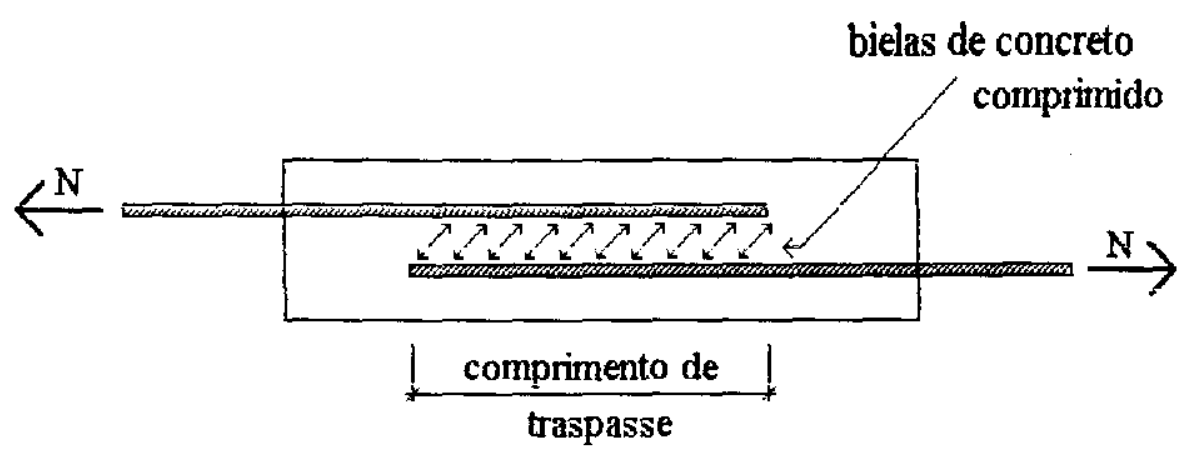

FIGURA 7.11 - Emendas por traspasse.

\subsubsection{Proporção de Barras Emendadas}

O Texto Base para a revisão da NBR - $6118 / 78$ considera como na mesma seção transversal as emendas que se superponham ou cujas extremidades mais próximas estejam afastadas de menos que $30 \%$ do comprimento do trecho de traspasse, tomando-se o maior dos dois comprimentos quando diferentes (FIGURA 7.12).

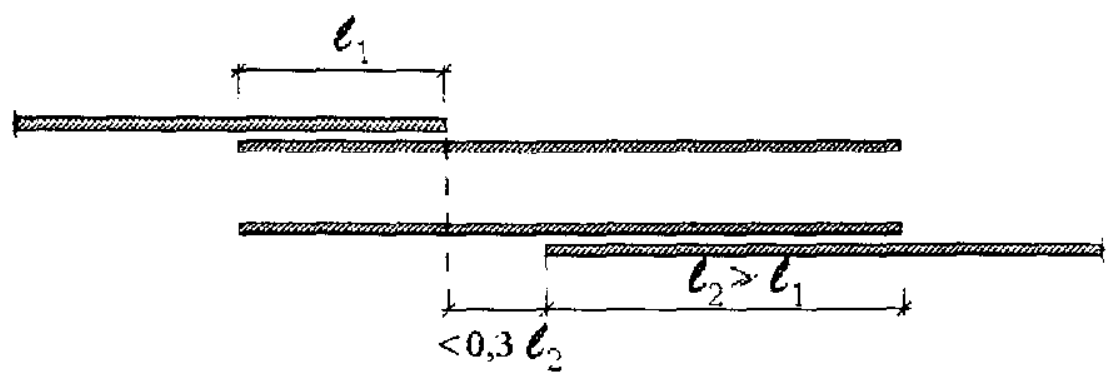

FIGURA 7.12 - Proporção de barras emendadas.

sendo

$\ell_{1}$ - comprimento de traspasse da barra superior;

$\ell_{2}$ - comprimento de traspasse da barra inferior.

A proporção maxima de barras tracionadas da armadura principal emendadas por traspasse na mesma seção transversal da peça está indicada na TABELA 7.1. 
TABELA 7.1 - Proporção máxima de barras emendadas na mesma seção transversal.

\begin{tabular}{|c|c|c|c|}
\cline { 3 - 3 } & \multicolumn{2}{|c|}{ Tipo de Barra } & \multicolumn{2}{c|}{ Efa dacão } \\
\hline Barra de alta & Apenas 1 camada & $100 \%$ & $100 \%$ \\
Aderència & Mais de 1 camada & $50 \%$ & $50 \%$ \\
\hline Barras & $\phi<16 \mathrm{~mm}$ & $50 \%$ & $25 \%$ \\
Lisas & $\phi \geq 16 \mathrm{~mm}$ & $25 \%$ & $25 \%$ \\
\hline
\end{tabular}

A adoção de proporções maiores deve ser justificada quanto à integridade do concreto na transmissão dos esforços e da capacidade resistente da emenda, como um conjunto, frente à natureza das ações que a solicitem.

No caso de peças comprimidas, o Texto Base para a revisão da NBR - 6118/78 permite que todas as barras podem ser emendadas na mesma seção.

\subsubsection{Comprimento de Traspasse}

Como este trabalho visa levantar aspectos importantes sobre o detalhamento de pilares, peças predominantemente comprimidas, é conveniente, então, abordar o cálculo do comprimento de traspasse de peças de concreto armado comprimidas. Na revisão da NBR - 6118/78 o comprimento por traspasse de barras comprimidas isoladas deve ser igual a $\ell_{\text {ncc }}$, calculado de acordo com a expressão (7.5).

\subsubsection{Armadura Transversal nas Emendas por Traspasse}

De acordo com o exposto acima, a transmissão dos esforços nas emendas por traspasse se dá com a mobilização de bielas comprimidas de concreto, sendo assim, para haver equilibrio, surgem tensões de tração perpendicularmente às bielas, necessitando de uma armadura transversal que evite a perda de aderência entre concreto e aço.

O Texto Base para a revisão da NBR - 6118/78, traz as seguintes recomendações para o uso de armadura transversal nas emendas por traspasse de peças comprimidas:

- Quando $\phi<16 \mathrm{~mm}$ ou a proporção de barras emendadas na mesma seção for menor que $25 \%$, a armadura transversal deve satisfazer as mesmas 
recomendações previstas para o cálculo da armadura transversal na ancoragem.

- Quando $\phi \geq 16 \mathrm{~mm}$ ou que a proporção de barras emendadas na mesma seção for maior ou igual a $25 \%$, a armadura transversal deverá:

- apresentar área total igual a área de uma barra emendada, considerando os ramos paralelos à direção que une os centros das barras emendadas.

- ser constituida por barras fechadas se a distância entre as duas barras mais próximas de duas emendas na mesma seção for $<10 \phi$.

- concentrar-se nos terços extremos da emenda.

Nas emendas de barras comprimidas, pelo menos uma barra da armadura transversal deve estar posicionada $4 \phi$ além das extremidades da emenda (FIGURA 7.13).

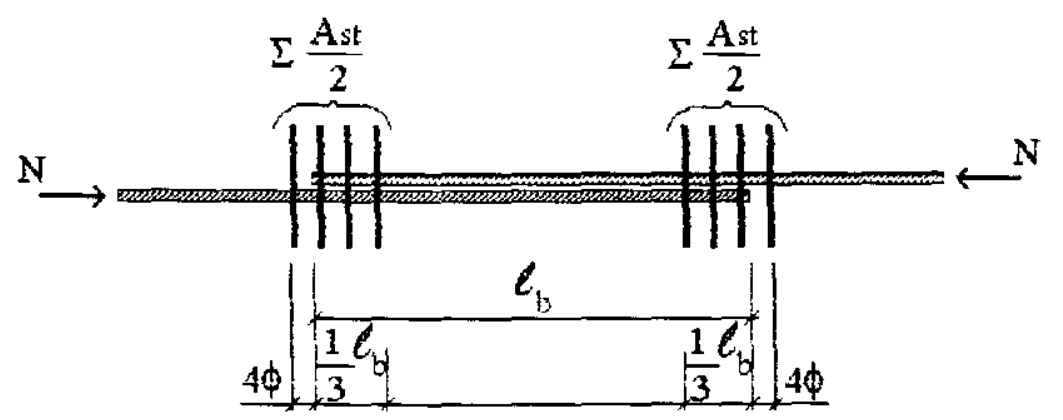

FIGURA 7.13 - Emenda de barras comprimidas.

Os outros tipos de emenda existentes, ou seja, através de luvas e soldas não serão abordados neste trabalho devido ao fato de serem processos anti-econômicos e de execução mais trabalhosa.

\subsection{DISPOSIĆ̃̃ES CONSTRUTIVAS DE PILARES}

A seguir, serão apresentados alguns aspectos importantes sobre o detalhamento de pilares, visando sua maior durabilidade.

O projeto de estruturas em concreto armado deve considerar, além dos aspectos de estabilidade, resistência e arquitetônico, o problema relativo a durabilidade da estrutura em questão 
Os altos investimentos exigidos na construção de uma estrutura de concreto armado, só se tornam viáveis à medida que a durabilidade da mesma, garanta o retorno, aos empreendedores, do capital utilizado.

As medidas necessárias a assegurar a vida útil de uma estrutura de concreto armado, estão diretamente ligadas às condições ambientais, métodos de execução da obra e importância da mesma.

\subsubsection{Condições Ambientais}

As condições do meio ambiente são responsáveis diretamente pela vida útil de uma obra, isto é, de acordo com a finalidade que uma estrutura tenha, ela pode estar submetida à processos quimicos nocivos que devem ser previstos e evitados da melhor maneira possivel.

As classes ambientais, segundo o Texto Base para a revisão da NBR - 6118/78, são divididas em:

- ambiente seco;

- ambiente úmido (lavanderias, cozinhas industriais, etc.);

- ambiente marinho ( ao longo ou na orla até onde se estenda a influência da maresia);

- águas tratadas (reservatórios e estações de tratamento);

- águas servidas (estações de tratamento de esgoto, condutos e canalizações);

- ambientes quimicamente agressivos:

- fracamente agressivos;

- moderadamente agressivos;

- fortemente agressivos;

- muito fortemente agressivos.

De acordo com o exposto acima, as características que um concreto deve ter à fim de se garantir a durabilidade da estrutura, estão expostas na TABELA 7.2. 
TABELA 7.2 - Caracteristicas do concreto de acordo com as condições ambientais.

\begin{tabular}{|c|c|c|c|c|c|c|c|}
\hline $\begin{array}{l}\text { Classes de } \\
\text { Exposição }\end{array}$ & $\begin{array}{l}\text { Tipo de } \\
\text { Concreto }\end{array}$ & \multicolumn{3}{|c|}{$\begin{array}{l}\text { Fator água/cim. } \\
\text { efetivo máximo }\end{array}$} & \multicolumn{2}{|c|}{$\begin{array}{l}\text { Consumo de } \\
\text { cim. }(\mathrm{kg} / \mathrm{m} 3)\end{array}$} & $\begin{array}{c}\text { Classes de resistência } \\
\text { NBR }-\mathbf{8 9 5 3}\end{array}$ \\
\hline $\begin{array}{l}\text { Ambiente } \\
\text { seco }\end{array}$ & $\begin{array}{l}\text { simples } \\
\text { estrut. } \\
\text { armado } \\
\text { protend. }\end{array}$ & & $\begin{array}{l}--- \\
--- \\
0,65 \\
0,60\end{array}$ & & & & $\begin{array}{l}-- \\
\text { C } 20 \\
\text { C } 25\end{array}$ \\
\hline $\begin{array}{l}\text { Ambiente } \\
\text { úmido }\end{array}$ & $\begin{array}{l}\text { simples } \\
\text { estrut. } \\
\text { armado } \\
\text { protend. }\end{array}$ & & $\begin{array}{l}--- \\
0,65 \\
0,60 \\
0,55\end{array}$ & & & & $\begin{array}{l}-- \\
\text { C } 20 \\
\text { C } 25 \\
\text { C } 30\end{array}$ \\
\hline $\begin{array}{l}\text { Ambiente } \\
\text { marinho }\end{array}$ & $\begin{array}{l}\text { simples } \\
\text { estrut. } \\
\text { armado } \\
\text { protend. }\end{array}$ & \multicolumn{3}{|c|}{$\begin{array}{l}--- \\
0,50 \\
0,45 \\
0,45\end{array}$} & \multicolumn{2}{|c|}{$\begin{array}{l}--- \\
350 \\
400 \\
400\end{array}$} & $\begin{array}{l}--- \\
\text { C } 35 \\
\text { C } 40 \\
\text { C } 40\end{array}$ \\
\hline $\begin{array}{l}\text { Aguas } \\
\text { tratadas }\end{array}$ & $\begin{array}{l}\text { simples } \\
\text { estrut. } \\
\text { armado } \\
\text { protend. }\end{array}$ & \multicolumn{3}{|c|}{$\begin{array}{l}--- \\
0,55 \\
0,55 \\
0,55\end{array}$} & \multicolumn{2}{|c|}{$\begin{array}{l}--- \\
325 \\
325 \\
325\end{array}$} & $\begin{array}{l}\cdots \\
C 20 \\
\text { C } 20 \\
\text { C } 25\end{array}$ \\
\hline $\begin{array}{l}\text { Águas } \\
\text { servidas }\end{array}$ & $\begin{array}{l}\text { simples } \\
\text { estrut. } \\
\text { armado } \\
\text { protend. }\end{array}$ & \multicolumn{3}{|c|}{$\begin{array}{l}--. \\
0,50 \\
0,50 \\
0,50\end{array}$} & \multicolumn{2}{|c|}{$\begin{array}{l}--- \\
350 \\
350 \\
350\end{array}$} & $\begin{array}{l}--- \\
\text { C } 25 \\
\text { C } 25 \\
\text { C } 30\end{array}$ \\
\hline $\begin{array}{l}\text { Ambientes } \\
\text { quimica/e } \\
\text { agressivos }\end{array}$ & $\begin{array}{l}\text { simples } \\
\text { estrut. } \\
\text { armado } \\
\text { protend. }\end{array}$ & $\begin{array}{c}a \\
-- \\
0,55 \\
0,55 \\
0,55\end{array}$ & $\begin{array}{c}b \\
\cdots, 50 \\
0,50 \\
0,50\end{array}$ & $\begin{array}{c}\mathrm{c} \\
-- \\
0,45 \\
0,45 \\
0,45\end{array}$ & \begin{tabular}{|c|}
$a$ \\
$\cdots-$ \\
280 \\
300 \\
350
\end{tabular} & $\begin{array}{c}b \\
--- \\
280 \\
300 \\
350\end{array}$ & $\begin{array}{l}--- \\
--- \\
---\end{array}$ \\
\hline
\end{tabular}

\subsubsection{Cobrimento das Armaduras}

O Texto Base para a revisão da NBR - 6118/78 prevê os valores minimos do cobrimento de armaduras passivas, considerando a classe de exposição da estrutura, de acordo com a TABELA 7.3. 
TABELA 7.3 - Cobrimento das armaduras.

\begin{tabular}{|c|c|}
\hline Classe de exposição & Cobrimento (cm) \\
\hline 1 & 1,0 \\
2 & 2,0 \\
3 & 3,0 \\
4 & 2,5 \\
5 & 2,5 \\
$6 . \mathrm{a}$ & 2,5 \\
$6 . \mathrm{b}$ & 3,0 \\
$6 . \mathrm{c}$ & $3,0\left(^{*}\right)$ \\
$6 . \mathrm{d}$ & 4,0 mais proteção \\
\hline
\end{tabular}

* verificar necessidade de proteção

OBS: Para efeito de cálculo e execução, o cobrimento mínimo deve ser acrescido de um valor $\Delta \mathrm{c}=1,00 \mathrm{~cm}$. Se a estrutura estiver sendo executada com um fator de qualidade rigoroso o valor $\Delta \mathrm{c}$ pode ser reduzido para 0,50 .

\subsubsection{Armadura Longitudinal}

Ao se calcular e posteriormente detalhar as armaduras longitudinais de pilares, $o$ engenheiro deve respeitar os limites máximo e minimo de porcentagem de aço, à fim de se evitar ninhos de concretagem (perigoso em estruturas comprimidas) em razão de uma concretagem malsucedida ou por outro lado, absorver algum esforço de flexão em virtude de excentricidades decorrentes da fase de execução da estrutura.

O Texto Base de novembro de 1992, não traz de forma bem definida as limitações e recomendações para se detalhar as armaduras longitudinais de pilares.

Sendo assim, será feito a seguir (TABELA 7.4) uma apresentação dos valores prescritos pela antiga NBR $-6118 / 78$. 


\subsubsection{Armadura Transversal}

A armadura transversal também denominada como estribos, também apresenta limitações que devem ser respeitadas ao se dimensionar pilares. Essas limitações, visam garantir as barras de compressão longitudinal contra a flambagem local e também, absorver esforços horizontais que possam existir.

A NBR- 6118/78 traz prescrições com respeito a três tipos de estribos, a saber:

- estribos poligonais;

- estribos suplementares;

- estribos curvilineos.

Os estribos poligonais evitam a flambagem local das barras longitudinais localizadas em suas quinas, além daquelas por elas abrangidas e situadas no máximo a uma distância de $20 \phi_{\mathrm{t}}$ da quina e ainda, se nesse trecho de comprimento $20 \phi_{\mathrm{t}}$, não existir mais de duas barras longitudinais não contando a da quina (FIGURA 7.14).
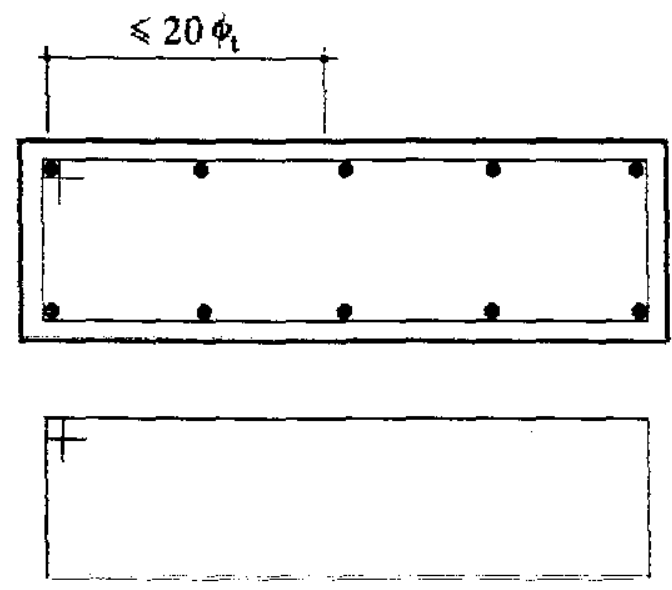

FIGURA 7.14 - Flambagem local das barras longitudinais.

Para situações diferentes do exposto acima, será necessário a colocação de grampos suplementares ou estribos poligonais de acordo com a FIGURA 7.15. 

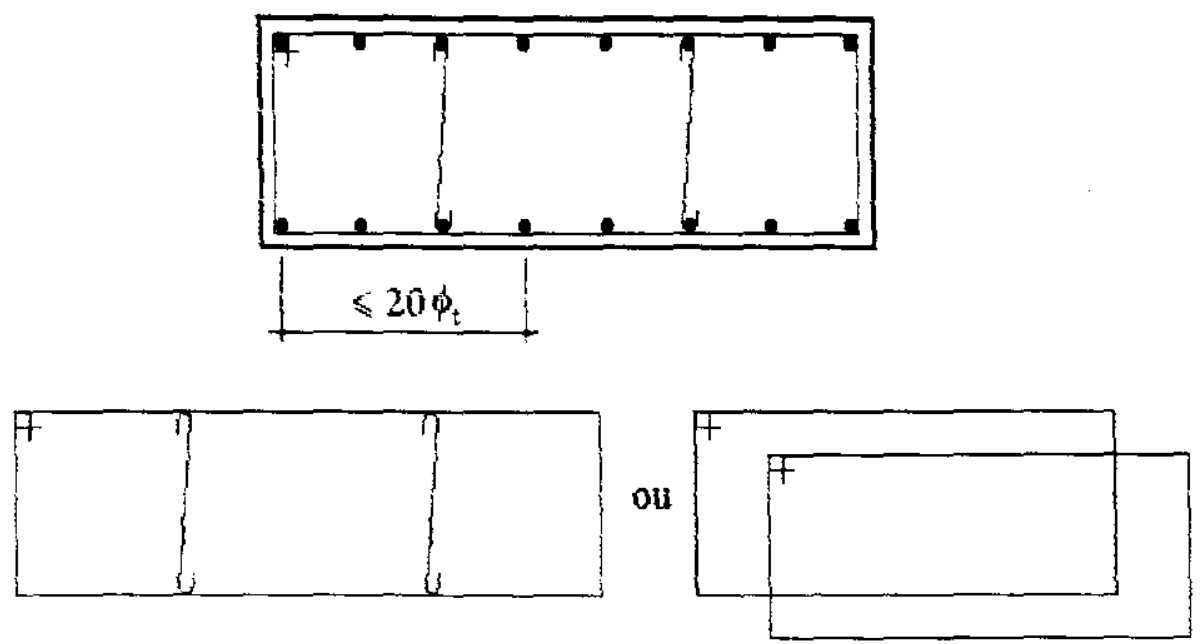

FIGURA 7.15 - Armadura transversal.

Quanto aos estribos curvilineos, a NBR - 6118/78 dispensa o seu emprego no caso de pilares circulares, visto que a concavidade está voltada para o interior do concreto. No caso de concavidade voltada para fora do concreto e se as ações estiverem localizadas nesta curva, deve-se então, prever para cada barra longitudinal, situada na curva, uma ancoragem pelo gancho de um estribo reto ou pela quina de um estribo poligonal (FIGURA 7.16).

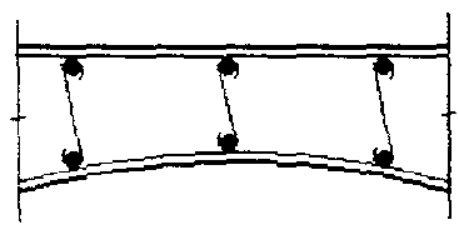

FIGURA 7.16 - Estribos curvilineos

A seguir (TABELA 7.5), são mostradas as principais prescrições previstas pela NBR-61 18/78 para o detalhamento das armaduras transversais de pilares. 
TABELA 7.5 - Recomendações para armadura transversal.

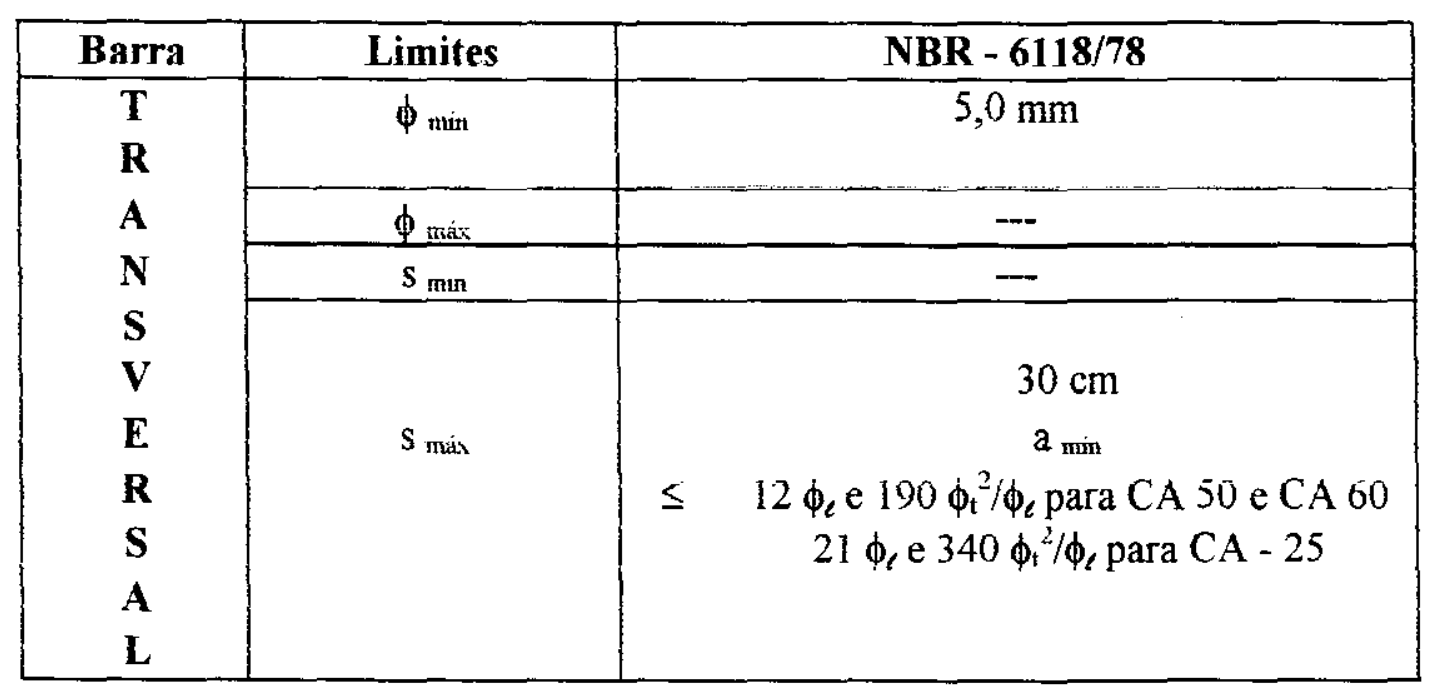

sendo:

$\phi_{\text {min }}$ - diâmetro minimo da armadura transversal;

$\phi_{\text {máx }}$ - diâmetro máximo da armadura transversal;

$a_{\text {min }}$ - menor dimensão da seção transversal do pilar;

$\phi_{\mathrm{t}}$ - diâmetro da armadura transversal;

$\phi_{\ell}$ - diâmetro da armadura longitudinal;

$\mathrm{S}_{\text {max }}$ - espaçamento máximo da armadura transversal;

$\mathrm{S}_{\min }$ - espaçamento minimo da armadura transversal. 


\section{CAPÍTULO 8: EXEMPLOS DE CÁLCULO}

Neste capitulo, são apresentados os aspectos importantes para o dimensionamento e detalhamento de pilares de concreto armado.

O dimensionamento será feito com base nas Tabelas de VENTURINI/1990] Dimensionamento de Peças Retangulares de Concreto Armado Solicitadas à Flexão Obliqua e PINHEIROI1994] Ábacos para Flexão Obliqua. Os esforços solicitantes utilizados neste capitulo foram obtidos da Dissertação de Mestrado do Eng ${ }^{\circ}$ José Fernão $M$. de A. Prado entitulada "Estruturas de Edificios em Concreto Armado Submetidas a Açòes Verticais e Horizontais". Para a obtenção dos esforços na estrutura, o Eng. José Fernão utilizou o modelo tridimensional com o auxilio do software SAP - 90. Os esforços nos pilares P22 e P13 estão no Apêndice 1 com as respectivas combinações de ações.

O Eng. José Fernão trabalhou com a estrutura do edificio Vitória Régia situado em São Carlos - SP, utilizando os dados fornecidos pelo Escritorio Técnico José Roberto Leme de Andrade S/C Ltda, autor do projeto estrututral. A seguir, as FIGURAS 8.1, 8.2, 8.3, $8.4,8.5$ e 8.6 mostram, em escala reduzida, a arquitetura do edificio em questão. 


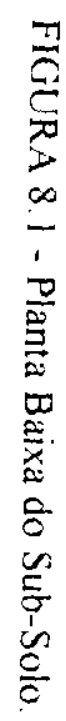

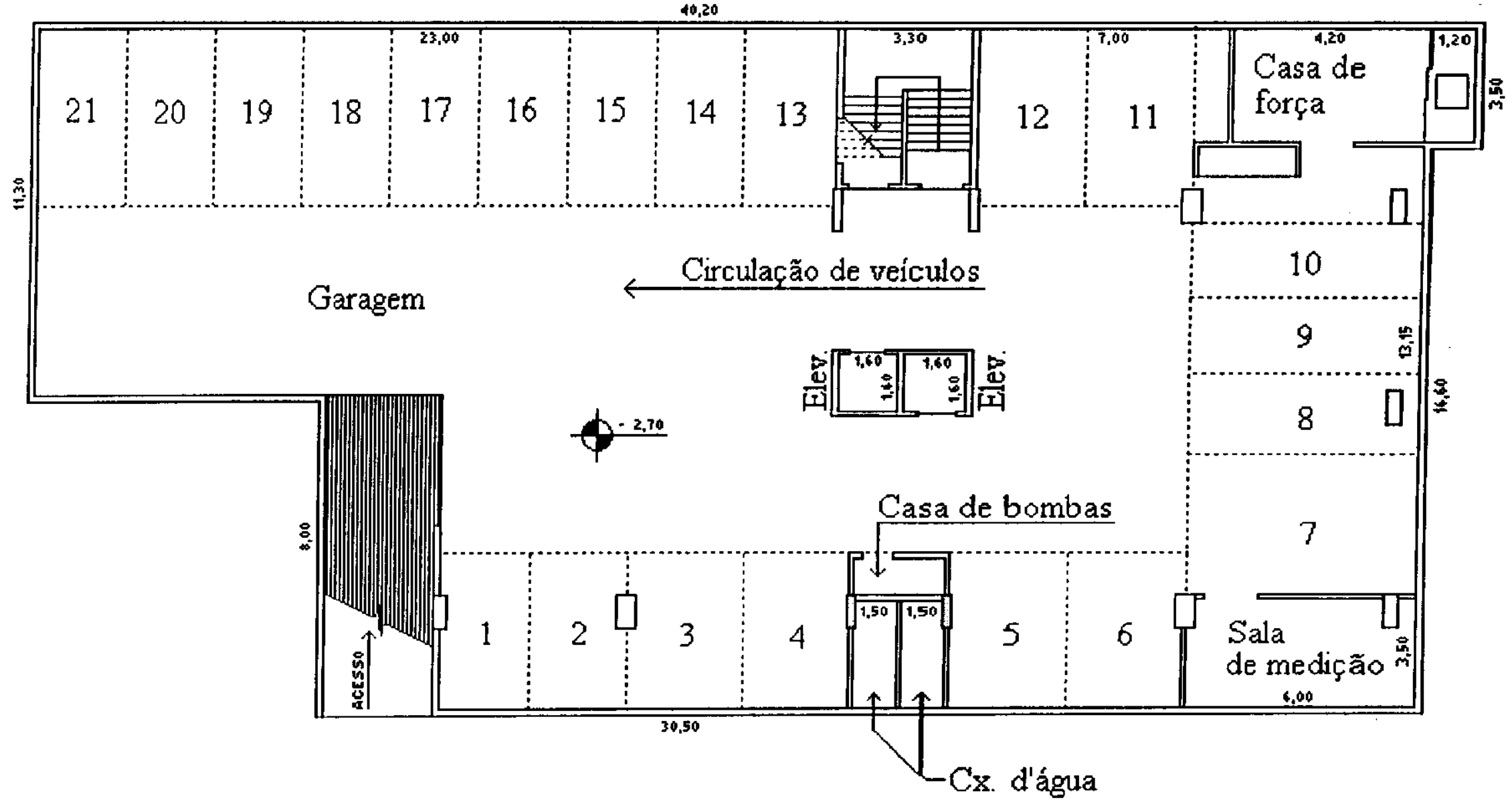




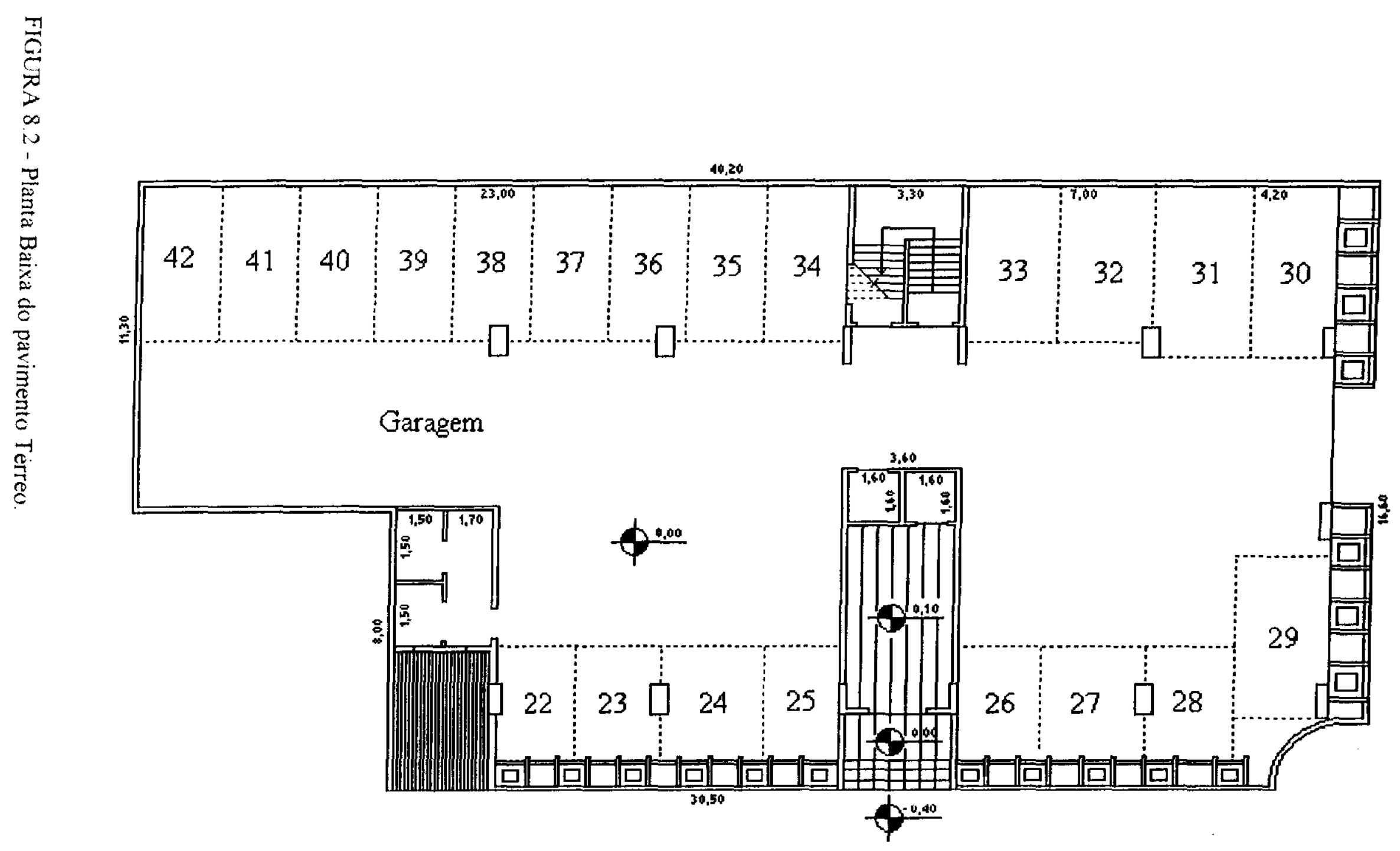




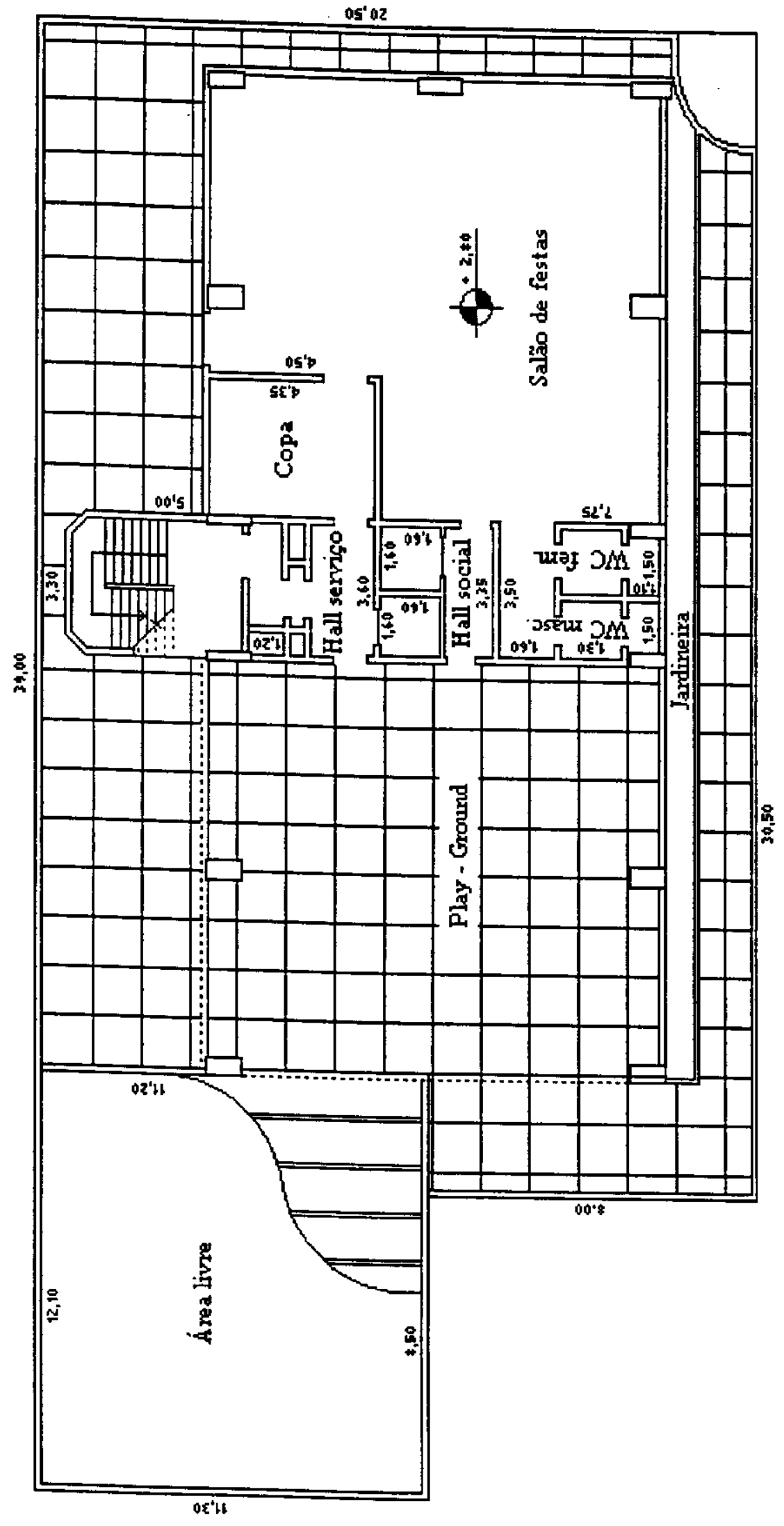

FIGURA 8.3 - Planta Baixa do Play-Ground 


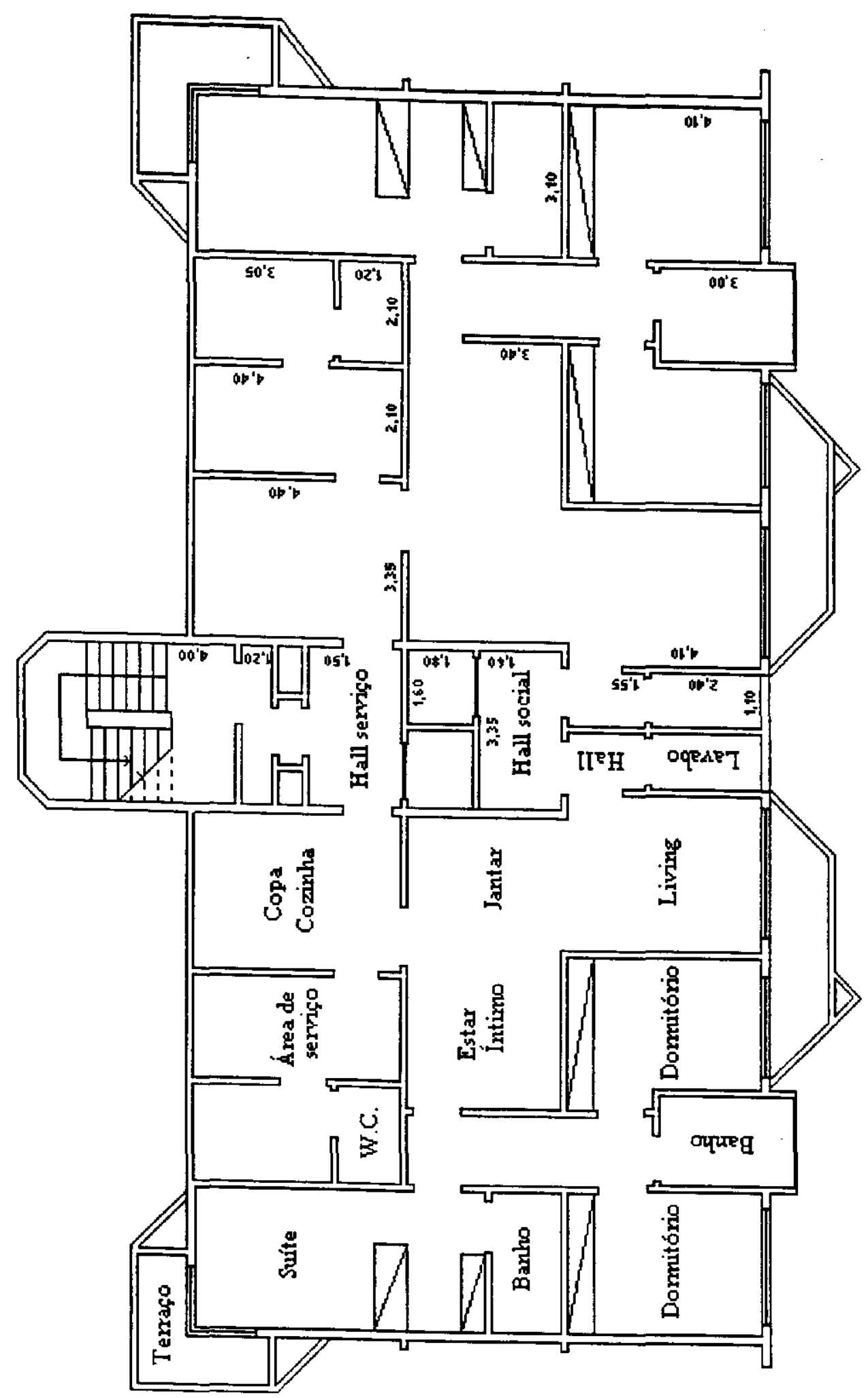

FIGURA 8.4 - Planta Baixa do Pavimento - Tipo. 


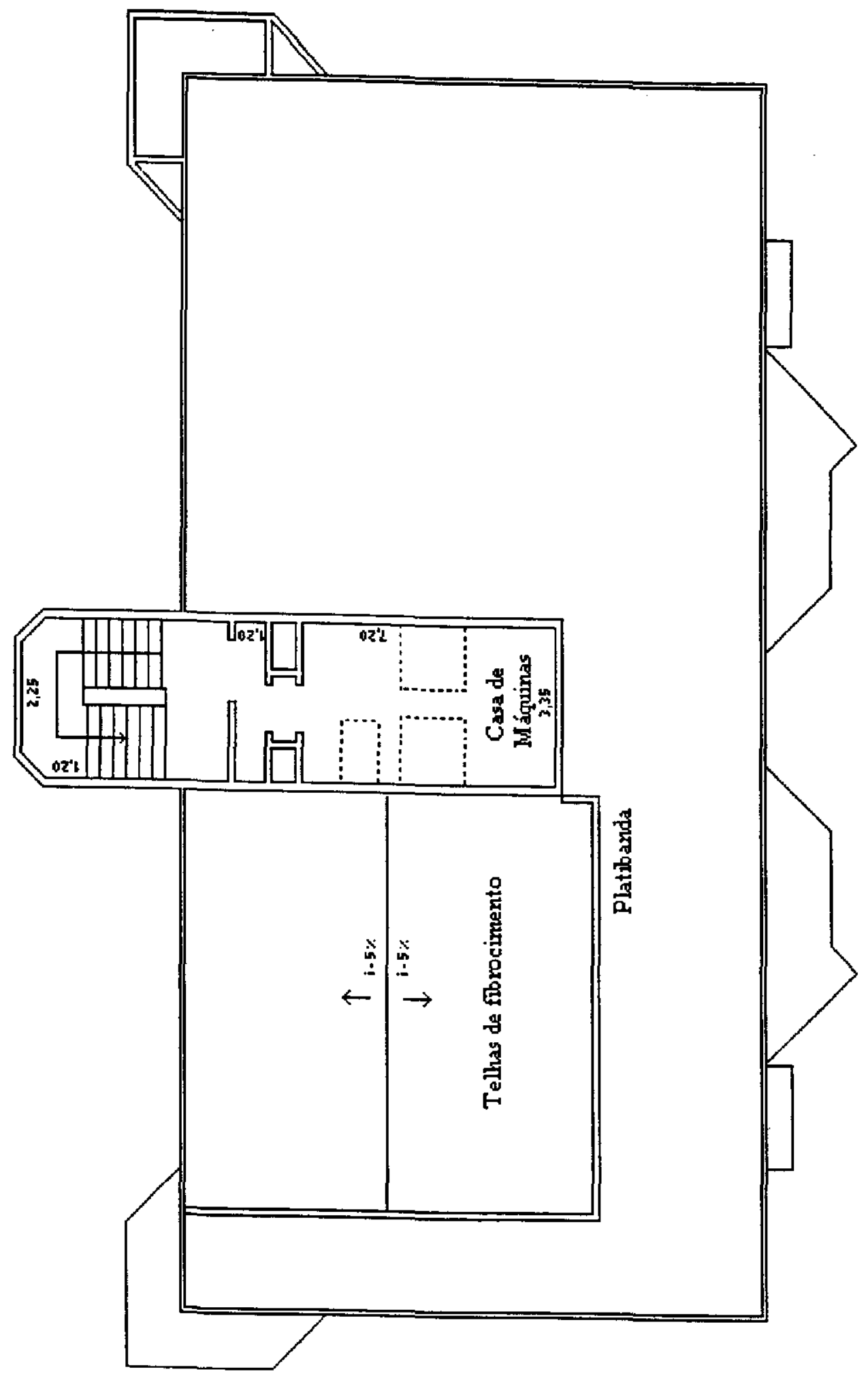

FIGURA 8.5 - Planta Baixa da Casa de Maquinas. 


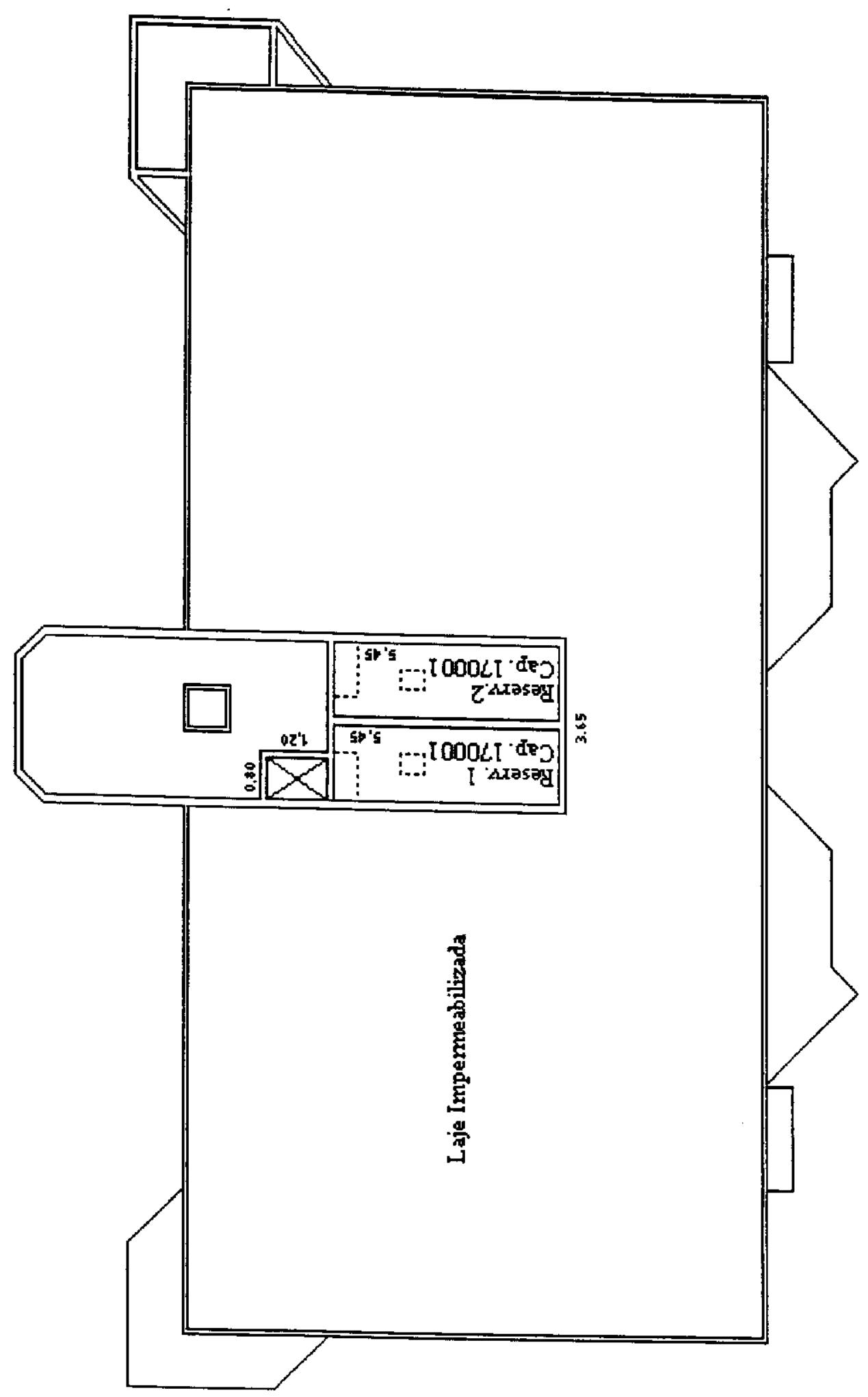

FIGURA 8.6 - Planta Baixa dos Reservatorios. 
Com base nos desenhos de arquitetura mostrados anteriormente, pode-se projetar a forma da estrutura, de acordo com as indicações previstas no Capitulo 2. A seguir são mostrados os desenhos de forma, em escala reduzida, do Edificio Vitória Régia.

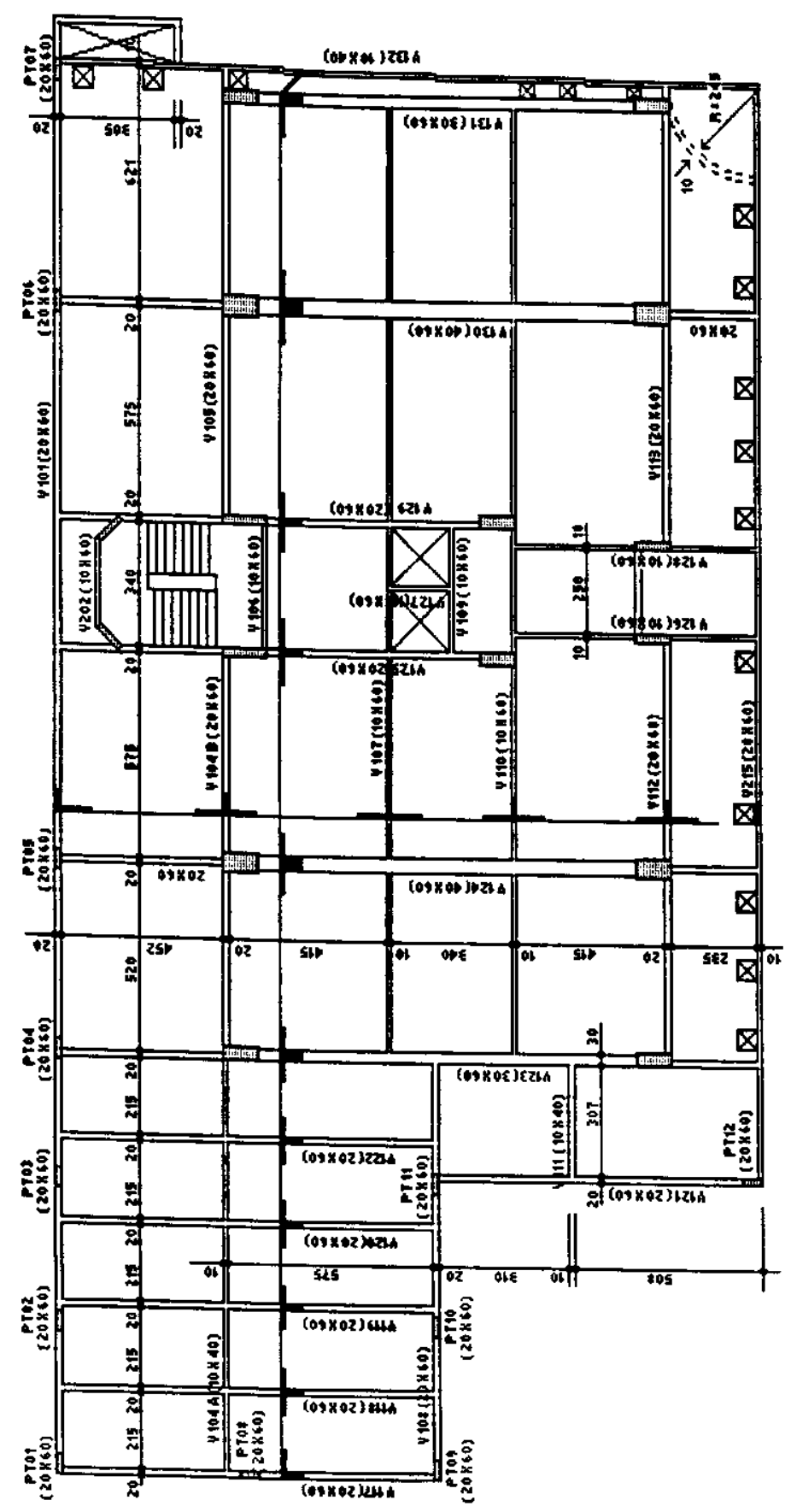

FIGURA 8.7 - Forma do Pavimento Térreo

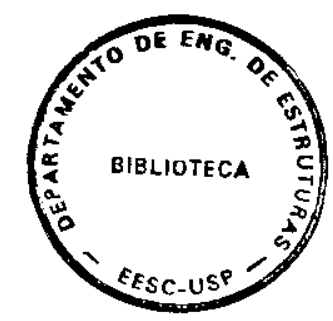




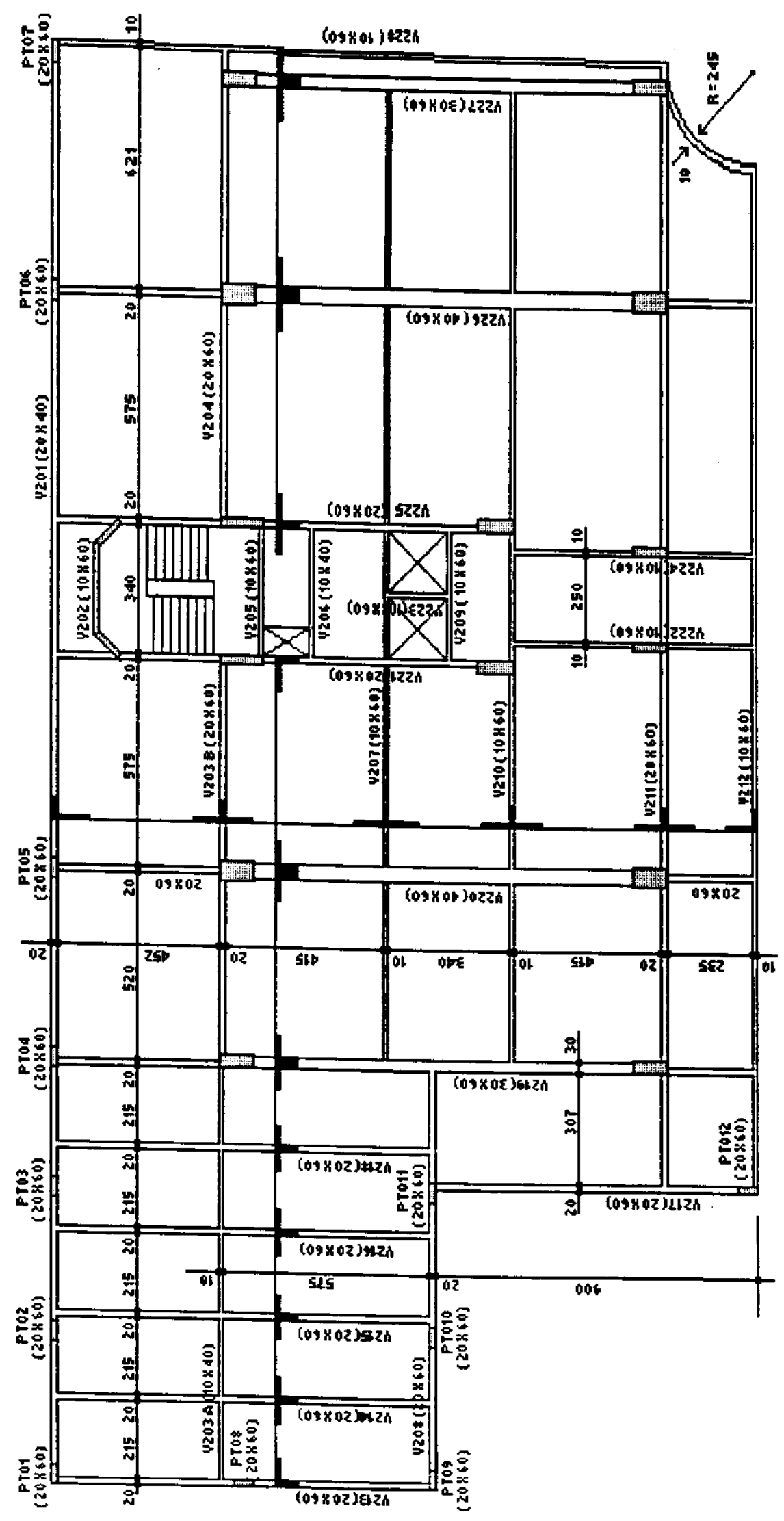

FIGURA 8.8 - Forma do Play - Ground ( ${ }^{\circ}$ Pav.). 


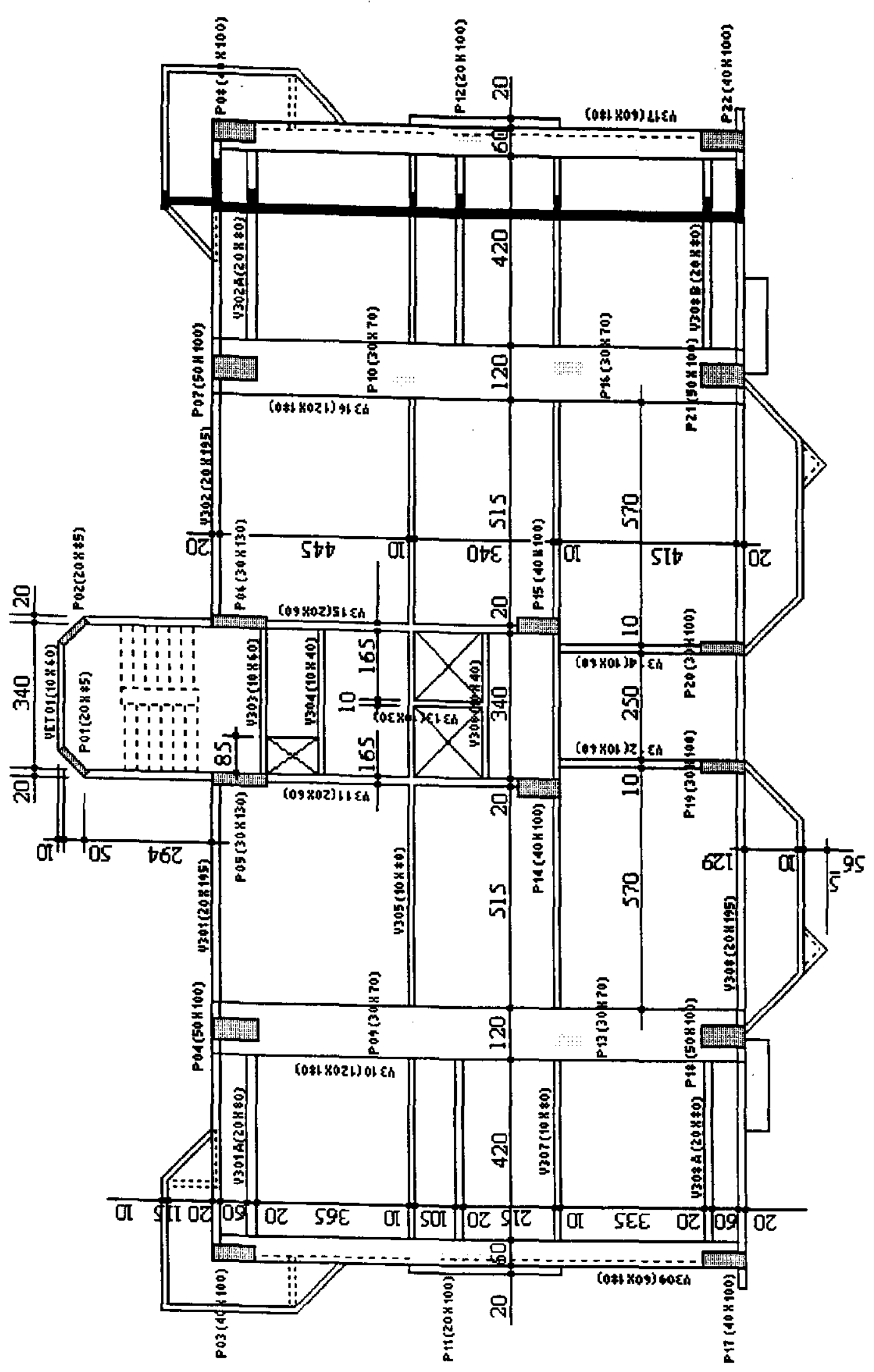

FIGURA 8.9 - Forma do Pavimento de Transição ( $2^{\circ} \mathrm{Pav}$ ). 


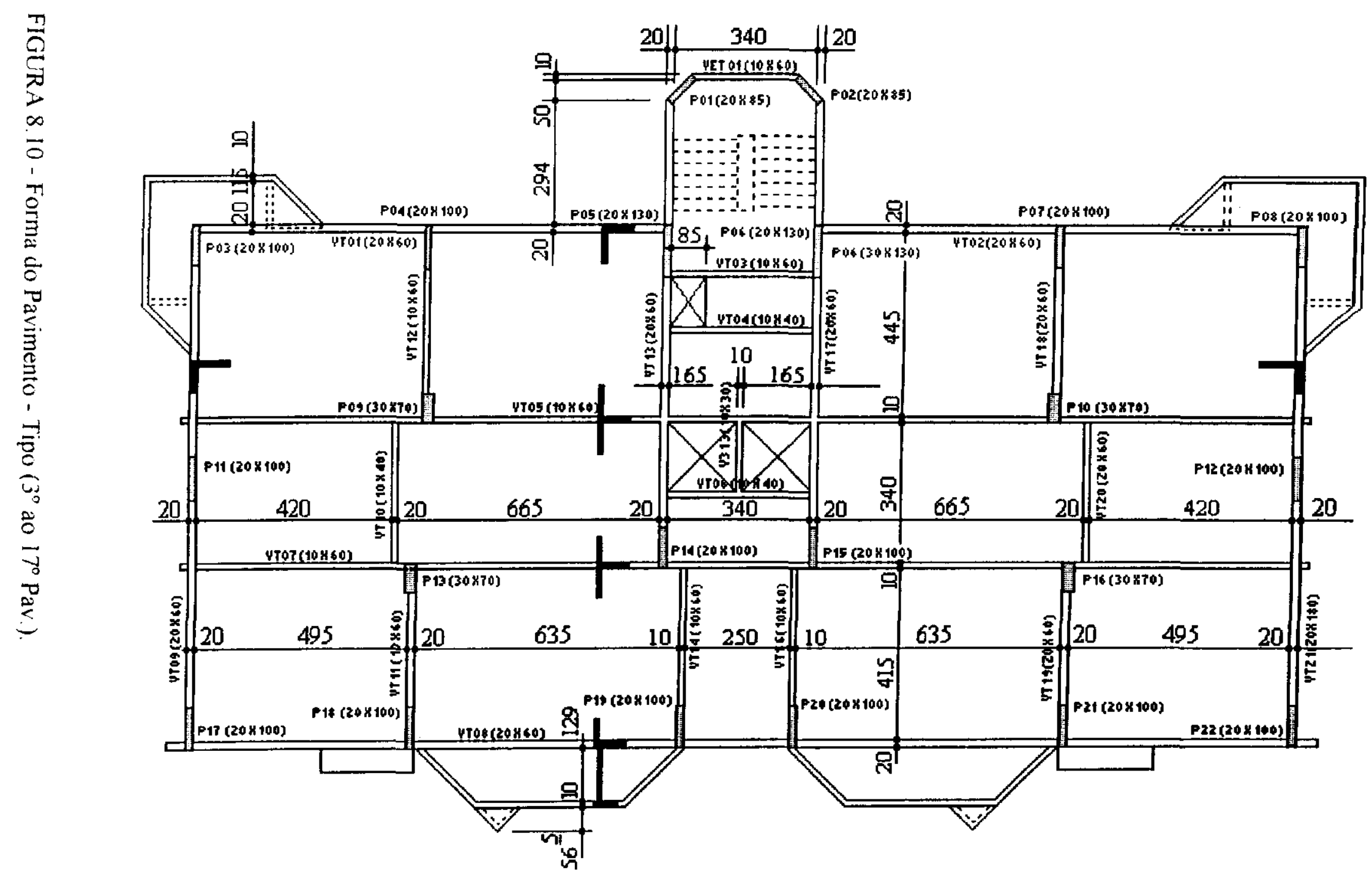




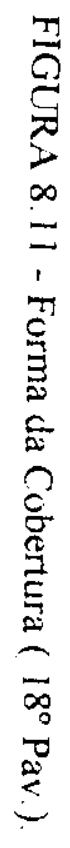

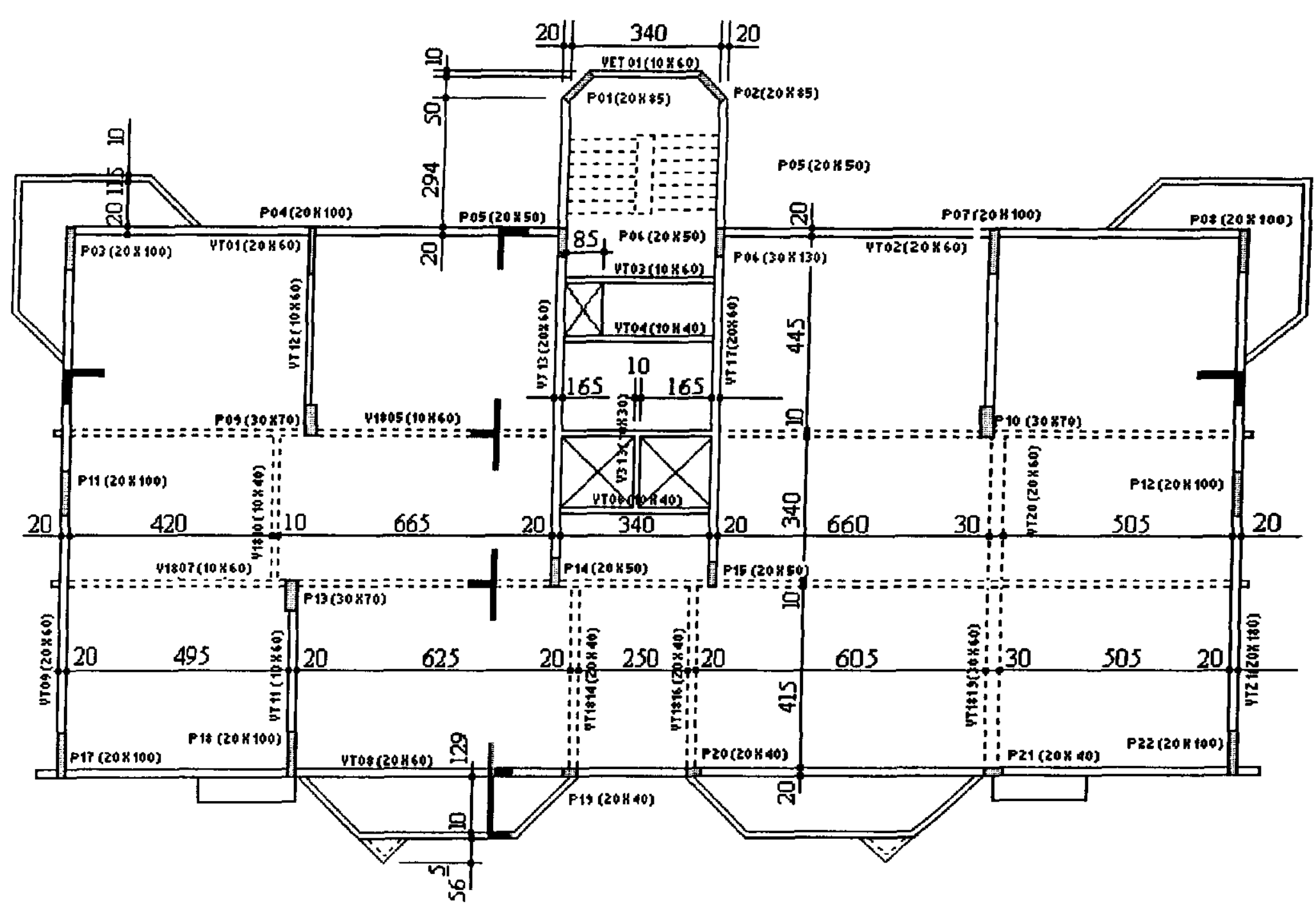




\subsection{PILAR P22}

A seguir é mostrado o dimensionamento do Pilar P22, considerando aço CA 50 e concreto $\mathrm{C} 18$

De forma esquematica a FIGURA 8.12 mostra a prumada do Pilar P22, mostrando as caracteristicas pertinentes ao seu dimensionamento, bem como a numeraçâo das barras para entendimento da listagem de esforços do Apèndice 1 .

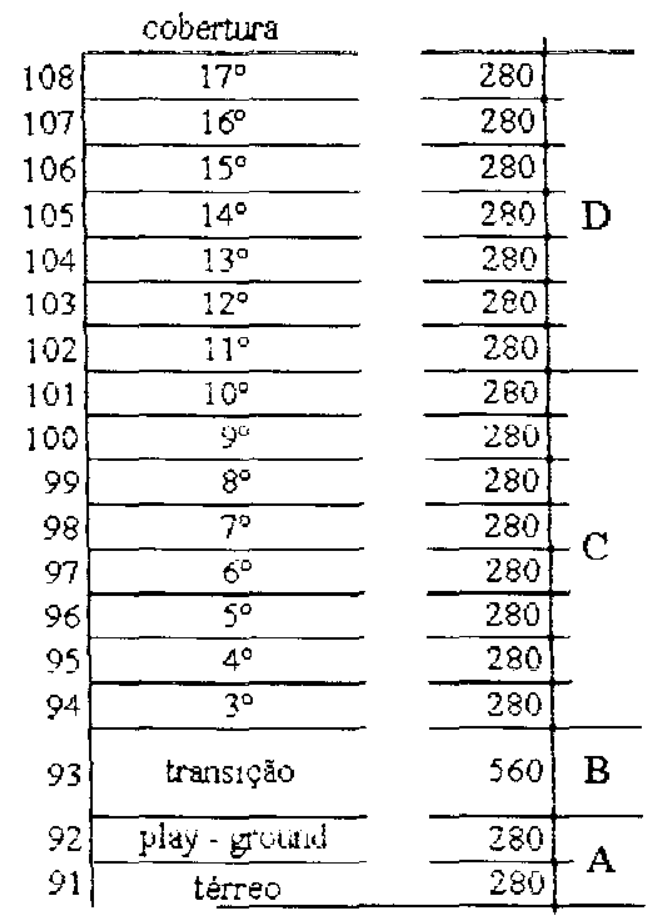

FIGURA 8.12 - Esquema da prumada do Pilar P22.

De acordo com a FIGURA 8.12, o dimensionamento é iniciado pelo trecho $\underline{\mathrm{A}} \mathrm{e}$ os esforços solicitantes estão indicados abaixo.

Trecho A (40 X 100): Diagramas de Esforços Solicitantes.

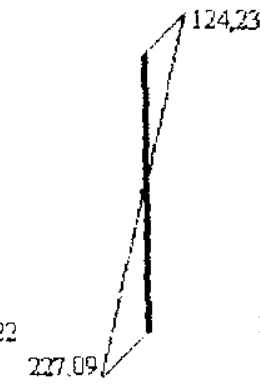

(it d (1-2)

(kisra)

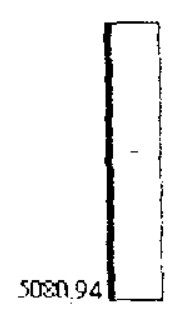

$N_{d}(1.2)$

(kw)

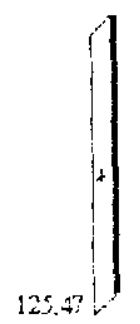

$\nabla_{d}(1-2)$ $(\mathrm{i} N)$

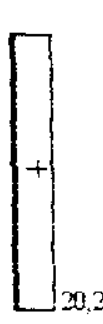

$V_{d(1-3)}$

(바)

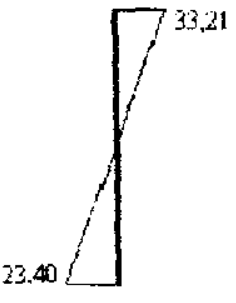

$\boldsymbol{M i t}_{a(1-3)}$

(Whim)

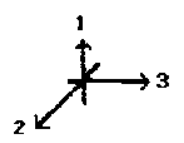

Sabe-se, peias plantas de forma indicadas anteriormente, que a seção transversal do pilar em $\underline{A}$ e $40 \times 100$, sendo assim, pode-se calcular as caracteristicas geometricas do mesmo 


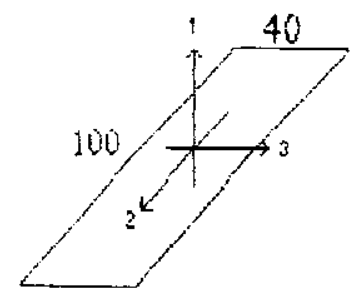

$$
\begin{aligned}
& \iota_{\mathrm{c}_{1-2}}=\iota_{\mathrm{c}_{1-3}}=280 \mathrm{~cm} \\
& \mathrm{I}_{1-2}=533.333 \mathrm{~cm}^{4} \therefore \mathrm{r}_{1-2}=11,55 \mathrm{~cm} \Rightarrow \lambda_{1-2}=24,25 \\
& I_{1-3}=3.333 .333 \mathrm{~cm}^{4} \therefore \mathrm{r}_{1-3}=28,87 \mathrm{~cm} \Rightarrow \lambda_{1-3}=9,70
\end{aligned}
$$

Sendo assim, não é preciso considerar o efeito local de segunda ordem em nenhuma das direçòes.

As excentricidades iniciais no topo e na base do pilar ao nivel do pavimento térreo (mais solicitado), são assim determinadas:

$$
\begin{aligned}
& \mathrm{e}_{\mathrm{itopo}_{1-2}}=\frac{\mathrm{M}_{\mathrm{topo}_{1-2}}}{\mathrm{~N}_{\mathrm{d}}}=\frac{124.23}{5080.94}=2.45 \mathrm{~cm} \\
& \mathrm{e}_{\mathrm{itopo}_{1-3}}=\frac{\mathrm{M}_{\mathrm{topo1}-3}}{N_{\mathrm{d}}}=\frac{33,21}{5080,94}=0,65 \mathrm{~cm} \\
& \mathrm{e}_{\mathrm{i}_{\text {bas: }-2}=}=\frac{\mathrm{M}_{\text {base! }-2}}{\mathrm{~N}_{\mathrm{d}}}=\frac{227,09}{5080,94}=4.47 \mathrm{~cm} \\
& \mathrm{e}_{\mathrm{i}_{\text {base }-3}}=\frac{\mathrm{M}_{\text {base }-3_{-3}}}{\mathrm{~N}_{\mathrm{d}}}=\frac{23,40}{5080,94}=0,46 \mathrm{~cm} \\
& \text { sendo: } \\
& \mathrm{e}_{\mathrm{i}_{\mathrm{t}, \mathrm{p} i \mathrm{i}-2}} \text { - excentricidade inicial no topo do pilar devido ao } \\
& \text { momento fletor atuante no plano } \mathrm{I}-2 \text {; } \\
& \mathrm{e}_{\mathrm{i}_{\text {lasel-2 }}} \text { - excentricidade inicial na base do pilar devido ao } \\
& \text { momento fletor atuante no plano 1-2; }
\end{aligned}
$$

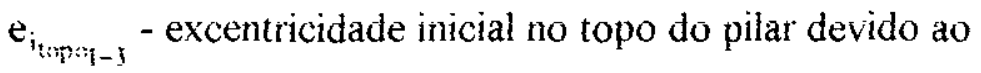

$$
\begin{aligned}
& \text { momento fletor atuante no plano } 1-3 \text {; } \\
& \mathrm{e}_{\text {itacel-3-3 }} \text { - excentricidade inicial na base do pilar devido ao } \\
& \text { momento atuante no plano } 1-3
\end{aligned}
$$


Obtido o cálculo das excentricidades para a situação $\underline{\mathrm{A}}$ pode-se determinar as situações de projeto e de cálculo para o pilar P22, ao nivel do pavimento térreo.

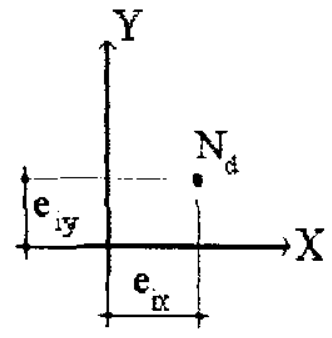

Situação de projeto

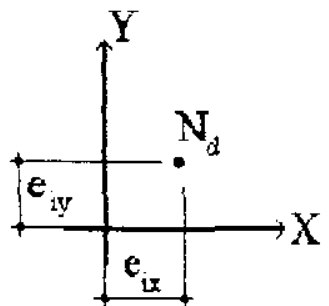

(I)

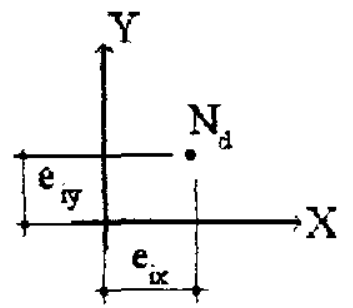

(II)

Situações de Cálculo

Seções de Topo/Base

FIGURA 8.13 - Situações de cálculo no trecho $\underline{\mathrm{A}}$.

Analisando as excentricidades obtidas anteriormente, observa-se que a situação critica é a seção de base.

Para esta situação os valores adimensionais relativos aos esforços normais e de flexão devem ser calculados, a fim de que os ábacos de VENTURINI/1990/ possam ser utilizados

Ábaco pg. 82

$$
\begin{aligned}
& v_{d}=\frac{5080,94}{40 \cdot 100 \cdot \frac{1,8}{1,4}}=0,99 \approx 1,00 \\
& \frac{d_{h}^{\prime}}{b}=0,075 \approx 0,10 \text { e } \frac{d_{h}^{\prime}}{h}=0,03 \approx 0,05
\end{aligned}
$$

- Situação (I)

$$
\begin{aligned}
\mu_{\mathrm{hd}}=0,04 \text { e } \mu_{\mathrm{hd}}=0,01 \Rightarrow \omega \cong \mathbf{0 , 3 0} \\
\mathbf{A}_{\mathbf{c}}=\mathbf{3 5 . 5} \mathbf{c m}^{2}\left(\mathbf{2 0} \phi \mathbf{1 6} \mathbf{~} \mathbf{m}=\mathbf{4 0 , 2} \mathbf{c m}^{2}\right)
\end{aligned}
$$

$O$ comprimento de traspasse necessário neste caso, será calculado conforme as prescriçòes do Capitulo 7 :

$$
\begin{aligned}
& \mathscr{b}_{\text {nex }}=a_{1} \cdot \varepsilon_{b} \cdot \frac{A_{\text {s.calc }}}{A_{\text {s.cx }}} \\
& \mathscr{b}_{-}-\frac{1,6}{4} \cdot \frac{43,5}{0.289}-60.1 \mathrm{~cm} \\
& \mathscr{b}_{\text {nex }}=1,0 \cdot 60.1 \cdot \frac{35,5}{40,2}=53 \mathrm{~cm}
\end{aligned}
$$


Sendo assim, a seção transversal do pilar $\mathrm{P} 22$ no trecho A poderá ser visualizada na FIGURA 8.14

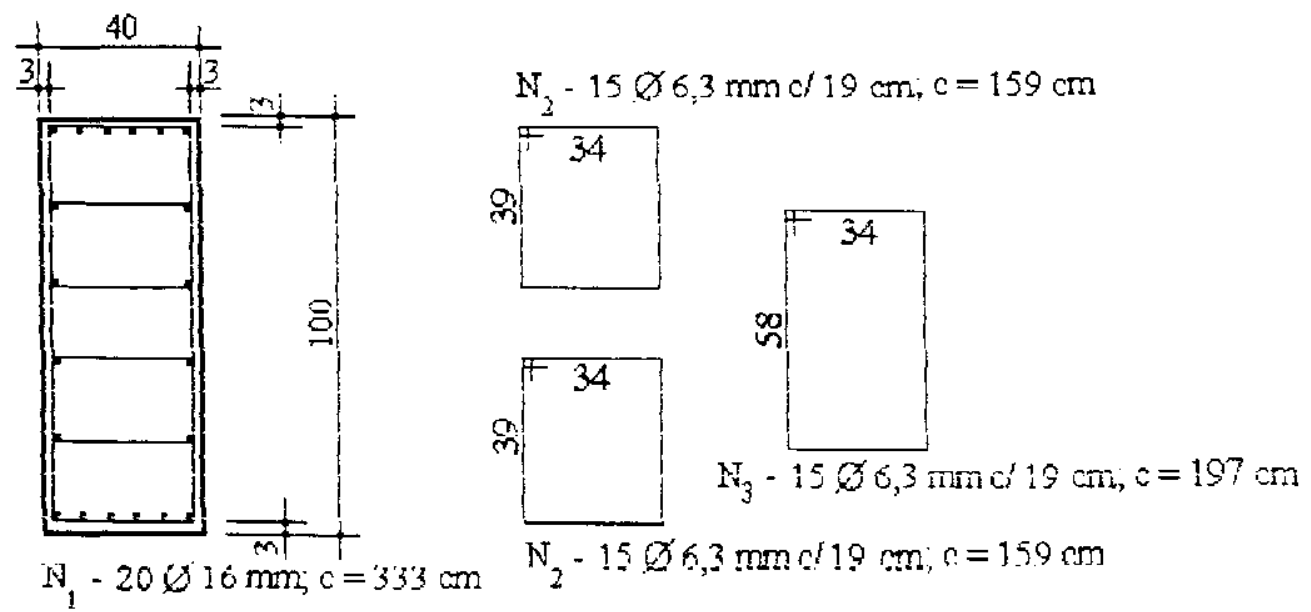

FIGURA 8.14 - Seção transversal do pilar P22 no trecho A.

Trecho B (40 x 100): Diagramas de Esforços Solicitantes.
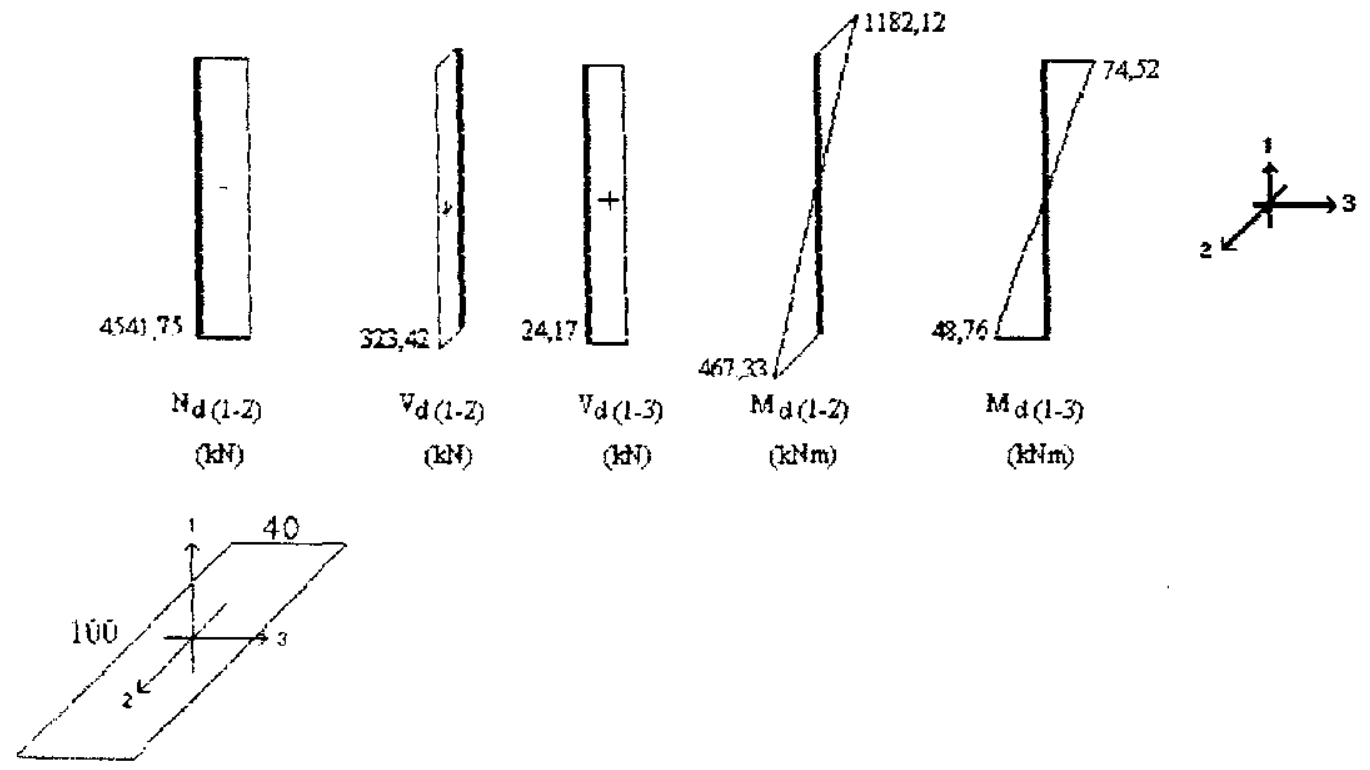

$$
\begin{aligned}
& \iota_{\mathrm{e}_{1-2}}=\iota_{\mathrm{e}_{1-3}}=510 \mathrm{~cm} \\
& \mathrm{I}_{1-2}=533.333 \mathrm{~cm}^{4} \therefore \mathrm{r}_{\mathrm{i}-2}=11.55 \mathrm{~cm} \Rightarrow \lambda_{i-2}=44,20 \\
& \mathrm{I}_{\mathrm{i}-3}=3333.333 \mathrm{~cm}^{4} \therefore \mathrm{r}_{\mathrm{i}-3}=28,87 \mathrm{~cm} \Rightarrow \lambda_{i-i}=17,67
\end{aligned}
$$

A excentricidade local de segunda ordem, deve ser considerada apenas na direção do eixo 3 pois, $\lambda_{1-2}>40$. 


$$
\begin{aligned}
& \mathrm{e}_{2(1-3)}=\frac{510^{2}}{10} \cdot \frac{\left(0,0035+\frac{43,5}{21.000}\right)}{(v+0,5) \cdot 40}, \text { com } v+0,5 \geq 1,0 \\
& \therefore \mathrm{e}_{2(1-3)}=2,63 \mathrm{~cm}
\end{aligned}
$$

Observando o diagrama de esforços criticos para a seção $\underline{B}$, as excentricidades iniciais para o pilar P22, ao nivel do pavimento de transição, são assim determinadas:

$$
\begin{aligned}
& \mathrm{e}_{\mathrm{i}, \text { topol-2}}=\frac{\mathrm{M}_{\mathrm{i}, \mathrm{topol}-2}}{\mathrm{~N}_{\mathrm{d}}}=\frac{1182,12}{4541,75}=26,00 \mathrm{~cm} \\
& \mathrm{e}_{\mathrm{i}, \text { topol-3 }}=\frac{\mathrm{M}_{\mathrm{i.topol-3}}}{\mathrm{N}_{\mathrm{d}}}=\frac{74,52}{4541,75}=1,64 \mathrm{~cm} \\
& \mathrm{e}_{\mathrm{i}, \text { basi } 1-2}=\frac{\mathrm{M}_{\text {ibasel-2 }}}{\mathrm{N}_{\mathrm{d}}}=\frac{467,33}{4541,75}=10,29 \mathrm{~cm} \\
& e_{i, \text { base }-3}=\frac{M_{\text {ibasel-3 }}}{N_{d}}=\frac{48,76}{4541,75}=1,07 \mathrm{~cm}
\end{aligned}
$$

A excentricidade inicial na seção intermediária, é obtida de acordo com a expressão abaixo:

$$
\mathrm{e}_{\mathrm{i}_{\mathrm{int}}}=0,6 \cdot \mathrm{e}_{\mathrm{i}_{\mathrm{A}}}+0,4 \cdot \mathrm{e}_{\mathrm{iB}_{\mathrm{B}}} \geq 0,4 \cdot \mathrm{e}_{\mathrm{A}}
$$

sendo:

$$
\begin{gathered}
\mathrm{e}_{\mathrm{i}_{\mathrm{mt}}} \text { - excentricidade inicial na seção intermediária do pilar; } \\
\mathrm{e}_{\mathrm{i}_{A}} \text { e } \mathrm{e}_{\mathrm{i}_{\mathrm{B}}} \text { - excentricidades iniciais nas seções de topo / base, com } \\
\qquad\left|\mathrm{e}_{\mathrm{i}_{A}}\right| \geq\left|\mathrm{e}_{\mathrm{i}_{B}}\right| \\
\mathrm{e}_{\mathrm{i} \text { int }(1-2)}=0,6 \cdot 26,00-0,4 \cdot 10,29=11,48 \mathrm{~cm} \\
\mathrm{e}_{\mathrm{i}, \text { innu }(1-3)}=0,4 \cdot 1,64=0,66 \mathrm{~cm}
\end{gathered}
$$

A excentricidade devido ao desaprumo $\left(\mathrm{e}_{\mathrm{d}}\right)$ local do pilar, pode ser determinada conforme se segue: 


$$
\mathrm{e}_{\mathrm{d}_{\operatorname{int}(1-2)}}=\mathrm{e}_{\mathrm{din}_{\min (1-3)}}=\phi_{1} \cdot \frac{\ell}{2}=0,0025 \cdot \frac{510}{2}=0,64 \mathrm{~cm}
$$

Obtido o cálculo das excentricidades, pode-se determinar as situaçôes de projeto e de cálculo para o pilar P22, ao nivel do pavimento de transição.

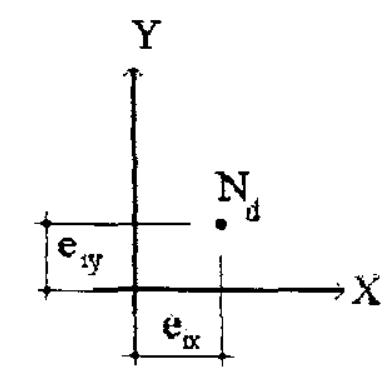

Situação de projeto

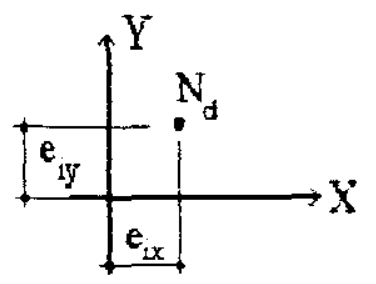

(I)

Situação de cálculo

Seção de Topo/Base

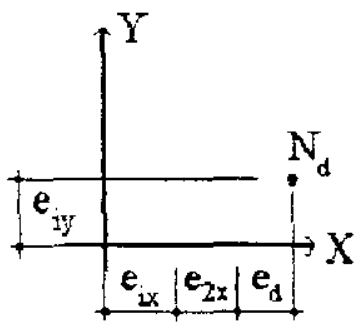

(II)

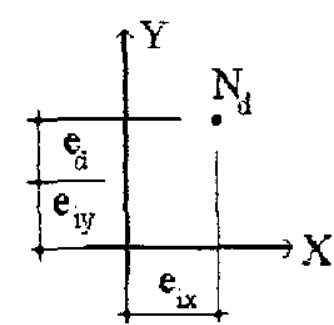

(III)

Situações de cálculo

Seção Intermediária

FIGURA 8.15 - Situações de cálculo no trecho $\underline{B}$.

Observando as situações de cálculo acima e substituindo os valores das excentricidades, verifica-se que a situação crítica é a ( I ) na seção de topo.

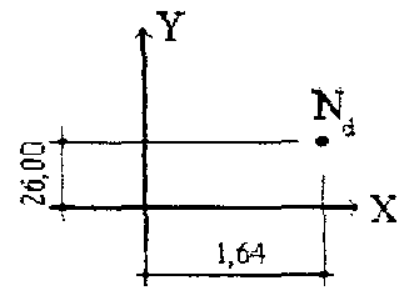

(I)

Os valores adimensionais para o pilar em questão são:

$$
\begin{aligned}
& v_{\mathrm{d}}=0,88, \mu_{\mathrm{dx}}=0,04 \mathrm{e} \mu_{\mathrm{dy}}=0,23 \\
& \frac{\mathrm{d}_{\mathrm{h}}^{\prime}}{\mathrm{h}}=0,03 \approx 0,05 \in \frac{\mathrm{d}_{\mathrm{h}}^{\prime}}{\mathrm{b}}=0,075 \equiv 0,10
\end{aligned}
$$


Através do ábaco da pag. 82 de VENTURINI[1990] e fazendo-se uma interpolação entre os valores de $v_{d}$ para 0,80 e 1,00 , obtém-se $\omega \cong 0,82$. Resultando em uma área de armadura igual a $96,9 \mathrm{~cm}^{2}\left(20 \phi 25 \mathrm{~mm}=98,2 \mathrm{~cm}^{2}\right)$.

Sendo assim, de acordo com as expressôes (8.8), (8.9) e (8.10) o comprimento de traspasse resulta em:

$$
\begin{aligned}
& \varepsilon_{\mathrm{b}}=\frac{2,5}{4} \cdot \frac{43,5}{0,289}=94,0 \mathrm{~cm} \\
& \zeta_{\text {nec }}=1,0 \cdot 94,0 \cdot \frac{96,9}{98,2} \cong 93,0 \mathrm{~cm}
\end{aligned}
$$
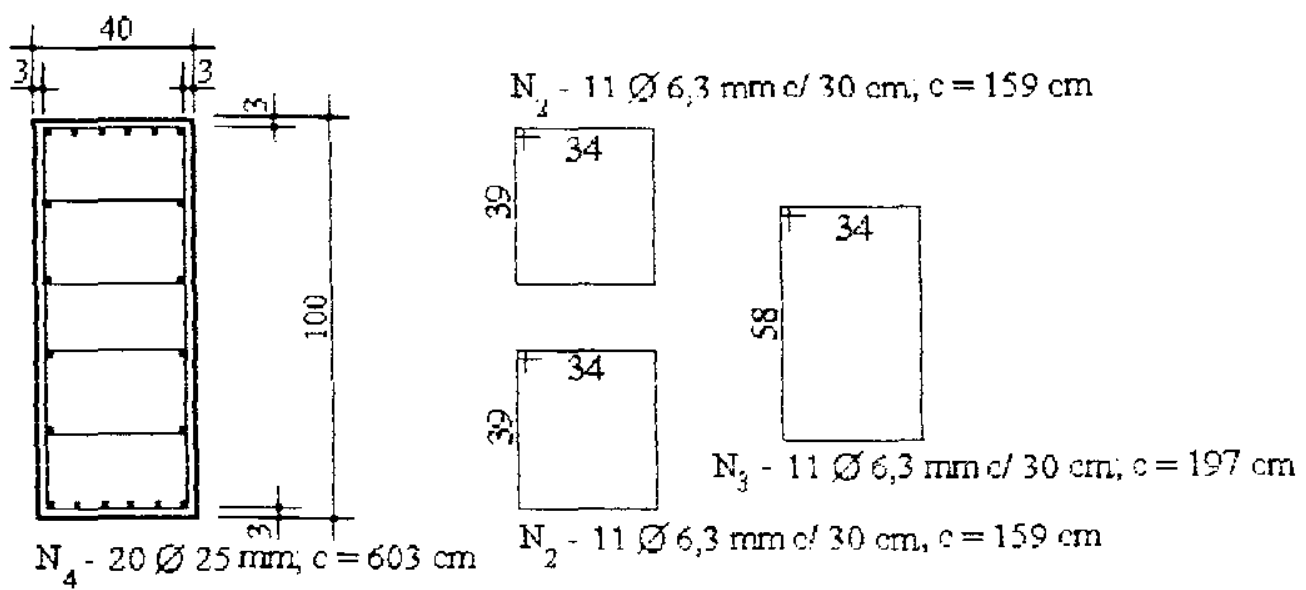

FIGURA 8.16 - Seção transversal do Pilar P22 no trecho $\underline{\mathrm{B}}$.

Trecho C (20 x 100): Diagramas de Esforços Solicitantes.

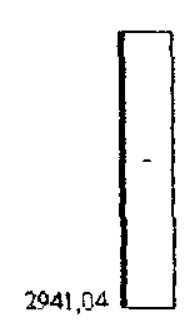

$\mathrm{H}_{\alpha(1-2)}$

(kid)

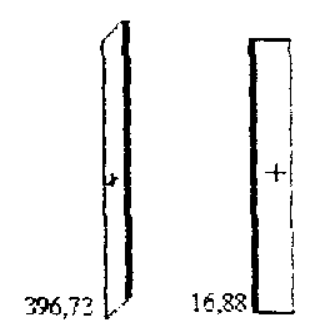

$v_{d(1-2)}$

(kts)

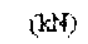

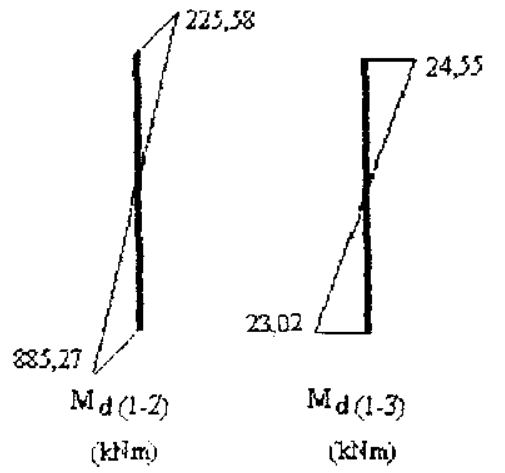

(Kism)

$(\mathrm{kH}+\mathrm{mi}$
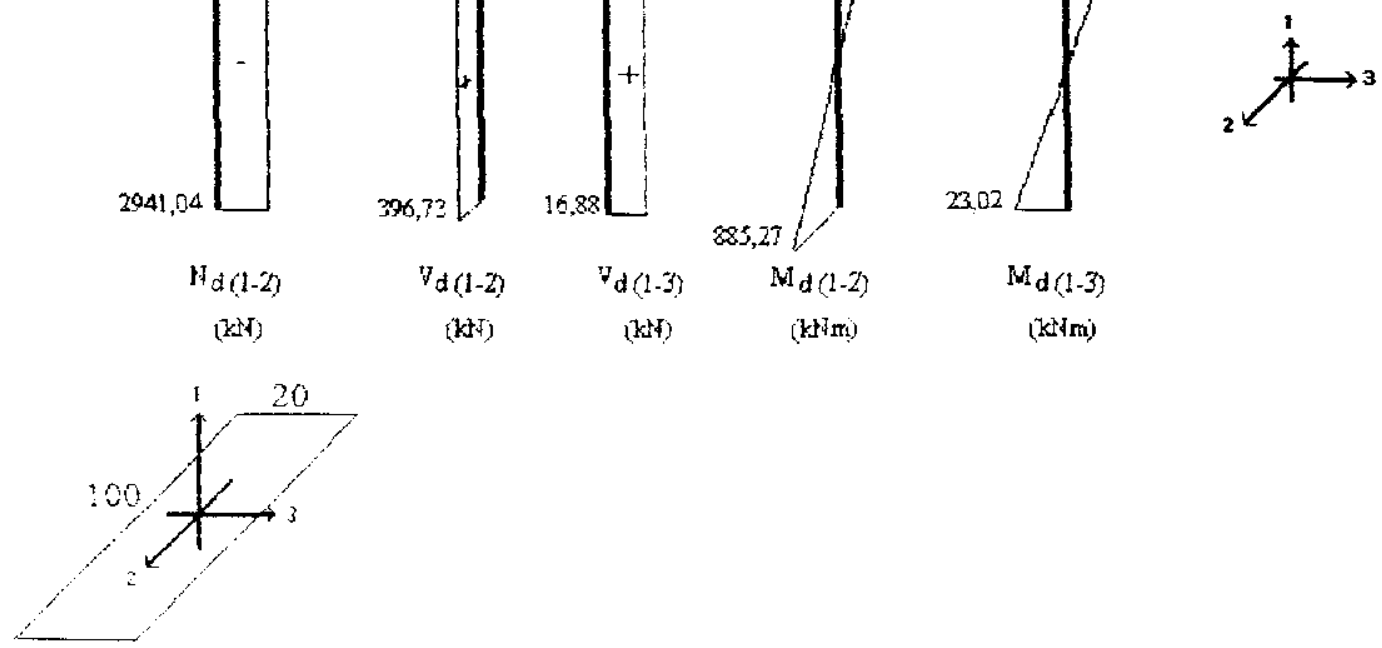

$$
\iota_{c_{1}}=\iota_{c_{1}}=280 \mathrm{~cm}
$$




$$
\begin{aligned}
& I_{i-\hat{\imath}}=66.667 \mathrm{~cm}^{4} \therefore r_{i-\hat{\imath}}=5,77 \mathrm{~cm} \Rightarrow \lambda_{i-\hat{\imath}}=48,50 \\
& I_{i-3}=1.666 .667 \mathrm{~cm}^{4} \therefore r_{i-3}=28,87 \mathrm{~cm} \Rightarrow \lambda_{i-3}=9,69
\end{aligned}
$$

A excentricidade local de segunda ordem, deve ser considerada apenas na direção do eixo 3.

$$
\begin{aligned}
& \mathrm{e}_{2(1-3)}=\frac{280^{2}}{10} \cdot \frac{\left(0,0035+\frac{43,5}{21.000}\right)}{(v+0,5) \cdot 20}, \operatorname{com} v+0,5 \geq 1,0 \\
& \therefore \mathrm{e}_{2(1-3)}=1,33 \mathrm{~cm}
\end{aligned}
$$

As excentricidades iniciais para o pilar $\mathrm{P} 22$, ao nível do trecho $\underline{\mathrm{C}}$, serão assim determinadas:

$$
\begin{aligned}
& \mathrm{e}_{\mathrm{i} \text {,topol-2 }}=\frac{\mathrm{M}_{\mathrm{i} \text {.topol-2 }}}{\mathrm{N}_{\mathrm{d}}}=\frac{225,58}{2941,04}=7,67 \mathrm{~cm} \\
& \mathrm{e}_{\mathrm{i}, \text { topol-3 }}=\frac{\mathrm{M}_{\mathrm{i} \text {.topol-3 }}}{\mathrm{N}_{\mathrm{d}}}=\frac{24,53}{2941,04}=0,83 \mathrm{~cm} \\
& \mathrm{e}_{\mathrm{i}, \text { basel-2 }}=\frac{\mathrm{M}_{\mathrm{i} \text {.basel-2 }}}{\mathrm{N}_{\mathrm{d}}}=\frac{885,27}{2941,04}=30,10 \mathrm{~cm} \\
& \mathrm{e}_{\mathrm{i}, \text { basel-3 }}=\frac{\mathrm{M}_{\mathrm{i} \text {.basel-3 }}}{\mathrm{N}_{\mathrm{d}}}=\frac{23,02}{2941,04}=0,78 \mathrm{~cm}
\end{aligned}
$$

A excentricidade inicial na seção intermediária, é obtida de acordo com a expressão (8.16).

$$
\begin{aligned}
& e_{i . \text { int }(1-2)}=0,6 \cdot 30,10-0,4 \cdot 7,67=15,00 \mathrm{~cm} \\
& e_{i . \text { int }(1-3)}=0,4 \cdot 0,83=0,33 \mathrm{~cm}
\end{aligned}
$$

A excentricidade devido ao desaprumo local na seção intermediária do pilar P22 no trecho $\underline{C}$, e assim determinada:

$$
\mathrm{e}_{\mathrm{d}_{\text {int }(\mathrm{I}-2)}}=\mathrm{e}_{\mathrm{d}_{\text {int }(1-3)}}-\frac{\phi}{\psi 1} \cdot \frac{\ell}{2}-0,0025 \cdot \frac{280}{2}-0,35 \mathrm{~cm}
$$


Obtido o cálculo das excentricidades, pode-se determinar as situações de projeto e de cálculo para o pilar $\mathrm{P} 22$, ao nivel do trecho $\underline{\mathrm{C}}$.

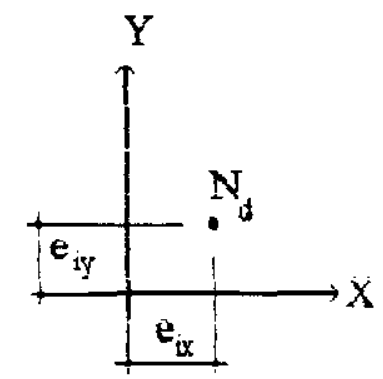

Situação de projeto

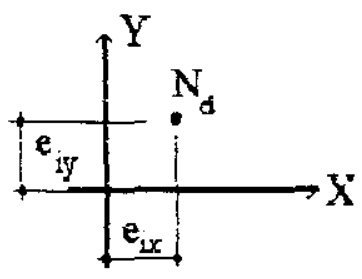

(I)

Situação de cálculo

Seção de Topo/Base

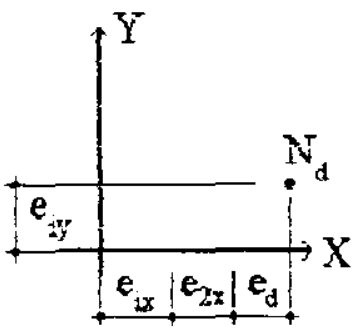

(II)

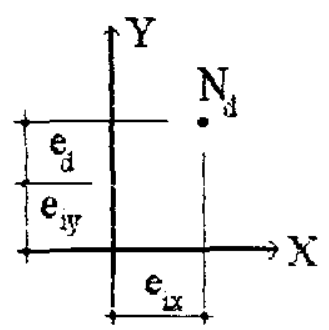

(III)

Situações de cálculo

Seção Intermediária

FIGURA 8.17 - Situações de cálculo no trecho $\underline{\mathrm{C}}$.

De acordo com as situações de projeto e cálculo expostas acima, pode-se observar que o caso ( I ), na seção da base, é o critico.

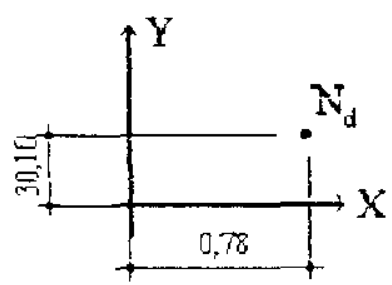

Os valores adimensionais para o pilar em questão são

$$
\begin{aligned}
& v_{\mathrm{d}}=1,14, \mu_{\mathrm{ix}}=0,04 \mathrm{e} \mu_{\mathrm{dy}}=0,34 \\
& \frac{\mathrm{d}_{\underline{y}}^{\prime}}{\mathrm{h}_{\mathrm{y}}^{\prime}}=0,03 \approx 0,05 \mathrm{e} \frac{\mathrm{d}_{\underline{x}}^{\prime}}{\mathrm{h}_{\mathrm{x}}}=0,15
\end{aligned}
$$

Atravès do ábaco A-16 de PINHEIRO/1994/ e fazendo-se uma interpolação de $v_{d}$ entre os valores de 1,00 e 1,20, obtem-se o valor de $\omega \equiv 1,66$. Resultando em uma área de armadura igual a $98.1 \mathrm{~cm}^{2}\left(20 \phi 25 \mathrm{~mm}=98.2 \mathrm{~cm}^{2}\right)$.

$$
\varepsilon_{b}-\frac{2,5}{4} \cdot \frac{43.5}{0.289}-94,0 \mathrm{~cm}
$$




$$
\begin{aligned}
l_{\mathrm{b}} & =1,0 \cdot 94,0 \cdot \frac{98,1}{98,2} \cong 94,0 \mathrm{~cm} \\
& \longrightarrow \mathrm{N}_{8}-2 \times 15 \varnothing 6,3 \mathrm{~mm} / 20 \mathrm{~cm} ; \mathrm{c}=30 \mathrm{~cm}
\end{aligned}
$$

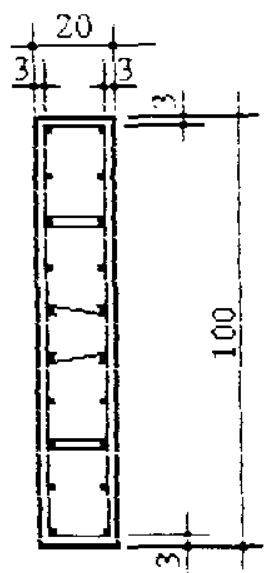

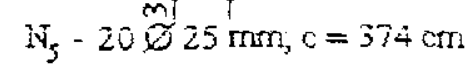

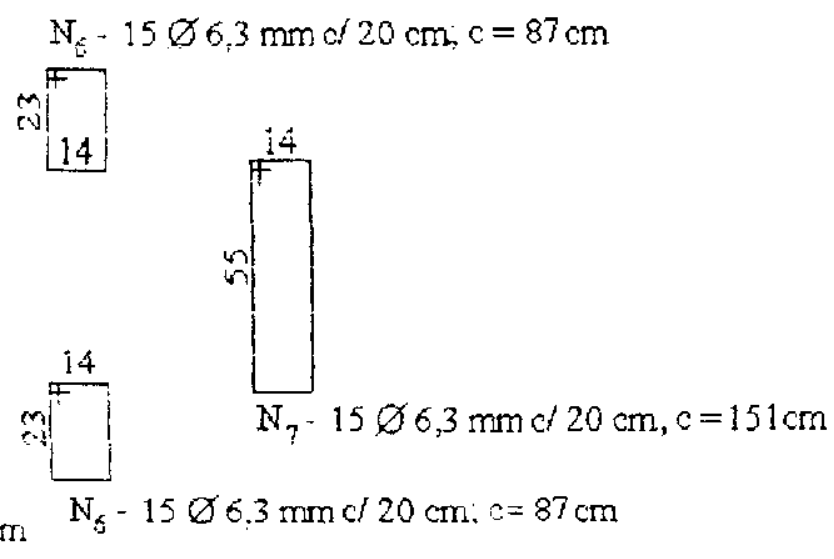

FIGURA 8.18 - Seção transversal do pilar P22, no trecho $\underline{\mathrm{C}}$.

Trecho D (20x 100): Diagramas de Esforços Solicitantes.

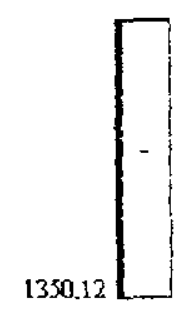

$$
N_{d(1-Z)}
$$

$(\mathrm{k}+\mathrm{s})$

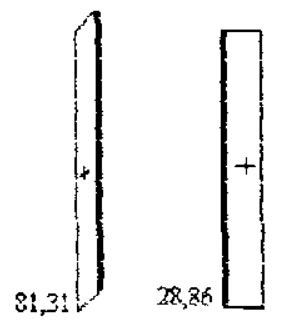

$y_{d}(1-2)$

(kst)

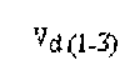

(k\$)

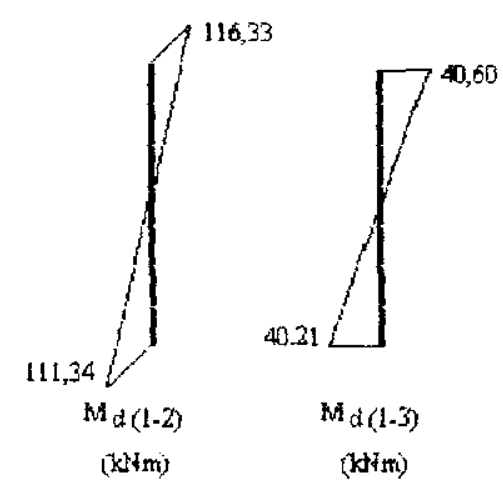

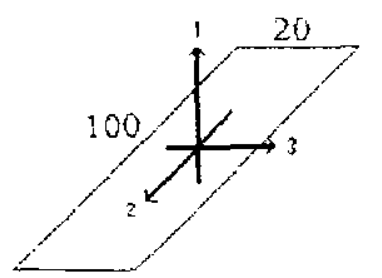

$$
\begin{aligned}
& \ell_{\mathrm{c}_{12}}=\ell_{\mathrm{c}_{13} 3}=280 \mathrm{~cm} \\
& \mathrm{I}_{1-2}=66.667 \mathrm{~cm}^{4} \therefore \mathrm{r}_{1-2}=5.77 \mathrm{~cm} \Rightarrow \lambda_{1-2}=48.50 \\
& \mathrm{I}_{1-3}=1.666 .667 \mathrm{~cm}^{4} \therefore \mathrm{r}_{1-3}=28,87 \mathrm{~cm} \Rightarrow \lambda_{1-3}=9.69
\end{aligned}
$$

Sendo assim, a excentricidade de segunda ordem deve ser considerada apenas na direção do eixo 3 


$$
\begin{aligned}
& \mathrm{e}_{2(1-3)}=\frac{280^{2}}{10} \cdot \frac{\left(0,0035+\frac{43,5}{21.000}\right)}{(v+0,5) \cdot 20}, \text { com } v+0,5 \geq 1,0 \\
& \therefore \mathrm{e}_{2(1-3)}=2,13 \mathrm{~cm}
\end{aligned}
$$

As excentricidades iniciais para o pilar $\mathrm{P} 22$, ao nivel do trecho $\underline{\mathrm{D}}$, são assim determinadas:

$$
\begin{aligned}
& \mathbf{e}_{i, \text { topol-2 }}=\frac{M_{i, \text { topol-2 }}}{N_{d}}=\frac{116,33}{1350,12}=8,60 \mathrm{~cm} \\
& \mathbf{e}_{i, \text { topol-3 }}=\frac{M_{i . \text { topol-3 }}}{N_{d}}=\frac{40,60}{1350,12}=3,00 \mathrm{~cm} \\
& e_{i, \text { basel-2 }}=\frac{M_{i . \text { basel-2 }}}{N_{d}}=\frac{111,34}{1350,12}=8,25 \mathrm{~cm} \\
& \mathbf{e}_{i, \text { basel-3 }}=\frac{M_{i, \text { basel-3 }}}{N_{d}}=\frac{40,21}{1350,12}=2,98 \mathrm{~cm}
\end{aligned}
$$

A excentricidade inicial na seção intermediária, é obtida de acordo com a expressão (8.16).

$$
\begin{aligned}
& e_{i . i n t(1-2)}=0,4 \cdot 8,60=3,44 \mathrm{~cm} \\
& e_{i . \text { inu(1-3) }}=0,4 \cdot 3,00=1,20 \mathrm{~cm}
\end{aligned}
$$

O efeito local do desaprumo para a seção intermediária é assim determinada:

$$
\varepsilon_{d_{\text {int }(1-2)}}-\hat{e}_{d_{\text {int }(1-3)}}-\frac{\psi_{\psi}}{\psi_{1}} \cdot \frac{\ell}{2}-0,0025 \cdot \frac{280}{2}-0,35 \mathrm{~cm}
$$

As situações de projeto e de cálculo para o pilar $\mathrm{P} 22$, ao nivel da seção $\underline{\mathrm{D}}$, são mostradas a seguir. 


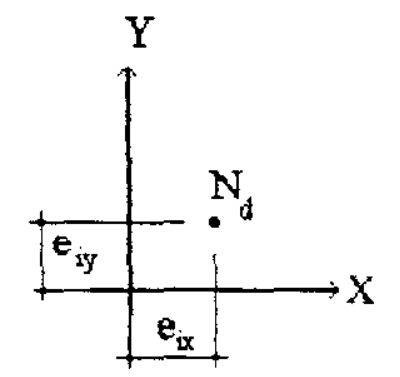

Situação de projeto

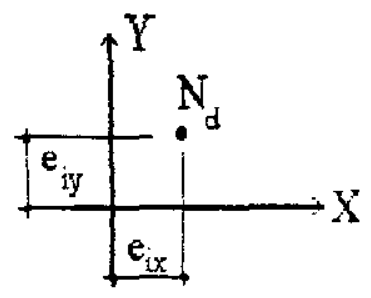

(I)

Situação de cálculo

Seção de Topo/Base

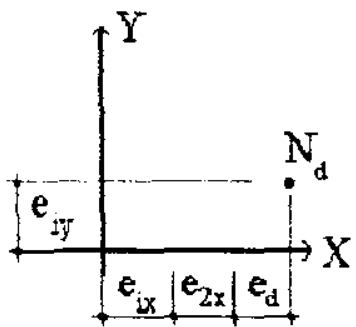

(II)

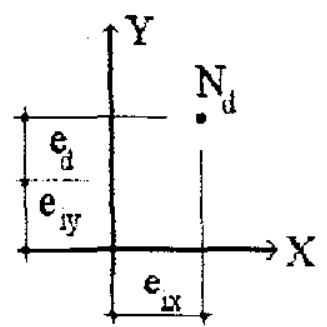

(III)

Situações de cálculo

Seção Intermediária

FIGURA 8.19 - Situações de cálculo no trecho D.

Substituindo os valores das excentricidades obtidas anteriormente, conclui-se que a situação critica é a ( I ) para o topo do pilar.

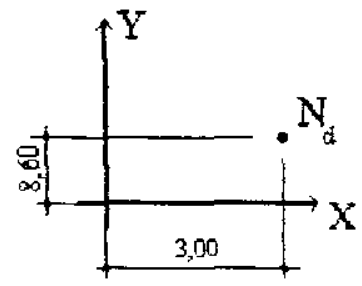

Os valores adimensionais para o pilar em questão são:

$$
\begin{aligned}
& v_{\mathrm{d}}=0,53, \mu_{\mathrm{dx}} \cong 0,08 \mathrm{e} \mu_{\mathrm{dy}} \cong 0,05 \\
& \frac{\mathrm{d}_{\mathrm{y}}^{\prime}}{\mathrm{hy}}=0,030 \cong 0,050 \mathrm{e} \frac{\mathrm{d}_{\mathrm{x}}^{\prime}}{\mathrm{hx}}=0,150
\end{aligned}
$$

A partir do ábaco A - 41 de PINHEIRO[1994] e fazendo uma interpolação de $v_{\mathrm{d}}$ entre 0.40 e 0.60 obtém-se $\omega \approx 0.13$ : resultando numa área de armadura de $7.7 \mathrm{~cm}^{2}$ Porém, a taxa de armadura é inferior ao minimo previsto pela NBR - 6118/78, sendo assim, será utilizado $8 \phi 16 \mathrm{~mm}(\rho \cong 0,80 \%)$. Logo, o comprimento de traspasse obtido conforme a expressão $(8.8)$ e (8.9), resulta em $60,0 \mathrm{~cm}$. 


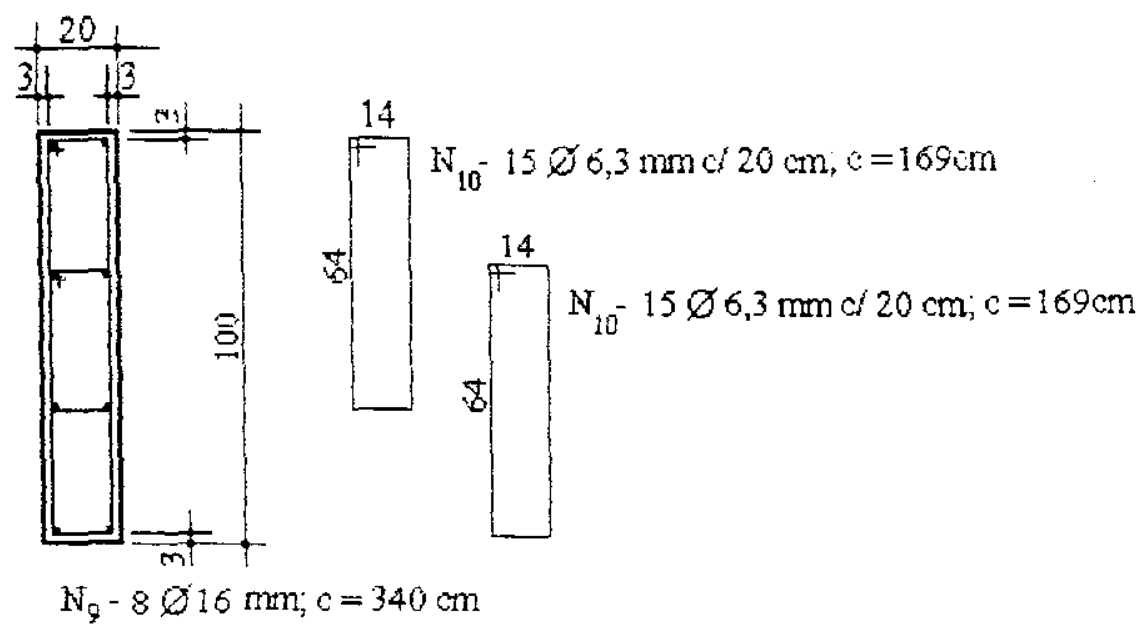

FIGURA 8.20 - Seção transversal do pilar P22, no trecho $\underline{\mathrm{D}}$.

Finalizando, deve-se verificar o último tramo do pilar P22, pois o esforço normal é relativamente pequeno se compararmos com o momento fletor atuante na ligação viga - pilar.

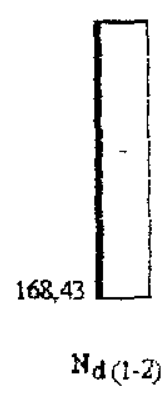

(k)

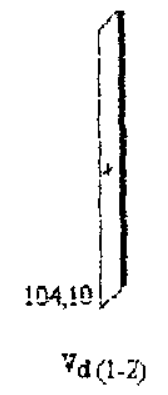

(k15)

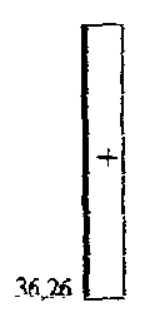

$v_{d(1-3)}$

(ks)

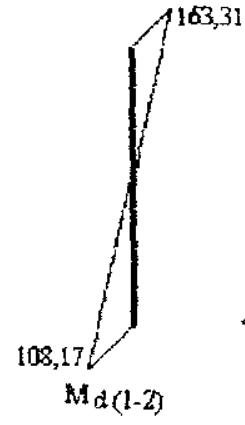

(kitri)

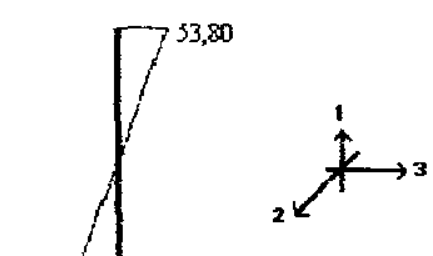

$M d(1-3)$

(kłlai)

A seção transversal do pilar no último tramo é exatamente igual às seçòes $\underline{C}$ e $\underline{D}$. Sendo assim, a excentricidade local de segunda ordem deve ser considerada apenas na direção do eixo 3 .

$$
\therefore \mathrm{e}_{2(1-3)}=2,18 \mathrm{~cm}
$$

De acordo com os esforços mostrados acima, as excentricidades iniciais resultam nos seguintes valores:

$$
\begin{aligned}
& \mathrm{e}_{\mathrm{itoper(-2)}}=108,8 \mathrm{~cm}
\end{aligned}
$$

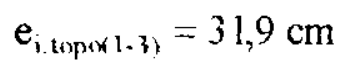

$$
\begin{aligned}
& \mathrm{e}_{\mathrm{i} . \text { lawket 1-2) }}=64,2 \mathrm{~cm} \\
& \mathrm{e}_{\text {i. haset 1.3) }}=28,3 \mathrm{~cm}
\end{aligned}
$$


A excentricidade inicial na seção intermediária, é obtida de acordo com a expressào (8.16).

$$
\begin{aligned}
& \mathrm{e}_{\mathrm{i}, \mathrm{inn}(1-2)}=43,5 \mathrm{~cm} \\
& \mathrm{e}_{\mathrm{i}, \mathrm{nnt}(1-3)}=12,80 \mathrm{~cm}
\end{aligned}
$$

O efeito local do desaprumo para a seção intermediária tém o seguinte valor:

$$
\mathrm{e}_{\mathrm{d}_{\mathrm{int}(1-2)}}=\mathrm{e}_{\mathrm{d}_{\mathrm{int}(1-3)}}=0,35 \mathrm{~cm}
$$

As situações de projeto e de cálculo para o pilar P22, no último tramo, são mostradas a seguir.

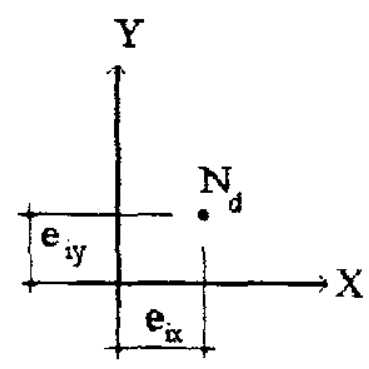

Situação de projeto

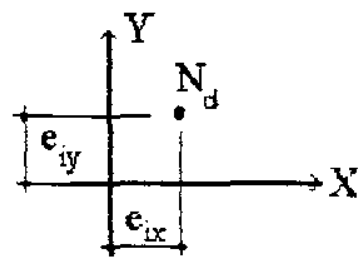

(I)

Situação de cálculo Seção de Topo/Base

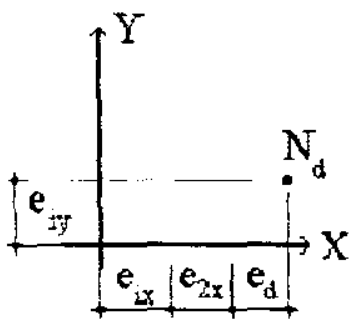

(II)

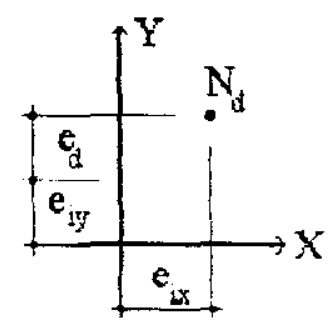

(III)

Situaçðes de cálculo

Seçăo Intermediária

FIGURA 8.21 - Situaçòes de cálculo no trecho $\underline{D}$.

A situação critica é a ( I ) para a seção do topo do pilar. Os valores adimensionais dos esforços normais e fletores são:

$$
\begin{aligned}
& \mathrm{v}_{\mathrm{d}} \cong 0,07, \mu_{\mathrm{dx}}=0,11 \text { e } \mu_{\mathrm{dy}}=0,07 \\
& \frac{\mathrm{d}_{\mathrm{y}}^{\prime}}{\mathrm{hy}}=0,030 \cong 0,050 \mathrm{e} \frac{\mathrm{d}_{\underline{x}}^{\prime}}{\mathrm{hx}}=0,150
\end{aligned}
$$

$\therefore$ Ábaco A - 41 PINHEIRO/1994] $\Rightarrow \omega \approx 0,24$.

$$
\text { As }=14.2 \mathrm{~cm}^{2}<16,0 \mathrm{~cm}^{2} ; \text { armadura minima } \Rightarrow 8 \phi 16 \mathrm{~mm}
$$


Sendo assim, pode-se concluir que no último tramo do pilar P22, a armadura determinada para o trecho $\mathrm{D}$ é suficiente.

A seguir é mostrado o detalhamento da prumada do pilar P22.

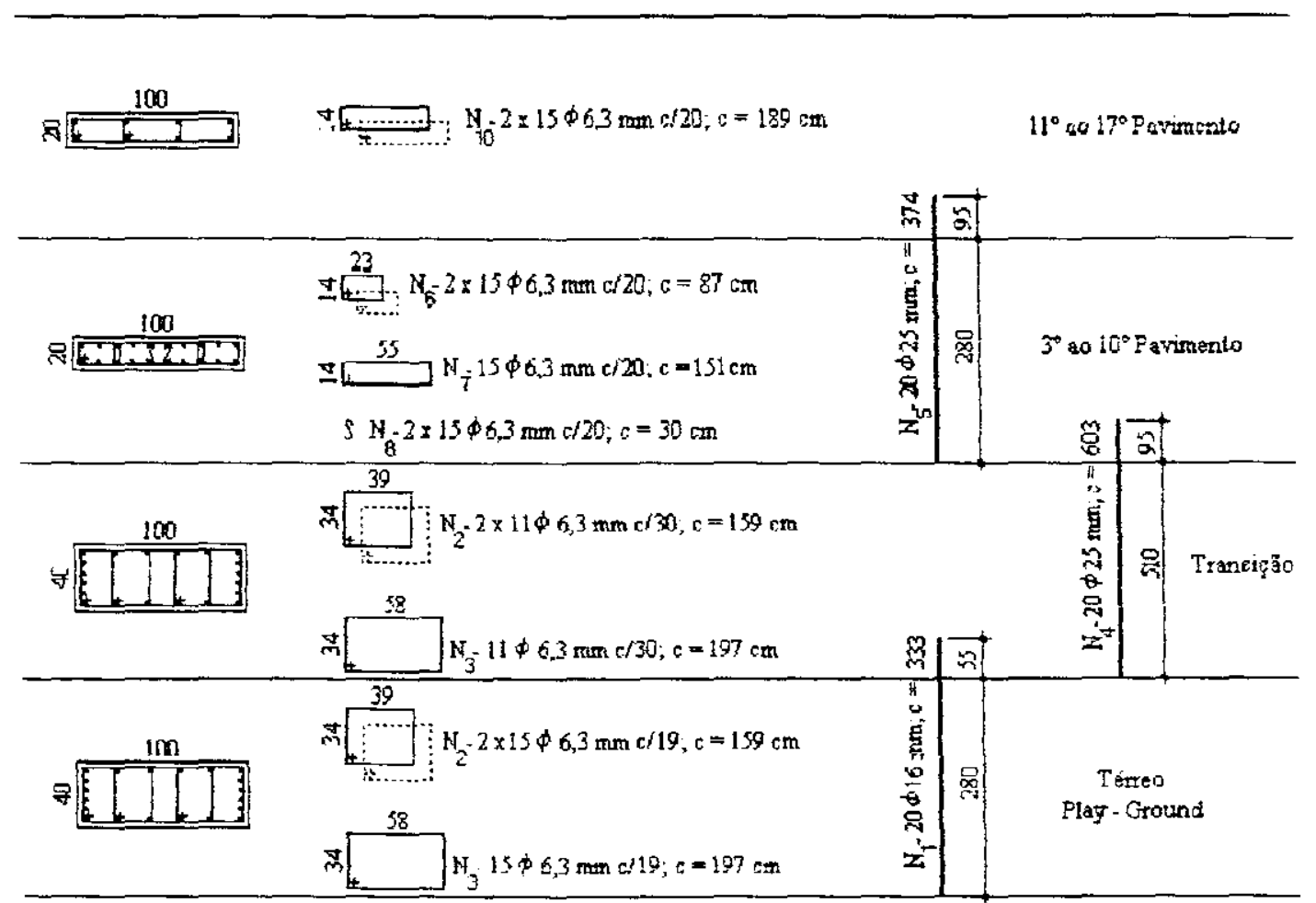

FIGURA 8.22 - Detalhamento da prumada do pilar P22. 


\subsection{PILAR P13}

A FIGURA 8.22 representa as caracteristicas necessárias da prumada do Pilar P13 a fim de que o seu dimensionamento possa ser realizado.

\begin{tabular}{|c|c|c|c|}
\hline & cobertura & & \\
\hline 213 & $17^{\circ}$ & 280 & \\
\hline 212 & $16^{\circ}$ & 280 & \\
\hline 211 & $15^{\circ}$ & 280 & $\mathrm{C}$ \\
\hline 210 & $14^{\circ}$ & 280 & \\
\hline 200 & $13^{\circ}$ & 280 & \\
\hline 208 & $12^{\circ}$ & 280 & \\
\hline 207 & $11^{\circ}$ & 280 & \\
\hline 206 & $10^{\circ}$ & 280 & B \\
\hline 205 & $9^{\circ}$ & 280 & \\
\hline 204 & $8^{\circ}$ & 280 & \\
\hline 203 & $\overline{7^{\circ}}$ & 280 & \\
\hline 202 & $6^{\circ}$ & 280 & \\
\hline 201 & $5^{\circ}$ & 280 & $A$ \\
\hline 200 & $4^{\circ}$ & 280 & \\
\hline 199 & $3^{\circ}$ & 280 & \\
\hline
\end{tabular}

FIGURA 8.23 - Esquema da prumada do Pilar P13.

Trecho A (30 x 70): Diagrama de Esforços Solicitantes.

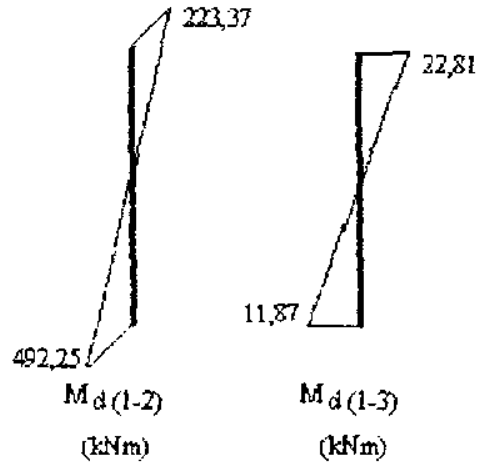

(kNm)

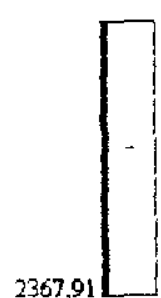

$N_{d(1-2)}$

(xt5)

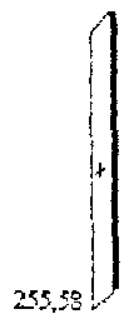

पd(1-2)

(kN)

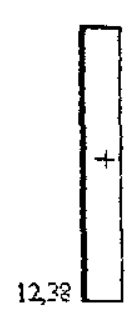

$v_{d(1-3)}$

(WW)

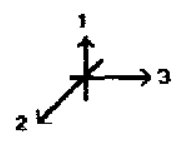

$\mathrm{I}_{1-i}=157.500 \mathrm{~cm}^{4} \therefore \mathrm{r}_{1-2}=8,66 \mathrm{~cm} \Rightarrow \lambda_{1-2}=32,3$

$I_{1-3}=857.500 \mathrm{~cm}^{4} \therefore r_{1-3}=20,21 \mathrm{~cm} \Rightarrow \lambda_{1-3}=13,90$

$\ell_{\mathrm{c}_{12}}=\ell_{\mathrm{c}_{1,3}}=280 \mathrm{~cm}$

Sendo assim, a excentricidade local de segunda ordem não precisa ser considerada em nenhuma das direções. 
De acordo com o diagrama de esforços críticos para o trecho A, pode-se determinar as excentricidades iniciais nas seções de topo e base do pilar, nas duas direçòes.

$$
\begin{aligned}
& \mathrm{e}_{i, \text { topo }(1-2)}=\frac{223,37}{2367,91}=9,43 \mathrm{~cm} \\
& \mathrm{e}_{i, \text { tope(1-3) }}=\frac{22,81}{2367,91}=0,96 \mathrm{~cm} \\
& \mathrm{e}_{i, \text { base (1-2) }}=\frac{492,25}{2367,91}=20,79 \mathrm{~cm} \\
& \mathrm{e}_{i, \text { base(1-3) }}=\frac{11,87}{2367,91}=0,50 \mathrm{~cm}
\end{aligned}
$$

Obtido o cálculo das excentricidades para o trecho $\underline{\mathrm{A}}$ podem-se determinar as situações de projeto e de cálculo para o pilar P13.

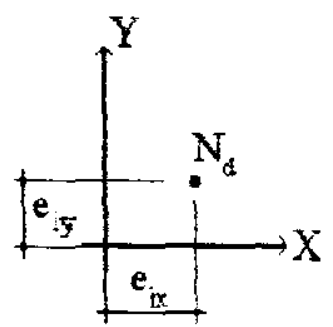

Situaçäo de projeto

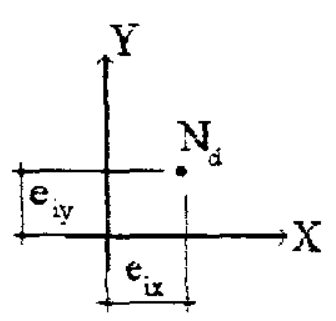

(I)

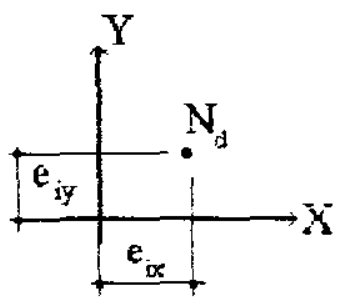

(II)

Situaçðes de Cálculo

Seçöes de Topo/Base

A situação mais desfavorável é a (I ) para a seção de base. Os valores adimensionais para este caso estão mostrados abaixo:

$$
\begin{aligned}
& v_{d}=0,88, \mu_{x d} \equiv 0,02 \text { e } \mu_{y d}=0,20 \\
& \frac{d_{y}^{\prime}}{h y}=0,04 \equiv 0,05 \text { e } \frac{d_{x}^{\prime}}{h x}=0,10
\end{aligned}
$$

A partir do Ábaco A - 7 de PINHEIRO/1994], obtem-se $\omega \approx 1,06$. Logo a área de armadura è igual a $65.8 \mathrm{~cm}^{2}\left(20 \phi 20 \mathrm{~mm}=62,8 \mathrm{~cm}^{2} \cong 65,8 \mathrm{~cm}^{2}\right)$.

$O$ comprimento de traspasse, neste caso, resulta em: 


$$
\begin{aligned}
& \xi_{b}=\frac{2,0}{4} \cdot \frac{43,5}{0,289}=75,3 \mathrm{~cm} \\
& \varepsilon_{\text {nec }}=1,0 \cdot 75,3 \cdot \frac{65,8}{62,8}=79,0 \mathrm{~cm}
\end{aligned}
$$

A seção transversal do Pilar P13, no trecho A, poderá ser visualizada através da FIGURA 8.24.
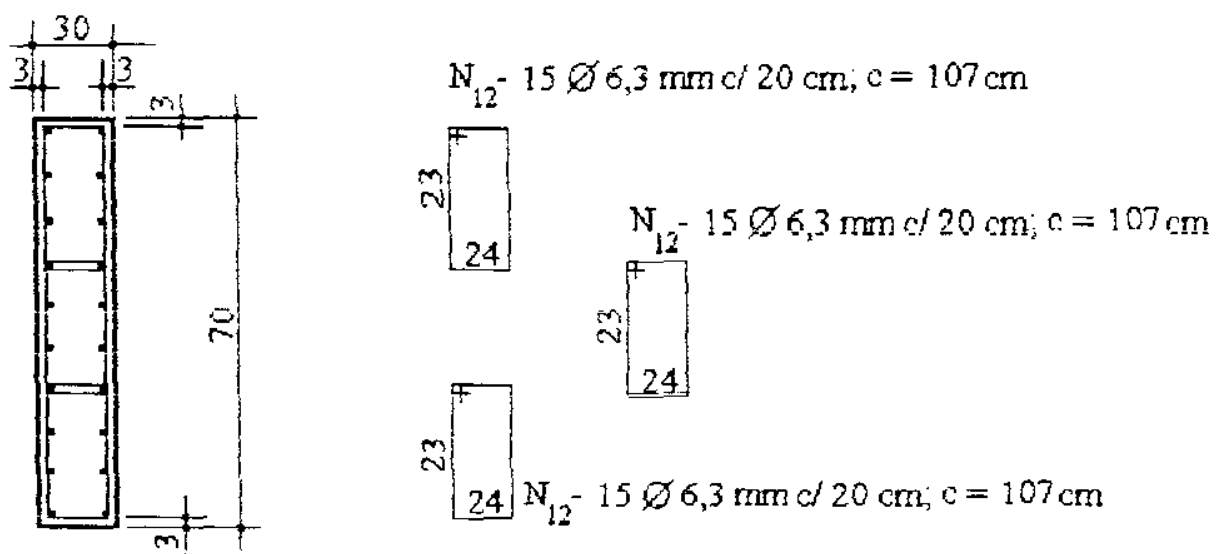

$\mathrm{N}_{11}-20 \varnothing 20 \mathrm{~mm}, \mathrm{c}=359 \mathrm{~cm}$

FIGURA 8.24 - Seção transversal do Pilar P13 no trecho $\underline{A}$.

Trecho B e C ( $30 \times 70)$ : Diagrama de Esforços Solicitantes.

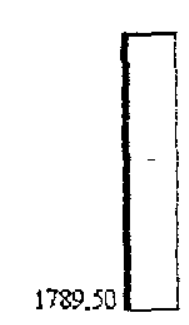

$\mathrm{N}_{d(1-\overline{2})}$

(NN)

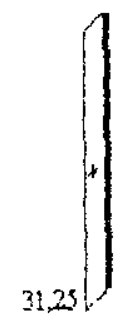

$v_{d(1-2)}$

(kN)

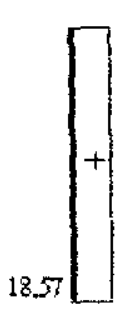

$v_{\alpha(1-3)}$

(kr)

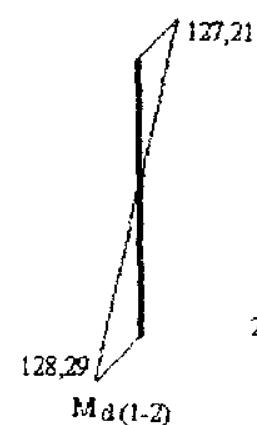

(kNi)

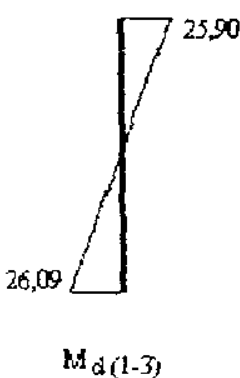

(k+1m)

$I_{1-2}=157.500 \mathrm{~cm}^{4} \therefore r_{i-2}=8,66 \mathrm{~cm} \Rightarrow \lambda_{i-2}=32,3$

$\mathrm{I}_{i_{-3}}=857.500 \mathrm{~cm}^{4} \therefore \mathrm{r}_{1-3}=20,2 \mathrm{Icm} \Rightarrow \lambda_{1-3}=13,90$

$\ell_{\mathrm{c}_{12}}=\ell_{\mathrm{c}_{1,3},}=280 \mathrm{~cm}$

As excentricidades iniciais nas seções de topo e base do pilar P13, estão mostradas abaixo 


$$
\begin{aligned}
& \mathrm{e}_{i, \text { topo (1-2) }}=\frac{127,21}{1789,50}=7,11 \mathrm{~cm} \\
& \mathrm{e}_{i, \text { baser }(1-2)}=\frac{128,29}{1789,50}=7,17 \mathrm{~cm} \\
& \mathrm{e}_{i, \text { topo(1-3) }}=\frac{25,90}{1789,50}=1,45 \mathrm{~cm} \\
& \mathrm{e}_{i, \text { bave(1-3) }}=\frac{26,09}{1789,50}=1,46 \mathrm{~cm}
\end{aligned}
$$

Obtido o cálculo das excentricidades para a situação $\underline{B}$ e $\underline{C}$, pode-se determinar as situaçãoes de projeto e de cálculo para o pilar P13.

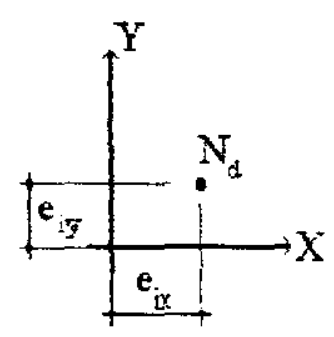

Situaçáo de projeto

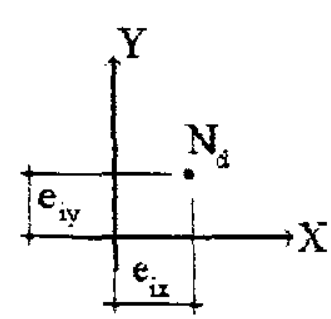

(I)

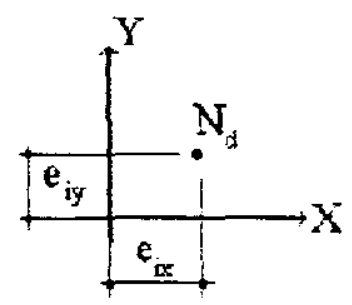

(II)

Situaçães de Cálculo

Seçóes de Topo/Base

A situação mais desfavorável para este caso é a ( I ) para a seção da base do pilar e os valores adimensionais para a utilização dos Ábacos são:

$$
\begin{aligned}
& v_{d}=0,06, \mu_{x d} \equiv 0,05 \text { e } \mu_{y d} \cong 0,07 \\
& \frac{d_{y}^{\prime}}{h y}=0,04 \equiv 0,05 \text { e } \frac{d_{x}^{\prime}}{h x}=0,10
\end{aligned}
$$

Através do Ábaco A - 8 de PINHEIRO/1994], obtem-se $\omega \approx 0,10 \mathrm{e}$, consequentemente, a área de armadura igual a $6,2 \mathrm{~cm}^{2}$, menor do que a minima prevista pela NBR - 6118. Sendo assim, utilizaremos $A_{\text {-min }}=0,8 \% \cdot 30 \cdot 70=16,8 \mathrm{~cm}^{2}(8 \phi 16$ $\mathrm{mm}$ ). Logo, o comprimento de traspasse resulta em $60,0 \mathrm{~cm}$.

A FIGURA 8.25 mostra a seçâo transversal do pilar $\mathrm{P} 13$ para os trechos $\underline{B}$ e $\underline{\mathrm{C}}$. 


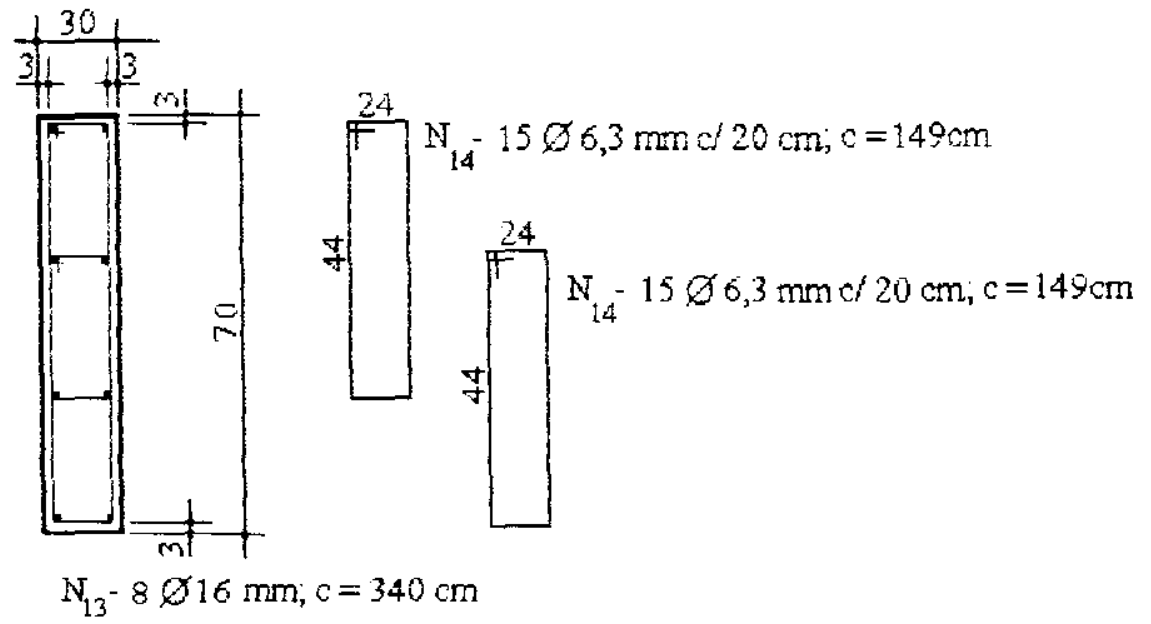

FIGURA 8.25 - Seção transversal do pilar P13 nas seçôes $\underline{B}$ e $\underline{\mathrm{C}}$.

Para finalizar, necessita-se fazer a verificação do ultimo tramo do pilar P13, pois as excentricidades iniciais são elevadas em virtude do baixo valor da força normal relativamente ao momento fletor atuante.

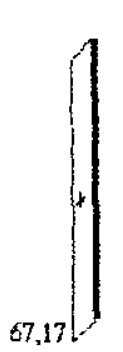

$y_{d}(1 \cdot 2)$

(kiv)

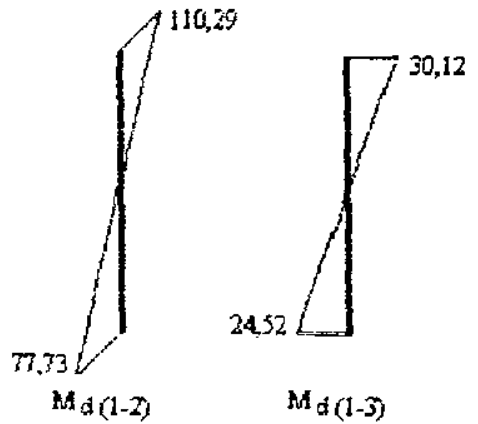

(ktim)

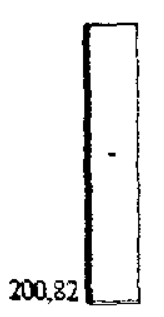

$N_{d}(1-2)$

(di)

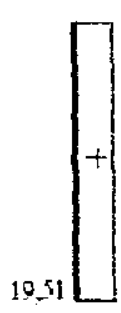

$v_{a(1-3)}$

(Ad)

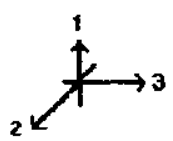

Pelos diagramas de esforços acima, as excentricidades iniciais poderào ser obtidas:

$$
\begin{aligned}
& \mathrm{e}_{i, \text { topo(1-2) }}=\frac{110,29}{200,82}=54,92 \mathrm{~cm} \\
& \mathrm{e}_{i, \text { baset (1-2) }}=\frac{77,79}{200,82}=38,74 \mathrm{~cm} \\
& \mathrm{e}_{i, \text { topor (1-3) }}=\frac{30,12}{200,82}=15,00 \mathrm{~cm} \\
& \mathrm{e}_{i, \text { baset (1-3) }}=\frac{24,52}{200,82}=12,21 \mathrm{~cm}
\end{aligned}
$$

Sendo assim, analisando as situaçòes de cálculo, para o pilar em questào, pode-se afirmar que a situaçào critica ocorre na seçào do topo, conforme FIGURA 8.26. 


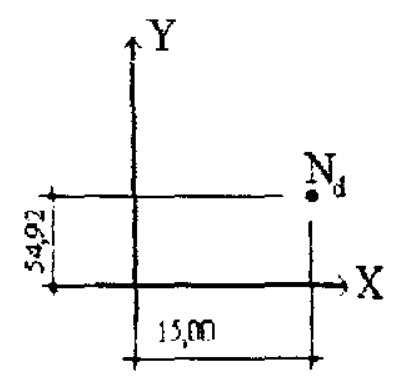

FIGURA 8.26 - Situaçâo critica para o pilar Pl3, no ultimo tramo.

Ao se trabalhar com os valores adimensionais obtidos, os Ábacos existentes indicarão uma ảrea de armadura inferior ao minimo previsto pela NBR-6118/78. Sendo assim, a armadura obtida para as seçôes $\underline{B}$ e $\underline{C}$ se verifica para o último tramo.

A seguir, FIGURA 8.27, é mostrado o detalhamento da prumada do pilar P13.

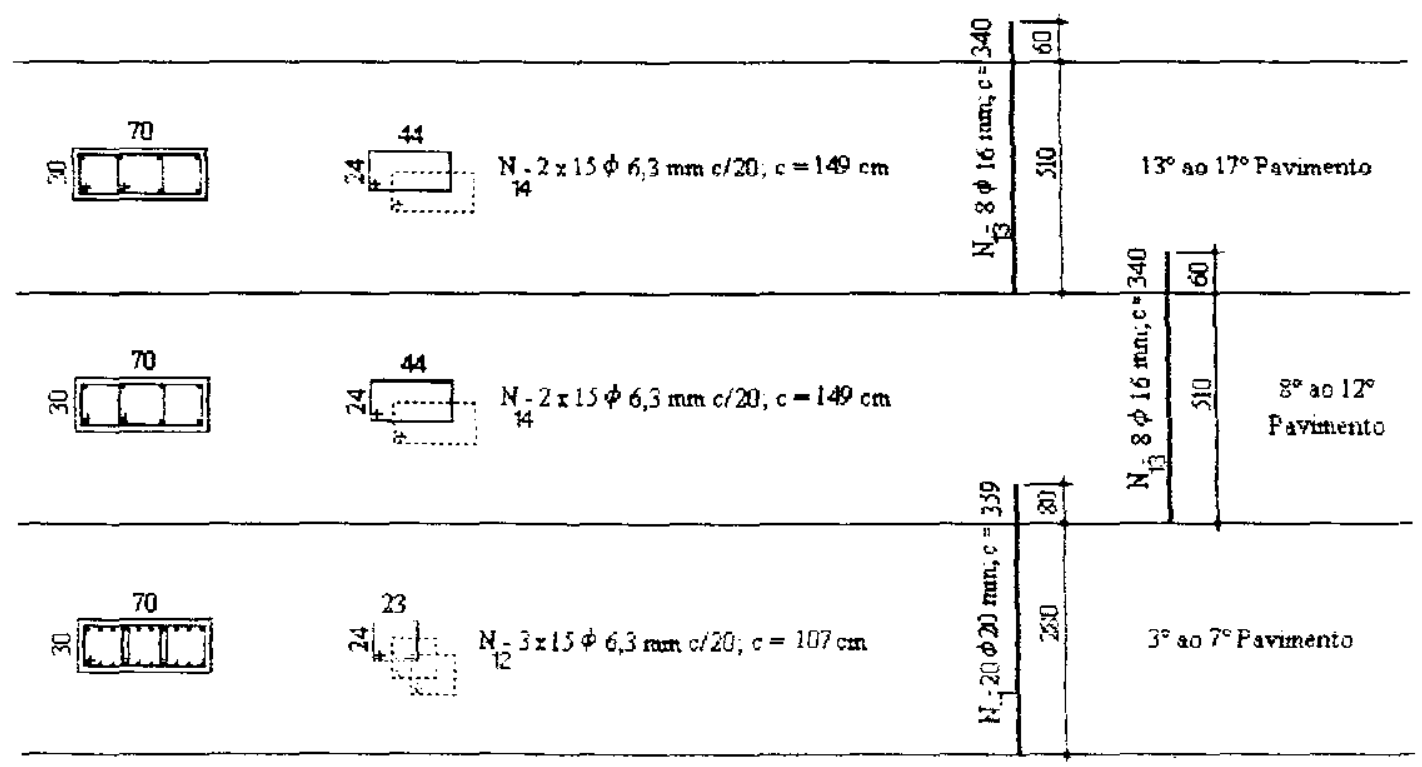

FIGURA 8.27 - Detalhamento da prumada do pilar P13. 


\section{CAPÍTULO 9: CONCLUSÃo}

Nos últimos anos, aumentou consideravelmente o uso de softwares específicos para o dimensionamento e detalhamento de estruturas de concreto.

A facilidade de modificaçâo de alternativas estruturais a um custo reduzido, é o fator preponderante para a expansâo da informática na área de estruturas.

Porém, a análise comportamental da estrutura, bem como o estudo dos resultados oferecidos pelo computador, deve ser feito por um profissional que domine teoricamente tais conhecimentos.

Sendo assim, este trabalho procura transmitir os conhecimentos teóricos necessários para que o profissional da área de estruturas possa entender as fases que englobam o dimensionamento e o detalhamento de pilares de concreto armado.

Procurou-se dar ênfase às etapas: Instabilidade de pilares e Estabilidade global.

O Texto Base para a revisão da NBR - 6118/78, também foi abordado nesta dissertação nas etapas que se fizeram necessárias, principalmente no que tange ao detalhamento de pilares de concreto armado.

No Capitulo 2, além de transmitir alguns conceitos importantes relativos ao projeto da forma da estrutura compativel com o projeto arquitetônico, foi proposto um criterio simplista para o pré - dimensionamento de pilares internos, de extremidade e de canto.

No Capitulo 3 a análise da Estabilidade Global de um edificio é comentada e relacionada com o projeto estrutural de pilares, visto que, é este estudo que permite avaliar se as deformaçôes impostas à estrutura pelo carragamento vertical e horizontal, geram esforços de segunda ordem consideráveis ou năo

O Capitulo 5, fornece informaçôes importantes para que o Engenheiro de Estruturas possa avaliar a estabilidade de um determinado pilar. O Método Geral, Método do Pilar Padrão com o Método Geral e o Método Simplificado da NBR - 6118/78 são discutidos, mostrando as restrições e limitaçôes de cada método.

O estudo do detalhamento de pilares, Capitulo 7, é realizado segundo as prescrições do Texto Base para a revisão da NBR - 6118/78. O cálculo da tensão de aderència 
considera as situações de aderência e a dimensão das bitolas das barras ancoradas, ao passo que, na NBR - 6118/78 a tensão de aderència nâo considera a influència dessas variàveis.

No Capitulo 8, os exemplos práticos foram desenvolvidos a partir de esforços obtidos pelo Engo. José Fernão M. de A. Prado quando do desenvolvimento de sua Dissertaçâo de mestrado Estruturas de Edificios em Concreto Armado Submetidas a Açōes Verticais e Horizontais. Em virtude do cálculo tridimensional realizado pelo Eng ${ }^{\circ}$ José Fernão, os pilares apresentaram excentricidades iniciais em duas direções distintas, independentemente da posição dos mesmos na estrutura. Sendo assim, o dimensionamento dos pilares P22 e P13, efetuados neste trabalho, foram feitos considerando flexão obliqua composta.

Finalmente, ao se concluir este trabalho, verifica-se que foram transmitidas informações importantes quando o projeto estrutural de pilares se fizer necessário. 


\section{REFERÊNCIAS BIBLIOGRÁFICAS}

ASSOCIAÇÃO BRASILEIRA DE NORMAS TÉCNICAS. "NBR-8681 - Ações e segurança nas estruturas". Rio de Janeiro, 1984.

ASSOCIAÇÃO BRASILEIRA DE NORMAS TÉCNICAS. "NBR-6120 - Cargas para o cálculo de estruturas de edificações". Rio de Janeiro, 1980.

ASSOCIAÇÃO BRASILEIRA DE NORMAS TÉCNICAS. “NBR-6123 - Forças devidas ao vento em edificações”. Rio de Janeiro, 1988.

ASSOCIAÇÃO BRASILEIRA DE NORMAS TÉCNICAS. "NBR-6118 - Projeto e execução de obras de concreto armado". Rio de Janeiro, 1980.

ASSOCIAÇÃO BRASILEIRA DE NORMAS TÉCNICAS. "Texto Base para a revisão da NBR - 6118/78 - Iª versão. Rio de Janeiro, 1992.

BECK, H. \& KÖNIG, G. "Restraining forces in the analysis of tall buildings". Symposium on tall Buildings - Oxford, 1966.

CEOTTO, L. H. "Superestruturas de edificios comerciais e residenciais: análise sucinta de duas alternativas". Notas de aula para exame de qualificação. Escola de Engenharia de São Carlos, Universidade de São Paulo.

COMITÉ EURO-INTERNACIONAL DU BÉTON. Código Modelo do CEB - FIP(1990). COMITÉ EURO-INTERNACIONAL DU BÉTON. Código Modelo do CEB - FIP(1978).

FRANCO, M. "Problemas de estabilidade nos edificios de concreto armado". In: Reunião do IBRACON: Colóquio sobre estabilidade global das estruturas de concreto armado. São Paulo, 22-26 julho, 1985.

FRANCO, M; VASCONCELOS, A.C. "Practical assesment of second order effects in tall buildings". In: Colóquium on the CEB - FIP, Model Code 90. Rio de Janeiro, 1991.

FUSCO, P. B. “Estruturas de Concreto: Solicitações Normais". Rio de Janeiro: Guanabara Dois, 1981.

Mac GREGOR, J. E. \& HAGE, S.E. "Stability analysis and design of concrete frames", J. Structural Division, ASCE, 1977.

Mac GREGOR, J. E. "Reinforced concrete: mechanics and design. $2^{\circ}$ ed. Engewood Cliffs, Prentice-Hall, 1992. 
PINHEIRO, L. M. “Ábacos para flexão obliqua”. São Carlos, 1995. Escola de Engenharia de São Carlos, Universidade de São Paulo.

PRADO, J. F. M. A. "Estruturas de Edificios em Concreto Armado Submetidas Açōes Verticais e Horizontais". São Carlos, 1995. Dissertação de Mestrado - Escola de Engenharia de São Carlos, Universidade de São Paulo.

VASCONCELOS, A. C. "Critérios para dispensa da consideração do efeito de segunda ordem". In: Reunião do IBRACON: Colóquio sobre estabilidade global das estruturas de concreto armado. São Paulo, 22-26 julho, 1985.

VASCONCELOS, A. C. "Como especificar a segurança quando há efeitos de segunda ordem a considerar". Colóquio sobre estabilidade global de estruturas de concreto armado. Porto Alegre, UFRGS, 1987.

VENTURINI, W. S. "Dimensionamento de peças retangulares de concreto armado solicitadas à flexão obliqua". São Carlos, 1990. Escola de Engenharia de São Carlos, Universidade de São Paulo. 


\section{BIBLIOGRAFIAS}

BACARJI, E. "Análise de estruturas de edificios: projeto de pilares". São Carlos, 1993.

Tese de Mestrado - Escola de Engenharia de São Carlos, Universidade de São Paulo.

CARMO, R. M. S. "Efeitos de segunda ordem em edificios de concreto armado". São

Carlos, 1995. Tese de Mestrado - Escola de Engenharia de São Carlos, Universidade de São Paulo.

EVANGELINELIS, K. G. “Aspectos de detalhamento de pilar, segundo o CEB - 90 e a

NBR -6118 , visando sua durabilidade”. In: I Congresso de Eng. Civil da Universidade

Federal de Juiz de Fora. Juiz de Fora, 1995.

FRANÇA, S., LEOPOLDO, R. "Exemplo de cálculo do esforço de segunda ordem global em um edificio de concreto armado". In: Reunião do IBRACON: Colóquio sobre estabilidade global das estruturas de concreto armado. São Paulo, 22-26 julho, 1985.

FUSCO, P. B. "Fundamentos da técnica de armar". São Paulo: Grêmio Politécnico, 1975.

GIONGO, J. S. "Concreto armado estudo de pilares de edificios". Texto de apoio para a disciplina concreto armado II. São Carlos, 1995. Escola de Engenharia de São Carlos, Universidade de São Paulo.

GIONGO, J. S. “Concreto armado: projeto estrutural de edificios”. São Carlos, 1994.

Escola de Engenharia de São Carlos, Universidade de São Paulo.

LEONHARDT, F., MÖNNING, E. "Construçōes de concreto: principios básicos do dimensionamento de estruturas de concreto armado". Rio de Janeiro: Interciência, 1977

PINHEIRO, L. M. "Concreto armado: tabelas e ábacos". São Carlos, 1986. Escola de Engenharia de São Carlos, Universidade de São Paulo.

RODRIGUES, R. O. "Automatização do projeto estrutural de pilares de concreto armado".

São Carlos, 1992. Tese de Mestrado - Escola de Engenharia de São Carlos, Universidade de São Paulo. 


\section{APÊNDICE 1}

Ao se verificar a segurança de uma estrutura quanto aos estados limites últimos, os carregamentos atuantes deverão ser admitidos respeitando as combinações últimas, previstas na NBR - 8681[ ] - Ações e Segurança nas Estruturas.

Para o dimensionamento de pilares de edificios residenciais, no Estado Limite Último, deve-se utilizar as Combinações Últimas Normais pois, são as combinações referentes às ações provenientes do uso da estrutura, ou seja, ações permanentes e variáveis comuns da edificação:

$$
F_{d}=\sum_{i=1}^{m} \gamma_{g i} F_{O i, k}+\gamma_{q}\left[F_{O l . k}+\sum_{j=2}^{n} \psi_{o j} F_{O j . k}\right]
$$

sendo

$F_{\mathrm{d}}$ - valor de cálculo das ações;

$F_{G i . k}$ - valor característico das ações permanentes;

$F_{Q 1, k}$ - valor característico da ação variável considerada como ação principal para a combinação;

$\psi_{o j} F_{Q i, k}$ - valor reduzido de combinação de cada uma das demais ações variáveis.

Utiliza-se, ao todo, cinco combinações para a obtenção dos esforços que permitirão o dimensionamento dos pilares P22 e P13, nos exemplos práticos. A FIGURA AP. 1 apresenta um esquema da planta da edificação, indicando a atuação das açoes 2 e 3 , utilizadas no processamento da estrutura. $O$ carregamento $F_{1}$ corresponde às ações verticais atuantes na estrutura. 


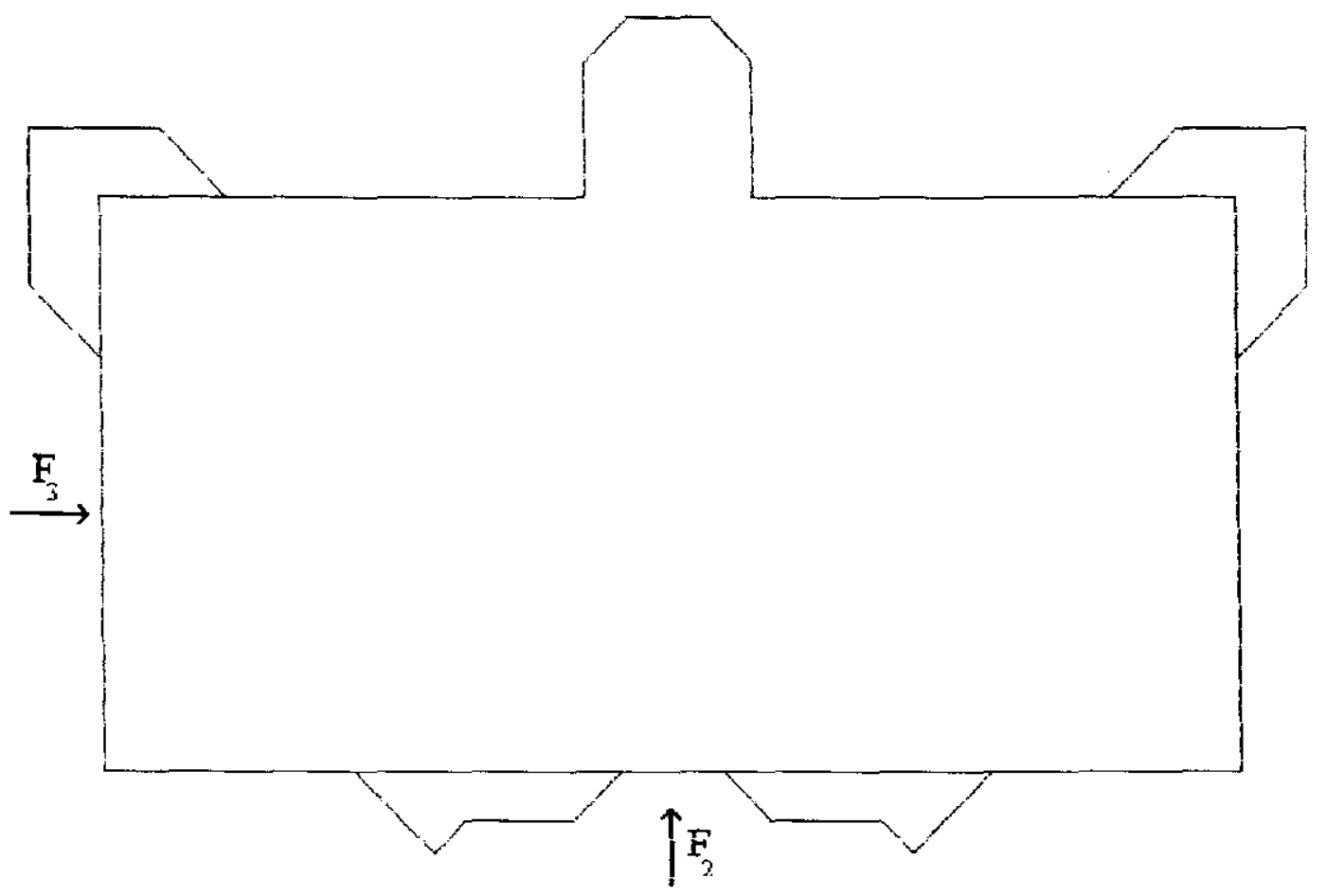

FIGURA AP. 1 - Ação do vento na edificação.

As combinaçōes utilizadas sāo as seguintes:
(1) $1,40 \cdot \mathrm{F}_{1}$
(2) $1,40 \cdot F_{1}+1,40 \cdot 0,60 \cdot F_{2}$
(3) $1,40 \cdot F_{1}-1,40 \cdot 0,60 \cdot F_{2}$
(4) $1,40 \cdot F_{1}+1,40 \cdot 0,60 \cdot F_{3}$
(5) $1,40 \cdot F_{1}-1,40 \cdot 0,60 \cdot F_{3}$

É usual, aproximar a multiplicação $1,400,60=0,84$ para 1,00 . Logo, as combinações finais resultarão em:
(1) $1,40 \cdot F_{1}$
(2) $1,40 \cdot F_{1}+1,00 \cdot F_{2}$
(3) $1,40 \cdot F_{1}-1,00 \cdot F_{2}$
(4) $1,40 \cdot F_{1}+1,00 \cdot F_{3}$
(5) $1,40 \cdot F_{1}-1,00 \cdot F_{3}$ 


\section{LOAD COMBINATION MULTIPLIERS}

\begin{tabular}{|c|c|c|c|}
\cline { 2 - 4 } \multicolumn{1}{c|}{} & \multicolumn{3}{c|}{ LOADS } \\
\hline COMBINATION & 1 & 2 & 3 \\
\hline 1 & 1.40 & 0.00 & 0.00 \\
\hline 2 & 1.40 & 1.00 & 0.00 \\
\hline 3 & 1.40 & -1.00 & 0.00 \\
\hline 4 & 1.40 & 0.00 & 1.00 \\
\hline 5 & 1.40 & 0.00 & -1.00 \\
\hline
\end{tabular}

\section{PILAR P22}

MEMBERS WTTH NUMBERS BETWEEN $1 \& 32000$

\begin{tabular}{|c|c|c|c|c|c|c|c|}
\hline \multirow{2}{*}{$\begin{array}{l}\text { MEM } \\
\text { LOAD }\end{array}$} & \multirow{2}{*}{$\begin{array}{l}\text { AXLAL } \\
\text { FORCE }\end{array}$} & \multirow{2}{*}{$\begin{array}{c}\text { DIST I } \\
\text { (m) }\end{array}$} & \multicolumn{2}{|c|}{1 - 2 PLANE } & \multicolumn{2}{|c|}{ 1-3 PLANE } & \multirow{2}{*}{$\begin{array}{c}\text { AXIAL } \\
\text { TORQUE }\end{array}$} \\
\hline & & & SHEAR & MOMENT & SHEAR & MOMENT & \\
\hline \multirow[t]{3}{*}{1} & -4790.94 & & & & & & 0.01 \\
\hline & & 0.0 & -93.29 & 63.89 & -16.88 & 15.25 & \\
\hline & & 2.8 & -93.29 & -197.33 & -16.88 & -32.01 & \\
\hline \multirow[t]{3}{*}{2} & -4500.90 & & & & & & -4.43 \\
\hline & & 0.0 & -61.11 & -99.31 & -13.54 & 7.10 & \\
\hline & & 2.8 & -61.11 & -270.43 & -13.54 & -30.81 & \\
\hline \multirow[t]{3}{*}{3} & -5080.94 & & & & & & 4.43 \\
\hline & & 0.0 & -125.47 & 227.09 & -20.22 & 23.40 & \\
\hline & & 2.8 & -125.47 & 124.23 & -20.22 & -33.21 & \\
\hline \multirow[t]{3}{*}{4} & -4934.90 & & & & & & 1.20 \\
\hline & & 0.0 & -88.29 & 42.17 & -36.39 & 59.56 & \\
\hline & & 2.8 & -88.29 & -205.06 & -36.39 & -42.31 & \\
\hline \multirow[t]{3}{*}{5} & -4646.97 & & & & & & -1.20 \\
\hline & & 0.0 & -98.29 & 85.60 & 12.27 & -29.06 & \\
\hline & & 2.8 & -98.29 & -189.60 & 12.27 & -21.70 & \\
\hline & -4539.96 & & & & & & 0.01 \\
\hline & & 0.0 & -46.74 & 163.11 & -31.90 & 45.58 & \\
\hline & & 2.8 & -46.74 & 32.23 & -31.90 & -43.74 & \\
\hline
\end{tabular}




\begin{tabular}{|c|c|c|c|c|c|c|c|}
\hline 2 & -4257.07 & & & & & & -4.74 \\
\hline & & 0.0 & -21.70 & 64.79 & -27.56 & -27.54 & \\
\hline & & 2.8 & -21.70 & -4.02 & -27.56 & -27.04 & \\
\hline 3 & -4822.85 & & & & & & 4.74 \\
\hline & & 0.0 & -81.80 & 261.42 & -36.24 & 52.19 & \\
\hline & & 2.8 & -81.80 & 60.43 & -36.24 & -50.71 & \\
\hline 4 & -4669.87 & & & & & & 1.29 \\
\hline & & 0.0 & -42.80 & 155.03 & -48.19 & 74.08 & \\
\hline & & 2.8 & -42.80 & 35.20 & -48.19 & -60.87 & \\
\hline 5 & -4410.05 & & & & & & -1.29 \\
\hline & & 0.0 & -52.27 & 171.19 & -15.61 & 17.08 & \\
\hline & & 2.8 & -52.27 & 29.25 & -15.61 & 26.61 & \\
\hline 1 & -4268.74 & & & & & & 0.02 \\
\hline & & 0.0 & -266.63 & 400.56 & -22.08 & 45.36 & \\
\hline & & 5.1 & -266.63 & -959.23 & -22.08 & -67.23 & \\
\hline 2 & -3995.73 & & & & & & -4.62 \\
\hline & & 0.0 & -209.83 & 333.79 & -19.98 & 41.96 & \\
\hline & & 5.1 & -209.83 & -736.35 & -19.98 & 59.95 & \\
\hline 3 & -4541.74 & & & & & & 4.62 \\
\hline & & 0.0 & -323.42 & 467.33 & -24.17 & 48.76 & \\
\hline & & 5.1 & -323.42 & -1182.12 & -24.17 & -74.52 & \\
\hline 4 & -4379.68 & & & & & & 1.24 \\
\hline & & 0.0 & -266.29 & 403.54 & -39.90 & 80.07 & \\
\hline & & 5.1 & -266.29 & -954.52 & -39.90 & -123.42 & \\
\hline 5 & -4002.48 & & & & & & -1.24 \\
\hline & & 0.0 & -266.97 & 397.58 & 8.37 & -10.65 & \\
\hline & & 5.1 & -266.97 & -963.94 & 8.37 & 11.42 & \\
\hline 1 & -2742.67 & & & & & & -0.02 \\
\hline & & 0.0 & -354.90 & 767.16 & -16.28 & 21.93 & \\
\hline & & 2.8 & -354.90 & -226.57 & -16.28 & -23.66 & \\
\hline 2 & -2544.29 & & & & & & -1.48 \\
\hline & & 0.0 & -313.07 & 649.05 & -15.58 & 20.84 & \\
\hline & & 2.8 & -313.07 & -227.56 & -15.58 & -22.79 & \\
\hline 3 & -2941.04 & & & & & & 1.48 \\
\hline & & 0.0 & -396.73 & 885.27 & -16.98 & 23.02 & \\
\hline & & 2.8 & -396.73 & -225.58 & -16.98 & -24.53 & \\
\hline 4 & -2813.10 & & & & & & 0.43 \\
\hline & & 0.0 & -358.84 & 773.53 & -26.10 & 37.10 & \\
\hline & & 2.8 & -358.84 & -231.23 & -26.10 & -35.98 & \\
\hline 5 & -2672.23 & & & & & & -0.43 \\
\hline & & 0.0 & -350.96 & 760.79 & -6.47 & 6.76 & \\
\hline & & 2.8 & -350.96 & -220.05 & -6.47 & -11.35 & \\
\hline I & -2564.12 & & & & & & -0.01 \\
\hline & & $\begin{array}{l}0.0 \\
2.8\end{array}$ & $\begin{array}{l}-19.40 \\
-19.40\end{array}$ & $\begin{array}{l}-13.44 \\
-6775\end{array}$ & $\begin{array}{l}-19.10 \\
-1910\end{array}$ & $\begin{array}{r}26.27 \\
-27.21\end{array}$ & \\
\hline
\end{tabular}




\begin{tabular}{|c|c|c|c|c|c|c|c|}
\hline 2 & -2382.96 & & & & & & -1.49 \\
\hline & & 0.0 & 3.67 & -58.70 & -18.16 & 24.94 & \\
\hline & & 2.8 & 3.67 & -48.43 & -18.16 & -25.92 & \\
\hline 3 & -2745.28 & & & & & & 1.48 \\
\hline & & 0.0 & -42.46 & 31.83 & -20.04 & 27.60 & \\
\hline & & 2.8 & -42.46 & -87.07 & -20.04 & $-28.5 \mathrm{I}$ & \\
\hline 4 & -2625.23 & & & & & & 0.42 \\
\hline & & 0.0 & -18.32 & -16.45 & -28.43 & 39.36 & \\
\hline & & 2.8 & -18.32 & -67.74 & -28.43 & -40.25 & \\
\hline 5 & -2503.01 & & & & & & -0.42 \\
\hline & & 0.0 & -20.48 & -10.42 & -9.77 & 13.19 & \\
\hline & & 2.8 & -20.48 & -67.75 & -9.77 & -14.17 & \\
\hline I & -2388.62 & & & & & & 0.00 \\
\hline & & 0.0 & -78.45 & 124.35 & -21.02 & 28.99 & \\
\hline & & 2.8 & -78.45 & -95.31 & -21.02 & -29.86 & \\
\hline 2 & -2226.88 & & & & & & -1.47 \\
\hline & & 0.0 & -59.18 & 93.44 & -20.08 & 27.69 & \\
\hline & & 2.8 & -59.18 & -72.25 & -20.08 & -28.53 & \\
\hline 3 & -2550.36 & & & & & 7020 & 1.46 \\
\hline & & 0.0 & -97.72 & 155.26 & -21.96 & 30.29 & \\
\hline & 240001 & 2.8 & -97.72 & -114.30 & -21.96 & -31.19 & \\
\hline 4 & -2440.91 & & & & & & 0.41 \\
\hline & & 0.0 & -78.57 & 124.89 & -29.67 & 41.02 & \\
\hline 5 & -244090 & 2.8 & -78.57 & -95.12 & -29.67 & -42.04 & 048 \\
\hline & & 00 & -7833 & $\mathrm{I} 238 \mathrm{I}$ & -1237 & 1605 & -0.41 \\
\hline & & 2.8 & $\begin{array}{l}-10.52 \\
-78.33\end{array}$ & $\begin{array}{l}125.01 \\
-95.51\end{array}$ & -12.37 & 16.95 & \\
\hline 97 & & & & & & & \\
\hline I & -2210.09 & & & & & & 0.00 \\
\hline & & 0.0 & -67.62 & 99.03 & -22.74 & 31.46 & \\
\hline & & 2.8 & -67.62 & -90.30 & -22.74 & -32.22 & \\
\hline 2 & -2068.23 & & & & & & -1.39 \\
\hline & & 0.0 & -48.07 & 70.72 & -21.89 & 30.29 & \\
\hline 3 & 235105 & 2.8 & -48.07 & -63.88 & -21.89 & -31.01 & 39 \\
\hline$J$ & -2531.95 & 00 & -87.16 & 127.34 & -23.59 & 32.63 & \\
\hline & & 2.8 & -87.16 & -116.72 & -23.59 & -33.43 & \\
\hline 4 & -2497.03 & & & & & & 0.39 \\
\hline & & 0.0 & -67.69 & 99.64 & -30.68 & 42.49 & \\
\hline & & 2.8 & -67.69 & -89.90 & -30.68 & -43.43 & \\
\hline 5 & -2542.53 & & & & & & -0.39 \\
\hline & & 0.0 & -67.54 & 98.42 & -14.80 & 20.43 & \\
\hline & & 2.8 & -67.54 & -90.69 & -14.80 & -21.01 & \\
\hline 1 & -2029.87 & & & & & & 0.00 \\
\hline & & 0.0 & -69.22 & 102.53 & -24.25 & 33.62 & \\
\hline & & 2.8 & -69.22 & -91.28 & -24.25 & -34.29 & \\
\hline
\end{tabular}




\begin{tabular}{|c|c|c|c|c|c|c|c|}
\hline \multirow[t]{3}{*}{2} & -1907.54 & & & & & & -1.27 \\
\hline & & 0.0 & -50.73 & 78.27 & -23.51 & 32.60 & \\
\hline & & 2.8 & -50.73 & -63.76 & -23.51 & -33.24 & \\
\hline \multirow[t]{3}{*}{3} & -2152.19 & & & & & & 1.27 \\
\hline & & 0.0 & -87.71 & 126.78 & -24.99 & 36.05 & \\
\hline & & 2.8 & -87.71 & -118.81 & -24.99 & -35.34 & \\
\hline \multirow[t]{3}{*}{4} & -2066.67 & & & & & & 0.36 \\
\hline & & 0.0 & -69.38 & 103.34 & -31.50 & 43.68 & \\
\hline & & 2.8 & -69.38 & -90.93 & -31.50 & -44.53 & \\
\hline \multirow[t]{3}{*}{5} & -1993.06 & & & & & & -0.36 \\
\hline & & 0.0 & -69.06 & 101.72 & -17.00 & 23.56 & \\
\hline & & 2.8 & -69.06 & -91.64 & -17.00 & -24.04 & \\
\hline \multirow[t]{3}{*}{1} & -1847.97 & & & & & & 0.00 \\
\hline & & 0.0 & -68.64 & 100.88 & -25.58 & 35.51 & \\
\hline & & 2.8 & -68.64 & -91.32 & -25.58 & -36.10 & \\
\hline \multirow[t]{3}{*}{2} & -1744.28 & & & & & & -1.12 \\
\hline & & 0.0 & -51.34 & 79.85 & -24.96 & 34.66 & \\
\hline & & 2.8 & -51.34 & -63.91 & -24.96 & -35.22 & \\
\hline \multirow[t]{3}{*}{3} & -2096.82 & & & & & & 1.12 \\
\hline & & 0.0 & -85.92 & 121.91 & -26.19 & 36.37 & \\
\hline & & 2.8 & -85.92 & -118.73 & -26.19 & -36.98 & \\
\hline \multirow[t]{3}{*}{4} & -1878.06 & & & & & & 0.32 \\
\hline & & 0.0 & -68.82 & 101.72 & -32.15 & 44.62 & \\
\hline & & 2.8 & -68.82 & -90.98 & -32.15 & $-45.4 \mathrm{I}$ & \\
\hline \multirow[t]{3}{*}{5} & -1817.88 & & & & & & -0.32 \\
\hline & & 0.0 & -68.46 & 100.04 & -19.00 & 26.41 & \\
\hline & & 2.8 & -68.46 & -91.66 & -19.00 & -13.76 & \\
\hline \multirow[t]{3}{*}{1} & -1664.65 & & & & & & 0.00 \\
\hline & & 0.0 & -68.48 & 100.17 & -26.73 & 37.17 & \\
\hline & & 2.8 & -68.48 & -91.58 & -26.73 & -37.68 & \\
\hline \multirow[t]{3}{*}{2} & $-\mathrm{I} 578.40$ & & & & & & -0.97 \\
\hline & & 0.0 & -52.44 & 74.68 & -26.24 & 36.48 & \\
\hline & & 2.8 & -52.44 & -54.18 & -26.24 & -36.97 & \\
\hline \multirow[t]{3}{*}{3} & $-[750.89$ & & & & & & 0.97 \\
\hline & & 0.0 & -84.52 & 125.66 & -27.23 & 37.85 & \\
\hline & & 2.8 & -84.52 & -128.98 & -27.23 & -38.39 & \\
\hline \multirow[t]{3}{*}{4} & -1688.69 & & & & & & 0.29 \\
\hline & & 0.0 & -68.73 & 101.46 & -32.58 & 45.25 & \\
\hline & & 2.8 & -68.73 & -91.25 & -32.58 & -45.99 & \\
\hline \multirow[t]{3}{*}{5} & -1640.61 & & & & & & -0.29 \\
\hline & & 0.0 & -68.24 & 98.87 & -20.88 & 29.09 & \\
\hline & & 2.8 & -68.24 & -91.91 & -20.88 & 29.37 & \\
\hline \multirow[t]{3}{*}{1} & -1480.09 & & & & & & 0.00 \\
\hline & & 0.0 & -68.28 & 99.35 & -27.73 & 38.60 & \\
\hline & & 2.8 & -68.28 & -91.83 & -27.73 & -39.04 & \\
\hline
\end{tabular}




\begin{tabular}{|c|c|c|c|c|c|c|c|}
\hline \multirow[t]{3}{*}{2} & -1238.80 & & & & & & -0.83 \\
\hline & & 0.0 & -53.60 & 83.89 & -27.35 & 38.08 & \\
\hline & & 2.8 & -53.60 & -66.20 & -27.35 & -38.50 & \\
\hline \multirow[t]{3}{*}{3} & -1350.12 & & & & & & 0.83 \\
\hline & & 0.0 & -82.95 & $114.8 \mathrm{I}$ & -28.11 & 39.12 & \\
\hline & & 2.8 & -82.95 & -117.07 & -28.11 & -39.58 & \\
\hline \multirow[t]{3}{*}{4} & -1308.42 & & & & & & 0.24 \\
\hline & & 0.0 & -68.56 & 100.26 & -32.87 & 45.69 & \\
\hline & & 2.8 & -68.56 & -91.71 & -32.87 & -46.35 & \\
\hline \multirow[t]{3}{*}{5} & -1280.50 & & & & & & -0.24 \\
\hline & & 0.0 & -67.99 & 98.44 & -22.59 & 31.52 & \\
\hline & & 2.8 & -67.99 & -91.94 & -22.59 & -31.73 & \\
\hline \multirow[t]{3}{*}{1} & -1294.46 & & & & & & 0.00 \\
\hline & & 0.0 & -68.12 & 98.61 & -28.59 & 39.84 & \\
\hline & & 2.8 & -68.12 & -92.11 & -28.59 & -40.21 & \\
\hline \multirow[t]{3}{*}{2} & -1238.80 & & & & & & -0.70 \\
\hline & & 0.0 & -54.92 & 85.88 & -28.32 & 39.46 & \\
\hline & & 2.8 & -54.92 & -67.89 & -28.32 & -39.82 & \\
\hline \multirow[t]{3}{*}{3} & -1350.12 & & & & & & 0.70 \\
\hline & & 0.0 & -81.31 & 111.34 & -28.86 & 40.36 & \\
\hline & & 2.8 & -81.31 & -116.33 & -28.86 & -40.76 & \\
\hline \multirow[t]{3}{*}{4} & -1308.42 & & & & & & 0.21 \\
\hline & & 0.0 & -68.43 & 99.49 & -33.03 & 40.21 & \\
\hline & & 2.8 & -68.43 & -92.08 & -33.03 & -46.55 & \\
\hline \multirow[t]{3}{*}{5} & -1280.50 & & & & & & -0.21 \\
\hline & & 0.0 & -67.81 & 97.74 & -24.15 & 33.75 & \\
\hline & & 2.8 & -67.81 & -92.17 & -24.15 & -33.88 & \\
\hline 103 & & & & & & & \\
\hline \multirow[t]{3}{*}{1} & -1107.93 & & & & & & 0.00 \\
\hline & & 0.0 & -67.97 & 97.93 & -29.32 & 40.89 & \\
\hline & & 2.8 & -67.97 & -92.40 & -29.32 & -41.20 & \\
\hline \multirow[t]{3}{*}{2} & -1065.18 & & & & & & -0.58 \\
\hline & & 0.0 & -56.34 & 87.90 & -29.14 & 40.65 & \\
\hline & & 2.8 & -56.34 & -69.84 & -29.14 & -40.95 & \\
\hline \multirow[t]{3}{*}{3} & -1150.68 & & & & & & 0.58 \\
\hline & & 0.0 & -79.61 & 107.95 & -29.50 & 41.13 & \\
\hline & & 2.8 & -79.61 & -114.96 & -29.50 & -41.46 & \\
\hline \multirow[t]{3}{*}{4} & -1117.85 & & & & & & 0.17 \\
\hline & & 0.0 & -68.29 & 98.74 & -33.06 & 46.01 & \\
\hline & & 2.8 & -68.29 & -92.40 & -33.06 & -46.56 & \\
\hline \multirow[t]{3}{*}{5} & -1084.12 & & & & & & -0.17 \\
\hline & & 0.0 & -67.22 & 97.12 & -25.88 & 35.77 & \\
\hline & & 2.8 & -67.22 & -92.33 & -25.88 & -35.84 & \\
\hline \multirow{4}{*}{1} & & & & & & & \\
\hline & -920.63 & & & & & & 0.00 \\
\hline & & 0.0 & $\begin{array}{l}-67.90 \\
-6700\end{array}$ & 97.31 & -29.93 & 41.76 & \\
\hline & & 2.8 & -67.90 & -92.82 & -29.93 & -42.03 & \\
\hline
\end{tabular}




\begin{tabular}{|c|c|c|c|c|c|c|c|}
\hline \multirow[t]{3}{*}{2} & -889.12 & & & & & & -0.48 \\
\hline & & 0.0 & -57.89 & 89.94 & -29.83 & 41.63 & \\
\hline & & 2.8 & -57.89 & -72.16 & -29.83 & -41.89 & \\
\hline \multirow[t]{3}{*}{3} & -952.14 & & & & & & 0.48 \\
\hline & & 0.0 & -77.91 & 104.67 & -30.02 & 41.90 & \\
\hline & & 2.8 & -77.91 & -113.48 & -30.02 & -41.80 & \\
\hline \multirow[t]{3}{*}{4} & -927.19 & & & & & & 0.14 \\
\hline & & 0.0 & -23.92 & 98.06 & -32.98 & 45.92 & \\
\hline & & 2.8 & -23.92 & -92.96 & -32.98 & -46.42 & \\
\hline \multirow[t]{3}{*}{5} & -904.91 & & & & & & -0.14 \\
\hline & & 0.0 & -23.31 & 96.57 & -26.87 & 37.61 & \\
\hline & & 2.8 & -23.31 & -92.68 & -26.87 & -40.27 & \\
\hline \multirow[t]{3}{*}{ I } & -732.71 & & & & & & 0.00 \\
\hline & & 0.0 & -67.63 & 96.63 & -30.41 & 42.47 & \\
\hline & & 2.8 & -67.63 & -92.73 & -30.41 & -42.67 & \\
\hline \multirow[t]{3}{*}{2} & -710.71 & & & & & & -0.39 \\
\hline & & 0.0 & -59.29 & 91.82 & -30.38 & 42.44 & \\
\hline & & 2.8 & -59.29 & -74.20 & -30.38 & -42.63 & \\
\hline \multirow[t]{3}{*}{3} & -754.71 & & & & & & 0.39 \\
\hline & & 0.0 & -75.96 & 101.44 & -30.43 & 42.51 & \\
\hline & & 2.8 & -75.96 & -111.25 & -30.43 & -42.71 & \\
\hline \multirow[t]{3}{*}{4} & -736.57 & & & & & & 0.12 \\
\hline & & 0.0 & -67.93 & 97.28 & -32.77 & 45.66 & \\
\hline & & 2.8 & -67.93 & -92.92 & -32.77 & -46.11 & \\
\hline \multirow[t]{3}{*}{5} & -728.85 & & & & & & -0.12 \\
\hline & & 0.0 & -67.33 & 95.98 & -24.72 & 39.28 & \\
\hline & & 2.8 & -67.33 & -92.54 & -24.72 & -39.23 & \\
\hline \multirow[t]{3}{*}{ I } & -544.24 & & & & & & -0.01 \\
\hline & & 0.0 & -68.56 & 96.62 & -30.86 & 43.09 & \\
\hline & & 2.8 & -68.56 & -95.36 & -30.86 & -43.31 & \\
\hline \multirow[t]{3}{*}{2} & -530.03 & & & & & & -0.30 \\
\hline & & 0.0 & -61.97 & 94.18 & -30.89 & 43.13 & \\
\hline & 550 & 2.8 & -61.97 & -79.33 & -30.89 & -43.36 & \\
\hline \multirow[t]{2}{*}{3} & -558.44 & & & & & & 0.30 \\
\hline & & $\begin{array}{l}0.0 \\
2.8\end{array}$ & $\begin{array}{l}-75.16 \\
-7516\end{array}$ & $\begin{array}{r}99.06 \\
-1140\end{array}$ & $\begin{array}{l}-30.82 \\
-3087\end{array}$ & $\begin{array}{c}43.04 \\
-4327\end{array}$ & \\
\hline \multirow[t]{3}{*}{4} & -546.10 & & & & & & 0.10 \\
\hline & & 0.0 & -68.85 & 97.16 & -32.54 & 45.32 & \\
\hline & & 2.8 & -68.85 & -95.61 & -32.54 & -45.79 & \\
\hline \multirow[t]{3}{*}{5} & -542.38 & & & & & & -0.10 \\
\hline & & 0.0 & -67.89 & 96.08 & -29.17 & 40.85 & \\
\hline & 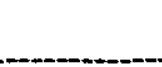 & 2.8 & -67.89 & -95.18 & -29.17 & -40.84 & \\
\hline \multirow[t]{3}{*}{1} & -355.57 & & & & & & 0.00 \\
\hline & & 0.0 & -62.87 & 93.55 & -30.54 & 43.02 & \\
\hline & & 2.8 & -62.87 & -82.49 & -30.54 & -42.49 & \\
\hline
\end{tabular}




\begin{tabular}{|c|c|c|c|c|c|c|c|}
\hline \multirow[t]{3}{*}{2} & -347.49 & & & & & & -0.21 \\
\hline & & 0.0 & -58.02 & 93.03 & -30.62 & 43.13 & \\
\hline & & 2.8 & -58.02 & -69.42 & -30.62 & -42.60 & \\
\hline \multirow[t]{3}{*}{3} & -363.64 & & & & & & 0.21 \\
\hline & & 0.0 & -67.73 & 94.08 & -30.46 & 42.91 & \\
\hline & & 2.8 & -67.73 & -95.57 & -30.46 & -42.39 & \\
\hline \multirow[t]{3}{*}{4} & -356.11 & & & & & & 0.07 \\
\hline & & 0.0 & -63.08 & 93.94 & -31.55 & 44.31 & \\
\hline & & 2.8 & -63.08 & -82.69 & -31.55 & -44.03 & \\
\hline \multirow[t]{3}{*}{5} & -355.02 & & & & & & -0.07 \\
\hline & & 0.0 & -62.66 & 92.62 & -29.53 & 41.74 & \\
\hline & & 2.8 & -62.66 & -82.30 & -29.53 & -40.95 & \\
\hline \multirow[t]{3}{*}{1} & -164.99 & & & & & & -0.02 \\
\hline & & 0.0 & -100.97 & 108.64 & -36.39 & 47.91 & \\
\hline & & 2.8 & -100.97 & -174.07 & -36.39 & -53.98 & \\
\hline \multirow[t]{3}{*}{2} & -161.55 & & & & & & -0.12 \\
\hline & & 0.0 & -97.84 & 109.12 & -36.51 & 48.07 & \\
\hline & & 2.8 & -97.84 & -164.83 & $-36.5 \mathrm{I}$ & -54.15 & \\
\hline \multirow[t]{3}{*}{3} & -168.43 & & & & & & 0.12 \\
\hline & & 0.0 & -104.10 & 108.17 & -36.26 & 47.74 & \\
\hline & & 2.8 & -104.10 & -183.31 & -36.26 & -53.80 & \\
\hline \multirow[t]{3}{*}{4} & $-\mathrm{I} 64.94$ & & & & & & 0.05 \\
\hline & & 0.0 & -101.21 & 108.95 & -36.61 & 48.16 & \\
\hline & & 2.8 & -101.21 & -174.43 & -36.61 & -54.35 & \\
\hline \multirow[t]{3}{*}{5} & -165.03 & & & & & & -0.03 \\
\hline & & 0.0 & -100.73 & 107.90 & -35.84 & 47.65 & \\
\hline & & 2.8 & -100.73 & $-173.7 \mathrm{I}$ & -35.84 & -53.60 & \\
\hline
\end{tabular}




\section{PILAR P13}

\section{MEMBERS WITH NUMBERS BETWEEN $1 \& 32000$}

\begin{tabular}{|c|c|c|c|c|c|c|c|}
\hline \multirow{2}{*}{$\begin{array}{l}\text { MEM } \\
\text { LOAD }\end{array}$} & \multirow{2}{*}{$\begin{array}{l}\text { AXIAL } \\
\text { FORCE }\end{array}$} & \multirow{2}{*}{$\begin{array}{c}\text { DIST I } \\
\text { (m) }\end{array}$} & \multicolumn{2}{|c|}{1 - 2 PLANE } & \multicolumn{2}{|c|}{ 1 - 3 PLANE } & \multirow{2}{*}{$\begin{array}{c}\text { AXIAL } \\
\text { TORQUE }\end{array}$} \\
\hline & & & SHEAR & MOMENT & SHEAR & MOMENT & \\
\hline \multirow[t]{3}{*}{ I } & -2523.78 & & & & & & 0.00 \\
\hline & & 0.0 & -191.91 & 355.29 & -10.91 & 10.20 & \\
\hline & & 2.8 & -191.91 & -182.05 & -10.91 & -20.36 & \\
\hline \multirow[t]{3}{*}{2} & -2679.44 & & & & & & 0.25 \\
\hline & & 0.0 & -128.24 & 218.33 & -9.44 & 8.52 & \\
\hline & & 2.8 & -128.24 & -140.73 & -9.44 & -17.91 & \\
\hline \multirow[t]{3}{*}{3} & -2367.91 & & & & & & -0.25 \\
\hline & & 0.0 & -255.58 & 492.25 & -12.38 & 11.87 & \\
\hline & & 2.8 & -255.58 & -223.37 & -12.38 & -22.81 & \\
\hline \multirow[t]{3}{*}{4} & -2504.23 & & & & & & -0.07 \\
\hline & & 0.0 & -192.85 & 357.68 & -28.98 & $41.2 \mathrm{I}$ & \\
\hline & & 2.8 & -192.85 & -182.30 & -28.98 & -39.94 & \\
\hline \multirow[t]{3}{*}{5} & -2543.32 & & & & & & 0.07 \\
\hline & & 0.0 & -190.97 & 352.90 & 13.40 & -26.64 & \\
\hline & & 2.8 & -190.97 & -181.79 & 13.40 & 10.86 & \\
\hline \multirow[t]{3}{*}{1} & -2415.00 & & & & & & 0.00 \\
\hline & & 0.0 & $-6 I .00$ & 78.28 & -19.51 & 28.24 & \\
\hline & & 2.8 & -61.00 & -92.52 & -19.51 & -26.38 & \\
\hline \multirow[t]{3}{*}{2} & -2542.63 & & & & & & 0.18 \\
\hline & & 0.0 & -21.22 & -27.89 & -16.93 & 24.60 & \\
\hline & & 2.8 & -21.22 & -42.58 & -16.93 & -22.81 & \\
\hline \multirow[t]{3}{*}{3} & -2287.37 & & & & & & -0.25 \\
\hline & & 0.0 & -100.78 & 139.72 & -22.08 & 31.87 & \\
\hline & & 2.8 & -100.78 & -142.46 & -22.08 & -29.95 & \\
\hline \multirow[t]{3}{*}{4} & -2397.90 & & & & & & -0.07 \\
\hline & & 0.0 & -61.88 & 79.69 & -32.38 & 45.88 & \\
\hline & & 2.8 & -61.88 & -93.57 & -32.38 & -44.79 & \\
\hline \multirow[t]{3}{*}{5} & -2432.09 & & & & & & 0.07 \\
\hline & & 0.0 & -60.12 & 76.87 & -6.63 & 10.60 & \\
\hline & & 2.8 & -60.12 & -91.05 & -6.63 & -7.97 & \\
\hline \multirow[t]{3}{*}{1} & -2276.71 & & & & & & 0.00 \\
\hline & & 0.0 & -73.66 & 109.26 & -17.49 & 24.53 & \\
\hline & & 2.8 & -73.66 & -96.99 & -17.49 & -24.44 & \\
\hline \multirow[t]{3}{*}{2} & -2374.97 & & & & & & 0.38 \\
\hline & & 0.0 & -32.80 & 50.09 & -14.86 & 20.91 & \\
\hline & & 2.8 & -32.80 & -41.75 & -14.86 & -20.70 & \\
\hline \multirow[t]{3}{*}{3} & -2178.45 & & & & & & -0.38 \\
\hline & & 0.0 & -114.52 & 168.42 & -20.12 & 28.14 & \\
\hline & & 2.8 & -114.52 & -152.23 & -20.12 & -28.18 & \\
\hline
\end{tabular}




\begin{tabular}{|c|c|c|c|c|c|c|c|}
\hline 4 & -2262.35 & & & & & & -0.07 \\
\hline & & 0.0 & -74.42 & 110.29 & -29.95 & 41.66 & \\
\hline & & 2.8 & -74.42 & -98.09 & -29.95 & -42.20 & \\
\hline 5 & -2291.07 & & & & & & 0.10 \\
\hline & & 0.0 & -72.90 & 108.23 & -5.03 & 7.40 & \\
\hline & & 2.8 & -72.90 & -95.88 & -5.03 & 6.68 & \\
\hline I & -2131.54 & & & & & & 0.00 \\
\hline & & 0.0 & -66.59 & 97.12 & -17.07 & 24.05 & \\
\hline & & 2.8 & -66.59 & -89.34 & -17.07 & -23.74 & \\
\hline 2 & -2202.60 & & & & & & 0.44 \\
\hline & & 0.0 & -28.61 & 44.81 & -14.38 & 20.33 & \\
\hline & & 2.8 & -28.61 & -35.30 & -14.38 & -19.95 & \\
\hline 3 & -2060.49 & & & & & & -0.25 \\
\hline & & 0.0 & -104.58 & 149.44 & -19.76 & 27.78 & \\
\hline & & 2.8 & -104.58 & -143.37 & -19.76 & -27.53 & \\
\hline 4 & -2119.60 & & & & & & -0.12 \\
\hline & & 0.0 & -67.18 & 97.83 & -28.59 & 39.79 & \\
\hline & & 2.8 & -67.18 & -90.28 & -28.59 & -40.26 & \\
\hline 5 & -2143.49 & & & & & & 0.12 \\
\hline & & 0.0 & -66.00 & 96.42 & -5.55 & 8.31 & \\
\hline & & 2.8 & -66.00 & -88.40 & -5.55 & 7.22 & \\
\hline I & -1977.65 & & & & & & 0.00 \\
\hline & & 0.0 & -63.09 & 92.05 & -16.49 & 23.22 & \\
\hline & & 2.8 & -63.09 & -84.61 & -16.49 & -22.97 & \\
\hline 2 & -2024.95 & & & & & & 0.44 \\
\hline & & 0.0 & -28.28 & 45.34 & -13.85 & 19.55 & \\
\hline & & 2.8 & -28.28 & -33.84 & -13.85 & -19.25 & \\
\hline 3 & -1930.36 & & & & & & -0.44 \\
\hline & & 0.0 & -97.91 & 138.77 & -19.13 & 26.88 & \\
\hline$\Delta$ & 106784 & 2.8 & -97.91 & -135.38 & -19.13 & -26.69 & 013 \\
\hline+ & -1907.04 & 00 & -6351 & 9250 & -27.18 & 3780 & -0.13 \\
\hline & & 2.8 & -63.51 & $\begin{array}{r}-85.34 \\
-850\end{array}$ & -27.18 & -38.32 & \\
\hline 5 & -1987.46 & & & & & & 0.13 \\
\hline & & 0.0 & -62.67 & 91.60 & -5.80 & 8.63 & \\
\hline & & 2.8 & -62.67 & -83.88 & -5.80 & -7.62 & \\
\hline 1 & -1816.79 & & & & & & 0.00 \\
\hline & & 0.0 & -59.77 & 86.96 & -16.01 & 22.52 & \\
\hline & & 2.8 & -59.77 & $-80.4 \mathrm{I}$ & -16.01 & -22.30 & \\
\hline 2 & -1844.07 & & & & & & 0.41 \\
\hline & & 0.0 & -28.30 & 45.62 & -13.45 & 18.96 & \\
\hline & & 2.8 & -28.30 & -33.62 & -13.45 & -18.70 & \\
\hline 3 & -1789.51 & & & & & & -0.41 \\
\hline & & $\begin{array}{l}0.0 \\
2.8\end{array}$ & $\begin{array}{l}-91.25 \\
-91.25\end{array}$ & $\begin{array}{r}128.29 \\
-127.21\end{array}$ & $\begin{array}{l}-18.57 \\
-18.57\end{array}$ & $\begin{array}{c}26.09 \\
-25.90\end{array}$ & \\
\hline
\end{tabular}




\begin{tabular}{|c|c|c|c|c|c|c|c|}
\hline \multirow{3}{*}{4} & -1808.85 & & & & & & \multirow[t]{3}{*}{-0.11} \\
\hline & & 0.0 & -60.05 & 87.20 & -25.86 & 35.91 & \\
\hline & & 2.8 & -60.05 & -80.94 & -25.86 & -36.49 & \\
\hline \multirow[t]{3}{*}{5} & -1824.73 & & & & & & \multirow[t]{3}{*}{0.11} \\
\hline & & 0.0 & -59.50 & 86.72 & -6.16 & 9.13 & \\
\hline & & 2.8 & -59.50 & -79.88 & -6.16 & -8.11 & \\
\hline \multirow[t]{3}{*}{1} & -1649.93 & & & & & & \multirow[t]{3}{*}{0.00} \\
\hline & & 0.0 & -57.00 & 82.67 & -15.57 & 21.90 & \\
\hline & & 2.8 & -57.00 & -76.92 & -15.57 & -21.70 & \\
\hline \multirow[t]{3}{*}{2} & -1660.90 & & & & & & \multirow[t]{3}{*}{0.36} \\
\hline & & 0.0 & -29.14 & 46.85 & -13.12 & 18.48 & \\
\hline & & 2.8 & -29.14 & -34.75 & -13.12 & -18.26 & \\
\hline \multirow{3}{*}{3} & -1638.95 & & & & & & \multirow[t]{3}{*}{-0.36} \\
\hline & & 0.0 & -84.86 & 118.50 & -18.02 & 25.32 & \\
\hline & -1643.62 & 2.8 & -84.86 & -119.10 & -18.02 & -25.14 & \\
\hline \multirow{2}{*}{4} & & 0.0 & -57.14 & 82.72 & -24.48 & 3395 & \multirow{2}{*}{-0.11} \\
\hline & & 2.8 & -57.14 & -77.26 & -24.48 & -34.59 & \\
\hline \multirow[t]{3}{*}{5} & -1656.24 & & & & & & \multirow[t]{3}{*}{$0.1 \mathrm{I}$} \\
\hline & & 0.0 & -56.86 & 82.63 & -6.66 & 9.85 & \\
\hline & & 2.8 & -56.86 & -76.59 & -6.66 & -8.81 & \\
\hline \multirow[t]{3}{*}{1} & -1477.99 & & & & & & \multirow[t]{3}{*}{0.00} \\
\hline & & 0.0 & -54.65 & 79.01 & -15.19 & 21.35 & \\
\hline & & 2.8 & -54.65 & -74.02 & -15.19 & -21.18 & \\
\hline \multirow[t]{3}{*}{2} & -1476.23 & & & & & & \multirow[t]{3}{*}{0.31} \\
\hline & & 0.0 & -30.31 & 48.32 & -12.87 & 18.10 & \\
\hline & -147075 & 2.8 & -30.31 & -36.53 & -12.87 & -17.92 & \\
\hline \multirow{2}{*}{3} & $-1+19.15$ & & -79.00 & & & & \multirow{2}{*}{-0.31} \\
\hline & & $\begin{array}{l}2.0 \\
2.8\end{array}$ & $\begin{array}{l}-79.00 \\
-79.00\end{array}$ & -111.50 & -17.51 & $\begin{array}{l}24.00 \\
-24.44\end{array}$ & \\
\hline \multirow[t]{3}{*}{4} & -1473.06 & & & & & & \multirow[t]{3}{*}{-0.09} \\
\hline & & 0.0 & -54.66 & 78.90 & -23.16 & 32.09 & \\
\hline & & 2.8 & -54.66 & -74.16 & -23.16 & -32.77 & \\
\hline \multirow[t]{3}{*}{5} & -1482.92 & & & & & & \multirow[t]{3}{*}{0.09} \\
\hline & & 0.0 & -54.64 & 79.12 & -7.22 & 10.61 & \\
\hline & & 2.8 & -54.64 & -73.87 & -7.22 & -9.59 & \\
\hline 1 & -1301.79 & & & & & & 0.00 \\
\hline & & 0.0 & -52.69 & 75.91 & -14.85 & 20.87 & \\
\hline & & 2.8 & -52.69 & -71.63 & -14.85 & -20.72 & \\
\hline 2 & -1290.61 & & & & & & 0.26 \\
\hline & & 0.0 & -31.77 & 50.14 & -12.66 & 17.80 & \\
\hline 3 & & 2.8 & -31.77 & -38.81 & -12.66 & -17.66 & 0326 \\
\hline 3 & -1312.97 & 0.0 & -73.62 & 101.68 & -17.04 & 23.94 & -0.20 \\
\hline & & 2.8 & -73.62 & -104.46 & -17.04 & -23.78 & \\
\hline
\end{tabular}




\begin{tabular}{|c|c|c|c|c|c|c|c|}
\hline 4 & -1298.04 & & & & & & -0.08 \\
\hline & & 0.0 & -52.50 & 75.67 & -21.89 & 30.29 & \\
\hline & & 2.8 & -52.50 & -71.62 & -21.89 & -30.99 & \\
\hline 5 & -1305.54 & & & & & & 0.08 \\
\hline & & 0.0 & -52.78 & 76.15 & -7.82 & -11.46 & \\
\hline & & 2.8 & -52.78 & -71.64 & -7.82 & 10.45 & \\
\hline I & -1122.06 & & & & & & 0.00 \\
\hline & & 0.0 & -51.08 & 73.31 & -14.57 & 20.46 & \\
\hline & & 2.8 & -51.08 & -69.70 & -14.57 & -20.33 & \\
\hline 2 & -1104.57 & & & & & & 0.21 \\
\hline & & 0.0 & -33.47 & 52.27 & -12.52 & 17.58 & \\
\hline & & 2.8 & -33.47 & -41.46 & -12.52 & -17.47 & \\
\hline 3 & -1139.55 & & & & & & -0.21 \\
\hline & & 0.0 & -68.68 & 94.35 & -16.62 & 23.34 & \\
\hline & 440 & 2.8 & -68.68 & -97.95 & -16.62 & -23.19 & \\
\hline 4 & -1119.30 & & & & & & -0.06 \\
\hline & & 0.0 & -50.92 & 72.99 & -20.66 & 28.56 & \\
\hline & & 2.8 & -50.92 & -69.57 & -20.66 & -29.29 & \\
\hline 5 & -1124.82 & & & & & & 0.06 \\
\hline & & 0.0 & -51.24 & 73.63 & -8.48 & -12.36 & \\
\hline & & 2.8 & -51.24 & -69.84 & -8.48 & 11.37 & \\
\hline 1 & -939.43 & & & & & & 0.00 \\
\hline & & 0.0 & -49.79 & 71.17 & -14.33 & 20.11 & \\
\hline & & 2.8 & -49.79 & -68.24 & -14.33 & -20.01 & \\
\hline 2 & -918.56 & & & & & & 0.17 \\
\hline & & 0.0 & -35.43 & 54.70 & -12.42 & 17.42 & \\
\hline & & 2.8 & -35.43 & -44.49 & -12.42 & -17.35 & \\
\hline 3 & -960.29 & & & & & & -0.17 \\
\hline & & $\begin{array}{l}0.0 \\
28\end{array}$ & $\begin{array}{l}-64.15 \\
-64.15\end{array}$ & $\begin{array}{r}87.63 \\
-91.99\end{array}$ & $\begin{array}{l}-16.24 \\
-16.24\end{array}$ & $\begin{array}{r}22.80 \\
-22.68\end{array}$ & \\
\hline 4 & -937.48 & & & -31.27 & & & -0.06 \\
\hline & & 0.0 & -49.57 & 70.78 & -19.48 & 26.89 & \\
\hline & & 2.8 & -49.57 & -68.01 & -19.48 & -27.65 & \\
\hline 5 & -941.37 & & & & & & 0.06 \\
\hline & & 0.0 & -50.00 & 71.55 & -9.18 & -13.33 & \\
\hline & & 2.8 & -50.00 & -68.47 & -9.18 & 12.37 & \\
\hline 1 & -754.49 & & & & & & 0.00 \\
\hline & & 0.0 & -48.67 & 69.36 & -14.12 & 19.82 & \\
\hline & & 2.8 & -48.67 & -66.91 & -14.12 & -19.71 & \\
\hline 2 & -733.01 & & & & & & 0.14 \\
\hline & & 0.0 & -37.47 & 57.29 & -12.34 & 17.32 & \\
\hline & & 2.8 & -37.47 & -47.62 & -12.34 & -17.24 & \\
\hline 3 & $-1 / 15.06$ & & & & & & -0.14 \\
\hline & & $\begin{array}{l}0.0 \\
2.8\end{array}$ & $\begin{array}{l}-59.86 \\
-59.86\end{array}$ & $\begin{array}{c}81.43 \\
-86.19\end{array}$ & $\begin{array}{l}-15.89 \\
-15.89\end{array}$ & $\begin{array}{c}22.32 \\
-22.18\end{array}$ & \\
\hline
\end{tabular}




\begin{tabular}{|c|c|c|c|c|c|c|c|}
\hline 4 & -753.20 & & & & & & -0.04 \\
\hline & & 0.0 & -48.41 & 68.94 & -18.33 & 25.28 & \\
\hline & & 2.8 & -48.41 & -66.60 & -18.33 & -26.03 & \\
\hline 5 & -755.72 & & & & & & 0.04 \\
\hline & & 0.0 & -48.93 & 69.78 & -9.91 & -14.36 & \\
\hline & & 2.8 & -48.93 & -67.21 & -9.91 & 13.39 & \\
\hline $211-$ & -56783 & & & & & & 000 \\
\hline 1 & -301.03 & 0.0 & -48.47 & 68.35 & -14.08 & 19.67 & 0.00 \\
\hline & & 2.8 & -48.47 & -67.35 & $-[4.08$ & -19.74 & \\
\hline 2 & -548.41 & & & & & & 0.11 \\
\hline & & 0.0 & -40.31 & 60.42 & -12.42 & 17.35 & \\
\hline & & 2.8 & -40.31 & -52.44 & -12.42 & -17.43 & \\
\hline 3 & -587.25 & & & & & & -0.11 \\
\hline & & 0.0 & -56.62 & 76.28 & -15.73 & 22.00 & \\
\hline & & 2.8 & -56.62 & -82.26 & -15.73 & -22.05 & \\
\hline 4 & -566.56 & & & & & & -0.04 \\
\hline & & 0.0 & -48.18 & 67.91 & -17.34 & 23.81 & \\
\hline & & 2.8 & -48.18 & -66.99 & -17.34 & -24.75 & \\
\hline 5 & -568.60 & & & & & & 0.04 \\
\hline & & 0.0 & -48.76 & 68.79 & 10.82 & -15.54 & \\
\hline & & 2.8 & -48.76 & -67.71 & 10.82 & 14.73 & \\
\hline $212-\ldots$ & & & & & & & \\
\hline 1 & -379.53 & 0.0 & -44.80 & 65.40 & -13.27 & 19.00 & 0.00 \\
\hline & & 2.8 & -44.80 & -60.03 & -13.27 & -18.16 & \\
\hline 2 & -364.66 & & & & & & 0.09 \\
\hline & & 0.0 & $-39.6 \dot{9}$ & 61.28 & $-\mathrm{II} .80$ & 16.89 & \\
\hline & & 2.8 & -39.69 & -49.86 & -11.80 & -16.15 & \\
\hline 3 & -394.40 & & & & & & -0.09 \\
\hline & & 0.0 & -49.90 & 69.52 & -14.74 & 21.11 & \\
\hline & & 2.8 & -49.90 & -70.19 & -14.74 & -20.17 & \\
\hline 4 & -379.14 & & & & & & -0.03 \\
\hline & & 0.0 & -44.50 & 64.96 & -15.57 & 21.79 & \\
\hline & & 2.8 & -44.50 & -59.64 & -15.57 & -21.80 & \\
\hline 5 & -379.92 & & & & & & 0.03 \\
\hline & & 0.0 & -45.09 & 65.84 & 10.98 & -16.21 & \\
\hline & & 2.8 & -45.09 & -60.42 & 10.98 & 14.52 & \\
\hline 213 & -192.83 & & & & & & 0.00 \\
\hline & & 0.0 & -64.21 & 76.14 & -17.69 & 22.22 & \\
\hline & & 2.8 & -64.21 & -103.64 & -17.69 & -27.33 & \\
\hline 2 & -184.84 & & & & & & 0.06 \\
\hline & & 0.0 & -61.25 & 74.50 & -15.85 & 19.91 & \\
\hline & & 2.8 & -61.25 & -96.99 & -15.85 & -24.54 & \\
\hline 3 & -200.82 & & & & & & -0.06 \\
\hline & & 0.0 & -67.17 & 77.79 & -19.51 & 24.52 & \\
\hline & & 2.8 & -67.17 & -110.29 & -19.51 & -30.12 & \\
\hline
\end{tabular}




$\begin{array}{cccccccc}4 & -192.68 & & & & & \\ & & 0.0 & -63.83 & 75.70 & -17.13 & 23.76 & \\ 5 & 2.8 & -63.83 & -103.03 & -17.13 & -29.82 & \\ & -192.68 & & & & & & 0.02 \\ & & 0.0 & -64.58 & 76.58 & 16.25 & -20.68 & \\ & & 2.8 & -64.58 & -104.25 & 16.25 & 24.84 & \end{array}$

